\title{
Tasmanian landowner preferences for conservation incentive programs: A latent class approach
}

\author{
Ingrid van Putten \\ B.Ec. (La Trobe), M.Env.St. (Tasmania)
}

School of Economics and Finance

University of Tasmania

Submitted in fulfilment of the requirements for the Degree of

Doctor of Philosophy

University of Tasmania

Hobart, Tasmania, January 2008 


\section{Declaration}

This thesis contains no material which has been accepted for the award of any other higher degree or graduate diploma in any University or any other institution, and, to the best of my knowledge and belief, contains no material previously published or written by another person except where due reference is made in the text of the thesis, nor does the thesis contain any material that infringes on copyright.

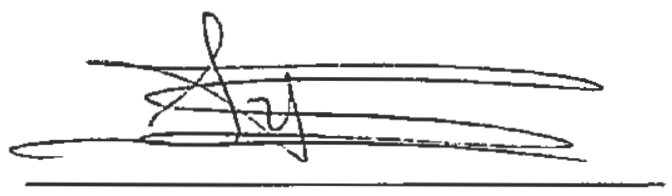

Ingrid van Putten

January 2008

\section{Statement of Authority of Access}

This thesis may be made available for loan. Copying of any part of this thesis is prohibited for two years from the date this statement was signed; after that time limited copying is permitted in accordance with the Copyright Act 1968.

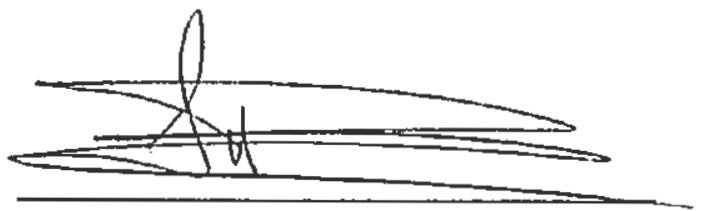

Ingrid van Putten

January 2008 


\section{Abstract}

Incentive programs aimed at encouraging private landowners to set aside areas of forest for their conservation value have existed in Australia for more than two decades. Many programs restrict the use of the land by legal agreements or other means and some programs offer the landowner financial compensation. Most programs are based on voluntary entry by landowners.

Programs available in Tasmania have added significantly to the total forest area conserved on private land. Nevertheless, in some regions more than 80 percent of land with conservation value remains unprotected and programs routinely fail to meet enrolment targets. This has resulted in considerable debate about the design of programs and has resulted in an increase in the amount of compensation offered and the introduction of more flexible conservation management options. In a limited number of situations, the option of forcing landowner entry into conservation incentive programs has also been considered.

The objective of this study is to provide information for policy makers that hasn't existed before and that can be used in designing conservation programs. An improved understanding of landowners' decision framework, their motivation and the strength of their behavioral response will facilitate better forecasting of landowner participation decisions which may lead to an increase in landowner enrolment in programs.

In this dissertation a conceptual model of landholders' participation choice is developed that combines a traditional utility maximisation framework with information about landowner attitudes. An empirical model of landowners' conservation incentive program choice is then developed. The model is estimated using stated preference data from a Best-Worst and a Choice survey. The responses to the Best-Worst survey, which was carried out first, were used to determine the choice set for the subsequent Choice survey. The Best-Worst survey was also used to explore differences between the perceived importance of program attributes by program designers and administrators, and landowners. 
The Choice survey gathered information on landowner preferences for incentive program attributes, the socio-economic characteristics of the landowner and their attitudes, and property characteristics.

Landowners were presented with two experiments mimicking program choice in a voluntary and forced choice scenario. Landowner heterogeneity was accounted for using a latent class approach to estimating preference parameters. These were compared to preferences estimated using a two step logit approach.

Three latent classes of landowners with different attitudes to the role and outcome of establishing conservation reserves on private land were identified: multi-objective owners; environment owners; and production owners.

Preferences for program attributes and estimated welfare impacts when forced to enter a 'restrictive' program are found to differ significantly between the landowner classes. Estimated welfare losses were lowest for environment owners and highest for production owners. Results suggest that compensation is not a main driver of program choice for any of the groups when entry is forced.

Only a small proportion of landowners were willing to voluntarily join a conservation program. Preferences for program attributes were not significantly different between landowner classes, even though groups differed in their attitude. The welfare implications of voluntarily joining a 'restrictive' program were small and compensation funding was, again, only of secondary importance in detemining program choice. The research also showed little difference in the perceived relative importance of different program attributes between landowners and program designers and administrators.

The results of this study will be of use to policy makers in the design of better targeted incentive programs. For instance, results suggest that when designing forced entry programs for environment owners special attention should be paid to the provision of logistical assistance, which is relatively important to this group. Furthermore, programs that do not permit any productive use of reserved areas do not deter entry by production owners. 


\section{Acknowledgement}

I first want to thank my supervisor Dr. Sarah Jennings for her patience, support, insight, and incredible skill and energy. Without her unwavering belief that I'd get there, things might not have eventuated. I also want to thank my other supervisor, Dr. Stuart Whitten, for giving me opportunities to extend my horizons and giving his support and thoughtful input when needed.

I'm very grateful to Prof. Jordan Louviere, of the University of Technology Sydney, for being welcoming and interested in my research and providing me with crucial advice at some major crossroads. It was an honour to have the opportunity to share my thoughts with his unbelievable mind, insight and invigorating enthusiasm.

I owe much gratitude to Dr. Leonie Burgess and Prof. Deborah Street at the Department of Mathematical Sciences, University of Technology Sydney. Without their support in finding the most efficient design for the choice experiment, the survey could not have been carried out.

I want to thank all those who contributed to the focus groups and provided input in the early stages of the research. Organisations that were of particular assistance in this context were: the Tasmanian Farmers and Graziers, the Private Forest Reserve Program, the Forest Practices Board, Protected Areas on Private Land Program, and Private Forests Tasmania.

The support of my colleagues and staff at the University of Tasmania, in particular Sue Abel, Tracy Kostiuk, and Dr. Hugh Sibly, was invaluable. Special mention also goes to Assoc. Prof. Graeme Wells for his contribution in the final stage of the thesis. A thank you goes to the Faculty of Business for granting me a scholarship to undertake this research.

Finally I would like to thank the special people in my life who've had to put up with this person in their life who seems to be eternally "finishing their thesis". Firstly, of course, I want to thank my pa en ma and my family over there on the other side of the world in Holland. Despite the distance you were always encouraging and supportive in every possible way. 
Then my friends here in Tasmania, in particular I want to thank Rosemary, who always manages to make me laugh, and Gay and Marion for being there when I most needed them - for food, love and kind words. There are many friends I have failed to mention to whom I owe much gratitude and whose support and friendship I cherish. 


\section{Table of contents}

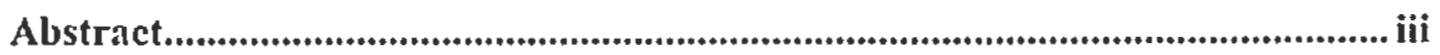

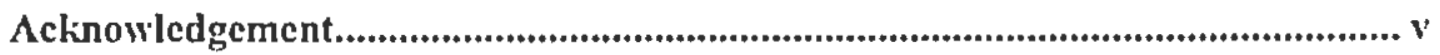

Table of contents....................................................................................... 1

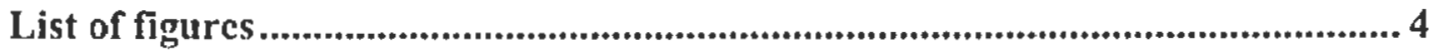

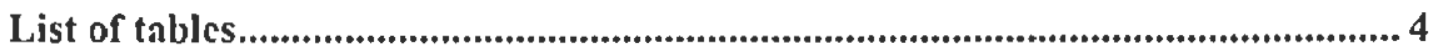

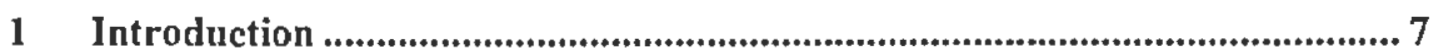

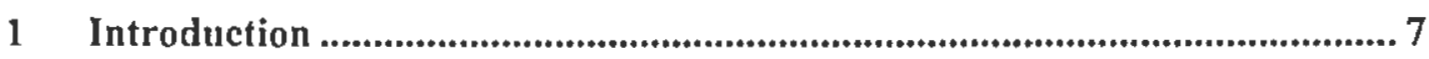

1.1 Motivation ...................................................................................

1.2 Objectives .............................................................................. 10

1.3 Methodological overview............................................................ 10

1.4 Contribution of this rescarch ........................................................ 11

1.5 Outline of the disscrtation .......................................................... 13

2 Biodiversity conscrvation .................................................................... 15

2.1 Conscrvation in Australia .......................................................... 15

2.1.1 Mecting biodiversity targets............................................................16

2.2 A case for government intervention.............................................. 17

2.2.1 Govermment instruments ...................................................................... 18

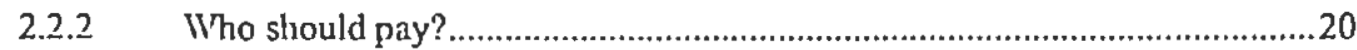

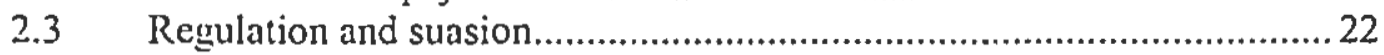

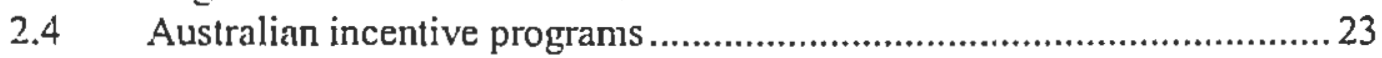

2.5 Tasmanian incentive programs ................................................. 28

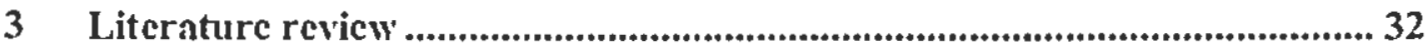

3.1 Voluntary conservation without participation in an incentive program.... 33

3.2 Economic approach to studying landowner choice................................. 34

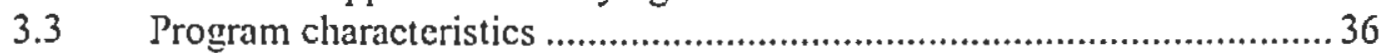

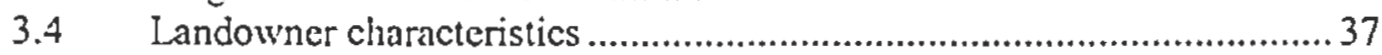

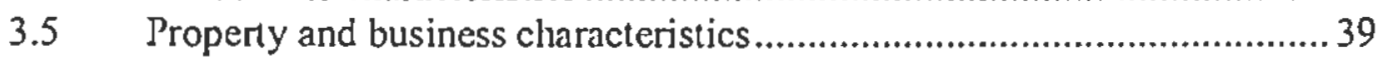

3.6 Landowner altitudes .................................................................... 41

3.7 Choice survey ...................................................................... 42

3.8 Econometric modelling approaches ............................................ 45

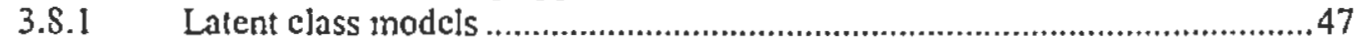

4 Theoretical framework ......................................................................... 49

4.1 Economic theory and behavioural foundation................................. 49

4.1.1 Behavioural foundation of the Stated Preference technique ..........................51

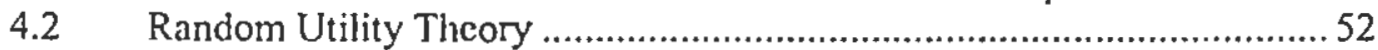

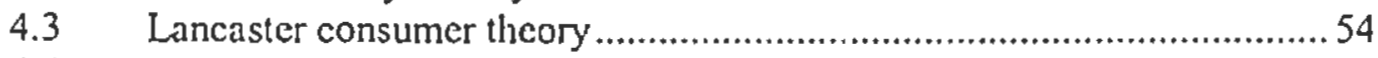

4.4 Theory of planned behavior......................................................... 55

5 Estimation methods and statistical analysis........................................... 59 


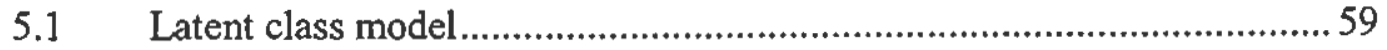

5.1.1 Welfare estimation.................................................................................62

5.1.2 Statistical indicators for latent class analysis ................................................63

5.2 Statistical analysis of attitude data ......................................................6.6. 65

5.3 Statistical analysis of Best-Worst data ..................................................... 67

6 Survey design and administration....................................................................... 71

6.1 Best-Worst survey ....................................................................... 71

6.1.1 The Tasmanian Best-Worst survey .........................................................73

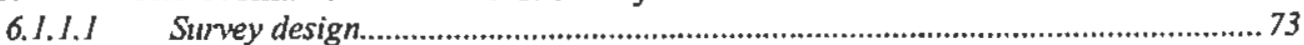

6.III.2 Survey layout ................................................................................................ 75

6.II.I.3 Pre-testing, sampling and survey administration................................................77

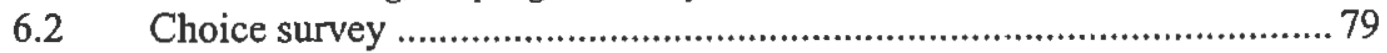

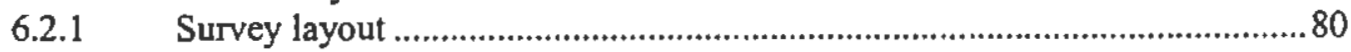

6.2.I.I Sample size and response rate......................................................................8I

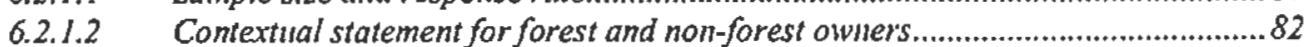

6.2.2 Specific Choice survey design issues..........................................................84

6.2.2.I Number of proffles...........................................................................................84

6.2.2.2 Number of choice sets.............................................................................................85

6.2.2.3 Number of attributes........................................................................................8

6.2.2.4 Orthogonal design..........................................................................................8

6.2.2.5 Willingness to accept .......................................................................................... 88

6.2.2.6 Inchusion of status quo .................................................................................. 89

$7 \quad$ Best-worst survey results ...................................................................................... 90

7.1 Descriptive Best-Worst data .................................................................90

7.2 Best-Worst data............................................................................ 91

7.3 Best-Worst attitude data and analysis .................................................... 94

8 Choice survey results and analysis ..............................................................98

8.1 Descriptive choice data ....................................................................... 98

8.1.1 Landowner demographic data ...............................................................99

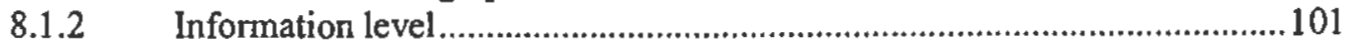

8.1.3 Business and property demographics ...........................................................102

8.1.4 Native forest and conservation management ..............................................104

8.1.5 Joining an incentive program ........................................................................107

8.1.6 Estimated market value ..........................................................................107

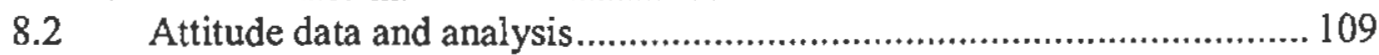

8.3 Latent class results ....................................................................... 113

8.3.1 Definition of latent class variables .............................................................113

8.4 Steps followed in estimation of latent class models .............................. 117

8.4.1 'Forced choice' model .......................................................................118

8.4.I.I Utility parameters for 'forced choice' model ....................................................I22

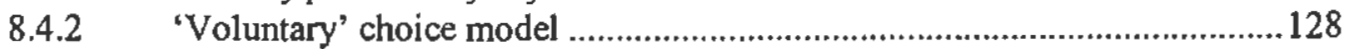

8.4.2.I Utility parameters for 'voluntary' model ...........................................................132

8.4.3 Welfare impact of program restrictions .......................................................137

8.4.4 A. two-step estimation procedure of landowner preferences .........................142

8.4.4.I Some differences between citusters and Iatent classes.........................................143

8.4.5 Two step estimation results ................................................................... 143

8.4.5.I Welfare impact for logit model ...............................................................149

9 Discussion and conclusions........................................................................... 151

9.1 Landowner preferences for program attributes: the forced choice case.. 151

9.2 Landowner preferences for program attributes: the voluntary case........ 156 


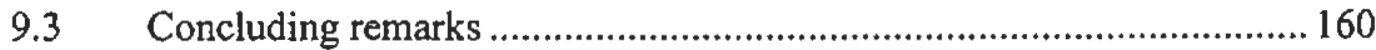

9.4 Recommendations for future research................................................ 161

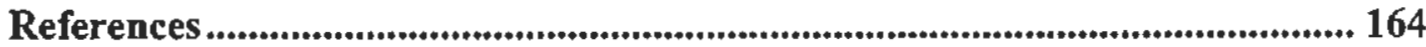

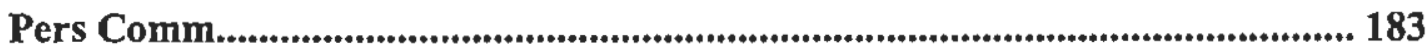

Appendix 1 - Best-Worst experimental design...................................................... 184

Appendix 2 - Best-Worst survey................................................................................ 185

Appendix 3 - Choice survey .................................................................................... 191

Appendix 4 - Choice survey experimental design ................................................... 183

Appendix 5 - Principal component analysis................................................................. 184

Appendix 6 - Communalities for principal component analysis .......................... 188

Appendix 7 - Correlation coefficients................................................................... 189

Appendix 8 - Probability means ................................................................... 190

Appendix 9 - Standard errors......................................................................................... 192

Appendix 10 - Cluster analysis..................................................................................... 193

Appendix 11 - Binary-choice models .......................................................................... 194 


\section{List of figures}

Figure 1: Policy tools available for managing environmental outcomes (based on Young and Gunningham 1996).

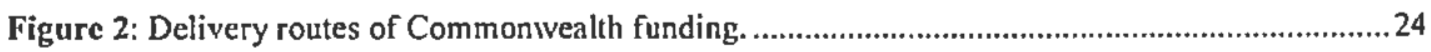

Figure 3: Groups of variables included in a landholder's land use decision framework, .......................50

Figure 4: The theory of planned behaviour (adapted from Beedell and Rehman 1999)......................56

Figurc 5: Relative importance of program attributes by landowncr class for the 3-class 'forced choice'

model.

Figure 6: Relative importance of program attributes by landowner class for the 3-class 'voluntary' model.

\section{List of tables}

Table 1: Rating questions aimed at cstablishing landowner attitudes to the role and impact of establishing reserves on private land.

Table 2: Best-IVorst score for 10 incentive program attributes for all respondents, PDAs, and landowners, and t-values (BV survey data).

Table 3: Ratio of ranking higher and lower than funding amount, Wilcoxon signed rank test, and $\mathrm{Z}$ score (BIV survey data).

Table 4: The BW scate and normalized stress indicator for all respondent, PDAs, and landowners for incentive program attributes (BW survey data).

Table 5: Respondent rating of the role and impact of establishing conservation reserves on private land (BW survey data).

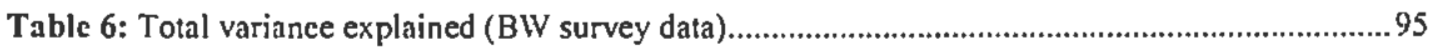

Table 7: Rotated component matrix (BW survey data).................................................................. 96

Table 8: Mean and standard deviation of socio-economic characteristics, property characteristics, and land management activities of survey respondents (Choice survey data)............................................99

Tablc 9: Survey respondent age statistics for males and females (Choice survey data). ..................... 100

Tablc 10: Demographic differences between male and female survey respondent (Choice survey data).

Table 11: Regional demographic differences (Choice survey data). 104

Table 12: Environmental and conservation management by survey respondents (Choice survey data).

Table 13: Environmental management by survey respondents (Choice survey data).

Table 14: Proportion of landowners who received some form of assistance to achieve environmenta! outcomes on their property (Choice survey data).

Tablc 15: Demographic differences between forest owning respondents and non-forest owning respondents (Choice survey data).

Table 16: Landowncr approach to valuing the native forest on their property (Choice survey data). . 108

Table 17: Respondent rating of the role and outcome of conscrvation reserves on private land (Choice survey data).

Table 18: Total variance explained in PCA for forest owners (Choice survey data) ...........................111

Table 19: Rotated component matrix (Choice survey data) ..........................................................112

Table 20: Statistics for the continuous socio-economic variables (Choice survey data)...................... 14

Table 21: Discretc socio-economic and attitude variable names and statistics (Choice survey data). 1 Is 
Table 22: Binary program characteristics, variable names and codes (Choice survey).

Table 23: Fit statistics of 1, 2, 3 and 4 latent class 'forced choice' regression model (Choice survey data).

Table 24: Fit statistics for 1, 2,3 and 4 latent class 'forced choice' model including significant covariates (Choice survey data).

Table 25: Classification of 'forced choice' model observations (percentage of observed program choice) (Choice survey data).

Table 26: Parameters, standard error, $\mathrm{z}$ statistics, Wald and p-value for attitude and socio-economic variables for the 3 class 'forced choice' model (Choice survey data).

Table 27: Parameters, standard error, z statistics, Wald and p-value for program attributes for a 3 class "forccd choicc" model (Choice survey data).

Table 28: Fit statistics for 1,2,3 and 4 latent class 'voluntary' regression models (Choice survey data).

Table 29: Fit statistics for 1, 2,3 and 4 latent class 'voluntary' model including significant covariates (Choice survey data).

Table 30: Classification of the final 3-class 'voluntary' model observations (percentage of observed program choice) (Choice survey data)

Table 31: Parameters, standard error, z statistics, Wald and p-value for attitude and socio-economic variables for the 3 class 'voluntary' model (Choice survey data).

Table 32: Parameters, standard error, $z$ statistics, Wald and p-value for program attributes for a 3 class 'voluntary' model (Choice survey data).

Table 33: Welfare impacts for changes in incentive program restrictiveness for the "forced choice" model, and the lower and upper $95 \%$ confidence interval (Choice survey data).

Table 34: Welfare impacts for changes in incentive program restrictiveness for the 'voluntary choice' model, and the lower and upper $95 \%$ confidence interval (Choice survey data)............................... 141

Table 35: Final cluster centres and number of cases in cluster (Choice survey data).

Table 36: Cross classification of respondents into landowner classes and clusters by the latent class and cluster methods (Choice survey data).

Table 37: Program choice classification and model statistics for forcst owner clusters (Choice survey data).

Table 38: Parameters, standard error, $\mathrm{z}$ statistics, and p-values for logit models program attributes for three clusters of forest orvner groups (Choice survcy data).

Table 39: The welfare impact of program attributes for changes in the restrictiveness of the incentive program attribute for the logit regression model (Choice survey data).

Table 40: The signs of the estimated utility coefficients for the 'forced choice" and "voluntary' model (Choicc survey data).

Table i: Communalities for all attitude variables (Choice survey data).

Table ii: Total variance explained in PCA for all respondents (Choice survey data) ......................... 185

Table iti: Rotated component matrix (Choice survey data).

Table iv: Comparison of components used in the 'voluntary' and 'forced choice' models (Choice survey data).

Table v: Communalities for all attitude variables (Choice survey data) ........................................ 188

Table vi: Correlation coeffjcients (Choice survey data) ...............................................................189

Table vit: Probability means for the 3-class 'voluntary' model (Choicc survey data)........................190

Table viti: Probability means for the 3-class 'forced choice" model (Choice survey data).................191 
Table ix: Standard errors for the quotient of two variables for the 'forced choice' model (Choice survey data).

Table x: Standard errors for the quotient of two variables for the 'voluntary choice' model (Choice survey data).

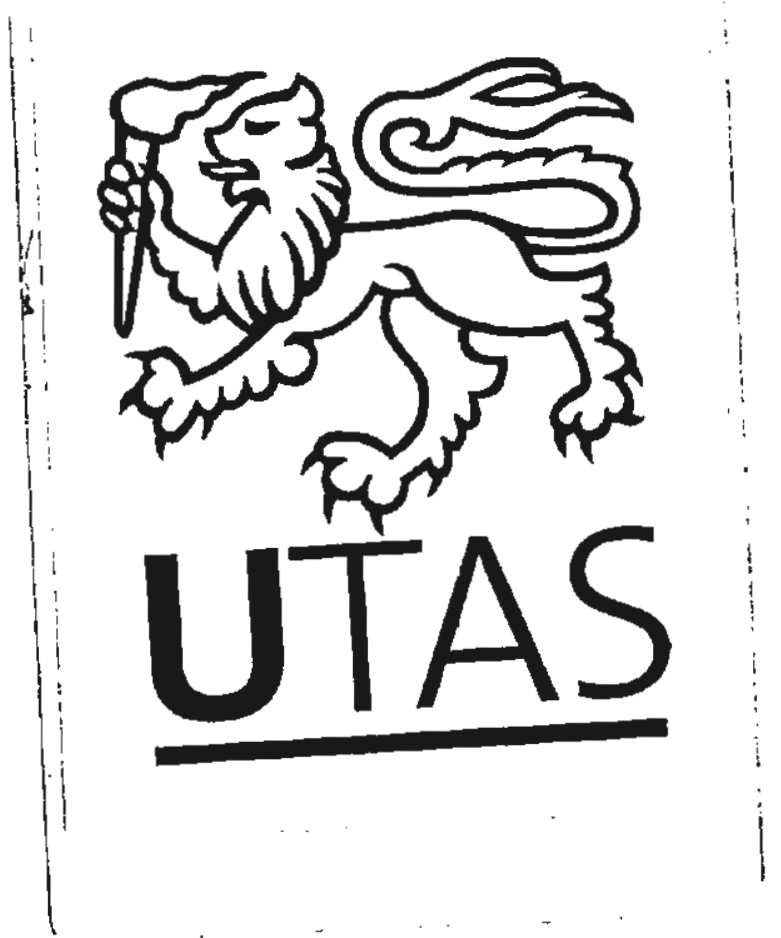


Conservation incentive programs that encourage landowners to set aside areas of privately owned forest have existed in Australia for more than two decades (Figgis 2004). Nevertheless, a comprehensive analysis of the way in which landowners make decisions about whether to join such programs has not previously been undertaken. This dissertation provides such an analysis by combining information about landowners' socio-economic and property characteristics and their attitudes, with incentive program choice data gathered by means of a Choice survey, within an econometric model of landowner behaviour. Incentive programs are modelled as 'bundles of attributes', allowing a comprehensive representation of incentive program choice. Landowner heterogeneity is accounted for by using a latent class approach to estimation. The results reported in this dissertation provide information that may be useful to policy makers wanting to forecast landowner participation decisions and to design programs that target particular groups of landowners.

\subsection{Motivation}

Australia possesses flora and fauna that is both highly endemic and has great species richness compared to many other parts of the world (Department of the Environment, Sport and Territories n.d.). However, much of Australia's rich biodiversity ${ }^{1}$ is threatened with extinction due to habitat loss or the degradation of habitat quality. The Australian Government has, on many occasions, indicated its commitment to avoiding further loss of biodiversity by increasing the area of reserves, while at the same time preventing further land clearing (Luzar and Diagne 1999).

Over 60 percent of land in Australia is managed by private landholders (Productivity Commission 2001). Consequently, many threatened ecosystems ${ }^{2}$ in Australia occur

\footnotetext{
I "Biological diversity or biodiversity refers to the variety of life forms: the different plants, animals and microorganisms, the genes they contain, and the ecosystems they form" (Department of the Environment, Sport and Territories n.d.).

2 Ar ecosystem is "... the dynamic and interrelating complex of plant and animal communities and their associated non-living environment" (www.biology-online.org/dictionary/ecosystem viewed on 5 October 2005). For instance a forest ecosystem is characterised by the predomtnance of trees, and the fauna, flora and ecological cycles (energy, water, carbon and nutrients) with which they are closely associated.
} 
on private land. It is important, therefore, to consider the role of private landholders in conserving high value biodiversity areas.

Standard presentations of the economics of biodiversity argue that undefined or inadequately defined property rights for this environmental resource may lead to reduced incentives for landowners to protect biodiversity on their own land. The market for biodiversity conservation on private land does not deliver an efficient or Pareto optimal outcome (e.g. Kahn 1995). This result underpins the suggestion that implementing policies to protect biodiversity on private land is a legitimate role of government (e.g. Callan and Thomas 2000). All levels of governments can provide incentives to motivate landowners to undertake conservation action and protect additional areas of private land with high nature conservation value. Motivation can be through financial incentives such as grants obtained by participation in incentive programs and tax breaks, but also through, for instance, education. Governments can also use other policy instruments such as direct legislation or the development of regional strategies.

Landowners make decisions about the implementation of conservation management actions and participation in conservation oniented programs in a complex environment. Landowner decisions in general have been shown to involve many factors including culture, social setting, property structure, finances, and perception (Vanclay and Lawrence 1995). The framework within which the decision to enrol land in legally-binding conservation incentive programs is made, is expected to be equally complex. Crase and Maybery (2004) find that by revealing the intricacies of the individual's decision framework and understanding their behavioural responses, incentive programs with high success rates can be designed.

By 2002 Tasmanian private landholder participation in incentive programs resulted in the protection of more than 32000 hectares of land for the purpose of biodiversity conservation (Resource Planning and Development Commission 2003). Nevertheless, landowner enrolment in conservation incentive programs in Tasmania has fallen short of achieving the total area targeted to be set aside for conservation. In some regions of Tasmania, more than 80 percent of the total targeted areas remained unprotected in 2003 (Resource Planning and Development Commission 2003). A significant proportion of this area occurs on private land. The Tasmanian Government has a stated commitment to protect additional areas on private land through funding 
incentive programs for private landholders (Department of the Environment and Water Resources 2004).

Research and anecdotal evidence both suggest that landholder participation in incentive programs will vary with the expected private costs and benefits of conserving land of conservation significance, as well as with various landowner, property and business characteristics such as productive income (e.g. Wilson 1996; Drake, Bergström et al. 1999; Greiner, Hert et al. 2003). Non-financial motives and environmental attitudes are also likely to play a role in the decision to enrol land in a conservation incentive program (e.g. Wynn, Crabtree et al. 2001). Lastly, the attributes of the incentive program itself are expected to play an important role in the participation decision (e.g. Purvis, Hoehn et al. 1989; Cooper and Keim 1996).

The attributes of conservation incentive programs, such as the legal implications and the restrictions placed on the use of land, are generally determined by the government officials who design and implement these programs. ${ }^{3}$ Since landowner participation rates are affected by program attributes, a better understanding of the importance ascribed by landowners to various attributes can potentially lead to the more effective design of programs.

Conservation incentive programs in Australia are currently based largely on voluntary entry into the program by landowners (CSIRO Wildlife and Ecology 2001) and there are only a few examples where govermment has compulsorily acquired land of conservation significance (e.g. Western Australian Public Works Act 1902 quoted in Stoneham, Crow et al. 2000). Continuing low private land enrolment rates may mean that governments are called upon to consider forcing landowner participation in order to aclieve stated policy objectives. This possibility makes an understanding of landowners' preferences for program attributes in the context of forced program entry both relevant and important.

Overall, an improved understanding of landowners' decision framework, their motivation, and the strength of their behavioural responses in the context of both forced and voluntary entry could lead to better tailoring of programs to suit particular landowners or groups of landowners. At the same time it would increase the

\footnotetext{
${ }^{3}$ Although the development of government programs frequently occurs in consultation with the target audience (e.g. Department of the Environment and Water Resources 2004).
} 
likelihood of achieving program goals and could result in more efficient financing of conservation targets.

\subsection{Objectives}

The overall aim of this dissertation is to contribute to an improved understanding of the way in which landowners make decisions about participating in incentive programs aimed at conserving biodiversity on private land in Tasmania as a basis for improving program design.

The following policy related research objectives are central to achieving this:

- To investigate landowner preferences for incentive program attributes in the context of both forced and voluntary choice. This involves identifying and quantifying the tradeoffs that landowners make between incentive program attributes, and exploring how such tradeoffs are affected by the socioeconomic characteristics of landowners, landowner attitudes and property characteristics.

- To compare the welfare implications of program 'restrictiveness' when choice is forced and voluntary.

- To compare landowners to program designers and administrators with respect to the perceived importance of incentive program attributes in the landowner decision framework.

\subsection{Methodological overview}

Achieving the above objectives involves the development of a theoretical model that describes landowner decisions to conserve biodiversity through participation in conservation incentive programs. A conceptual model of landholders' participation choice is developed that combines the traditional utility maximisation framework with information about landowner attitudes. The development of this model follows a review of the literature related to the economic modelling of the decision to participate in incentive schemes and the literature related to environmental attitudes and their measurement. 
The empirical study of choice and participation in incentive programs may be undertaken using information about landowner preferences as revealed by their actual participation in available programs or by eliciting stated preferences for incentive programs using survey methods. In this research an empirical model of landowner participation in conservation incentive programs is developed using data gathered by means of two separate, but related, stated preference surveys: a Best-Worst (BW) and a Choice survey. A review of existing programs and policies informs the design of both surveys.

The responses to the Best-Worst survey, which was carried out first, are used to determine the choice set for the subsequent Choice survey. The Best-Worst survey was also used to explore differences between the perceived importance of program attributes by program designers and administrators, and landowners.

The Choice survey gathered information on landowner preferences for incentive program attributes, the socio-economic characteristics of the landowner and their attitudes, and property characteristics.

Landowners were presented with two choice experiments mimicking program choice in a forced choice and voluntary scenario. Landowner heterogeneity was accounted for using a latent class approach to estimating preference parameters.

\subsection{Contribution of this research}

The approaches taken in this research are innovative for several reasons. Firstly, the Choice survey gathered information on landowner preferences for incentive program attributes. Although choice studies are frequently carried out to explore issues in environmental economics, a review of the literature has not shown any previous studies that applied this approach to the design of policy instruments in Australia. Investigating incentive program choice using choice modelling is a state of the art application of this approach for the design of new policy.

Secondly, the choice question in the survey was phrased in such a way that made it possible to consider landowner preferences for program attributes both in a situation where entry into a program is voluntary and where entry is compulsory or forced. The simulation and comparison of a forced and voluntary entry choice situation has not been carried out in Australia or elsewhere, in the context of conservation incentive 
programs. The comparison is important as different policy options for Australian Government incentive programs may need to be considered in the future if voluntary programs do not achieve their stated conservation aims.

Thirdly, to my knowledge, no other study has carried out an economic analysis of landowners' decision framework surrounding participation in incentive programs in which four classes of independent variables have been combined: socio-economic characteristics of landowners; landowner attitudes; property and business characteristics; and incentive program attributes. This study advances the understanding of attributes that are important in influencing incentive program choice which can therefore be targeted in future government initiatives aiming to increase landowner participation.

Moreover, the assessment of landowner attitudes is based on 'outcome evaluation' which varies from the more traditional classification of attitudes on the basis of a general environmental characterisation of the landowner. To my knowledge, this type of attitude variable has not previously been included in a model of incentive program choice and greatly adds to the comprehensiveness of the economic analysis.

Fourthly, the trade-offs between incentive program attributes are modelled using a latent class technique, rather than the more traditional two-stage cluster / logit approach. The latent class technique accounts for heterogeneity among landowners. Key variables that explain landowner participation can be identified using this method. The application of a latent class regression model to conservation program choice data, in which the difference in landowner choice behaviour is explained by landowner heterogeneity in terms of observable and unobservable characteristics, is novel. The results of the latent class estimation technique are compared to the more traditional two-stage cluster/ logit regression approach.

Lastly, although Best-Worst and Choice surveys have been combined in other studies (e.g. Sawtooth Software 2002), a Best-Worst survey has not previously been used to set attributes for a subsequent Choice survey. This type of Best-Worst survey application is an innovative and comprehensive survey approach which can lead to better Choice survey design. The Best-Worst survey was also used to explore differences between program designers and administrators, and landowners in relation to the perceived importance of different program attributes. This innovative use of 
the Best-Worst survey allows an appraisal of program designers' understanding of the importance of program attributes to stakeholder. A Best Worst survey has not previously been applied in this manner.

\subsection{Outline of the dissertation}

This dissertation is organised as follows:

Chapter 2 describes the current status and historical development of biodiversity conservation in Australia. The traditional economic treatment of biodiversity conservation as a public good and the occurrence of market failure is established. An outline of current incentive programs aimed at nature conservation in Australia in general, and Tasmania in particular, and participation in these programs is presented.

The empirically based literature related to modelling private landowner land use choice and the decision framework surrounding the participation in incentive programs is reviewed in Chapter 3. Previous application of the stated preference techniques used to gather data in this research is also reviewed.

The description of landowner choice in a utility maximising framework is presented in Chapter 4 followed by the behavioural theories which form the foundation of stated preference techniques. A brief introduction to decision making models in psychology as they relate to the development of a comprehensive model of landholder utility is presented.

The estimation technique and statistical methods applied in this dissertation are the subject of Chapter 5. In this chapter the use of the latent class estimation approach to account for heterogeneity in data is presented. The statistical indicators for the latent class, the Best-Worst, and the attitude data are also discussed.

The development of the Best-Worst and Choice survey instruments and the survey application methods are presented in Chapter 6. Survey design considerations are also discussed.

The empirical results for the Best-Worst and Choice models are reported in Chapter 7 and Chapter 8. In each chapter a descriptive analysis of the socio-economic and property characteristics data is followed by the statistical analysis of the data. 
The results are discussed in Chapter 9 and implications of the findings are presented. The tradeoffs that landowners make between incentive program attributes, and how these are affected by various socio-economic characteristics of landowners, landowner attitudes, and property characteristics are discussed. This is followed by a discussion of the effect of forced entry into conservation programs on landowner preferences for program attributes. Welfare estimates of changes in program restrictions under the two choice scenarios are also compared. Latent class estimates are then compared to the results obtained from a two-stage cluster analysis / logit regression. This is followed by a brief conclusion and recommendations for further research. 


\section{Biodiversity conservation}

In this dissertation conservation incentive programs are modelled as a bundle of attributes. In this context it is important to understand the makeup of existing programs, how they work, and where they fit into the current policy environment. This chapter begins with an outline of the current status of biodiversity conservation in Australia followed by a discussion of the traditional treatment of biodiversity conservation in economics. A discussion of policy tools available to government is followed by an outline of current incentive programs and participation in these programs.

\subsection{Conservation in Australia}

It is well established that there is a great species richness of plants and animals in Australia. Over 80 percent of Australian flowering plants, mammals, and inshore, temperate-zone fish are endemic (Department of the Environment, Sport and Territories n.d.). However, habitat loss or the degradation of habitat quality threatens much of Australia's rich biodiversity with extinction.

A natural rate of species extinction has occurred throughout the ages with the occasional massive and rapid extinction, such as that of the dinosaur (e.g. IUCN World Conservation Union 1999). Scientists have acknowledged that the relatively rapid rate of recent species extinctions cannot be attributed to naturally occurring environmental change but rather is the result of anthropogenic or human based factors (Kahn 1995). Maintaining current biodiversity levels, or at least slowing further species extinction, requires maintenance of habitat (e.g. Soule 1991).

Traditionally, the responsibility for the conservation of biodiversity in Australia has rested in the public domain. Recognising that habitat degradation needs to be halted, governments are spending funds in all sectors of the economy to protect biodiversity. The latest available Australian Bureau of Statistics (1997) information suggests that annual household expenditure on the protection of biodiversity and landscape in Australia was approximately $\$ 169$ million in 1996-97 and the amount spent by industry was approximately $\$ 173$ million in that same year. Some of the money spent 
on biodiversity conservation includes setting aside areas as reserves specifically aimed at preserving biodiversity.

The protection of biodiversity has to date been achieved largely through the creation of public parks and reserves. The conservation of biodiversity in these parks was often incidental because the parks were mainly created for their natural beauty and recreational values and less frequently for the protection of threatened species (Thackway and Olsson 1999). Governments have now detemnined, on behalf of society, that biodiversity conservation should be increased above current levels (Productivity Commission 2001) by creating more conservation reserves (Aretino, Holland et al. 2001).

\subsubsection{Meeting biodiversity targets}

The Australian national and state govemments' recognition of their role in setting targets for biodiversity conservation reached a new level in 1992 through their commitment to conserve a "... comprehensive, adequate, and representative sample of Australia's ecosystem types" (Thackway and Olsson 1999, p.89). The Interim Biogeographic Regionalisation for Australia (IBRA) provided a framework for setting protection priorities at a regional and national level (Thackway and Cresswell 1995; Thackway and Olsson 1999) for both private and public land.

Both the 1992 National Strategy for Ecologically Sustainable Development and the subsequent 1996 National Strategy for the Conservation of Australia's Biological Diversity (Department of Environment and Water Resources 1992) recognised the need for partnerships among all levels of government, industry and the community (Thackway and Olsson 1999). To ensure adequate representation of ecosystems in the process of conservation of biodiversity in Australia, protection needed to be on land of various tenure, and by both the public and private sectors (Productivity Commission 2001). To facilitate the process of biodiversity conservation, biodiversity resource reservation targets were determined by an extemal scientific process for each of the States and Territories in Australia.

As over 60 percent of land in Australia is managed by private landholders, many of the threatened and under-represented ecosystems in Australia occur on private land. It is therefore important to consider the role of private landholders in conserving important areas for biodiversity conservation. The question arises why, in a country 
such as Australia that is so reliant on markets, the market does not deliver the desired level in relation to biodiversity conservation? In other words, why do markets fail when it concerns the conservation of biodiversity?

\subsection{A case for government intervention}

Most resource and environmental economics textbooks classify biodiversity as an environmental resource that is a public good, that is, what Samuelson (1954) referred to as non-excludable and non-rival. Biodiversity is non-excludable because it is not possible to stop anyone from "consuming or enjoying" the good. It is non-rival as the enjoyment of biodiversity by someone does not reduce the amount of biodiversity available to others. For example, it is not possible for a landowner who protects an area of land on their property, thereby conserving biodiversity, to stop the neighbour enjoying the increasing number of native animals. At the same time, the neighbour's enhanced enjoyment will not reduce the farmer's own ability to enjoy the presence of these animals.

The non-rival and non-excludable nature of public goods may cause problems for their supply. These goods are one of several categories of goods where market failure may apply (Kahn 1995). Because no private individual or organisation can reap all the benefits of a public good which they have produced or made available, there will be insufficient incentive to produce it voluntarily. Consumers can take advantage of public goods without contributing sufficiently to their creation. This is called the 'free rider' problem (e.g. Samuelson 1954).

Specific to the production or protection of biodiversity, landowners may not have an incentive to protect biodiversity if they are unable to encourage others to contribute to the benefit they enjoy. Similarly, there may not be an incentive if the landowners are able to enjoy the benefits regardless of their own contribution. The landowner is able to free ride and will not incur the cost of producing the good (Söderqvist 2003). It may therefore be argued that an allocatively efficient outcome of biodiversity provision is not established with natural market incentives (Callan and Thomas 2000). 
A characteristic of biodiversity is that property rights ${ }^{4}$ are inadequately defined or are unprotected. Undefined or inadequately defined property rights mean that there are no valid claims to exclusive use of the resource and the resource cannot be sold. Property rights are generally limited by law and through social customs (Callan and Thomas 2000). The attribute of biodiversity as a public good in combination with insufficiently specified property rights makes it different from "an ordinary resource and leads to deficient market valuation" (Lerch 1998, p.286). Further, until recently biodiversity was perceived to be available in abundance. Property rights are generally not an issue where resources are not perceived as scarce (Anderson and Hill 2004).

In relation to deficient market valuation the Coase theorem suggests that "proper assignment of property rights to any good ... will allow bargaining between the affected parties such that an efficient solution can be obtained, regardless of which party is assigned those rights" (Callan and Thomas 2000, p.87). Some major obstacles in relation to the assignment of property rights to biodiversity exist, such as the development of equitable allocation methods. Additionally, potentially prohibitive transaction costs in trading may apply once property rights are allocated (e.g. Whitten and van Bueren et al. n.d).

Thus, the above discussion indicates that the public good nature of biodiversity is recognised and that govemment has a potential role to encourage the provision of biodiversity which will otherwise not be achieved through markets. The next section provides an overview of the instruments available to government to encourage biodiversity conservation, particularly on private land.

\subsubsection{Government instruments}

Governments may use regulations, suasion, and incentive programs to encourage biodiversity conservation actions on private land by landowners. Figure 1 summarises a variety of policy tools available to government for managing environmental outcomes, as broadly defined in the relevant literature.

\footnotetext{
${ }^{4}$ "Property rights include the right to acquire property, the right to dispose of property; the right 10 exclude others, the right against trespass, the right to quiet enjoyment and, importantly, the right of active use - with the general proviso, of course, that one may do so only as long as these rights do not hinder the rights of others to enjoy or use their property" (Nahan 1999).
} 

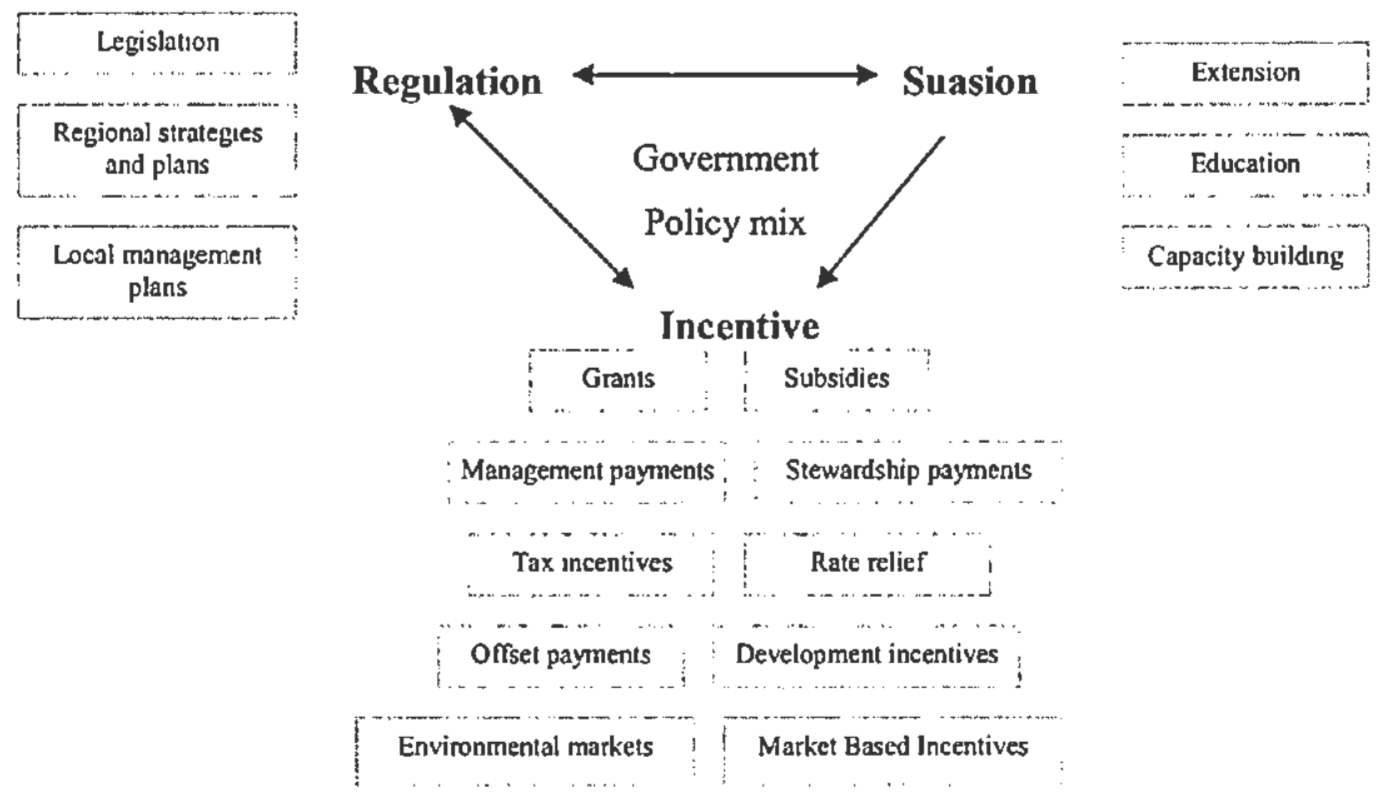

Figure 1: Policy tools available for managing environmental outcomes (based on Young and Gunningham 1996).

As is shown in Figure 1 above, conservation incentives provided to private landholders by different levels of government currently comprise grants (including management and stewardship payments ${ }^{5}$ ), subsidies, tax relief, rate relief, offset payments, development incentives, the creation of environmental markets, and market based incentives (MBIs). These incentives are aimed at encouraging management change and thereby improving environmental outcomes, such as water quality and the protection of biodiversity (e.g. James 1997).

Governments often use a combination of (overlapping) policy instruments, in particular incentives and legislation, to realise the full value of the biodiversity resource (e.g. Young and Gunningham 1997; Binning and Young 1999; Mountford and Keppler 1999). The focus of the next section is on the source of the funding the government uses to encourage conservation.

\footnotetext{
${ }^{5}$ Stewardship payments are to assist landowners to carry out tasks they have an obligation to do in any case. This implies some sort of duty of care on the landowner's behalf. A management payment is for a specific action and finishes when the action is carried out. Management and stewardship payments are often provided with the direct aim of protecting biodiversity and areas of conservation significance through specific management actions or reservation of land (Kabii 2004).
} 


\subsubsection{Who should pay?}

The public good nature of biodiversity suggests insufficient private incentive to conserve biodiversity and to use it in a sustainable way. The provision of incentives may encourage private landholders to set aside areas for conservation. However, there remains an argument as to who should bear the cost of conserving biodiversity on private land (Bates 2001).

Article 11 of the Convention on Biological Diversity raises the issue that individuals are likely to personally bear the costs associated with their conservation effort, however, "... most, if not all, of the associated benefits would accrue to society-atlarge" (United Nations Environment Program n.d.).

Numerous elements contribute to resolving this issue (Commonwealth of Australia 2001), but two central themes can be identified. These are referred to as equity ${ }^{6}$ and duty of care, which can be translated into a number of questions:

- Should the public pay landowners for conserving biodiversity?

- Which management actions should they be compensated for?

- Which landowners who undertake these actions should be paid? and

- How much should they be paid?

According to Coase (1960), the compensation obligation depends on who has the property rights. The property rights of private landowners are well defined in the Australian constitution, but the biodiversity values that occur on that private land are not (Wiebe, Tegene et al. 1997).

Where government compulsorily acquires property - for instance to protect biodiversity values - the compensation issue seems to be relatively straightforward. Legally, Part V - Powers of the Parliament, Section 51 (xxxi) of the Australian constitution states that if the government acquires property from any State or person "full and adequate compensation" has to be paid (Nahan 1999). ${ }^{7}$ However, where biodiversity conservation is achieved by changing management practices, but retaining private ownership, the government may be reluctant to pay compensation.

\footnotetext{
${ }^{6}$ Equity is interpreted here as the need to share the costs and benefits necessary to achieve biodiversity conservation (Kabii 2004).

'The 'just compensation' clause does not appear in the State's own constitutions.
} 
In this situation, the government may be perceived to compulsorily acquire part of the 'bundle' of property rights, while leaving the title with the landowner.

Binning and Young (1997) argue that conservation of biodiversity is a normal part of the production process for any landowner. After all, the landowner also captures some of the benefits of conservation. This means that the landowner has a "duty of care" and governments should not provide financial assistance to landowners to protect this biodiversity. Only those activities that go beyond the normal duty of care should be considered for cost sharing arrangements as the landowner is providing a community service by maintaining environmental quality beyond what is expected (Binning and Young 1997).

Nevertheless, the argument remains as to what constitutes more than the norm. Some studies seem to indicate that there is a relatively high level of community support for compensation payments to landholders independently of defining what is expected. For example, Whitten and Bennett (2001) undertook a Choice survey in the upper southeast of South Australia and the Murrumbidgee to investigate views on options for managing land in the region. In both regions, 68 percent of survey respondents felt that compensation should be paid to farmers if they were made worse-off by changes in land management practices to improve the environment. Only 9 percent of respondents felt that farmers should not be compensated, while the remainder were unsure. A Finnish study by Home (2004) suggested that a "clear majority of citizens are in favour of full compensation to the forest owners for lost revenues and possible costs of nature conservation action" (Horne 2004, p.2). These Finnish citizens indicated that they supported forest owners' sovereignty in forest management decisions.

Even though in Australia there seems to be strong support from community members for compensation payments to landowners, many landowners themselves remain unconvinced of the benefits that they are capturing by, for instance, retaining remnant vegetation areas on their farms. They indicate concern as to the effect on profitability. Not only are these landowners unsure about the benefits, they feel inadequately compensated for any costs arising from changing management actions aimed at conservation. Accordingly in the absence of attractive financial incentives or change in attitudes, the majority of farmers are likely to remain disinterested in the protection and management of conservation areas (Denys-Slee \& Associates 1998). 
A discussion of the programs and financial incentive available in Australia and Tasmania follows. Prior to this discussion however, a review of the relevant national and state regulation and suasion programs is presented. This review is not intended to be comprehensive, but rather to illustrate the range and extent of government involvement.

\subsection{Regulation and suasion}

The Commonwealth Government and through it, the states, is party to a number of conventions that pertain to conserving biodiversity. The International Convention on Biological Diversity is most relevant in this context (Nature Conservation Branch 2000).

A number of inter-governmental agreements exist between Tasmania and the Commonwealth which outline the respective responsibilities of the jurisdictions for various conservation related matters, such as the National Strategy for the Conservation of Australia's Biological Diversity (1996).

The Australian Government legislative mechanism for national environment protection and biodiversity conservation is by means of the Environment Protection and Biodiversity Conservation Act 1999 (EPBC Act). The Act provides for the protection of critical habitat, the preparation of protection plans, and the preparation of conservation agreements, among other things. When the EPBC Act was introduced, a national list of threatened species, ecological communities, and threatened processes that were endangered, vulnerable or extinct, was carried forward from the preceding Endangered Species Protection Act 1992. The list was expanded to include categories of threatened species that were critically endangered, conservation dependant, or extinct in the wild.

In Tasmania, the Threatened Species Protection Act 1995 provides for the conservation of threatened species and management of threatening processes. ${ }^{8}$ Schedules of the Act list more than 600 species of threatened plants and animals in

\footnotetext{
"A threatened process is defined in the Environment Protection and Biodiversity Consemation Act 1999 as such if it " ... threatens or may threaten the survival, abundance or evolutionary development of a native species or ecological community".
} 
Tasmania (Department of Primary Industries and Water - Threatened Species Section 2007).

The protection of biodiversity through the creation of conservation covenants is enabled under the Nature Conservation Act 2002. The Act sets out broad guidelines regarding the appropriate private reserve types (Protected Areas on Private Land Program 2003). Covenants and management agreements are enabled under the Land Use Planning and Approvals Act 1993. Section 71 of this Act allows a planning authority to enter into an agreement with a landowner and grant approval to register a covenant on the title which prohibits the clearing of vegetation (Binning and Young 1999). As well as legislation that underpins the conservation of biodiversity nationally and at a state level, the Australian Government supports many programs that can collectively be categorised as suasion (Figure 1).

Extension is achieved through, for example, the provision of funding to each State for a Threatened Species Network Coordinator. The coordinators provide advice and facilitate community involvement in the conservation of nationally listed species. A National Threatened Species Day is held every year to encourage biodiversity conservation. There are many more programs aimed at increasing the knowledge base with the ultimate aim of increasing conservation efforts. These programs include resource kits (e.g. Hands-on for habitat) and music kits (e.g. Logs have life inside), threatened species publications, threatened species networks, national poster competitions, and flora and fauna networks.

Idea and information exchange is also achieved by means of, for example, funding facilitators for the Land for Wildlife program in each State. The Federal Government funds Aboriginal education programs such as the Aboriginal Landcare Education Program in the Northern Territory (delivered through Greening Australia).

Aside from legislation and suasion, the government provides incentive programs aimed at biodiversity conservation. These are discussed in the next section.

\subsection{Australian incentive programs}

Much has been written about the different Federal, State and Municipal incentive programs aimed at achieving environmental outcomes that presently exist (e.g. James 1997; Bateson 2001; Comerford and Binney 2004). The programs that are on offer 
vary in their focus, and they are aimed at achieving different environmental outcomes: e.g. salinity reduction, soil degradation reduction, water quality improvement, and biodiversity conservation. A multitude of programs provide funding to undertaking management actions that are of benefit to conservation such as fencing and planting trees (e.g. Department of Environment and Water Resources 2006). In this study the focus is on programs that are aimed at biodiversity conservation through reservation.

The incentive programs aimed at biodiversity conservation have traditionally been delivered primarily by the three levels of govemment. Increasingly, however, the trend is to deliver the programs through Natural Resource Management (NRM) ${ }^{9}$ for instance Catchment Management Authorities (CMAs), stakeholder organisations such as farmers' federations, dedicated conservation organisations, and Non Government Organisations (NGOs). A summary of the delivery routes is shown in Figure $2 .^{10}$

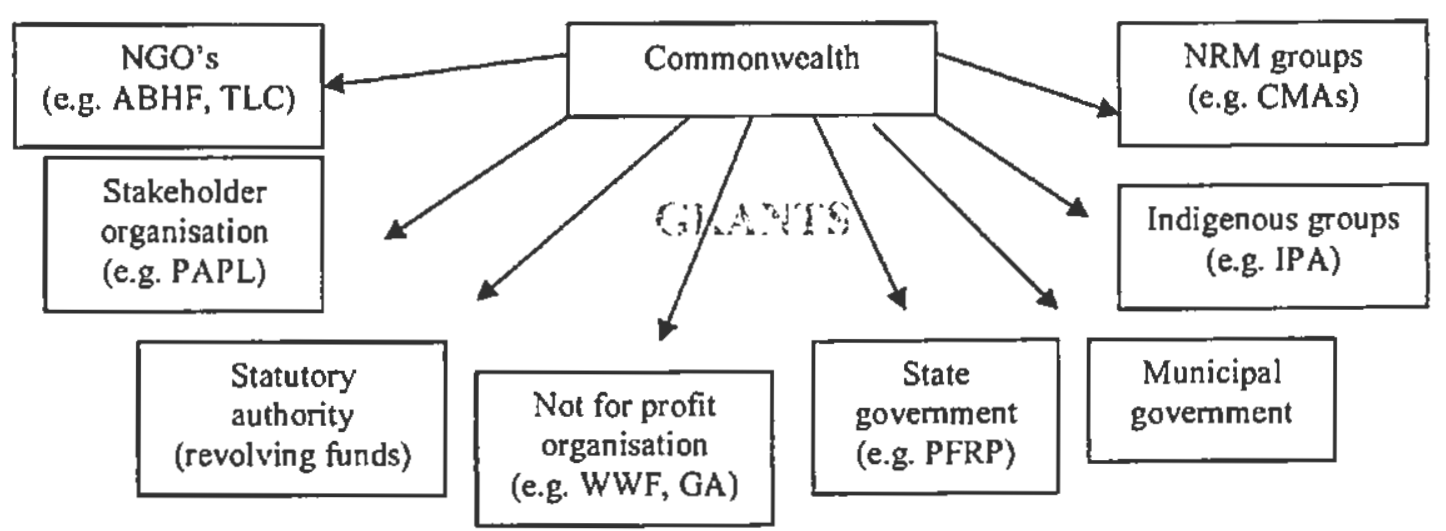

Figure 2: Delivery routes of Commonwealth funding.

One increasingly important method of achieving biodiversity conservation is through NGOs (see Bennett 1995). Funds donated to these NGOs to conserve biodiversity are, in most cases, fully tax deductible. Organisations such as the Australian Wildlife Conservancy (AWC), the Australian Bush Heritage Fund (ABHF), the former Earth

\footnotetext{
9 The delivery of NRM relies on the cooperation of Commonwealth, state and local governments, as well as that of regional NRM bodies specifically established to ensure delivery of at the regional level. Joint Australian and State/Territory Government steering committees are responsible for managing the delivery of the NAP and NHT across the states and teritories. NRM is delivered via the integrated implementation of the National Action Plan for Salinity and Water Quality (NAP) and the Natural Heritage Trust (Australian Government 2007).

${ }^{10}$ in this figure only Commonwealth funding is shown, obviously the States also collect and allocate taxes while NGOs also receive funding through private donations.
} 
Sanctuaries, and local organisations such as the Tasmanian Land Conservancy (TLC), buy land of conservation significance and tum private property into nature reserves. ${ }^{\prime \prime}$ The Australian Government indirectly provides these NGOs with means through which individual citizens can commit to protecting habitat (Kahn 1995).

The Commonwealth National Reserve System funding program (NRS) provides funding to local govermment, community groups, industry, and non-government conservation agencies to protect areas of land they purchase. The program provides two-thirds of the purchase price if the area is legally protected by means of a covenant and the proponents take responsibility for the management. This funding is not available to individual landowners (Department of Environment and Water Resources 2007).

Biodiversity is also protected by means of so-called revolving funds, which are a financially and legally effective method of ensuring conservation outcomes on private land (Mortimer 2003). The Commonwealth Department, Environment Australia (EA), developed a "Bush for Wildlife Revolving Fund" which is administered by statutory authorities or NGOs. The authorities that run these revolving funds purchase properties that contain an area of conservation significance. The authority subsequently protects the property by legal means (e.g. covenant on title) after which it is re-sold. After the re-sale of the land, the funds are retumed for new acquisitions.

Revolving funds have been established in New South Wales (Nature Conservation Trust of NSW), South Australia (Nature Foundation SA), Victoria (Trust for Nature), Queensland (Queensland Trust for Nature) and Western Australia (National Trust of Australia - Western Australia). These organisations are partly funded by Federal Govemment grants aimed at scheme establishment, covering administration costs, or creating employment opportunities. The Bush Brokers program in Western Australia was established in 1999 and also administers a revolving fund. The Brisbane City Council has a bushland acquisition program that is funded by an environmental levy,

\footnotetext{
"The growth in the private land conservation sector has been significant. For instance, incoming funds for the AWC increased from $\$ 2.5$ million to $\$ 5.5$ million in just one year. The "... AWC now owns and manages 10 properties across Australia covering more than 575,000 hectares (1.3 million acres) in the Kimberley, north Queensland, western NSW, the Flisders Ranges and the forests of southwestern Australia" (Australian Wildlife Conservancy 2002).
} 
which revolves properties after protecting their nature conservation values through rezoning or covenants.

Federal government "devolved grants" have been issued to Greening Australia (GA) to establish the Remnant Vegetation Fencing Incentive Scheme which grants conservation works for areas not necessarily under permanent protection. Funds are available through this scheme in New South Wales, Tasmania, Victoria, Queensland, and the Australian Capital Territory. Grants for on-ground conservation works for priority grassland are available through the Grassy Ecosystems Grants managed by the World Wildlife Fund (WWF).

Federal funds are provided to assist Indigenous landholders to manage protected areas on their land through the Indigenous Protected Areas (IPA) program. As well as the above direct grants programs, funds are delivered using different methods, for example Market Based Incentives (MBIs).

The majority of $\mathrm{MBI}$ schemes to date address land and water degradation problems. Transferable water entitlements in the irrigation regions of the Murray Darling in the early 1980 s and the performance bonds scheme implemented by the Great Barrier Reef Marine Park Authority in 1987 (van Bueren 2001) were some of the earliest quantity based MBIs in Australia other than fisheries quota systems ${ }^{12}$.

Property rights are an underpinning requirement for market creation and all tradeable right systems for different resources are based on this premise ${ }^{13}$. MBIs rely on enabling legislation and need a 'cap', or total load, to be set for a particular area (whether it be catchment or local government area) within which trading takes place.

Although the idea of biodiversity trading systems is widely debated at various forums (e.g. Key Issues in Australia's Biodiversity September 2000 Seminar Series, Discovery Centre, CSIRO, Black Mountain, Canberra) there is currently no such system that operates in Australia. However, recently an agreement for a biodiversity trading scheme was signed between the Environment Minister and the South Australian Farmers Federation (SAFF). Although no trading between farmers will

\footnotetext{
12 The most well known MBI is the tradeablc quotas that have been used in the fisheries industry for decades (for instance the Southern Bluefin Tuna Fisheries quota system commenced in 1984).

${ }^{13}$ The Agriculture and Resource Management Council of Australia and New Zealand (ARMCANZ) produced guidelines in relation to the creation of property right for water in 1995.
} 
take place, this agreement will allow farmers in the upper south-east of region South Australian to trade off their salt water drainage levy payments by protecting native vegetation and undertaking management activities on their property (Upper South East 2003). In a successful biodiversity trading market, landholders would protect an endangered ecological community or species, if the option is financially attractive when compared to other use options.

There are many concerns related to the feasibility and desirability of a system of biodiversity credits some of which centre around the intractable difficulties of creating markets in biodiversity due to the difficulties in allocating property rights (Doremus 2003). Some other issues that have been raised are the definition of trading units, the potential thinness of the market, the long production timeframe, and the geographical boundaries of the trading market.

The Department of Sustainability and Environment (2007) has been testing a system of auctioning government funds ("Bush Tender Trial") that may be used to undertake environmental management actions on private properties. ${ }^{14}$ This funds dispersal system is frequently categorised as a market-like approach. Prior to the auction, field officers visit the interested landholders in an area and agree on a management plan best suited to their property and which achieves optimal environmental outcomes. The landowner then submits a sealed bid nominating the amount of money required to undertake the management on their property. Assessing the nature conservation priority on the property and value for money, the auctioning body determines who will receive funding. Those who are elected to receive funding then sign at least a three-year agreement. ${ }^{15}$

An advantage of the process of auctioning the money available for environmental management is that it reveals market information about the minimum cost of various environmental management options. Because the auctioning process pays landowners at the price level they are willing to accept, the flexibility may result in a higher number of landowners being successful in obtaining these funds.

\footnotetext{
${ }^{14}$ Sometimes referred to as "price based MBIs" (Action Salinity and Water Australia 2002).

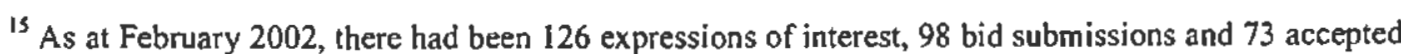
bids, accounting for $\$ 400,000$ in payments (Stoneham, Chaudhri et al. 2002 quoted in Chan, Laplagne et al. 2003).
} 
In Tasmania no auctioning of government funds has taken place to date. However, several programs disperse funding to landowners for conservation purposes. These are the subject of Section 2.5 .

\subsection{Tasmanian incentive programs}

In Tasmania a number of incentive progranıs are available to landowners to protect biodiversity. The Private Forest Reserves Program (PFRP) offers landowners funding for areas of high conservation significance if conservation covenants are placed on the land, or management agreements are entered into. The program was established through a $\$ 30$ million grant from the Commonwealth to the PFRP delivered through the State Government (Department of the Environment and Heritage n.d.). The program has been finalised and was replaced by the Forest Conservation Fund (FCF) Commonwealth program in mid $2006 .^{16}$

The PFRP offered two types of legally-binding conservation management agreements. ${ }^{17}$ The first was referred to as "a covenant", which is an agreement that is binding upon the title of the land. The second, referred to as "management agreements" involved personal contracts. Both these types of conservation agreements are "... contracts between a government authority, or NGO, ${ }^{18}$ and landholder, and they prescribe terms and conditions under which the landholder agrees to manage their land" (Public Land Use Commission 1996, p.37). The size and shape of the area of land to which the contract applies is determined in the agreement. In both types of conservation agreements, ownership of the land remains with the landowner.

The duration of conservation agreements can be fixed-term or permanent. A fixedterm, legally-binding management agreement is established through negotiation between the landowner and an NGO or government agency. The terms of the

\footnotetext{
${ }^{16}$ At the time this dissertation was commenced the PFRP was still in operation. Reference will thus be made to this program rather than the one that replaced it in 2006.

${ }^{17}$ Non-legaily-binding management agreements also exist where the landowner is not required to enter into contractual arrangements to receive funding. Land for Wildife is an example of a non-binding program which encourages and supports landholders to provide habital for native plants and animals on their property (e.g. Department of Sustainability and Environment 20n5).

18 The agreement can also be between all three: landowner, government authority and a NGO.
} 
agreement can only be altered with the agreement of all parties. The Private Forest Reserve Program in Tasmania offered temporary management agreements for periods up to 20 years. ${ }^{19}$

Covenants in perpetuity, also called permanent covenants, are developed in negotiation between the landowner and a government agency (or a government funded organisation). The document containing the covenant outlines the restrictions on the land and the management obligations and entitlements of the landowner (Binning and Young 1997). A management plan that sets out practical vegetation management actions is typically prepared in conjunction with a covenant. After the establishment of a covenant on title, the landowner may be able to access funds and/or assistance to achieve the vegetation management actions outlined in the management plan, such as technical assistance. The amount of technical advice and assistance available to landowners varies between covenanting scheme providers.

By 2005, protective conservation measures, including covenants, management agreements and operation plans, had been placed on 26,468 hectares comprising 180 properties under the PFRP. The program has paid an average of $\$ 536$ per hectare to secure these covenants, which was then approximately one third of the estimated market price. In exceptional cases, where no other options exist to protect a forest type, properties were purchased at an average cost of $\$ 1,022$ per hectare (Smith 2001). A total of 21 properties $(5,453$ hectares) had been purchased by the program at that time (Department of Primary Industries and Water n.d.).

Assistance and a range of incentives are provided by the Tasmanian Protected Areas on Private Land Program (PAPL) to place covenants or fixed-term management agreements on land. "PAPL is a joint initiative between the Natural Heritage Trust's National Reserve System, the Department of Primary Industries, Water and Environment, the Conservation of Freshwater Ecosystem Values Project, the Tasmanian Farmers and Graziers Association, and the Tasmanian Land Conservancy" (Department of Primary Industries and Water 2007). PAPL does not provide direct financial incentives in return for fixed-term conservation agreements, but does offer

\footnotetext{
${ }^{19}$ A 30 year agreement of the Remnant Vegetation Protection Scheme is offered in Western Australia (Kabii 2004); a 20 year property agreement is offered under the Native Vegetation Conservation Act 1997 in New South Wales. The Queensland Vegetation Incentives Program, the Heritage Agreement Scheme in South Australia offer temporary management agreements for periods up to 20 years.
} 
free technical advice, free drafting and registration of agreements. PAPL also assists in obtaining exemptions from State land tax for covenanted titles; and, in 15 of the State's 29 municipal areas, rate rebates for covenanted titles. Currently in Tasmania over 100 properties now have covenants established under PAPL (Jim Mulcahy, 2006, pers. comm.).

The development of management plans for Tasmanian properties is enabled through Private Forests Tasmania (PFT) as part of the property management planning process. PFT is a "government funded authority established to specifically promote, foster and assist the private forest sector to sustainably manage native forests and encourage the expansion of plantations" (Private Forests Tasmania 2006). The main focus of the program is forestry and plantation management but it has a limited provision for assistance in conservation matters. The program does not provide funds directly, but refers landowners to available programs in Tasmania.

Currently, no schemes provide funding to establish covenants and fixed-term management agreements on private land directly by municipal authorities in Tasmania. Fifteen out of 29 municipalities in Tasmania ${ }^{20}$ offer rate rebates for land that is protected by means of a covenant or management agreement. In some municipalities, a developer may negotiate to set aside some area for nature conservation in exchange for rezoning or other concessions. Rezoning is often referred to as a bonus development right where the developer foregoes the ability to develop a portion of a site.

Another tool for local councils is the so-called Green Offset. This is a market-based tool underpinned by the premise that the negative impact of a development can be offset by a positive environmental action on, or nearby, the development site. The organisation or person who wants to undertake the development will have to pay for the offset to take place or pay someone else to undertake the environmental action (Environment Protection Authority 2002).

The placement of a management agreement or covenant over a parcel of land is sometimes a prerequisite for gaining access to other monetary benefits, rebates, or

\footnotetext{
${ }^{20}$ These include: Burnie, Clarence, Devonport, George Town, Glamorgan/Spring Bay, Hobart, Huon Valley, Kentish, Kingborough, Latrobe, Launceston, Meander Valley, Soretl, Waratah/Wynyard, and West Tamar. Break O'Day had a scheme and cancelled it in April of 2005.
} 
concessions. For instance, tax relief is provided to landowners on the proviso that land is protected by means of a covenant or management agreement. ${ }^{21}$ Further, the landowner has access to subsidies and stewardship payments provided by all levels of government for the purpose of assisting the undertaking of further management actions on reserved land. For instance, PAPL monetary grants are available in some circumstances to assist with conservation works associated with conservation agreements (e.g. fencing). In some circumstances, entry into an agreement through PAPL may aiso attract priority assistance from other programs (Jim Mulcahy, 2006, pers. comm.).

The preceding discussion focussed on biodiversity conservation on private land through participation in a wide range of incentive schemes with different funding avenues. In the next chapter the literature concerned with the uptake of incentive programs and related conservation choice is reviewed.

21 The Federal Minister for the Environment and Heritage approved several covenanting programs for the purposes of the Income Tax Assessment Act 1997. In Tasmania the PFRP and PAPL were approved (Depariment of Environment and Water Resources 2006). 


\section{Literature review}

The previous chapter reviewed the incentive programs available to Australian landowners to conserve biodiversity on private land. Landowners are encouraged to participate in various incentive programs to formally protect areas of conservation significance on their land. By making such schemes available, govemments in Australia are aiming to increase landowner participation in conservation, thereby adding to currently existing areas of land set aside for biodiversity conservation. A better understanding of the decision framework surrounding the participation in incentive programs may help increase the total area of land set aside for biodiversity conservation in Australia.

An understanding of landowner participation can be gained through descriptive studies that look at, for instance, participation rates and areas managed sustainably (for instance in the annual reports of the former Private Forest Reserve Program in Tasmania; Vercoe 2003). Case studies can also provide an understanding of landowner behaviour. For instance, conservation auctions have provided information on the relationship between landowner participation and the level of compensation payment (Connor, Ward et al. 2007). Further, experimental economics can be used to understand landowner behaviour. This method was used to, for instance, test the efficacy of policy approaches and also to guide the "... design of an on-ground trial of a recharge cap and trade scheme" (Connor Ward $e l a l$. n.d., p.1). In addition, more complex studies based on behavioural models, having their origins in different disciplines, can also be undertaken to develop a complete picture of the decision to participate.

In this chapter the literature related to incentive program uptake and conservationrelated choice is reviewed. The focus of this review is on empirical studies carried out in the USA, Canada, Europe and Australia from the mid 1980s onwards and includes literature drawn from various disciplines. The review begins with an overview of biodiversity conservation by voluntary activity without receipt of funancial assistance. This is followed by a review of the behavioural models used in economics to study participation in incentive programs: profit maximisation and utility maximisation. These sections give an overview of the empirical literature as it 
relates to the behavioural models. Four groups of variables that are commonly found to affect participation are described. The last section of this chapter reviews different econometric approaches used to analyse the decision to participate in incentive programs, focussing particularly on the latent class method used in this dissertation.

\subsection{Voluntary conservation without participation in an incentive program}

Biodiversity values on private land can be protected by means of participating in an incentive program. However, biodiversity values can also be protected by voluntary activity without receipt of any financial or other assistance from any government or privately funded programs. The motivation for voluntarism may be the so-called "warm-glow effect" it generates (Becker 1992), but may also be explained by, for instance, tradition, reputation, or the desire for recognition by a community (Economic Focus 1998). Additionally, the landowner's short-term as well as longterm self-interest may be to protect biodiversity (Gunningham and Young 2001).

Voluntarism is not necessarily inconsistent with economic theory, which traditionally assumes that homo economicus operates in the pursuit of rational self-interest. From the perspective of behavioural economics ${ }^{22}$ it may be argued that self-interested individuals behave altruistically because they get some utility from doing so (e.g. Andreoni 1988, 1990).

Defining the characteristics of landowners who are likely to display voluntary behaviour is complex. Some studies have focussed on landowner experience as an important driver of voluntary behaviour. These studies have found that control and knowledge of the outcome of an action increases voluntarism (Slovic 1987; Kamppinen and Walls 1999). The more complex a system is believed to be, or the lower the level of knowledge about a system, the more cautious people are likely to be about change (Kamppinen 1997).

This finding is consistent with the success of education and awareness campaigns aimed at increasing the landowner's knowledge base which successfully increases

\footnotetext{
22 "A branch of economics that concentrates on explaining the economic decisions people make in practice. Behavioura] economists "... seeks to use psychology to inform economics" (Camerer 1999. p. 10575).
} 
voluntary protection of biodiversity by landowners (e.g. Kaplan 1984; Scherer 1990; Schrader 1995; Gilfedder and Kirkpatrick 1997). Gunningham and Young (2001, p.4) emphasise that motivational instruments and mechanisms that develop a "custodial ethic" and "community nom" are fundamental to successful biodiversity conservation.

The literature concludes that if there is a gap between public interest in biodiversity conservation and the private interests of the landowner it will make it more difficult to rely on voluntarism alone to meet conservation targets (Gunningham and Young 2001). Biodiversity values may be lost in the future if the reliance to conserve was solely on voluntary implementation of conservation practices, making a case for a range of policy instruments to be used (Chapter 2).

\subsection{Economic approach to studying landowner choice}

The importance of understanding the decision making process with regard to participation in policy programs was recognised, for instance, by Brotherton (1989). This recognition led to a focus on the development of theoretical behavioural models in economics (e.g. Lynne, Shonkwiler et al. 1988; Beedell and Rehman 2000), psychology, and the other social sciences (e.g. Sinden and King 1990).

In economics, the development of models explaining the decision of whether or not to participate in incentive programs have been based on two different behavioural assumptions: profit maximisation and utility maximisation. While the theoretical basis of these two behavioural approaches is discussed in Chapter 4, the empirically based literature that applies these models is reviewed in this section.

In a profit maximising framework, the decision of a landowner to participate in a conservation incentive program is guided by maximising profit in a single period or over time. Parks and Schor (1997) define the landowner's problem as maximising profit by choosing the optimum area of land to enrol in a program. This maximisation problem includes the option of selling the land.

Studies based on the profit maximisation framework clearly establish the link between participation rates and program funding amounts and the financial and resource constraints of landowners (Greiner, Herr et al. 2003). Plantinga, Alig et al. (2001) 
also find that policy instruments that offset higher opportunity costs are more attractive and encourage participation.

In a utility maximising framework other objectives the landowner may have for their land, including non-economic motivations can be incorporated (Chapter 4). These non-economic motivations have traditionally mainly been the focus of other disciplines (e.g. Vanclay and Lawrence 1995; Schaberg, Holmes et al. 1999; Vanclay 2004). More recently, however, many economic studies have found that both land ownership and management are strongly related to these non-economic variables (e.g. Erickson, Ryan et al. 2002; Jennings and van Putten 2003). These variables, which are now recognised as potentially having a significant impact on management decisions and participation rates, cannot be easily encompassed in a strict profit maximising framework. In this context a utility maximisation framework is a less restrictive framework and will accommodate these non-economic variables (Lynne, Shonkwiler et al. 1988).

A sizable empirical literature in economics has been developed, particularly agricultural economics, that examines the impact of a range of landowner characteristics, property characteristics, and the business aspects of the farm operation, on participation in incentive schemes within the utility maximising framework. For instance, several models were developed to describe landowner participation in programs aimed at changing management practices, in particular soil management (e.g. Ervin and Ervin 1982; Esseks and Kraft 1986; Drost, Long et al. 1996).

Where the utility maximising approach has been applied to the incentive scheme participation decision four main groups of variables form the landowners' decision framework: program characteristics; landowner characteristics; property and business characteristics; and landowner attitude (e.g. Purvis, Hoehn et al. 1989; Cooper and Keim 1996).

The next sections review the literature that has investigated participation in incentive schemes from the perspective of one or more of these four groups of variables. Not all studies reviewed apply the utility maximising approach and some studies are from other disciplines, such as, psychology. The headings of the sections below reflect the variable group on which that section focuses. 


\subsection{Program characteristics}

An incentive program may be characterised by a number of attributes, such as, funding amount, length of the commitment, and legal implications. A small number of studies has focused on the link between program attributes and landowner utility maximisation and the impact of the program attributes on the decision framework (e.g. Purvis, Hoehn et al. 1989; Cooper and Keim 1996).

Much of the literature linking the likelihood of participating in a scheme to the monetary rewards offered is based on findings from the soil conservation and management programs in the USA. These empirical studies confirm the relationship between the size of an inducement payment and the likelithood of participation. Farmers are found to be more likely to participate in a soil conservation program with higher payments for the implementation of a series of management actions (Purvis, Hoehn et al. 1989). This finding is confimmed by Cooper and Keim (1996) and Greiner, Herr et al. (2003) who found that the likelihood of implementing soil conservation practices increased with higher inducement payments. Lynch, Hardie et al. (2002) also found that installation of riparian buffer zones in Maryland in the USA increased with higher incentive payments.

Higher payments also increased participation in conservation reserve programs for highly erodable cropland in the USA (Esseks and Kraft 1986). Stevens, White et al. (2002) found that US landowners were guided by monetary motives and required 'realistic' levels of compensation in order for them to agree to participate in programs where they lose private rights such as access and timber rights (see also Chisholm and Dumsday 1988 in Australia). ${ }^{23}$

The positive relationship between higher payments and increased participation seems to be straightforward. However, there is little information on the shape of the curve describing this relationship. It is also unclear from the above studies whether there are any 'groups' for whom the response to higher payments varies, that is, who would not, under any circumstance, participate.

Several other program characteristics have also been found to impact on participation rates. Wynn, Crabtree et al. (2001), who studied the effect of participation in

\footnotetext{
${ }^{23}$ The study finds that U'S landowners are very reluctant to loose these rights.
} 
environmental schemes on farm income in Scotiand, found that high compliance cost, which effectively reduces total farm income and effort required after joining the program, would both decrease the likelihood of participation.

Many studies also suggest that longer periods of commitment to a scheme had a significant negative impact on the uptake of a program (Esseks and Kraft 1986; Gasson and Hill 1990; Stevens, White et al. 2002; Horne 2004). The relationship between scheme duration and the likelihood of scheme participation was not found to be significant in a study in the UK by Wilson (1997).

Program flexibility, in particular allowing for easy succession planning for families, was also found to affect participation (Wilson 1997). Johnston, Swallow el al. (1999) found in a valuation study, which estimated citizens' willingness to pay (WTP) for a watershed management plan in the USA, that confidence in the payment mechanism as an efficient and guaranteed funding source had a significant positive impact on program uptake. Dedrick, Hall et al. (2000) found that landowner attitude towards the agency responsible for delivering the program also determined participation.

Home (2004) examined the factors that affect the acceptability of biodiversity conservation and the amount of compensation needed in private forests in Finland. In this study it was found that the legal implications of joining a conservation incentive program had an impact on the acceptability of entering into a contract to protect biodiversity.

\subsection{Landowner characteristics}

Although only a small number of studies included program characteristics in their economic analysis (reviewed above), many studies have included the influence of socio-economic factors on landholder decision making and participation in incentive schemes. Wilson (1996), Drake, Bergström et al. (1999) and Greiner, Herr et al. (2003) all reported that socio-economic characteristics, such as age, education, and residency, were important in explaining farmer conservation behaviour and participation.

Younger people who were preoccupied with pursuing other activities were found less likely to participate in incentive schemes than older people by Steel (1996) and Lynch, Hardie et al. (2002) in the USA and Dupraz, Vanslembrouck et al. (2003) in 
Europe. Higher education had a positive effect on likely participation in Europe (Wilson 1997; Dupraz, Vanslembrouck et al. 2003) and longer residency increased the willingness to enter an incentive program in Wales in the UK (Wilson 1997).

Landowner tenure has also been found to have an impact on the willingness to participate in incentive programs in a number of studies. For instance, landowners were associated with faster entry into programs in Scotland than those who rented their land (Wynn, Crabtree et al. 2001). Further, non-farmers were more likely to participate in erosion control programs than full-time farmers (e.g. Force and Bills 1989; Kraft, Lant et al. 1996), possibly because non-farmers were in a more favourable financial situation.

Mixed results were found in studies that included the effect of succession plans on participation in incentive programs. The intention to transfer a farm to a successor, thereby extended the planning period length to include the successor, may discourage a landowner from addressing an environmental issue by means of participating in a scheme. Long term planning horizons may tend to discourage landowners from incurring costs to address environmental issues in the short run. In contrast, Ervin and Ervin (1982) found that longer planning periods were associated with lower discount rates which are associated with making participation more attractive. However, Wynn, Crabtree et al. (2001) report that in Scotland, the presence of a successor to lake over the farm did not have an impact on the likelihood of farmer participation in conservation schemes.

Landowner awareness of an environmental problem also has a significant impact on likely participation in incentive programs. Esseks and Kraft (1986) in the USA, and Sinden and King (1990) in Australia found that landowners who know of an environmental problem on their farm, were more likely to implement measures to control these problems on their property.

Landowner awareness of available incentive programs and the options provided by the programs, also impacted on participation. Landowners who did not participate in conservation incentive schemes were generally less aware of, and less informed about, available incentive schemes than those who participated. A history of prior participation in incentive schemes in Europe also significantly increased the 
likelihood of entry into another scheme (Drake, Bergström et al. 1999; Wynn, Crabtree et al. 2001).

Awareness of incentive schemes is frequently gained through neighbourhood networking. Networking increases the probability of participation in a program (Skerratt 1994 quoted in Wynn, Crabtree et al. 2001). Drake, Bergström et al. (1999) also found that participating neighbours and relatives had a positive influence on the likely participation of a landowner.

\subsection{Property and business characteristics}

Business and property characteristics that have been found to play a role in the decision framework include property size, agricultural use, income, and household debt. Landowners with larger farms in Europe were more likely to participate in environmental programs (Drake, Bergström et al. 1999; Dupraz, Vanslembrouck et al. 2003). Increased participation is likely to be due to economies of scale for larger farms in producing conservation benefits because fencing, for instance, can be carried out using existing infrastructure. Higher participation of larger farms may also be attributable to lower marginal utility of lost income.

An evaluation of the Environmentally Sensitive Area scheme (ESA) in the United Kingdom found that one of the main factors determining participation was the changes required to the land (Wynn, Crabtree et al. 2001). Where the scheme prescription fitted the farm situation better ${ }^{24}$, the probability of participation in a scheme increased. If there were many changes required to the way the farm was being managed, it was likely to impact negatively on the decision to participate in an incentive program (Vanclay and Lawrence 1995; Drost, Long et al. 1996) as it was more costly to enter.

Similarly, Esseks and Kraft (1986) found that participation in a conservation reserve program in the USA was more likely when some grazing was allowed, suggesting that this would allow landowners to continue their current practices relatively unaltered, thus making it less costly. A report prepared by Gilfedder and Kirkpatrick (1995)

\footnotetext{
${ }^{24}$ This can also be interpreted as the attribute of a scheme (section 3.3). However it is presented in this section as the focus is on changes to existing property characteristics.
} 
indicated that higher participation rates in Tasmania were likely when the landowner was paid for changing management practices while maintaining some productive capacity of the land.

The role of off-farm income has been found to have two potential effects on participation in incentive schemes: it may reflect the availability of additional funds (Loftus and Kraft 2003); and, on the other hand, it may reflect the need of the family to have additional income to cover living expenses (e.g. Tisdell and Harrison 1999). Farmers in the USA who were less reliant on farm income were found to be more likely to participate in a conservation reserve program (Loftus and Kraft 2003). Farmers, whose primary income source was from farming, who anticipated production losses, and hence lower farm income, from conserving biodiversity by setting aside forested areas were less likely to participate in incentive programs in Australia (Tisdell and Harrison 1999).

Landowners with larger farm debt, and who depended on farming for their income, were less likely to participate in incentive schemes or to implement conservation actions (Loftus and Kraft 2003). The authors speculated that these landowners may not have been financially able to incur what was perceived to be the high opportunity cost of setting aside productive areas of their property. Farmers with high debt levels may be forced to place greater weight on financial returns, which may not include conservation.

Force and Bills (1989) indicate that opportunity costs explained much of the participation in the soil conservation scheme in New York State. Landowners who were reliant on the income obtained from farming only, were less likely to participate in incentive programs. Landowners with fewer financial constraints were also more likely to join an incentive program (Gasson and Potter 1988).

The studies reviewed thus far found that a range of program characteristics, landowner characteristics, and property and business characteristics impacted on the decision to participate in an incentive program. The utility maximisation approach (discussed in detail in Chapter 4) also accommodates a range of non-economic motivations, including attitudes to environmental issues and conservation. The behavioural foundation for the role of attitudes in decision making originates in psychology (discussed in detail in Chapter 4). The ability to 'measure' attitudes 
allows them to be incorporated into an economic model. The effect of attitudes on participation is the subject of the next section.

\subsection{Landowner attitudes}

Attitudes $^{25}$ have been found to play a significant role in decision making processes. In this context, a number of studies have related environmental attitudes to the choice of participation in incentive programs aimed at conservation. Other studies that have incorporated a variable for attitude in landowner decision models have generally based this variable on the measurement of an individual's pro-environmental or antienvironmental attitude or belief (e.g. Aldrich et al. 2005). The measurement of environmental attitude was operationalised by Dunlap and van Liere (1978). Studies that incorporate environmental attitudes frequently measured these attitudes using Likert (1932) scale rating systems applied to questions that weigh the value of nature versus economic growth (Corbett 2002).

Klosowski, Stevens et al. (2001) established that those landholders who participated in incentive programs had a more favourable attitude towards the environment. Luzar and Diagne (1999) and Drake, Bergström et al. (1999) also found that their results supported the hypothesis that landowners with a positive environmental attitude were more likely to participate in reserve programs. In Europe Dupraz, Vanslembrouck et al. (2003) found that attitudinal characteristics towards the environment strongly affected participation in different agri-environmental schemes. Gasson and Potter (1988) in the UK found that farmers' responses to incentives were dependent on their attitude to conservation.

A variety of papers have examined the influence of attitude on conservation behaviour. For example, Söderqvist (2003) found that a landowner with a positive environmental attitude was guided by the feeling of 'doing some good for the larger community" and concluded that the relevance of the "public environmental benefits were a rather important motive for farmer participation" in incentive programs (Söderqvist 2003, p. 117). Lynne, Shonkwiler et al. (1988) also found that stronger conservation attitudes raised voluntary conservation effort in the USA and concluded

\footnotetext{
${ }^{25}$ Attitudes are leamed stable psychological tendencies to evaluatc particular entities with favour or disfavour.
} 
that this may reduce the need for net incoming-enhancing programs. Wynn, Crabtree et al. (2001) found that landowner attitude to conservation explained early entry into conservation schemes (timing) but did not impact on the probability of entry. The link between attitude and entry into a program is also questioned by Vanclay and Lawrence (1995) who indicated that landowner behaviour may change due to intervening factors, such as financial opportunity, even if the attitude remained the same.

As the literature discussed so far suggests, the participation decision is expected to depend on a number of variables that can be loosely classified as program characteristics, landowner characteristics, property and business characteristics, and landowner attitude.

As mentioned in Section 3.3, the attributes of an incentive program are expected to play a role in a landowner's decision to participate in a program. The Choice survey approach gathers data in a way that allows the measurement of the contribution of different attributes of a good or service, or in this case incentive program, to the choice. A brief review of the choice modelling literature, in particular environmental choice modelling, is given below.

\subsection{Choice survey}

The choice modelling approach investigates "... people's willingness to give up some amount of an attribute ${ }^{26}$ in order to achieve more of another" (Bennett 1999, p.3). Variation in the level of the environmental alternatives and an associated cost with at least one of the attributes means that the marginal rate of substitution of the attributes can be found or can be used to derive implicit prices or to develop welfare measures (Bennett 1999).

Choice modelling was first used in a marketing context (e.g. Wittink and Cattin 1989; Farber and Griner 2000) to elicit responses to goods and services with various potential combinations of attributes (e.g. Eamhart 2002 in the context of housing decisions). The choice technique was later used to assess the dollar value of goods,

\footnotetext{
${ }^{26}$ An attribute is the description of the environment/product/service (for example the colour red is the attribute of a car which is the product).
} 
such as environmental goods, that are often not traded in a market. More recently choice modelling has been used to investigate equity preferences in benefit cost analyses (Scarborough, Bennett et al. 2004), to value recreation, transport, health, and in the context of cultural valuation. The question of allocating funds to policy programs so that welfare is maximised can be addressed by measuring the effect of different policies and estimating the change in utility between different groups in society.

Rolfe, Bennett et al. (2000, p.i) used a choice experiment to " ... estimate the values held by Brisbane residents for both environmental and social factors associated with tree clearing in the Desert Uplands region of central-western Queensland". Mallawaarchchi, Blamey et al. (2001) examined placing a value on the protection of natural vegetation in areas suitable for cane production. Whitten and Bennett (2001) identified the non-market value of wetlands in the southeast and eastern region of Australia. The value of watershed quality improvements was investigated by Farber and Griner (2000) in the USA. A paper by Kerr and Sharp (2004) used choice modelling to estimate the types and scale of mitigation that were acceptable to local communities in New Zealand to compensate for adverse environmental effects in streams from development projects. Choice modelling was also used to assess the value of amenities and quality improvement of recreation locations by Schroeder and Louviere (1999) and Hearne and Salinas (2002) in Costa Rica. The latter study demonstrated that in general tourists preferred improving infrastructure, information, and low entrance fees. Tourists from outside the country preferred restrictions in the access to some trails and had a higher marginal willingness-to-pay for information.

Choice modelling has been used to estimate cultural values and trade-offs. Rolfe and Windle (2003) estimated the non-use value of protecting cultural heritage sites in relation to further water allocations to irrigation. Cultural values for large increases in protected areas, as estimated by non-indigenous groups, were lower than for aboriginal people. However, non-indigenous groups held positive values for small increases of protected cultural heritage site. A similar study was carried out by Windle and Rolfe (2002) that looked at the values held by aboriginal people and other groups in society on floodplain development. Again, differences between the way non-indigenous people and indigenous people value water were evident. The general 
community was more concerned about environmental issues than additional protection of cultural heritage sites.

Choice modelling has been used in the medical and health care sectors eliciting nonuse value for several health related issues. For instance, Scott, Watson et al. (2003) used choice modelling to determine patient preferences for 'out of hours' care. Farrara, Ryana et al. (2000) showed that choice modelling was useful within the area of health care priority setting to estimate cost per unit of benefit ratios for competing clinical service developments.

Very few studies have applied choice modelling to study preferences for the attributes of policy instruments. Conjoint analysis ${ }^{27}$ was used in a policy context to "... examine landholder attitude toward specific management program attributes and requirements" by Stevens, White et al. (2002, p.169). The study found that US landowners were reluctant to lose private rights such as access and timber rights and would not participate in incentive programs without realistic levels of compensation of between US\$ 53 and US\$185 per hectare per year.

A study by Home (2004) carried out in Finland was the only study at the time of writing that used choice modelling for a decision problem similar to that of this research. Home $(2004$, p.3) examined factors that affect the "acceptability of voluntary contracts of biodiversity in non-industrial private forests and the amount of compensation needed". If the forest owner is the initiator of the contract, an average compensation of 224 euro per hectare would be needed to protect small areas of forest for 10 years.

An overview of the econometric modelling methods that were used in the literature is presented in the next section. The econometric methods include logit, probit, multinomial logit models, tobit modeIs, and latent class analysis. The latent class analysis is used in this current research.

\footnotetext{
${ }^{27}$ Conjoint analysis is a statistical technique used to determine how people value different attributes of a product. Utilities of different levels of an attribute can be calculated on the basis of listing the combinations of product attributes in order of decreasing preference (Lilien and Kotler 1983).
} 


\subsection{Econometric modelling approaches}

The decision to participate in an incentive program is a binary choice (yes/no or $1 / 0$ ) and as such the dependent variable is a discrete outcome. In the logit and probit approaches the dependent variable is discrete. These models are collectively also known as qualitative response models (Green 2003). The goal of the models is to quantify the relationship between the independent variables (such as socio-economic and business characteristics) and the probability of joining a program. Logit models are most often used to analyse participation in incentive programs aimed at changing management that benefits environmental and conservation outcomes.

A logit model was used by Wynn, Crabtree et al. (2001) to predict the probability of entry into a scheme aimed at changing land management practices. The dependent variables in their model were related to landowner and property characteristics. Drake, Bergström et al. (1999) used the logit model to explain participation in an agrienvironment scheme. They also used socio-economic variables as the independent variables. In Australia, a logit model was applied to investigate the adoption of soil conservation measures in New South Wales by Sinden and King (1990). The independent variables in their study included the adoption process, land factors, personal factors, economic factors, and institutional factors.

Söderqvist (2003) applied a logit analysis to investigate the determinants of Swedish landowners' willingness to participate in a wetland creation program, including observable and non-observable landowner characteristics and attitudes. Stevens, White et al. (2002) applied a logit model including socio-economic and program characteristics (including funding amount), and attitude variables to predict participation in a forest management program. A logit model was applied by Force and Bills (1989) to examine participation rates in a conservation reserve program in New York. They included socio-economic as well as attitudinal variables in their model.

A study by Klosowski, Stevens et al. (2001) applied a logit model to estimate the effects of the economic incentives offered by a hypothetical scheme on the likelihood of participation. ${ }^{28}$ This study particularly focussed on the probability of coordinated

\footnotetext{
${ }^{28}$ The results were compared to those obtained using OLS regression.
} 
management between landowners and included attitudinal variables. Esseks and Kraft (1986) used a logit regression to determine whether changes to incentive scheme characteristics in southern Illinois would change likely participation.

In addition, Soule, Tegene et al. (2000) used a probit model to analyse the influence of land tenure on the adoption of conservation practices. Cooper and Keim (1996) used a probit model to predict farmer adoption of environmentally sound practice as a function of the payment offer. The predictive powers of the logit and probit specifications are generally comparable, but the higher computational demands of the probit model and the generally weak theoretical justification for employing a probit specification limits practical use of this model. This means that the logit model is more widely used in empirical work (Greene 2003).

The logit and probit models are used in the context of binary choice models. If these models are generalised to more than two alternatives they are referred to as multinomial logit models. Multinomial logit models are frequently used in studies that gather decision data using a choice modelling approach. A study by Horne (2004) in Finland applied a multinomial logit model to predict participation in a conservation incentive program. Horne's (2004) study incorporated independent variables related to landowner, property, and incentive program characteristics.

An early study by Purvis Hoehn et al. (1989) applied a tobit model to estimate the participation in a filter strip program. In tobit models the dependent variable is continuous instead of discrete, which allowed participation rates to be estimated. The independent variables included payment level, transaction cost, and future expectations and preferences as independent variables. Tobit models are a direct extension of the logit/probit models. Tobit models relate to both quantity and probability, frequently referred to as joint decisions models (Green 2003).

Another approach to analysing choice data that characterises heterogeneity in preferences for program attributes on the basis of attitude and socio-economic characteristics is the latent class approach. In this approach classes of individuals are assumed to be homogenous with respect to their preferences for alternatives as well as their sensitivity to changes in the levels of the attributes of the alternatives (Lee, Fujiwara et al. 2003). 
No previous study has used the latent class approach to incentive program choice as is applied in this dissertation. The development of latent class models and their application to date is reviewed below. The latent class model is specified in Section 5.1 .

\subsubsection{Latent class models}

The development of latent class models using empirical data is common in many disciplines including the health sciences (e.g. Bucholz et al. 1996; Sullivan, Kessler et al. 1998; Thatcher, Morey et al. 2003), social sciences (e.g. McCutcheon 1987; Yamaguchi 2000), marketing (e.g. Swait 1994), and in travel behaviour research (e.g. Lee, Fujiwara et al. 2003). The latent class approach has also been applied in a study by Bijmolt, Paas et al. (2003) to analyse country and consumer segmentation in Europe with respect to financial product ownership.

A limited number of studies has developed latent class models of environmental economic preferences (e.g. Boxall and Adamowicz 2002, Morey, Thatcher et al. 2006, Scarpa and Thiene 2004). The models in these studies are estimated with the intention of identifying and characterising heterogeneity in environmental preference data. Boxall and Adamowicz (2002) applied the latent class approach to wilderness park choice data. They developed a model of wilderness recreation demand for five wilderness parks in Canada incorporating attitudinal measures and stated preferences over wildemess park attributes. The results showed that four classes of recreationists exist. Morey, Thatcher et al. (2006) developed a latent class model characterising angler heterogeneity with respect to fishing characteristics of Green Bay in Wisconsin, USA. The results of this study suggest that "Green Bay anglers separate into a small number of distinct classes with varying preferences and willingness to pay for a PCB-free Green Bay" (Morey, Thatcher et al. 2006, p. 91). Scarpa and Thiene (2004) used the latent class approach to model the destination choice of rock climbers in the northeast Alps of Italy. Their study revealed four 'well defined classes' on the basis of climber preference for alpine climbing destination attributes. Unlike the previous two latent class studies, this study did not incorporate an attitude or motivation variable in the model.

In the current research the latent class modelling approach is applied to landowners' choice of conservation incentive programs incorporating landowner attitude and socio 
economic characteristics. The rationale for using the latent class approach is that it is expected that landowner heterogeneity is reflected in their preferences for incentive programs attributes. Understanding landowner heterogeneity is particularly important from a policy perspective. Understanding landowner heterogeneity would enable better targeting of incentive programs and can potentially help prepare managers for unintended consequences of some programs. It would also enable a better understanding of the distributional consequences of landuse policy and programs.

Some economic models account for heterogeneity by including socio-economic variables in the utility function or by stratifying individuals into segments on the basis of socio-economic variables. While these models 'account' for preference heterogeneity they do not adequately 'explain' the source of it, where heterogeneity may reflect other characteristics of individuals such as the motivation, attitude, and past experiences (Boxall and Adamowicz 2002).

To adequately explain heterogeneity in demand analysis " ... there must be a priori knowledge of the element of heterogeneity" (Boxall and Adamowicz 2002, p.422). The latent class approach has advantages in explaining heterogeneity by constructing classes on the basis of observed measures such as attitude scales. Latent class models enhance the explanation of heterogeneity by incorporating unobserved heterogeneity and by adding structure to the distribution of unobserved heterogeneity.

The latent class approach has not previously been applied in the type of study central to this research. The latent class choice modelling approach is discussed in detail in Chapter 5. Prior to this, Chapter 4 presents the theoretical foundations of the economic and psychological models used in this research. The use of choice modelling in the context of the theoretical approach is also discussed. 


\section{Theoretical framework}

Chapter 2 described the ways in which the market for biodiversity on private land in Australia fails to provide a socially optimal outcome. One of the ways in which govemment addresses this market failure is through the provision of incentive programs that make available funding for the protection of biodiversity. Convincing landowners to set areas aside for conservation is paramount if adequate protection is to be achieved through voluntary measures. Understanding the decision framework of landowners who own and manage land of conservation values is important to ensure adequate numbers enrol in the available schemes (Chapter 3). Moreover, it is important to understand landowner preferences in a scenario where entry is forced if voluntary measures do not adequately achieve conservation targets.

In Section 4.1 the economic theory and behavioural foundation of land use decisions by landowners is explored. The data used to build an empirical model describing landowner preferences for incentive program attributes are gathered in this research using a Stated Preference (SP) method called choice modelling. In Section 4.1.1, the behavioural foundation, based in the field of psychology, which underpins the use of the SP technique, is briefly explored. The SP choice modelling approach also has its roots in two distinct areas of economic theory: Random Utility Theory (RUT); and Lancaster consumer theory. In Sections 4.2 and 4.3 the latter two theories are discussed. Choice modelling is also founded in decision making theory developed in psychology discussed in Section 4.4. Chapter 5 presents the model estimation method and the statistical analysis used in this current research.

\subsection{Economic theory and behavioural foundation}

In economics the two most common approaches to studying landowner decision making are profit maximisation and utility maximisation (Chapter 3). Utility maximisation forms the basis of neoclassical theory of consumption. Standard consumer choice theory develops models that analyse a range of choice problems. In these models consumers are assumed to optimise their utility subject to budget constraints and other factors. Consumers are assumed to be rational decision makers who assign preferences to different bundles of goods and will choose the preferred 
alternative. If a consumer has stable preferences then a consistent pattern of choice emerges. Utility can explain economic behaviour in terms of individuals aiming to increase, or maximise their utility.

In this current research the landowner's decision to set aside a parcel of land for conservation is considered in the utility maximising framework. A landowner will conserve biodiversity values if the overall utility obtained from setting the land aside is greater than the utility of the status quo. From micro economic theory it follows that each individual chooses alternatives that maximise utility subject to budget constraints and other factors.

In the literature reviewed in Chapter 3 the variables that contribute to the decision to protect land for conservation purposes were explored. Schematically this decision framework is described in Figure 3.

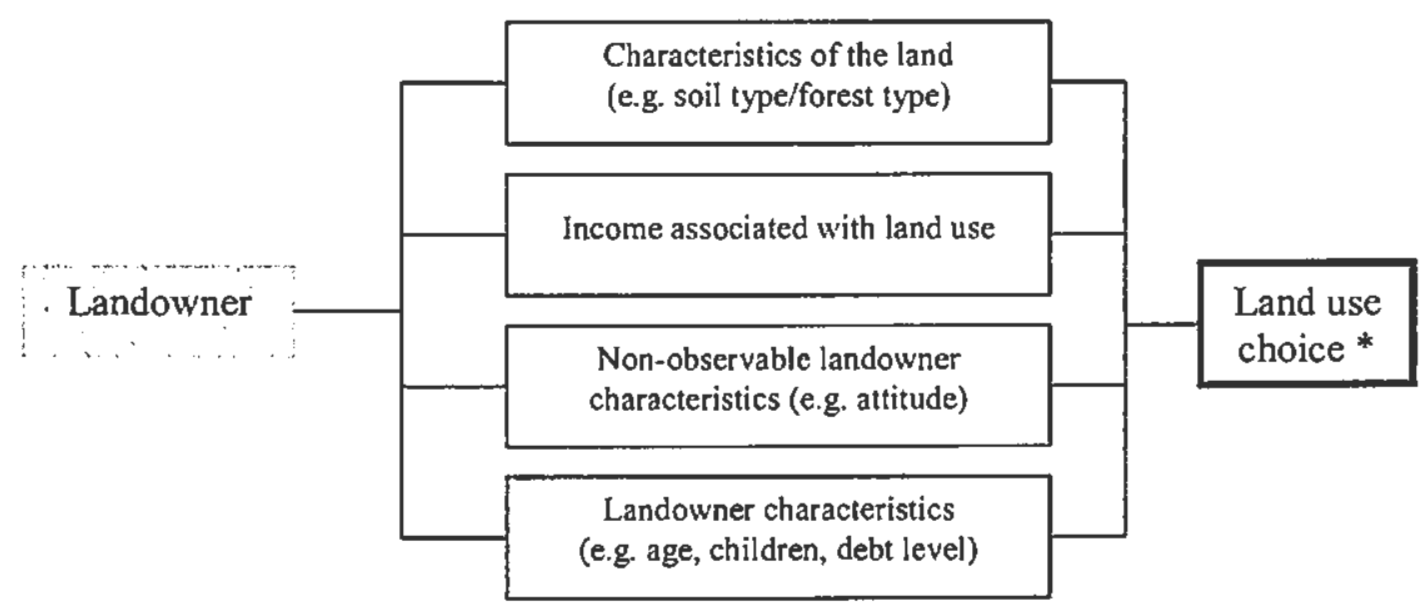

* e.g. Growmg Potntoes, Tourist accommodatıon, Vineyard, and/or Conservation.

Figure 3: Groups of variables included in a landholder's land use decision framework.

As shown in Figure 3 above the landowners' land use decision framework is made up of four groups of variables which are income, property characteristics, socio economic characteristics of the landowner, and landowner attitudes. ${ }^{29}$ The variables that make up the groups are likely to have varying impact on the land use choice. Some interaction between variables may also be expected. For example, property

\footnotetext{
${ }^{29}$ Although there is no general agreement in the psychology literature upon what the term attitude denotes, most psychological definitions includes statements about an underlying state of mind or a feeling or disposition to behave in a certain way (e.g. Strauss 1945).
} 
characteristics are expected to impact on income because soil types partly determine and limit production options. Landowner characteristics such as age or life stage may also impact on the land use choice, and thus on, for instance, conservation management activities. The land use choice for a parcel of land change to conservation only if the overall utility obtained from conserving the land is greater than the status quo, assuming the land is not already conserved.

In the literature reviewed in Chapter 3 the attributes of an incentive program were reported to have an affect on landowner participation in conservation incentive programs and thus, ultimately, on the landowner's land use decision. Program attributes included not only the subsidies received (hereafter referred to as compensation funding) but also, for instance, the legal implications and land use restrictions imposed by the incentive program.

The choice modelling approach is used in this current research to analyse choice behavior with respect to joining incentive programs. The data used to estimate landowner preferences for attributes of incentive programs are gathered using a Choice Survey. Choice modelling is one of a number of SP techniques used in the valuation of environmental goods. Others are, for instance, Contingent Valuation (CV), contingent rating, contingent ranking, and paired comparison (Morrison, Blamey et al. 1996). The behavioural assumptions that underlie SP techniques have their origins in psychology.

\subsubsection{Behavioural foundation of the Stated Preference technique}

Adamowicz, Louviere et al. (1998) note that SP techniques were developed as a natural analogue to the "... already well established Revealed Preference (RP) method" (p.7). RP techniques, which includes the travel cost method, hedonic pricing, and the averting behaviour methods, are also commonly used to assess environmental use and non-use values (Morrison, Blamey et al. 1996). The RP technique was not used in this research as this type of information was not available from previously defined programs.

The SP approach gathers data by asking subjects to make choices between hypothetical situations. The SP technique generates behavioural data from subject choices, but is in itself not a theory of behaviour (Adamowicz, Louviere et al. 1998). 
Consumer choice theory and econometric modelling techniques are applied to data gathered by means of SP techniques.

As mentioned previously, choice modelling is a SP technique. In choice modelling, respondents choose the most appealing/best/most important of two or more goods or services described by a number of attributes (sometimes also referred to as characteristics in the literature). The choice modelling approach elicits choices between different combinations and varying levels of the attributes describing a good. The marginal rate of substitution between pairs of attributes can be found using choice modelling (Bennett 1999) and implicit prices or welfare measures can be estimated.

The behavioral assumptions that underlie SP techniques, which are as such relevant to choice modelling, were developed by Thurstone $(1927,1959)$ and originate in psychology. The behavioral model that underlies the paired comparisons format posits that people are able to compare two states of being and determine what is, for example, 'best - worst', 'less preferred - more preferred', or 'most - least important' (Thurstone 1927). Later, Thurstone (1959) developed the behavioral assumption that supports the premise that people are able to make comparative judgments. Thurstone's models posit that people are able to choose between two extremes out of sets of three or more (Louviere 1994; Buckley, Devinney et al. 2004).

\subsection{Random Utility Theory}

The behavioural theory at the foundation of SP is consistent with random utility theory (RUT). It is consistent with utility maximisation as a conceptual economic framework (Adamowicz, Louviere et al. 1998). The behaviour of respondents can be forecast from an estimated utility function, which, in microeconomic theory is assumed to be coherent and invariant (Fujii and Gärling 2003).

RUT is used to estimate the probability of choice. To estimate these probabilities the utility $(U)$ that individual $(n)$ receives from choosing alternative $(i)$ can be represented by equation 1. Variations in consumer choice can be explained by including a random element in the utility function (following the presentation of Adamowicz, Louviere et al. (1998), Boxall and Adamowicz (2002) and Walker and Ben-Akiva (2002)).

$U_{m}=V_{m}+\varepsilon_{n t}$ 
$U_{m}=$ Unobserved utility of consumer $n$ from altemative $i$

$V_{n t}=$ Observable component of utility of consumer $n$ from alternative $i$

$\varepsilon_{m}=$ Random unobserved component of utility of consumer $n$ from alternative $i$

The observable component of utility is a vector of factors that affect consumer n's utility, including choice-specific or individual-specific factors. The systematic component of utility that specifies the relationship between the explanatory variables $(X)$ and choice behaviour can be written as follows:

$V_{m t}=\alpha_{m}+\beta X_{m t}$

Where $\beta$ is a vector of utility coefficients and $\alpha$ is the Alternative Specific Constant (ASC). The systematic component of utility can be identified, and the parameters estimated, by determining how choice varies with different levels of attributes and differences in individual decision makers (Adamowicz, Louviere et al. 1998). Due to the presence of a random component in the utility function, probabilistic statements about consumer behaviour can be made.

In the decision to join a conservation incentive program a landowner $(n)$ chooses from a finite set of incentive programs (C). Following Boxall and Adamowicz (2002) the probability ( $\pi$ ) that program $i$ will be chosen (equation 4) is equal to the probability that the utility gained from program $i$ is greater or equal to the utilities of choosing another program, $k$ in $C$.

$$
\pi_{n}(i)=\operatorname{Pr} o b\left\{V_{m}+\varepsilon_{n} \geq V_{n k}+\varepsilon_{n k} ; i \neq k, \forall k \in C\right\}
$$

Different assumptions about the random term give rise to different probabilistic models. If errors are assumed to be distributed according to a bivariate normal distribution, a binary choice model can be specified (Thurstone 1927), which can be generalised to a multivariate case with a multivariate probit model. Type I extreme value (GumbelI) distributions ${ }^{30}$ yield the conditional or multinomial logit model (McFadden 1974). A generalised extreme value distribution gives rise to the nested

\footnotetext{
${ }^{30}$ The 'three types theorem" by Fisher and Tippet asserts that there are only three types of distribution which can arise as limiting distributions of extreme values in random samples. In probability theory and statistics the Gumbel distribution is used to find the minimum (or the maximum) of a number of samples of various distributions. These distributions could be of the normal or exponential type
} 
multinomial model (McFadden 1981). The standard assumption in RUT has been that the error terms are Independently and Identically Distributed (IID) following the type I extreme value distributions.

Many economic models assume homogenous preferences. A conditional logit model, with a Gumbel distribution of the error term, can be used to estimate the probabilities where preferences are homogenous (McFadden 1981). When the attributes associated with each choice are substituted into $V$ the choice probability is given by equation 4 .

$\pi_{n}(i)=\frac{\exp \left(\mu \beta X_{t}\right)}{\sum_{k \in C} \exp \left(\mu \beta X_{k}\right)}$

Where $\beta$ is a vector of estimated parameters, not specific to $n$, and $\mu$ is a scale parameter assumed equal to 1 when the model is not segment specific (Boxall and Adamowicz 2002).

Lancaster consumer theory (discussed in the next section) gives rise to the idea that utility is obtained from the attributes of a good, in this case, the attributes of incentive programs.

\subsection{Lancaster consumer theory}

In the neoclassical tradition, utility models can be developed that analyse a range of choice problems. For each of these choice problems there are trade-offs between a range of alternatives. One branch of economic literature indicates that the attributes of a good determine the utility obtained from that good (Praag 1968). Lancaster's approach to consumer behavior gives rise to the idea that a good as such is not the ultimate object desired by consumers but rather that consumers demand the attributes which the good possesses (Lancaster 1971). Any good possesses an enormous number of these attributes, for instance, size, shape, colour, smell, and so on.

Lancaster's consumer theory poses that the utility of a good or service can be decomposed into separate utilities for the attributes of that good. The overall utility contributes to the choice of that good or service (Lancaster 1971).

Central to Lancaster's theory are the following observations (Lancaster 1991, p.13):

1. "The good per se, does not give utility to the consumer, it possesses characteristics, and those characteristics give rise to utility; 
2. In general, a good will possess more than one characteristic, and many characteristics will be shared by more than one good; and

3. Goods in combination may possess characteristics different from those pertaining to the goods separately".

Lancaster theory helps understand how the utility of a conservation incentive program can in fact be broken down into separate utilities for attributes of the program. The attributes of an incentive program are expected to have an effect on landowner choice of program. One such attribute is, for instance, the size of the compensation payment. In the tradition of Lancaster in the current research, a landowner maximises utility by their choice of incentive program characterised by a bundle of program attributes.

The actual theory that underpins the ability of an individual to make choices between bundles of attributes was based in psychology (Section 4.1.1). Theory on information processing and judgement in decision-making, which is also based in psychology, helps to understand how choices are made. Of particular interest in this context is the role of attitudes, which is the subject of the next section.

\subsection{Theory of planned behavior}

Both economic theory and psychology are concemed with behaviour and decision making. Findings that originate in psychology can help to understand how and why people make choices. One field of psychology which developed in parallel to economics focuses on the relationship between the environment and behaviour. Psychological theory states that the decision making process that underlies choice behaviour is "informed by perceptions" and beliefs based on available information, and influenced by affect ${ }^{32}$, attitudes, motives ${ }^{33}$, and preferences ${ }^{34}$ " (Ben-Akiva, McFadden et al. 1999, p.188).

The Theory of Planned Behaviour (TPB) (Ajzen 2001) is the psychological model most often used by economists to link attitudes to the prediction of behaviour. The

\footnotetext{
${ }^{31}$ Perception is the cognition of sensation.

${ }^{32}$ Affect is the emotional state of the decision maker and its impact on cognition of the decision task.

${ }^{33}$ Motives are drives directed towards perceived goals.

${ }^{34}$ Preferences are comparative judgements between entities.
} 
TPB "attempts to predict and understand behaviour by measuring the underlying determinants of that behaviour" (Beedell and Rehman 1999, p.174).

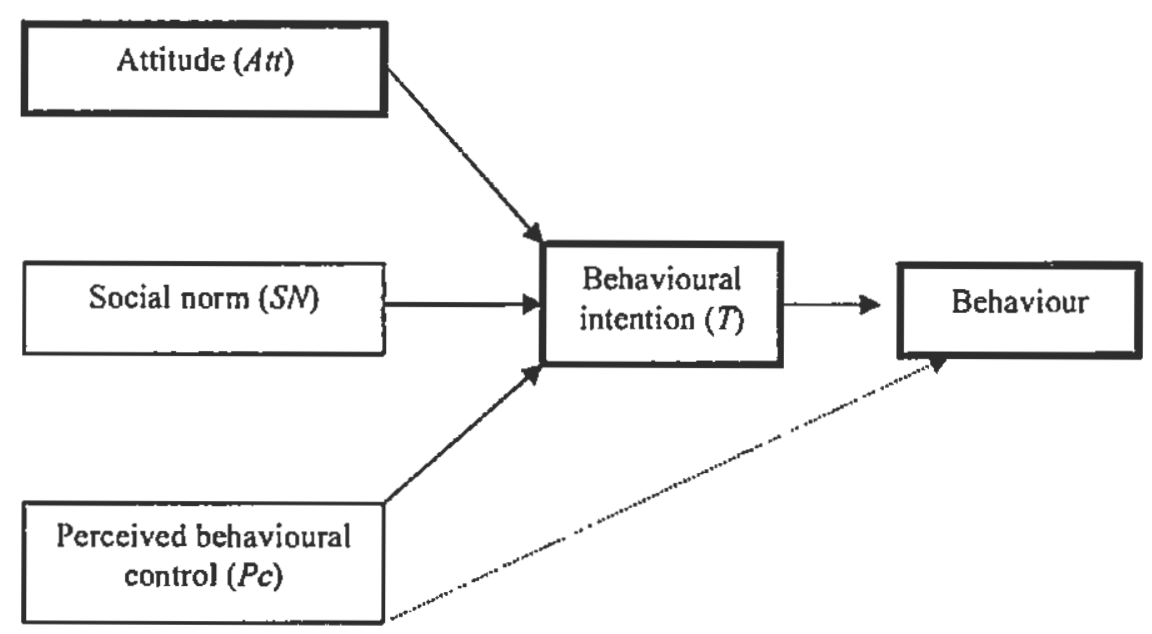

Figure 4: The theory of planned behaviour (adapted from Beedell and Rehman 1999)

An individual's attitude (Att) toward an issue and the perception of what others in society want, the Social Norm $(S N)$, as well as other socio-economic characteristics will lead to behavioural intention. The behavioural intention is also affected by the landowner's perception of how easy or difficult it is to carry out the behaviour $\left(P_{C}\right)$.

More formally the relationship between behavioural intention, attitude and social nom can be specified as (adapted from Luzar and Diagne 1999):

$T=w_{A t t} A t t+w_{S N} S N+w_{P c} P C$

Where $(T)$ is the intention to perform a behaviour, which is related to the attitude toward performing the behaviour and the social norm for performing the behaviour. The weights $(w)$ are empirically determined. The strength of the intention is closely associated with the cause of the behaviour. Attitudes are empirically measurable, in an indirect way. To say that an individual has a strong attitude towards an activity is another way of stating that they gain a large amount of utility from an action (Lynne, Shonkwiler et al. 1988).

There is some debate regarding the relative strength of intention and attitude on behaviour. Gärling, Gillholm et al. (1998) reported that the correlation between intention and behaviour was greater than between attitude and behaviour and 
measuring relative intention improved the prediction of behaviour. Despite the lack of consensus on the relative importance of attitudes in the process of decision making, it is acknowledged they play a role in behaviour.

The field of environmental psychology explores the relationship between environmental attitude and behaviour. Kaiser, Wölfing et al. (1999) report that in 1999, more than 1,400 publications in the field of psychology dealt with environmental problems. Of these, more than one third dealt with ecological behaviour of which more than one third (153 papers) related environmental attitude to ecological behaviour.

Environmental attitudes are commonly divided into three main groups: egoistic (egocentric), social-altruistic (or anthropocentric), and biocentric (or ecocentric ${ }^{35}$ ) (Stern and Dietz 1994; Merchant 1992 quoted in Schultz and Zelezny 1999; Ruijgrok, Vellinga et al. 1999). Studies have found that individuals who held more ecocentric attitudes tended to be more supportive of protection-oriented management. Anthropocentric individuals were more likely to support resource extraction strategies (McFarlane and Boxall 2003).

There may be some interaction between environmental attitudes and socio-economic variables which impacts on behaviour. For instance, women are perceived to have more strongly held views towards environmental protection than males. Environmental attitudes are also positively related to higher income and the attainment of higher education levels (Stern and Dietz 1994; Steel 1996). The potential interaction between environmental attitudes and other variables leads both Kaiser, Wölfing et al. (1999) and Steel (1996) to the conclusion that the direct relationship between environmental attitude and behaviour is tenuous. However, in a robust analysis these interactions would be identified.

Some of the literature reviewed in Chapter 3 which looked at participation in incentive programs (e.g. Drake, Bergström et al. 1999; Stevens, White et al. 2002; Söderquist 2003) and setting aside land for conservation (e.g. Force and Bills 1989;

\footnotetext{
${ }^{35}$ Dunlap and van Liere (1978) and Fransson and Garling (1999) argue that the New Environmental Paradigm (NEP) constitutes another environmental attitude in which humans perceive themselves as an integral part of nature. The NEP incorporates the relatively new the concepts of 'limits to growth' and 'spaceship earh'. Although some may argue that these concepts are also inherent to the bio- or ecocentric attitude.
} 
Klosowski, Stevens et al. 2001), included environmental attitude variables in a utility maximisation framework. The role of environmental attitudes in predicting participation in incentive schemes was significant in all the above studies.

In the current research attitudes were also evaluated and included as a variable in the decision model. The description of attitude used here is different to that defined in the above cited studies. In this current research it is assumed that a landowner's belief about the impact and outcome of establishing reserves on their land reflects their attitude. This approach was taken because extension programs tend to focus on changing 'attitudes' by providing information that affects people's evaluation of outcomes of reserve establishment. Thus, outcome evaluation of reserve establishment influences behaviour and reflects landowner attitudes.

As discussed in the preceding sections, the RUT approach can be used to investigate a landowner's decision to set aside land for conservation. The utility maximisation framework allows the incorporation of socio-economic and attitude variables to explain the decision. The TPB underpins the inclusion of attitudes as a separate explanatory variable in the utility maximisation model.

The next chapter presents the econometric approach (Section 5.1 and 5.1.1) used to model choice data gathered in this research and the statistical method (Section 5.1.2) used to analyse the data. The statistical methods used to analyse attitude data gathered as part of the same survey is presented in Section 5.2. The statistical method used to analyse the Best-Worst survey data, which was gathered prior to the Choice survey, is also presented (Section 5.3). 


\section{Estimation methods and statistical analysis}

As mentioned in Section 4.2, many economic models assumc homogenous preferences. The probabilities for models with homogeneous preferences are estimated using, for instance, the conditional logit model (equation 4). However, the assumption of preference homogeneity is often not appropriate. For instance, landowner heterogeneity as reflected in preferences for incentive program attributes is to be expected. Some economic models have accounted for heterogeneity by including socio-economic variables in the utility function or by stratifying individuals into segments on the basis of socio-economic variables. Other studies have accounted for heterogeneity by following a two-step modelling procedure (e.g. Söderqvist 2003; Horne 2004). In a two-step model cluster analysis is used to divide individuals into groups on the basis of their stated attitudes. The second step is then to apply a logit or multinomial logit approach to each of the groups.

These models 'account' for preference heterogeneity but do not adequately 'explain' its source, where heterogeneity may reflect other characteristics of individuals such as their motivations, attitudes, and past experiences (Boxall and Adamowicz 2002). The latent class approach (also referred to as the finite mixture approach) discussed in the section below, can account for heterogeneity. ${ }^{36}$

\subsection{Latent class model}

To account for heterogeneity in choice analysis "... there must be a priori knowledge of the element of heterogeneity" (Boxall and Adamowicz 2002, p.422). The latent class approach accounts for heterogeneity by constructing classes on the basis of observed measures such as attitude scales. In constructing these classes socioeconomic characteristics can also be included as covariates.

The inclusion of attitudes in the preference function has generated some discussion in the literature (e.g. Provencher \& Moore 2006). The discussion centres around two criticisms. The first criticism relates to the value of including attitudes in terms of explaining a choice situation. Provencer \& Moore (2006) argued that some 'common

\footnotetext{
36. The latent elass approach will be compared to the two-step method in section 8.4.4.
} 
sense' interpretation of latent classes would make attitudinal scales redundant for purposes of resource management. However, it is acknowledged that latent class analysis does provide a relatively easy and cheap source of class identification (Provencher \& Moore 2006).

The second criticism relates to the likelihood of attitudes being endogenous variables in the explanation of choices. This would arise in this current research if a landowner choice of program were to influence his/her attitude. It is however argued that the attitude variable in this current research, that is, a landowner's attitude toward the role and impact of private conservation reserves, reveals a 'deeper' attitude that drives the utility derived from joining an incentive program. The attitude variable thus expresses a fundamental attitude that precedes joining an incentive program. The research therefore proceeds on the assumption that a landowners' attitude toward the role and impact of private conservation reserves is not an expression of incentive program related preferences.

In the latent class approach respondents make up several distinct segments $(S)$ each with a different set of preferences (Provencher, Baerenklau et al. 2002). Assuming that individual $n$ belongs to segment $s(\mathrm{~s}=1, \ldots, \mathrm{S})$ the utility function can be written as:

$$
U_{n, \mid s}=\beta_{s} X_{n t}+\varepsilon_{n \mid s}
$$

The latent class approach assigns individuals to "... classes with identical preferences and estimates the probability of membership to each class along with their respective preference weights" (Scarpa and Thiene 2004, p.2).

Equation 4 can now be written as:

$$
\pi_{m s}(i)=\frac{\exp \left(\mu_{s} \beta_{s} X_{1}\right)}{\sum_{\mathrm{k} \in C} \exp \left(\mu_{s} \beta_{s} X_{k}\right)}
$$

where $\beta$ and $\mu$ are now utility and scale parameters specific to a segment (Boxall and Adamowicz 2002). Individuals can be allocated to one of the segments on the basis of their characteristics and their latent attitudes. To achieve this, a latent membership likelihood function is used. The membership likelihood function $\left(M_{n s}^{*}\right)$ of individual $n$ and segment $s$ is given by equation 8 . 
$M_{n s}^{*}=\tau_{p s} P_{n}^{*}+\tau_{s} S_{n}+\zeta_{n s}$

$P_{n}^{*}$ is a vector of latent attitudes held by individual $n . S_{n}$ is a vector of observed sociodemographic characteristics of individual $n$. Where $\tau_{p s}$ and $\tau_{s}$ are parameter vectors. $P_{n}^{*}$ can be defined by a vector of observed indicators of latent attitudes $\left(P_{n}\right)$

$P_{n}^{*}=\varpi_{p} P_{n}+\zeta_{n p}$

where $\varpi_{p}$ are parameter vectors of the latent attitudes to be estimated. $\zeta_{n s}$ and $\zeta_{n p}$ represent the error terms in equation 8 and 9 respectively.

If equation 9 holds, $M^{*}$ can be expressed at an individual level by equation 10 .

$M_{n s}^{*}=\lambda, Z_{n}+\zeta_{n s}$

$Z_{n}$ is a vector of both the psychometric constructs $\left(P_{n}\right)$ and the socio-economic characteristics $\left(S_{n}\right)$ and $\lambda_{s}$ is a vector of parameters. In equation 11 the assumptions are incorporated into the probability of membership in segment $s$.

$\pi_{n s}=\frac{\exp \left(\alpha \lambda_{s} Z_{n}\right)}{\sum_{s=1}^{s} \exp \left(\alpha \lambda_{s} Z_{n}\right)}$

If the joint probability of an individual belonging to segment $s$ and choosing alternative $i$ is given by equation 12 ,

$\pi_{n}(i)=\pi_{n s} \pi_{n \mid s}(i)$

then the probability that a randomly chosen individual $n$ chooses altemative $i$ is given by equation 13 .

$\pi_{n}(i)=\sum_{s=1}^{S} \pi_{n s} \pi_{n \mid s}(i)$

The data used for estimating segment membership can be combined with preference data related to choice of product or service, thus allowing "... joint estimation of the explanators of heterogeneity and the explanators associated with attributes of cboice" (Boxall and Adamowicz 2002, p.422). 
$\pi_{n}(i)=\sum_{s=1}^{s}\left[\frac{\exp \left(\alpha \lambda_{s} Z_{n}\right)}{\sum_{s=1}^{s} \exp \left(\alpha \lambda_{s} Z_{n}\right)}\right]\left[\frac{\exp \left(\mu_{s} \beta_{s} X_{s}\right.}{\sum_{k \in C} \exp \left(\mu_{s} \beta_{s} X_{h}\right)}\right]$

Welfare can be estimated for latent class choice models to understand the distributional impact of change in the attributes. This topic is discussed in the next section.

\subsubsection{Welfare estimation}

The ultimate aim of many choice studies is to estimate the welfare implications of changes in one or more of the attributes of a product. The welfare impact associated with the increase or decrease of an attribute reflects the amount of compensation needed to maintain utility at a certain level. For instance a change in environmental quality, waiting time in a hospital que, or in this case, land use restrictions or legal implications of an incentive program, is associated with a welfare estimate reflecting a change in utility.

Estimation of the welfare impact in latent choice models is based on Hanemann's (1982) theory of welfare estimation in conditional logit models (quoted in Boxall and Adamowicz 2002). Boxall and Adamowicz (2002) estimate the compensation variation on a segment by segment basis for latent choice models. As this current research involves estimating a WTA, the equivalent variation $(E V)$ rather than the eompensation variation is estimated. Following Boxall and Adamowicz (2002) the segment specific equivalent variation for individual $n$ is given by:

$$
E V_{\mathrm{n} \mid s}=\frac{1}{\gamma_{s}}\left[\ln \left(\sum_{h \in C} \exp \left(\beta_{s} X_{h}^{0}\right)-\ln \left(\sum_{\lambda \in C} \exp \beta_{s} X_{h}^{\prime}\right)\right]\right.
$$

Where $\gamma_{s}$ is the segment specific marginal utility of income, $\beta_{s} X_{k}$ is the segment specific indirect utility over $k$ choice, 0 is the initial state and $I$ is the new state following a change in an attribute level in $X$ in at least one of the choices in $k$. Accounting for segment membership in generating the welfare measure can be done by multiplying equation 15 by the probability of membership of segment $s$, namely $\sum_{s=1}^{s} \pi_{s}$ 


\subsubsection{Statistical indicators for latent class analysis}

In this dissertation the latent class approach was used to model landowner preferences for incentive program attributes. The data used to estimate the model was obtained by means of a Choice survey. Landowner characteristics and attitudes, as well as property characteristics, collected in the same survey, were used as variables in the latent class analysis. The computer program used for estimating the latent class model was LatentGOLD Choice 4.0.

As discussed in Section 5.1.1. latent class models classify individuals into classes. In addition to the standard goodness of fit, classification and prediction statistics, practitioners of the latent class approach use information criteria to determine the number of classes.

The chi-squared $\left(\chi^{2}\right)$ statistic with the corresponding degrees of freedorm yields the asymptotic $p$-values, which can be used to determine whether the specified model fits the data. The Bayesian Information Criterion (BIC) and Akaike Information Criterion (AIC), based on the $L^{2}$, are used to "weigh and fit the parsimony of a model" (Vermunt and Magidson 2005, p.46).

The number of classes in a latent class model cannot be predefined and the optimal number of classes must be selected on the basis of statistical criteria. Moreover, Boxall and Adamowicz $(2002$, p.433) suggest that " ... conventional rules for this purpose do not exist and judgement and simplicity play a role in the final selection of the size of $S^{\prime \prime}$.

The BIC, the AIC, the explanatory power of the model $\left(\mathrm{R}^{2}\right)$, and the inherent intuitive correctness of the model, e.g. the signs of estimated parameters, serve as the main guides to determining the number of classes (see also Boxall and Adamowicz 2002; Scarpa and Thiene 2004; Morey, Thatcher et al. 2006).

The BIC (sometime referred to as the Schwarz criterion) is a statistical information criterion. Following Morey, Thatcher et al. (2006), the BIC is given in equation 16, where $(d)$ is the number of free parameters to be estimated, $(n)$ is the number of observations and $(B)$ is the maximised value of the likelihood function of the estimated model.

$B I C=-2 \ln B+d \ln (n)$ 
Equation 16 becomes equation 17 under the assumption that the model error is nomally distributed.

$$
B I C=n \ln \left(\frac{R S S}{n}\right)+d \ln (n)
$$

The BIC is a decreasing function of the Residual Sum of Squares (RSS) from the estimated model and an increasing function of the number of free parameters to be estimated. Lower values of the BIC for multiple class regression models, in comparison to a single class regression model, suggest heterogeneity in the data. Lower values of the BIC indicate a better model in terms accounting for heterogeneity.

The AIC is a measure of the goodness of fit of an estimated statistical model (equation 18). The AIC trades off the complexity of an estimated model against how well the model fits, assuming that the model errors are normally distributed. Similar to the BIC, smaller values of the AIC indicate better solutions.

$A I C=-2 \ln (B)+2 d$

The AIC sometimes over estimates the number of classes (Scarpa and Thiene 2004). It is therefore important that the number of chosen classes also account for the significance and the meaningfulness of the parameter estimates according to the ".... analyst's own judgement" (Scarpa and Thiene 2004, p.9).

Another statistic is the Dissimilarity Index (DI), a descriptive measure which indicates how much "... observed and estimated cell frequencies differ from each other" (Vermunt and Magidson 2005, p.46). The DI is defined as follows:

$$
D I=\frac{\left\{\left(\sum_{t^{*}=1}^{I^{*}}\left(\left|n_{t^{*}}-\hat{q}_{t^{*}}\right|\right)+\left(N-\sum_{1^{*}=1}^{f^{*}} \hat{q}_{t^{*}}\right)\right\}\right.}{2 N}
$$

where $q$ is a particular alternative and is distributed as $\chi^{2}$. The classification statistic provides information on how well observed values predict latent classes, or how well the classes are separated. Classification is based on class membership probabilities. Observed and predicted values can be presented in a classification table where each cell reports the number of observations correctly or incorrectly classified. 
In the preceding section the statistical methods used to analyse data obtained from the Choice survey was presented. The latent class approach used in this research to estimate the decision model allows the inclusion of several variables, including attitudes. Attitude data was obtained from a question included in the survey which asked landowners to rate how much they agreed with a number of statements regarding the role and outcome of establishing conservation reserves on private land. The section that follows shows how the attitude variable included in the latent class analysis was derived. The statistical method used in the analysis of the attitude data is also discussed.

\subsection{Statistical analysis of attitude data}

Attitude data were collected as part of both the BW and the Choice survey. In the survey respondents were asked to indicate their level of (dis)agreement with statements related to the role and outcome of conservation reserves on private land on a Likert scale. For instance the first 3 statements in this part of the survey were as follows:

Conservation reserves on private land:

\begin{tabular}{|c|c|c|c|c|c|}
\hline & \multicolumn{5}{|c|}{ Please tick $\nabla$ only 1 of the 5 options } \\
\hline & $\begin{array}{c}++ \\
\text { Strongly } \\
\text { Agree }\end{array}$ & $\begin{array}{c}+ \\
\text { Agree }\end{array}$ & $\begin{array}{c}+/- \\
\text { Neutral }\end{array}$ & Disagree & $\begin{array}{l}\text { Strongly } \\
\text { Disagree }\end{array}$ \\
\hline $\begin{array}{l}\text { Are an effective way to ensure wildlife } \\
\text { survival }\end{array}$ & $\square$ & $\square$ & $\square$ & $\square$ & $\square$ \\
\hline Are expensive to manage & $\square$ & $\square$ & $\square$ & $\square$ & $\square$ \\
\hline Create a good image for landowners & $\square$ & $\square$ & $\square$ & $\square$ & $\square$ \\
\hline
\end{tabular}

The attitude data were analysed using a Principal Component Analysis (PCA). PCA is a multivariate technique that reduces a large body of data so that a maximum of the variance is extracted (Harman 1967). PCA involves a mathematical procedure that transforms a number of (possibly) correlated variables into a (smaller) number of uncorrelated variables called principal components. The first principal component accounts for as much of the variability in the data as possible, and each succeeding component accounts for as much of the remaining variability as possible.

More formally, the object of component analysis is to represent a variable in terms of several underlying factors, or hypothetical constructs. The model for component analysis is: 


$$
Z_{J}=a_{j 1} F_{1}+a_{j 2} F_{2}+\ldots+a_{j n} F_{n} \quad(\mathrm{j}=1,2, \ldots, \mathrm{n})
$$

Each of $n$ observed variables is described linearly in terms of $n$ new uncorrelated components, $F_{l}, F_{3}, \ldots, F_{n}$. Ar important property of this method, insofar as the summarisation of data is concerned, is that each component in turn makes a maximum contribution to the sum of the variances of the $n$ variables. The sum of the variances of all $n$ principal components is equal to the sum of the variances of the original variances when $n \rightarrow \infty$ (Harman 1967).

A component analysis can be conducted with any method of factor extraction as long as the matrix to be operated on by these methods is initially the unreduced correlation matrix with ones in its principal diagonal.

A brief mathematical summary of PCA (adapted from Mulaik 1972) is as follows:

$Z=F X$

where $Z$ is the $n x I$ random vector whose coordinates arc $n$ variables and $X$ is a $n x I$ random vector whose coordinates are the $n$ principal components for the $n$ variables. $F$ is the $n \times n$ square matrix of principal-axes factor loadings of the $n$ variables on the $n$ principal components. The matrix $F$ is given as:

$F=A D^{\star}$

where $\mathrm{A}$ is the $n \times n$ eigenvector matrix and $\mathrm{D}$ is the $n \times n$ diagonal eigenvalue matrix for the matrix $R$. $R$ contains the correlations between the $n$ variables such that:

$R=E\left(Z Z^{\prime}\right)$ and $A^{\prime} R A=D$

The coordinates of $X$, representing the principal components, are mutually orthogonal so that:

$E\left(\mathrm{XX}^{\prime}\right)=I$

PCA yields a matrix of correlations between variables and factors. The advantage of PCA is the mathematical convenience of working with the eigenvalues and eigenvectors to determine the number of factors that are to be retained and to compute factor scores (Mulaik 1972). 


\subsection{Statistical analysis of Best-Worst data}

In Sections 5.1 and 5.2 the statistical methods for analysis of the choice and attitude data were reported. Prior to carrying out the Choice survey, a Best Worst survey was administered. In the BW survey respondents were asked to to indicate the most and least important incentive program attribute, out of a different combination of five of 10 attributes. They were asked to repeat this a total of 18 times. $^{37}$

The main aim of the BW survey was to the rank the program attributes in order of importance and thus limit the number of attributes used in the subsequent Choice survey to only the most important ones. Limiting the number of attributes was thought to minimise Choice survey complexity. An additional aim of administering the BW survey was to test for any differences between landowners and professionals who administer and manage incentive schemes in the ranking of the relative importance of the incentive program attributes. The degree of importance of incentive program attributes was measured on an underlying continuum of importance.

In the BW survey, the respondent was asked to choose the most and least important program attributes from a different set of five attributes several times. For example, the first and second question of the survey were as follows:

Which program attribute do you think is most important and which do you think is least important to a landowner who is thinking about joining an incentive program to protect native vegetation?

Part 1

\begin{tabular}{|clc|}
\hline Most important & Tick only one Program attribute & Least important \\
\hline$\square$ & Funding amount & $\square$ \\
$\square$ & Funding agency & $\square$ \\
$\square$ & Program duration & $\square$ \\
$\square$ & Application procedure & $\square$ \\
$\square$ & Technical support availability & $\square$ \\
\hline
\end{tabular}

Part 2

\begin{tabular}{|clc|}
\hline Most important & Tick only one Program attribute & Least important \\
\hline$\square$ & Payment method & $\square$ \\
$\square$ & Application procedure & $\square$ \\
$\square$ & Monitoring \& survey requirements & $\square$ \\
$\square$ & Funding allocation process & $\square$ \\
$\square$ & Funding agency & $\square$ \\
\hline
\end{tabular}

\footnotetext{
${ }^{37}$ The data BW were collated in Excel and statistical analysis was carried out in SPSS 13.0.0 and StataSE 8.
} 
The joint probability of choosing the most important attribute (i) and the least important attribute $(j)$ across all blocks of 5 attributes can be estimated independently of the marginal probabilities using the appropriate block design and its complement (Appendix 1) (Auger, Devinney et al. 2004; Buckley, Devinney et al. 2004).

Following the presentation of Louviere (1994) and Buckley, Devinney et al. (2004) the choice process associated with each attribute pair $i$ and $j$ can be represented as follows:

$D_{y}=\delta_{y}+\varepsilon_{y}$

$D_{v}$ is the unobservable true difference between attributes $i$ and $j$ on the underlying continuum of importance; $\delta_{v}$ is the observable (mean) difference revealed by the choices that a respondent makes; and $\varepsilon_{v}$ is a random error component of choice. The probability that a respondent chooses the $i j$ pair of attributes in each subset is given by:

$$
P\left\langle i j \mid B_{n}\right\rangle=P\left(\delta_{y}-\varepsilon_{y j}\right) \quad \text { all other } K-1\left(\delta_{t k}+\varepsilon_{t k}\right) \text { pairs }
$$

$B_{n}$ is the block (subset) of attributes faced by respondent $n$; and $K$ is the number of attributes per block. Assuming that $\varepsilon_{y}$ is distributed according to a Gumbell distribution leads to a Multinomial Logit Model (MNL) for analysis (Louviere 1994; Boxall, Adamowicz et al. 1996, Blamey; Bennett et al. 2000; Louviere, Hensher et al. 2000). If $\delta_{v}$ can be expressed as two scale values $h_{i}-h_{i}$ then the choice probability can be expressed as:

$$
P\left(i j\left|B_{n}\right\rangle=\exp \left(h_{t}-h_{\jmath}\right) / \sum_{t k} \exp \left(h_{t}-h_{k}\right) \quad \text { for all } \mathrm{K}\left(h_{t}, h_{k}\right) \text { pairs in } i_{c}\right.
$$

The formal measurement assumptions that apply to BW scaling are summarized by the following (following Marley and Louviere 2005):

- The latent dimension $\left(\delta_{i j}\right)$ can be decomposed into the desired scale values $\left(h_{\text {, }}\right.$ $\left.h_{k}\right)$ and the unexplained portion of the difference $\left(\varepsilon_{y}\right)$.

- The respondent is able to identify the most important and least important item in choice sets that have more than 3 items.

- There is stochastic transitivity in the choice: if $A$ is more important than $B$ and 
$B$ is more important than $D$ than $\mathrm{A}$ is more important than $D$.

There is symmetry of choice: the probability that $A$ is most important and $B$ least important is the same as the probability that $B$ is least important and $A$ is most important.

The parameters in the model are the differences between one particular attribute and all others on the common underlying scale of importance. Using the Balanced Independent Block Design (BIBD), the scale value for each attribute is the number of times it is chosen most important against the number of times that it is chosen least important. The estimated scale values can be approximated by the simple score $\delta\left(m_{i} l_{1}\right)$ which is the total most important $(m) i$ minus the total least important $(l) i$ counts for each attribute. This approximates the unknown difference $s_{1}-s_{\text {, for }}$ each individual. For example, in this study each attribute appeared 9 times, so the individual level scale ranges from +9 to -9 . "This implies that [the scores] are linearly related to the true scale values and interval scale measures ... on the underlying continuum of [importance]" (Finn and Louviere 1992, p.14). For example, a score of +1 is obtained if a respondent rated an attribute most important 5 times and least important 4 times (Auger, Devinney et al. 2004).

The individual aggregate difference scores provide a crude measure for the level of importance. In this study an additional procedure is carried out (Section 7.2). The individual BW scores were used in Multi-Dimensional Scaling (MDS) analysis. Cohen and Neira (2003) compared the aggregate difference scores to MDS results concluding they both yield the same scale information. But MDS provides additional information on how similar or how different two attributes are.

MDS is a technique that uses proximities as input which indicates the perceived similarity or difference between attributes (Kruskal and Wish 1978). A common procedure for obtaining proximity data is to ask survey respondents to directly judge the "psychological distance" (or closeness) between stimulus objects. MDS is used to visualize these proximities in a low dimensional space. It uncovers relationships between attributes by restricting the solution to a linear combination of independent variables. The dissimilarity measures for data analysed using MDS is the Euclidian distance which is the square root of the sum of the squared differences between values 
for the variables. MDS measures how well the configuration approximates the distances between the attributes by the "stress", where

$$
\text { Stress }=\sum_{g}\left(d_{v}-f\left(\delta_{i j}\right)\right)^{2}
$$

and $d_{y}$ is the constructed distance between attribute $i$ and $j$ in the given number of dimensions, $\delta_{i j}$ is the observable distance, or difference between $i$ and $j$, and $f$ is a transformation that preserves the rank order of the input distance (Kruskal and Wish 1978). Lower stress figures indicate a better representation of the input distances in the configuration.

In the preceding sections the statistical methods used to analyse data gathered by means of the BW and Choice surveys was discussed. In the next chapter details of the survey design are reported. 


\section{Survey design and administration}

This research explores the decision framework of private landowners surrounding participation in conservation incentive programs. The data used to develop and estimate the decision model was gathered by means of a Choice survey of Tasmanian landowners. The Choice survey instrument was also used to gather attitude data.

Prior to administering the Choice survey, a BW survey was carried out. The primary aim of the BW survey was to rank conservation incentive program attributes in order of importance and use the results to assist in developing the choice set for the Choice survey. Ordering the attributes in order of importance minimised the complexity of the Choice survey and ensured that the choice question presented an accurate reflection of the "real" decision framework. A second aim was to establish any differences in the relative importance of program attributes between landowners and professionals who administer and manage conservation schemes.

In this chapter a brief review of the BW survey method is presented, followed by a discussion of the BW survey design. ${ }^{38}$ A detailed discussion of the Choice survey design concludes this chapter.

\subsection{Best-Worst survey}

BW scaling is a direct, scale-free method of measuring the weight or importance of the attributes or features of a choice (Finn and Louviere 1992; Cohen and Neira 2003; Louviere and Towhidul 2004). Developed by Louviere (1991), the BW scaling technique presents respondents with a profile, or a set of attributes, of a good or service. The respondent is asked to choose the attribute combination that is most important and least important (or best and worst).

Several advantages and strengths are associated with using the BW scaling technique (Cohen and Neira 2003). Most importantly BW scaling has been found to be very easy to use (Cohen and SHC \& Associates 2003). Much research suggests that binary responses (responses with two outcomes) are simple and reliable (e.g. Buckley, Devinney et al. 2004). Further, when Cohen and Neira (2003) compared BW scaling

\footnotetext{
${ }^{38}$ The statistical tools used to analyse the BW survey results were pieviously discussed in Section 5.3 .
} 
to alternatives, such as the five-point scale rating method, they found that BW is preferred as it avoids context biases and is rating scale free. They concluded that overall, BW scaling was easier to understand and resulted in "better" results.

In the first application of BW scaling, Finn and Louviere (1992) examined the importance of various food safety issues of public concern. They combined BW scaling with a choice experiment. They first asked respondents to indicate their first choice and then choose their last choice from the remainder. The BW survey determined the consumers' true level of concern about food safety issues. The choice experiment then assessed "... how preference for actions [was] likely to change with characteristics of the food safety incident or problem" (Finn and Louviere 1992, p.14). The study found that BW scaling provided an appropriate research method for " ... policy makers who need consunner input to help determine how to allocate their managerial and marketing resources" (Finn and Louviere 1992, p.23).

The BW method has subsequently been applied in many different areas of research. For example Auger, Devinney et al. (2004) used BW scaling to investigate 16 different issues of consumer social belief. In this study cross-cultural comparison was facilitated due to the scalar inequivalence of BW scaling. Cohen and Neira (2003) used $\mathrm{BW}$ in an international study into the benefits of drinking coffee. BW was used in a study that measured preferences for benefits of computer servers (Cohen and SHC \& Associates 2003). With respect to foreign direct investment options Buckley, Devinney et al. (2004) investigated managerial preferences using BW.

In a theoretical context BW is frequently compared to other SP survey techniques (e.g. Cohen and SHC \& Associates 2003; Cohen and Neira 2003). In an empirical context $\mathrm{BW}$ is mostly used alone or in combination with a choice question (e.g. Finn and Louviere 1992). There are few empirical examples where BW is used prior to carrying out a Choice survey to inform attribute selection for a Choice survey, the approach used in this research. Only one study was found that used the BW approach, along with several other rating techniques, to explore the issue of identifying attributes for inclusion in a subsequent choice study (Sawtooth Software 2002).

Buckley, Devinney et al. (2004) and Flynn, Louviere et al. (unpublished) used BW in combination with a Choice survey to check that the results generated by the BW survey were consistent with a choice experiment. Flynn, Louviere et al. 
(unpublished) point out that combining the "easy" BW task with a Choice survey may be appropriate for the purpose of comparisons of marginal changes in attributes used in the Choice survey. In this approach a respondent is asked to choose the best and worst of a number of options and then indicate their preference for the remainder of options (see also Louviere, Burgess et al. 2004). The BW task aspect is, therefore, an integral part of the question in the Choice survey, as opposed to being a separate survey as in this research.

Population segments can be identified to understand patterns in the $\mathrm{BW}$ data using a simple cluster analysis on the basis of additional information gathered as part of the BW survey (e.g Auger, Devinney et al. 2004; Buckley, Devinney et al. 2004). In this current research the attitude data was also gathered with the aim of determining segments in the population (Section 8.2). ${ }^{39}$

\subsubsection{The Tasmanian Best-Worst survey}

The BW survey was administered to two groups of respondents, landowners, and professionals who administer and manage incentive programs (referred to as program designers and administrators - PDAs). Both groups were given the same $\mathrm{BW}$ rating task. Slightly different questions were asked regarding personal characteristics of the two groups.

\subsubsection{Survey design}

Incentive program attributes included in the BW survey were determined by expert opinion, that is, a focus group composed of incentive program field staff, program managers, and landowners. ${ }^{40}$ This group of 12 persons met in September 2004. The choice of incentive program attributes was further informed by review of existing conservation incentive schemes and the literature. The resulting 10 program attributes that were included in the final BW survey were:

(1) funding amount;

\footnotetext{
${ }^{39}$ Small response numbers, however, did not allow a significant analysis of the BW attitude data to be undertaken.

${ }^{40}$ Program attribute levels for the Choice survey (discussed in Section 5.2.3) and a series of statements about the perceived role and impact of creating conservation reserves on private land were also developed in these focus groups.
} 
(2) monitoring and survey requirements;

(3) funding agency;

(4) program duration;

(5) technical support availability;

(6) funding allocation process;

(7) land use restriction;

(8) legal mechanism;

(9) application procedure; and

(10) payment method.

In the BW survey respondents were asked to indicate the most and least important incentive program attribute, out of a combination of five attributes. As there were a total of 10 attributes, respondents were asked to repeat this question a number of times, each time with a different block of five of the 10 attributes.

BW uses experimental designs to place program attributes in the different blocks. All possible sets of program attributes ( $t$ ) can be given by the complete factorial (2) but this would require a prohibitive number of blocks $(k)$ to be presented in a survey. A Balanced Incomplete Block Design (BIBD) was used to construct the sets and determine the number of sets (as in Auger, Devinney et al. 2004). BIBD has been used for many years in experiments where individuals are presented with different objects and are asked to make a comparative rating (Cochran and Cox 1957).

Two variables used to construct the BIBD were predetermined in this BW survey: the 10 attributes, and the size of the block, which was five. The decision to limit the number of attributes in a choice set to five was the result of feedback received from subjects who provided comments in the pre-testing phase. Other BW surveys also seemed to favor smaller rather than larger sets. For example, Cohen SHC \& associates (2003) and Finn and Louviere (1992) both use four attributes per set.

The result was a design with a total number of 18 blocks (b). Each attribute appeared nine times within those 18 blocks $(r)$ and appeared four times in combination with each other attribute $(\lambda)$. The design (and its complement) used in the survey ${ }^{41}$ is shown in Appendix 1. Using the BIBD design ensures that each respondent makes

\footnotetext{
4t The design was obtained from home.hccnet.nl/kees.duineveld/xbibd/bib10.18.9.5.4.view.txt viewed on 24 April 2005.
} 
“... a sufficient number of choices to measure his or her values for each [attribute]" (Finn and Louviere 1992, p. 14).

\subsubsection{Survey layout}

The BW survey, for both landowners and PDAs, consisted of three parts ${ }^{42}$ (the full survey for PDAs is shown in Appendix 2). The main aim of the first part of the survey was to gain an understanding of the respondent's experience with conservation issues. Landowners were asked about their involvement with conservation and incentive schemes, general property characteristics, past management activities, and a number of personal questions. The first part of the PDA survey asked a series of multiple-choice questions which established their working situation and frequency of interaction with landowners.

The actual BW task was presented in the second part of the survey. Both landowners and PDAs were asked to indicate the most and least important incentive program attribute, out of a combination of five attributes. The introduction to the $\mathrm{BW}$ task was worded differently between the landowner and PDA surveys. The introduction to the BW task in the landowner's survey stated:

Which program attribute do you think is most important and which do you think is least important when you are considering whether to join an incentive program to protect native vegetation?

The introduction to the BW task in the PDA survey stated:

Which program attribute do you think is most important and which do you think is least important to landowners when they are considering whether to join an incentive program to protect native vegetation?

The third part of the survey explored the respondent's attitude to the role and impact of establishing conservation reserves on private land. Survey respondents were asked to express their level of agreement or disagreement with a total of 26 statements. These statements indicated behavioral beliefs and were developed on the basis of a literature review, informal interviews with landowners, and expert opinion. The statements are roughly centered around six general foci (the numbers in brackets indicate the statement number in Table 1):

\footnotetext{
${ }^{42}$ A glossary defining each of the attributes was provided with the survey.
} 
1. Impact on productive capacity of the property $(13,16,23)$;

2. Impact on current income or future potential income $(12,17,20,21,22,24)$;

3. Personal impact on the landowner $(6,7,8,18,25)$;

4. Environmental impact on property $(3,9,15)$;

5. General environmental impact $\left(2,4,5,11^{43}\right)$; and

6. Trans-boundary impact and management options $(1,10,14)$.

In the rating question respondents were asked to express their level of agreement or disagreement with the statements in Table 1. A uni-dimensional five point Likert scale (Likert 1932) was used to measure attitude. The middle label on the response scale was labelled "neutral" thereby offering the option of neither agreeing or disagreeing. The other four labels included strongly disagree, disagree, agree, and strongly agree.

${ }^{43}$ Statement 11 explored the landowner's perception of intergenerational equity. 
Table 1: Rating questions aimed at establishing landowner attitudes to the role and impact of establishing reserves on private land.

\begin{tabular}{lll}
\hline No. & Conservation reserves on private land & Code \\
\hline 1 & Will benefit others as much as the landowner & BENOTH \\
\hline 2 & Provide a good way to protect species from extinction & PROTECT \\
\hline 3 & Will reduce the potential for soil erosion and salinity & EROSION \\
\hline 4 & Add to the beauty of the landscape & BEAUTY \\
\hline 5 & Are an effective way to ensure wildlife survival & WILDL \\
\hline 6 & Create a good image for landowners & IMAGE \\
\hline 7 & Give the landowner a sense of fulfilment & FULFIL \\
\hline 8 & Will inerease the landowner's understanding of the environment & LEARNING \\
\hline 9 & Are of value for stock shelter and control & STOCK \\
\hline 10 & Are best established where neighbours work together to protect areas & NEIGHB \\
\hline 11 & Will mainly benefit the future generation & FUTGEN \\
\hline 12 & Increase the opportunities to earn income from recreation/tourism & INCOP \\
\hline 13 & Create a harbour for animals that are a pest to farming & PESTS \\
\hline 14 & Should be left alone with minimal management & LEFTALONE \\
\hline 15 & Increase the fire threat to the landowners' property & FIRE \\
\hline 16 & Create a harbour for weeds & WEEDS \\
\hline 17 & Are expensive to manage & EXPMAN \\
\hline 18 & Take up a lot of time to manage & TIME \\
\hline 19 & Reduce the property value & PROPVALU \\
\hline 20 & Reduce the landowners' opportunity to diversify & DIVERSE \\
\hline 21 & Reduce the security of future income & INCSEC \\
\hline 22 & Reduce the potential to earn income from the rest of the property & INCRED \\
\hline 23 & Will make the management of the remainder of the property more complicated & COMPLEX \\
\hline 24 & Can be expensive as they lead to reduced productivity due to shading & REDPROD \\
\hline 26 & Threaten the landowners' livelihood & LIVELY \\
\hline & Are only desirable if there is no other valuable use for the land & OTHERUSE \\
\hline
\end{tabular}

The last statement (26) was included as it was frequently mentioned in informal interviews with landowners. The statement establishes a relative priority of private reserves over other uses for the land. However, it does not fit neatly into the framework surrounding landowner attitudes.

\subsubsection{Pre-testing, sampling and survey administration}

The landowner survey was pre-tested by eight landowners randomly selected from the databases of the Private Forest Reserve Program (PFRP), Private Area Protected Program (PAPL), and Greening Australia (GA). Landowners were contacted by phone and, after having the survey's aims briefly explained to them, were asked if they were willing to participate in pre-testing the survey. Upon the landowner's agreement, a survey was sent in the mail with a stamped return envelope. The main 
comments received from the pre-testing concemed the length and repetitive nature of the survey. As a result, minor alterations were made to the final version.

The PDA survey was pre-tested by officials who filled in the survey while the researcher was present and thus provided direct feedback. A mail-out version was developed for landowners and an online version of the BW survey was developed for PDAs. The surveys were administered in June 2004 and no follow-up procedures were implemented.

The funal landowner survey was mailed to 100 landowners randomly selected from the Tasmanian Farmers and Graziers Association (TFGA) database. This database contains the addresses of all primary producers in Tasmania. The sample was stratified on the basis of commodity group: wool (30), meat (30), dairy (30), and vegetables (10), representing the approximate proportion of landowners in each of these groups. The landowner survey was administered by mail as administration of the survey via email was thought to be inefficient. ${ }^{44}$ Discussions with PDAs confurmed this, based on their experience in dealing with landowners.

An estimated 60 professionals work for the 6 different organisations that implement or develop conservation incentive programs in Tasmania. These organisations are GA, PFRP, PAPL, Private Forests Tasmania (PFT), the Forest Practice Board (FPB), and the Department of Primary Industries, Water and Environment (DPIWE). The stated focus of these organisations activities ranges from "mainly forestry" to "private land conservation". However, all the abovementioned organisations employ "conservation officers". All organisations were approached to participate and agreement was obtained from the most senior person in the organisation. ${ }^{45}$

The survey for PDAs was administered via the internet. The website details were emailed to a central contact person in each participating organisation. The contact person was then asked to forward the email to colleagues using their internal email system. The email contained a "live link" to a website where respondents were

\footnotetext{
44 The main reason for not administering the survey via email or the internet was that, even though in Tasmania more than 65 percent of rural landholders use computers (www.defra.gov.uk/corporate/ebus/maffrole/usage.htm viewed on 4 August 2005), members of the focus group believed that low responses would result.

${ }^{45}$ As there is currently little guidance for defining sample sizes for BW surveys where heterogeneity in respondent preferences is expected (Flynn, Louviere et al. unpublished), approaching all organisations was considered best.
} 
presented with the survey. After completion of the survey respondents were asked to "submit" the survey. The survey results were saved to a predetermined location on the University of Tasmania server.

The response rate for landowners was 31 percent. A total of 32 useable PDA surveys was returned. This corresponds to a 53 percent response rate based on the estimated 60 persons working in the incentive program sector in Tasmania.

\subsection{Choice survey}

The main aim of the Choice survey (Appendix 3) in this research was to understand the decision framework of landowners surrounding incentive program participation and, in particular, to understand the trade-offs between incentive program attributes. It is important to gain an understanding of the decision problem most akin to the decisions that individuals make in real life when developing a Choice survey (Adamowicz, Louviere et al. 1998). Two steps were taken in this research to ensure an accurate interpretation of the decision problem: a focus group meeting with incentive program field staff, program managers, and landowners was held; and a BW survey was carried out to identify the most important attributes to be included in the Choice survey. Both the focus group meetings and the BW survey have been discussed previously in Section 6.1.

After development of the Choice survey, a draft version was pre-tested by 10 landowners randomly selected from the databases of the PFRP, PAPL, and GA. These landowners were contacted by phone and those who agreed to participate were sent a survey in the mail with a stamped return envelope. Some minor wording changes were incorporated on the basis of feedback received.

Two covering letters were included with the Choice survey. The first letter was from the TFGA encouraging landowners to participate (Appendix 3). The purpose of this letter was to emphasize the importance of landowner participation and the relevance of the survey to them. The letter was also aimed at increasing the credibility of the researchers. In the letter it was explained that the researchers had previously worked successfully with the TFGA, the stakeholder group representing landowners in Tasmania. The letter further emphasized the fact that participation was anonymous. At no stage did the landowner have to provide a name or contact details. Anonymity 
in surveys minimises respondents reporting what they think is socially desirable. This is recognised as a common problem with gathering survey data and has been extensively researched (e.g. Krosnick 1999; Nancarrow and Brace 2000).

The second letter included with the survey was printed on University of Tasmania letterhead. This letter outlined how the survey would enable landowners to influence policy with regard to private land conservation incentive programs. Clear information was provided about the aim of the survey and the benefit to the participant of filling out the survey. A so-called "hypothetical bias" may otherwise be generated if the survey is not perceived to be realistic (Frykblom and Shogren 2000).

The covering letter from the University contained contact information for the researchers. It also provided information on where and how the results of the survey could be obtained (Dillman 1978). The latest retum date for the survey, 30 September 2004, was stated on the covering letter. The final survey was mailed to 500 Tasmanian landowners in early September 2004. No follow-up procedures attempting to influence the response rate were initiated ${ }^{46}$.

\subsubsection{Survey layout}

The final Choice survey was divided into four parts. The first part contained 16 questions: property and business characteristics; the landowner's past conservation management activities; and past involvement in conservation incentive programs.

The second part of the survey contained eight choice questions. Each choice question presented two conservation incentive programs described by five program attributes. The five program attributes (land use restrictions; funding amount; legal implications; technical advice availability; and payment method) were set at a different level for each of the two programs (discussed in Section 6.2.3). Survey respondents were asked which of the two programs they would voluntarily join, or to indicate they would not join either of the programs. In the next part of the question respondents were asked which program was most preferred if they had to choose and did not have the option of not joining either program (Section 6.2.3.1). Descriptions of the

\footnotetext{
${ }^{46}$ Even though a follow-up process is a standard procedure (Dillman 1978), the process was not undertaken in this current research due to financial limitations.
} 
attributes used in the choice section were defined in a glossary. An example of how to fill out the choice question was printed on the back of the glossary (Appendix 3).

In the third part of the Choice survey respondent were asked to rate 24 statements about the role, impact and environmental outcome of establishing conservation reserves on private land. This question contained the same statements as those used in the BW survey. ${ }^{47}$ The last part of the Choice survey contained 11 questions which established the socio-economic characteristics of the landowner.

\subsubsection{Sample size and response rate}

The final version of the Choice survey was mailed out to 500 randomly selected Tasmanian landowners ${ }^{48}$ from the TFGA database. The sample was stratified into four different commodity groups representing the approximate proportion of landowners in each of these groups in Tasmania: wool (30 percent); meat (30 percent); dairy ( 30 percent); and vegetables ( 10 percent). ${ }^{49}$

The usual considerations of accuracy and collection cost guided the survey sample size (Adamowicz, Louviere et al. 1998). The sample comprised approximately 12.5 percent of the estimated 4,000 rural landowners in Tasmania. ${ }^{50}$ This lies between the minimum sample $(n)$ of between 384 and 576 for a choice probability of between 0.4 and 0.5 as recommended by Louviere, Hensher et al. (2000, p. 264).

A total of 10 surveys was undeliverable and returned to sender, giving an effective mail-out of 490 surveys. Over the month following the mail-out, 145 surveys were returned, comprising a 30 percent response rate. Of these, 13 surveys were incomplete and deemed unuseable. The final response rate was therefore 27 percent

\footnotetext{
${ }^{47}$ Two of the statements were removed from the original 26 that were included in the BW survey. After analysis of the BW survey results, it was clear that these two statements were not statements about the outcome of reserve establishment.

${ }^{48}$ The landowners who had been sent a BW survey were included in the population sample for the Choice survey. Due to the random selection of the landowners and confidential nature of the survey, it ts unknown if any landowners received both a BW and Choice survey. If this was the case, the numbers are likely to be small as there were a total of 4,000 landowners from which the sample was drawn.

${ }^{49}$ It was unknown if the individuals contained in the sample had any native forest on their land or not.

${ }^{50}$ The ABS Natural Resource Managcment Survey of Tasmanian farmers samples 728 individuals in this sector which represents a 100 percent response rate due to the compulsory nature underpinned in legislation of ABS surveys (David Rankin Pers. Comm., 2006).
} 
(132 surveys). This response rate is adequate according to Louviere, Hensher et al. (2000, p. 264) who recommend a minimum number of respondents of between 48 and 72 for simple models. The incorporation of preference heterogeneity generally requires larger sample sizes. It may therefore be argued that the sample in this current research is somewhat low.

Non-response bias, caused by over-complex survey instruments, is increasingly recognised as a challenge in valuation surveys. It is possible that a certain 'type' of person is more likely to be a non-respondent to a complex survey than another (e.g. Stewart, Anderson et al. 1993) therefore biasing estimates. As the issue of nonresponse bias was not specifically addressed in this current research, it must be considered a caveat on any discussion of the results (Section 9).

\subsubsection{Contextual statement for forest and non-forest owners}

The Choice survey sample contained both landowners who currently owned forest and landowners who owned no forest at all. The choice section of the survey required that these groups be directed to a different section of the survey containing a contextual introduction relevant to their particular choice situation. As choice decisions are made on the basis of stimuli presented (Adamowicz, Louviere et al. 1998), respondents need to able to relate to the choice situation. If respondents cannot relate to the situation, or are not motivated by the information presented, they are unlikely to be able to choose between the options provided (Ajzen, Brown et al. 1996).

Landowners who owned native forest were asked to think about one particular area of native forest on their property and describe it in terms of its physical characteristics. They were also asked whether they thought the particular tract had conservation values. Landowners were subsequently asked what the "market value" of this area of forest was and on what basis the market value was estimated. The contextual paragraph was as follows:

To set the scene for the next section of the survey we ask you to think about a particular area of native forest on your property that has some conservation value (it doesn't matter what the type of forest is or where it is on your property). If you don't own an area of forest with conservation values please think of any other tract of native forest on your land. Please answer these brief questions about that area of native forest. 
Landowners who did not own native forest were asked to imagine that 10 percent of their farm was covered in native forest and that this area had an estimated market value of $\$ 5,000$ per hectare. This represents an average per hectare value for Tasmania. ${ }^{\text {st }}$

The contextual paragraph for landowners with no native forest was as follows:

Even though you currently don't own any land with native forest, we are interested in your opinion about the sort of incentive prograin that would appeal to you if you did own forested land.

To set the scene for the next two sections please place yourself in the position of someone who owns an area of native forest. Please imagine that $10 \%$ of your property is covered with one single contiguous block of native forest.

Say that similar forested land in your region has sold for around $\$ 5,000$ per hectare in the past year. On this basis a fair market value for the area of native forest would be $\$ 5,000$ per hectare times the size of the area you indicated above.

Imagine that this forest has conservation value and is eligible to be enrolled in a conservation incentive scheme. Enrolling the land may mean you will have to change the use of that land but you would retain ownership of the land.

Both types of landowners were then asked to answer the same choice question with respect to the parcel of land they previously described. ${ }^{52}$

A well documented issue that can arise with stated preference surveys is so-called hypothetical bias. Hypothetical bias is the difference between slated and revealed values caused by the "hypothetical nature of [stated preference] surveys which [...] can result in responses that are significantly greater than actual payments" (Murpliy, Allen et al. 2005, p. 313). Research by Murphy, Stevens et al. (2005) indicates that one way in which hypothetical bias can be avoided in some instances is by using

\footnotetext{
51 This estimate was based on discussion with landowners and PDAs as well as the real estate industry particulatly focused on agriculturail land. Land values are higher in the North West and lower in the Midlands of Tasmania by several thousands of dollars per hectare but the overall average was agreed to be around $\$ 5,000$ per hectare.

52 No follow up test was implemented to investigate differences in landowner cognisance of the level of the monetary attribute in a situation where landowners are explicitly shown the dollar amount in the choice question and where the dollar amount is not explicitly stated, as in this current research.
} 
'cheap talk'. Cheap talk "... entails reading a script that explicitly highlights the hypothetical bias problem before participants make any decisions, as a means of generating unbiased responses" (Murphy, Stevens et al. 2005, p. 327). Other methods include debriefing or certainty statements (e.g. Blumenschein, Blomquist et al. 2007). No specific strategy was implemented in this current research to address the possibility of hypothetical bias. The potential implications of this type of bias can therefore not be directly assessed in this current research.

\subsubsection{Specific Choice survey design issues}

Many papers and textbooks have been written that deal with simple survey design issues aimed at maximising response rates (e.g. Dillman 1978; Jenkins and Dillman 1995; Greer, Chuchiniprakarn et al. 2000). For instance, in order to maximise response rates, the relevance of the issue to the respondent has to be ensured and the cost minimised (e.g. Greer, Chuchiniprakarn et al. 2000). Other issues which will maximise response rates are, for instance, the inclusion of a stamped retur envelope (e.g. Veiga 1984), anonymity (e.g. Tyagi 1989), offering survey results (e.g. Kalifatix and Tsogas 1994), and inclusion of a covering letter (e.g. Jobber, Birro et al. 1988), The design details presented in the sections that follow is not exhaustive and will only discuss selected issues such as for example the number of profiles, choice sets, attributes, and the attribute levels.

\subsubsection{Number of profiles}

Landowners were asked to choose between participation in two conservation incentive programs. In the literature, the choice options, hereafter referred to as programs, are called "profiles": "A profile is a single attribute level combination in a complete factorial combination of attribute levels" (Adamowicz, Louviere et al. 1998, p.13).

In the Choice survey, respondents were asked to indicate in which conservation incentive program they would enroll their land: program 1 or program 2 . They were also able to choose not to enroll their land in either prograin 1 or 2 (hereafter, where it relates to this research, referred to as the 'voluntary' option). Respondents were subsequently asked to indicate in which program they would chose to enroll their land if they had to choose and did not have the option of not enrolling their land in either 
(hereafter, where it relates to this research, referred to as the 'forced choice' option). The choice in this case was limited to program 1 or program 2.

Descriptive labels were not used for the 2 profiles, which were simply called "program 1" and "program 2". The inclusion of policy labels or headers, such as "environmental option" - "financial option" - "social option", in environmental Choice surveys appears to reduce the attention respondents pay to the attributes of the choice set (Blamey, Bennett et al, 2000). Simply labelling the choice options program 1 and program 2 avoided potential anchoring ${ }^{53}$ to what respondents perceive to be the most preferable policy label.

Anchoring may also occur where an example survey question is given to explain the survey approach to the participant. The respondent is likely to anchor their estimate to values the survey designer has given in the example (Tversky and Kahneman 1974). The chance of this occurring was reduced in this research by ensuring that the example question included with the survey was not used in the choice sets subsequently presented to respondents.

\subsubsection{Number of choice sets}

Choice survey respondents are generally presented with six to 10 choice sets. A single set contains two or three alternatives and one base option (often the status quo). The literature is unclear what effect the number of choice sets presented has on responses. On the one hand it is reasonable to expect that fatigue may affect the reliability of the results. For example, Mazzotta and Opaluch (1995) and DeShazo and Fermo (2002) find that choices among alternatives become complex if there are many alternatives, or if the alternatives differ in terms of a large number of attributes. They find that this may impact on choice consistency which will in tum impact on welfare estimates.

Hensher, Stopher et al. (2001) also tested the effect of administering various numbers of choice sets $(4,8,16,24$, and 32$)$ on the ability of respondents to comprehend and respond. They found that the number of treatments placed before people did not generate a problem, even for the 32-treatment design, and thus did not support the

\footnotetext{
${ }^{53}$ Anchoring is the effect of the respondent being pulled toward an anchor and is often referred to as "starting point bias" (Tversky and Kahneman 1974).
} 
principle of fatigue effects. They did find, however, some evidence that four treatments were inadequate to allow sufficient variability in responses.

To explore the effects of fatigue in this study 12 randomly selected landowners were asked to pre-test the survey with 16 choice sets containing 10 attributes. Subjects were asked to provide the researcher with feedback about the survey.

Most landowners voiced concems about the number of repeat questions and the number of attributes. As most subjects were unfamiliar with this type of survey, suspicions were aroused. Comments received regarding the number of repeated questions were for example:

"I got completely disinterested by the $10^{\text {th }}$ time and didn"t care what I answered";

"I gave up after number 8 ".

On the basis of the comments received and following further discussion with the subjects, the number of choice sets was limited to eight. Guidance on the number of choice sets was also taken from other studies (e.g. Whitten and Bennett 2001; Boxall and Adamowicz 2002; Rolfe and Windle 2003; Home 2004). Comments were also received in relation to the repetitive nature of the questions. For instance:

"Are you trying to catch us out?"

"Why don't you just ask what we think a program should look like instead of all this complicated stuff?"

"Are you trying to find inconsistencies in our answers?"

To avoid arousing suspicion and consequently reducing the survey response rate, the nature of the questioning was explained in the covering letter and in the survey itself. As such, it was explicitly stated that the survey was not aimed at finding responses inconsistencies. Due to the "informal nature" of pre-testing the survey, no further statistical analysis of the pre-test results was carried out.

\subsubsection{Number of attributes}

Users of Choice surveys have used different numbers of attributes in the profiles. Home (2004) uses five attributes to describe alternative policy options aimed at increasing areas of land protected for conservation. Kerr and Sharp (2004) use six attributes to evaluate offsite mitigation of adverse environmental effects resulting 
from development on streams in New Zealand. Rolfe and Windle (2003) use five attributes to value the protection of aboriginal cultural heritage sites. Boxall and Adamowicz (2002) use five attributes to evaluate wildemess park choice.

In the pre-testing phase of the current survey, subjects were presented with 10 attributes in each choice set. The comments received regarding the number of attributes presented in the program profile suggested that 10 attributes increased survey complexity. For example:

"I only ended up looking at the first two things - too much to remember"

"By the time I'd read the last one, I'd forgotten what the first one was".

On the basis of comments received, and the literature reviewed, the number of program attributes was set at five. The five most important attributes out of the initial set of 10 were determined using the BW survey (Chapter 7).

\subsubsection{Orthogonal design}

The design of a Choice survey involves selecting a sample of profiles which have particular statistical properties allowing the estimation of the coefficients of a utility function. Linear model design theory underpins the published catalogue and specialized software that is used to develop designs. However, Adamowicz, Louviere et al. (1998) point out that care should be taken when simply applying "canned" designs as many choice problems have built in constraints.

The assistance of Dr. Leonie Burgess and Prof. Deborah Street, Department of Mathematical Sciences, University of Technology Sydney, was sought to develop the most efficient design for the choice experiment within the constraints of the application. The method, which is outlined in Burgess and Street (1999, 2005, forthcoming), starts with a Fractional Factorial Design (FFD) and adds generator(s) to create the other options in the choice sets. In this case, a FFD was constructed to allow for the estimation of all the main effects plus the two-factor interactions between the first attribute and each of the other attributes. This FFD was used as the first options in 16 choice sets, and a generator was added to the FFD to obtain the second options in the choice sets. 
The design for the Choice survey allowed for five attributes, four of which have two levels and one with four levels (Appendix 4). All main effects and the interaction between the first two level attribute (land use restrictions) and the four level attribute (funding amount) can be estimated independently of each other (i.e. they are uncorrelated). The 16 sets and their complements were randomly allocated to two separate eight-set surveys. ${ }^{54}$

\subsubsection{Willingness to accept}

Choice experiments generally contain at least one attribute that is expressed in dollar value. Such as the cost of travel mode (Hensher and Sullivan 2003), or additional tax paid for conservation purposes (Whitten and Bennett 2001). This is essential if marginal utilities and implicit prices are to be estimated.

The attribute expressed in dollar value in this research was the market value of an area of land. Survey respondents were asked to estimate a fair market value for their land. The level of the estimated market value was then varied in the program profile in the choice experiment to a proportion of the original base amount. In other words, the landowner was offered either less, the same as, or more than the market value in compensation funding for joining a conservation incentive program.

This approach to determining a base level for the monetary attribute in a choice experiment has previously been applied in the transport literature. For instance Hensher and Greene (2003a) set the base amount in a stated choice experiment for urban commuting by asking respondents to identify their current trip details (including running cost and toll charges).

In the current research the landowner was asked to accept money for setting aside land. The landowner is asked to reveal their Willingness To Accept (WTA) a monetary reimbursement for a "loss" of potential future income. ${ }^{55}$ The loss is the use of that land for productive purposes (agriculture or forestry). Landowners are assumed to hold rights and in a voluntary setting accept compensation to give up these

\footnotetext{
54 Alternative designs were investigated and deemed too complicated.

55 The psychological foundation of loss aversion is relevant to Choice surveys of non-use value. Kahneman and Tversky (1979) first established that people dislike losses more than they value gains, which is the central theme of prospect theory. Even though this issue is important to Choice surveys it is beyond the scope of this dissertation to investigate this any further.
} 
rights. Therefore, WTA estimation adopted in this dissertation is the only acceptable framework. Most other choice experiments, particularly where they focus on environmental issues, ask respondents their Willingness to Pay (WTP) for a combination of environmental characteristics. The level of their "payment" will result in a specified set of environmental "gains".

\subsubsection{Inclusion of status quo}

The introduction to the choice section of the survey established that the landowner could enroll the land they have in mind regardless of the current status. The landowner was able to choose not to enroll their land if neither program 1 nor 2 appealed. This part of the choice question formed the basis of a voluntary choice scenario. An absolute measure of value of changes in individual attributes can be determined if a "choose no or neither" option is included in the choice set (Morrison, Blamey et al. 1996).

Other studies (eg. Horne 2004) have found that a large proportion of respondents choose the "status quo" option. This results in significant differences in per hectare welfare estimates between the analysis that includes and excludes the status quo (e.g. Horne 2004). It was expected that a large number of survey respondents in this current Choice survey would also choose not to join a program.

In this research a model was estimated for a voluntary choice scenario, but also one where the landowner is forced to choose one of two programs (the "forced choice" model). The second scenario was included to simulate a choice situation where, for instance, forest owners were forced to conserve their land by government regulation.

Chapter 5 presented the statistical method used to interpret the choice, BW, and attitude data. Chapter 6 presented a review of the BW and Choice survey methods. In Chapter 7 these statistical methods are applied to the BW data and the results are presented. Similarly, in Chapter 8 the results of the Choice survey are presented. 


\section{$7 \quad$ Best-worst survey results}

This section presents the results of the Best-Worst (BW) survey. Firstly, the general results, such as experience and work focus are described. Secondly, the BW and attitude data are analysed, using the statistical methods previously discussed in Section 5.2 .

\subsection{Descriptive Best-Worst data}

Two BW surveys were sent out: one to Program Designers and Administrators (PDAs); the other to landowners (abbreviated in the tables below as LOs). The BW survey was emailed to an estimated 60 PDAs, professionals working for six different organisations that implement or develop incentive schemes in Tasmania. A total of 32 responses was received, resulting in an estimated 53 percent response rate.

PDAs had worked in jobs related to resource conservation for an average of 12 years (the longest was 30 years and the shortest was one year). The largest proportions of PDAs described their positions as scientific (29 percent) and extension officers (23 percent). A total of 23 percent were policy officers or in management positions. The PDAs that did not fit into any of the categories listed in the survey described themselves as bureaucrats, a project officer, and an ecologist. Around one third of PDAs worked in the field and had face-to-face contact with landowners once or twice per week. For about half of the PDAs this contact occurred less than once per month. Only a small proportion of PDAs never visited landowners and properties (less than 10 percent).

For landowners the BW survey was mailed out. A total of 100 landowners received a survey, and 31 responses were returned giving a 31 percent response rate for the landowner survey.

Landowners had been engaged in conservation related activities for an average of 11 years and had owned their property for an average of 17 years. Male landowners comprised 61 percent of respondents. Overall, 83 percent of landowners identified themselves as the owner and manager of the property. The average age of landowners was 47 years old. Slightly more than 50 percent had completed TAFE or had tertiary 
qualifications. An average of 64 percent of landowners earned the majority of their income from farming. At the same time, 75 percent earned some off-farm income.

\subsection{Best-Worst data}

In the second part of the survey respondents were asked to identify the most and least important attributes of incentive programs out of five attributes. They were asked to repeat this 18 times, each time for a different combination of the 10 attributes.

Every respondent's assessment of the relative importance of the 10 incentive program attributes was determined by subtracting the number of times it was rated least important from the number of times it was rated most important. The potential score ranged from +9 to -9 . 'The mean individual BW scores provide a measure of the level of importance for each of the incentive program attributes (Finn and Louviere 1992).

The mean scores for all respondents are shown in column one of Table 2.

Table 2: Best-Worst score for 10 incentive program attributes for all respondents, PDAs, and landowners, and t-values (BW survey data).

\begin{tabular}{|c|c|c|c|c|c|}
\hline 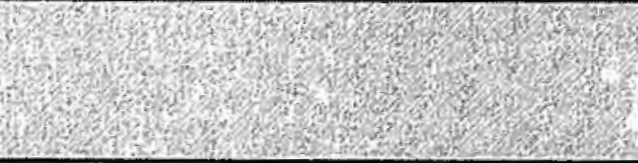 & $\begin{array}{l}\text { Mean } \\
\text { score } \\
\text { (all resp.) }\end{array}$ & $\begin{array}{l}\text { Mean } \\
\text { score } \\
\text { (PDAs) }\end{array}$ & $\begin{array}{l}\text { Mean } \\
\text { score } \\
\text { (LOs) }\end{array}$ & t-value & $\begin{array}{l}\text { Sig. } \\
(2 \\
\text { ailed) }\end{array}$ \\
\hline $\begin{array}{ll}\text { Land use restrictions } & \text { (RESTRICT) } \\
\end{array}$ & 5.92 & 7.16 & 4.55 & 0.591 & 0.557 \\
\hline (FUNDAMOUNT) & 3.56 & 5.06 & 1.90 & 0.966 & 0.338 \\
\hline Legal implications & 0.70 & 0.94 & 0.45 & -2.024 & 0.048 \\
\hline Technical support availability (TECHSUPP) & $0.3 \overline{4}$ & 0.13 & 0.59 & -1.976 & 0.053 \\
\hline $\begin{array}{ll}\text { Payment method } & \text { (PAYMETH) }\end{array}$ & 0.02 & -0.53 & 0.62 & -0.560 & 0.578 \\
\hline Program duration & -0.89 & -1.66 & -0.03 & 0.966 & 0.338 \\
\hline Application procedure (APPLICATION) & -0.89 & -1.44 & -0.28 & -2.231 & 0.029 \\
\hline Funding allocation process (ALLOCPROC) & -1.52 & -2.09 & -0.90 & 3.520 & 0.001 \\
\hline Monitoring \& survey requirem.(MONITOR) & -2.61 & -2.22 & -3.03 & -1.758 & 0.084 \\
\hline $\begin{array}{ll}\text { Funding agency } & \text { (AGENCY) }\end{array}$ & -4.61 & -5.34 & -3.79 & -1.778 & 0.081 \\
\hline
\end{tabular}

\# Levene's Test for Equality of Variances was $>0.05$ for all variables indicating that equal variances could be assumed between the two different groups.

Table 2 shows that for all respondents (column 1) the five most important attributes in the decision framework were land use restrictions, funding amount, legal implications, technical support availability, and payment method. These same attributes were also ranked as the five most important for landowners and PDAs when considered separately (columns 2 and 3 ). The only difference between the two groups lies in the relative ranking of the legal implications, rated fifth for landowners and third for PDAs. 
A Student's t-test for the equality of mean scores for PDAs and landowners indicates a significant difference at the 5 percent level in the rating of incentive scheme attributes for LEGAL, TECHSUPP, APPLICATION, and ALLOCPROC (shown in bold).

Table 3 shows the number of times each attribute was more important than funding amount and the second column the number of times it was less important than funding amount. The Z-score is for the Wilcoxon matched pairs signed rank test where the null hypothesis is that the attribute and the funding amount are equally important. The null hypothesis is rejected at the 1 percent level of significance for all attributes.

Table 3: Ratio of ranking higher and lower than funding amount, Wilcoxon signed rank test, and $Z$ score (BW survey data).

\begin{tabular}{|c|c|c|c|c|}
\hline 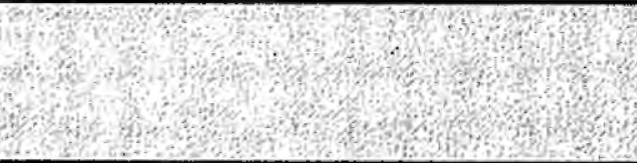 & $\begin{array}{l}\text { Ranking } \\
\text { of } \\
\text { attributes }\end{array}$ & $\begin{array}{l}\text { Ranked } \\
\text { higher than } \\
\text { FUND } \\
\text { AMOUNT }\end{array}$ & $\begin{array}{l}\text { Ranked } \\
\text { lower than } \\
\text { FUND } \\
\text { AMOUNT }\end{array}$ & Z-score \\
\hline Land use restrictions & 1.926 & 39 & 17 & 3.050 \\
\hline (FUNDAMOUNT) & 3.057 & - & - & - \\
\hline Legal implications & 4.910 & 14 & 41 & 3.625 \\
\hline Technical support availability (TECHSUPP) & 5.303 & 12 & 46 & 3.968 \\
\hline $\begin{array}{ll}\text { Payment method } & \text { (PAYMETH) }\end{array}$ & 5.385 & 10 & 46 & 4,487 \\
\hline Program duration & 5.959 & 9 & 49 & 4.876 \\
\hline Application procedure $\quad$ (APPLICATION) & 6.107 & 8 & 46 & 5.133 \\
\hline Funding allocation process (ALLOCPROC) & 6.623 & 6 & 52 & 6.122 \\
\hline Monitoring \& survey requirem.( MONITOR) & 7.238 & 4 & 54 & 6.412 \\
\hline $\begin{array}{ll}\text { Funding agency } & \text { (AGENCY) }\end{array}$ & 8.492 & 5 & 54 & 6.428 \\
\hline
\end{tabular}

The ranking score for the attributes and for each respondent was scaled using MDS analysis (Table 4). The proximities were scaled at an ordinal level as the normalized raw stress increased when proximities were scaled at a ratio level (Section 5.3). This procedure was carried out for all respondents and each respondent group separately. 
Table 4: The BW scale and normalized stress indicator for all respondent, PDAs, and landowners for incentive program attributes (BW survey data).

\begin{tabular}{|c|c|c|c|c|}
\hline 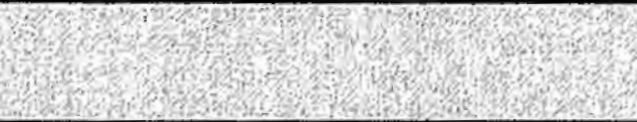 & $\begin{array}{l}\text { BW scale } \\
\text { (all resp) }\end{array}$ & $\begin{array}{l}\text { Norn. } \\
\text { raw } \\
\text { stress }\end{array}$ & $\begin{array}{l}\text { BW } \\
\text { scaling } \\
\text { PDAs }\end{array}$ & $\begin{array}{l}\mathrm{BW} \\
\text { scaling } \\
\mathrm{LOS}\end{array}$ \\
\hline $\begin{array}{ll}\text { Land use restrictions } & \text { (RESTRICT) }\end{array}$ & 1.451 & 0.0025 & 1.454 & 1.355 \\
\hline (FUNDAMOUNT) & 0.827 & 0.0054 & 0.886 & 0.567 \\
\hline Legal implications & 0.142 & 0.0128 & 0.244 & 0.041 \\
\hline Technical support availability (TECHSUPP) & 0.043 & 0.0157 & -0.137 & 0.161 \\
\hline Payment method $\quad$ (PAYMETH) & -0.068 & 0.0090 & -0.076 & 0.290 \\
\hline Program duration & -0.206 & 0.0047 & -0.248 & -0.014 \\
\hline Application procedure $\quad$ (APPLICATION) & -0.271 & 0.0049 & -0.352 & -0.161 \\
\hline Funding allocation process (ALLOCPROC) & -0.314 & 0.0034 & -0.366 & -0.278 \\
\hline Monitoring \& survey requirem.(MONITOR) & -0.533 & 0.0095 & -0.399 & -1.090 \\
\hline $\begin{array}{ll}\text { Funding agency } & \text { (AGENCY) }\end{array}$ & -1.072 & 0.0077 & -1.006 & -0.872 \\
\hline Resp Norm. Raw Stress & 0.0076 & & 0.0058 & 0.0401 \\
\hline Dispersion Accounted For & 0.9924 & & 0.9942 & 0.9600 \\
\hline Tucker's Coef. of Congruence & 0.9962 & & 0.9971 & 0.9798 \\
\hline
\end{tabular}

The stress and fit measures indicate that the distances in the solution approximate the original distances well for all respondents. A higher stress figure was obtained for landowners. Although lower stress measures and higher fit measures (Tucker's coefficient of congruence) indicate better solutions, the figures obtained for landowners are considered acceptable.

The quantitative scale represents the psychological response of the respondent to the perceived importance of the incentive program attributes. The column of normalised stress identify TECHSUPP $(0.0157)$ and LEGAL $(0.0128)$ as the attributes that contribute most to the overall stress of the solution for all respondents. FUNDAMOUNT contributes most to the overall stress of the solution for landowners (not shown in the table).

Even though the ranking order of legal implications and the payment method differs between PDAs and landowners, both groups included the same attributes in their list of five most important. The five most important attributes that are included in the Choice survey (Chapter 8) are: FUNDAMOUNT (funding amount); LEGAL (legal implications); RESTRICT (land use restrictions), TECHSUPP (technical support availability); and FUNDMETHOD (funding method). 


\subsection{Best-Worst attitude data and analysis}

The last section of the BW survey asked respondents to rate 26 statements on the role and impact of establishing conservation reserves on private land. Mean ratings and standard deviations for both PDAs and landowners are shown in Table 5. A score of 1 indicated "strongly agree", 2 indicated "agree", 4 indicated "disagree", and 5 indicated "strongly disagree". A score of three indicated that the respondent felt "neutral" about the statement. The attitude question asked in the survey and the definition of the codes in Table 5 were previously given in Table 1 of Section 5.1.1.2.

Table 5: Respondent rating of the role and impact of establishing conservation reserves on private land (BW survey data).

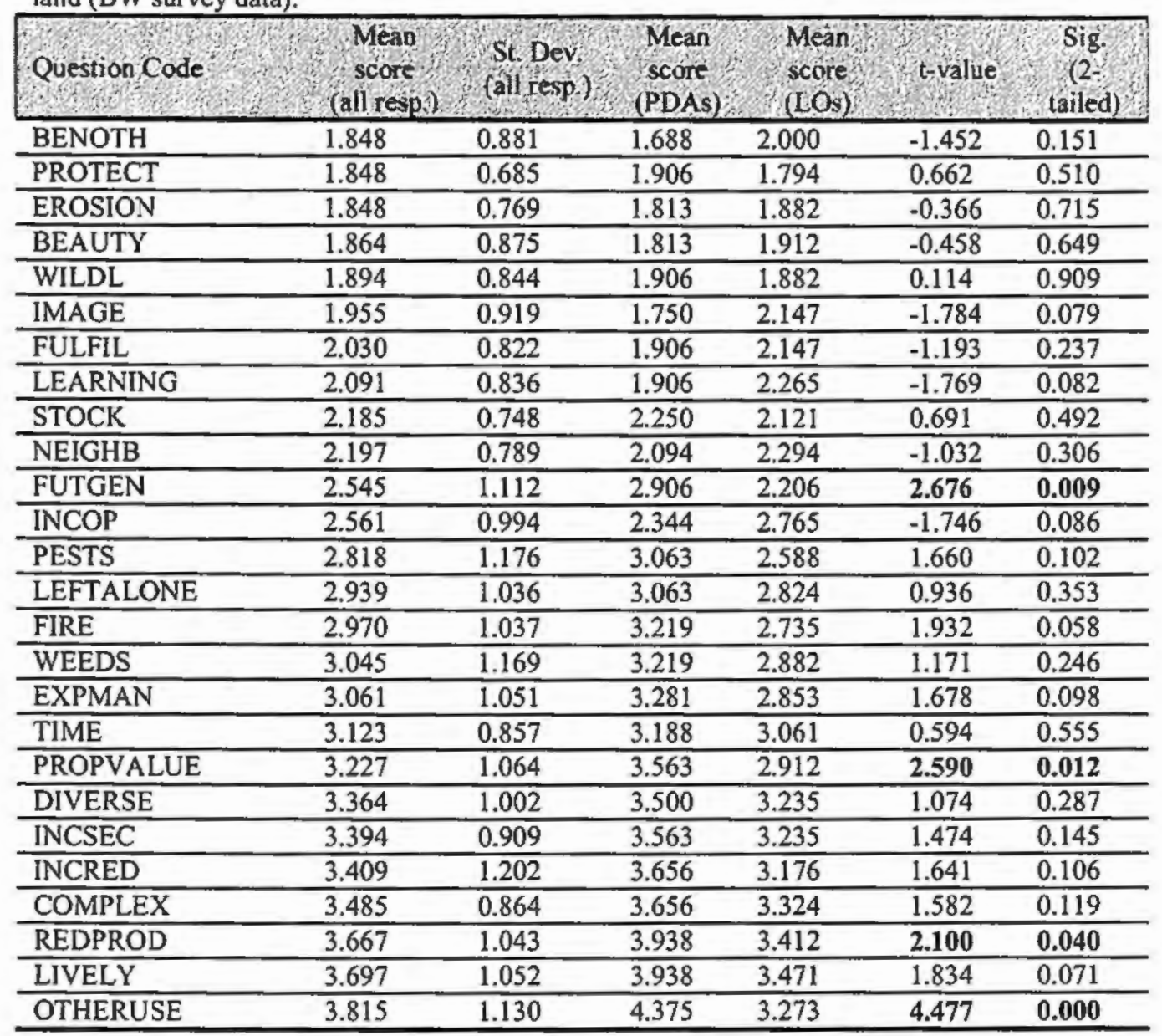

A test of the equality of mean scores for PDAs and landowners indicates a significant difference, at the 5 percent level, in the rating of the following attitudes (shown in bold in Table 5): OTHERUSE (0.000); FUTGEN (0.009); PROPVALUE (0.012); REDPROD (0.040). PDAs more strongly disagreed that reserving areas of forest was only useful if there was no other use for the land. Landowners more strongly agreed 
that reserve establishment mainly benefited the future generation and that it reduced property values. Landowners less strongly disagreed that reserve establishment could be expensive as it leads to reduced productivity due to shading.

A PCA and VARIMAX rotation method (SPSS version 11.0.0) was used to condense the original 26 attitude variables to form a reduced number of interpretable variables (Mulaik 1972). Firstly, the communalities for all attitude variables were examined. Variables with extraction communality values smaller than 0.2 were dropped from the PCA, as this indicated that they did not fit well with the factor solution. The next step in the PCA involved determining the number of factors (Table 6). There are severaI methods by which this can be done, including Cattell's scree test, identifying eigenvalues greater than 1, and interpretability of the resultant factors. Using a combination of these methods, i.e. an eigenvalue greater than 1 and the component must add around 10 percent to the factor solution, resulted in two factors being extracted. $^{56}$

Table 6: Total variance explained (BW survey data).

\begin{tabular}{|c|c|c|c|c|c|c|c|c|c|}
\hline \multirow[t]{2}{*}{ Component } & \multicolumn{3}{|c|}{ Initial Elgenvalues } & \multicolumn{3}{|c|}{$\begin{array}{l}\text { Extraction Sums of Squared } \\
\text { Loadings }\end{array}$} & \multicolumn{3}{|c|}{$\begin{array}{l}\text { Rotation Sums of Squared } \\
\text { I cadings }\end{array}$} \\
\hline & Total & $\begin{array}{c}\% \text { of } \\
\text { variance }\end{array}$ & $\begin{array}{c}\text { Cum. } \\
\%\end{array}$ & Total & $\begin{array}{c}\% \text { of } \\
\text { variance }\end{array}$ & $\begin{array}{c}\text { Cum. } \\
\%\end{array}$ & Total & $\begin{array}{c}\% \text { of } \\
\text { variance }\end{array}$ & $\begin{array}{c}\text { Cum. } \\
\%\end{array}$ \\
\hline 1 & 7.907 & 35.940 & 35.940 & 7.907 & 35.940 & 35.940 & 4.134 & 18.789 & 18.789 \\
\hline 2 & 2.724 & 12.383 & 48.323 & 2.724 & 12.383 & 48.323 & 3.847 & 17.486 & 36.275 \\
\hline 3 & 1.617 & 7.349 & 55.673 & 1.617 & 7.349 & 55.673 & 2.862 & 13.010 & 49.285 \\
\hline 4 & 1.114 & 5.062 & 60.735 & 1.114 & 5.062 & 60.735 & 2.145 & 9.750 & 59.035 \\
\hline 5 & 1.037 & 4.713 & 65.448 & 1.037 & 4.713 & 65.448 & 1.411 & 6.413 & 65.448 \\
\hline
\end{tabular}

* Components with eigenvalues smaller than 1 are not shown.

Table 6 shows that the first two components explain around 48 percent of the total variation in the original variables. Variables with loadings greater than 0.400 in the rotated component matrix for two principal components were assumed to fit well within the factor solution (shown in Table 7). The PCA was also carried out separately for PDAs and landowners. No significant difference resulted in the factor solution between the two groups.

\footnotetext{
${ }^{56}$ Even though the third component explains 7 percent of the variance, this component was difficult to categorise into a specific impact focus. The third component was therefore not retained in the analysis (Table 7).
} 
Table 7: Rotated component matrix (BW survey data).

\begin{tabular}{lll}
\hline & $\begin{array}{c}\text { Production } \\
\text { impact }\end{array}$ & $\begin{array}{c}\text { Environment } \\
\text { impact }\end{array}$ \\
\hline BEAUTY & PC 2 \\
\hline BENOTH & 0.705 \\
\hline COMPLEX & & 0.551 \\
\hline DIVERSE & 0.664 & \\
\hline FULFIL & 0.662 & 0.779 \\
\hline IMAGE & & 0.628 \\
\hline INCOP & & 0.503 \\
\hline INCRED & & \\
\hline INCSEC & 0.807 & \\
\hline LIVELY & 0.739 & \\
\hline OTHERUSE & 0.826 & 0.519 \\
\hline PROPVALUE & & \\
\hline PROTECT & 0.620 & 0.796 \\
\hline REDPROD & 0.510 & \\
\hline
\end{tabular}

Extraction Method: Principal Component Analysis.

Rotation Method: Varimax with Kaiser Normalization (Kaiser 1958).

Rotation converged in 7 iterations.

Kaiser-Meyer-Olkin Measure of Sampling Adequacy is $0.759^{57}$

Bartlett's Test of Sphericity ${ }^{58}$ : Approx. Chi-Square $=914.167, \mathrm{df}=231, \mathrm{Sig}=<0.0001$

Standard tests of the adequacy of the PCA indicate that a factor analysis is useful for this reduced variable set. A 0.759 Kaiser-Meyer-Olkin Measure of Sampling Adequacy indicates a high proportion of variance in the data can be explained by the underlying factors. Further the significance level of $<0.0001$ for Bartlett's test of sphericity, with approximate Chi-square of 914.167 and 231 degrees of freedom, indicates significant relationships among the variables.

Table 7 shows that the first factor $(\mathrm{PC1})$ includes attitudes that focus on the impact of reserves on the production capacity of an agricultural enterprise. The second factor (PC2) relates to attitudes that focus on the impact of reserves on environmental values and on the personal value to the landowner. The two factors can consequently be labelled production impact and environmental impact.

The PCA attitude data was not further analysed and a cluster analysis was not applied due to the small number of observations. In general, however, the PCA results for the BW attitude data presented above compare well to the Choice survey attitude results

${ }^{57}$ The Kaiser-Meyer-Olkin Measure of Sampling Adequacy is a statistic which indicates the proportion of variance in the variables which is common variance, i.e. which might be caused by underlying factors. High values (close to 1.0) generally indicate that a factor analysis may be useful with the data.

${ }^{58}$ Bartlett's test of sphericity indicates whether the correlation matrix is an identity matrix, which would indicate that the variables are unrelated. A significance level of less than 5 percent indicates that there are probably significant relationships among the variables. 
discussed in the next chapter. The factors are similar in that they comprise a factor focused on environmental outcomes, and one with a focus on the production impact of establishing reserves. 


\section{Choice survey results and analysis}

In this chapter the results of the Choice survey are presented. First, a descriptive analysis of the socio-economic characteristics of survey respondents and their property is outlined. This is followed by the statistical analysis of the attitude data gathered as part of the Choice survey. Lastly, a model of landowner preferences for incentive program attributes is estimated. A discussion of the results in this Chapter and Chapter 7, as they relate to the objectives stated in Chapter 1 , is reserved for the concluding Chapter 9.

As described in Chapter 6, the Choice survey was mailed out to 500 Tasmanian landowners, stratified into three different commodity groups. A total of 132 useable surveys was returned resulting in a 27 percent response rate. The response rate is consistent with that of other landowner surveys in Tasmania (Jennings and van Putten 2001, 2003) and also compares well with mail-out Choice surveys carried out elsewhere (e.g. Whitten and Bennett 2001).

\subsection{Descriptive choice data}

In the next section, survey respondent characteristics are outlined followed by property and business characteristics, and their native forest holding and conservation management activities. The characteristics of respondents in the sample are compared to Tasmanian Iandowners as described by the Australian Bureau of Statistics census data, previous landowner surveys, and the BW survey data. Where significant, differences between male and female respondents and between regions are identified. General respondent statistics (the mean and standard deviation) are shown in Table 8 below. 
Table 8: Mean and standard deviation of socio-economic characteristics, property characteristics, and land management activities of survey respondents (Choice survey data).

\begin{tabular}{|c|c|c|c|c|}
\hline Descriptive Statistics & Unit & $\begin{array}{l}\text { Number } \\
\text { of obs.* }\end{array}$ & Mean & $\begin{array}{l}\text { Standard } \\
\text { Deviation }\end{array}$ \\
\hline The number of years the property has been owned & Years & 125 & 32.13 & 34.498 \\
\hline Number of years involved in conservation activities & Years & 132 & 13.98 & 17.124 \\
\hline The age of the respondent & Years & 128 & 50.64 & 10.766 \\
\hline The size of the property & Hectares & 132 & $2,942.83$ & 11056 \\
\hline The size of native forest on the property & Hectares & 132 & 885.41 & 4561.910 \\
\hline The number of dependent children on the property & Number & 129 & 1.44 & 1.391 \\
\hline Annual Gross Farm Turnover & \$/year & 108 & 599,011 & 684303 \\
\hline The landowner owns and manages the property & $\%$ of total $\mathrm{N}$ & 132 & $92 \%$ & 0.277 \\
\hline Property is owned as a partnership or by the family & $\%$ of total $\mathrm{N}$ & 132 & $49 \%$ & 0.502 \\
\hline The landowner resides on the property & $\%$ of total N & 132 & $92 \%$ & 0.266 \\
\hline $\begin{array}{l}\text { The property is situated in the southern region of } \\
\text { Tasmania }\end{array}$ & $\%$ of total N & 132 & $23 \%$ & 0.426 \\
\hline $\begin{array}{l}\text { The property is situated in the central region of } \\
\text { Tasmania }\end{array}$ & $\%$ of total N & 132 & $42 \%$ & 0.495 \\
\hline $\begin{array}{l}\text { The property is situated in the northwest region of } \\
\text { Tasmania }\end{array}$ & $\%$ of total $\mathrm{N}$ & 132 & $36 \%$ & 0.481 \\
\hline The landowner has received assistance for fencing & $\%$ of total $\mathrm{N}$ & 132 & $53 \%$ & 0.501 \\
\hline The landowner owns an area of NF & $\%$ of total $\mathrm{N}$ & 132 & $73 \%$ & 0.443 \\
\hline $\begin{array}{l}\text { The landowner does not use the area of NF for } \\
\text { anything }\end{array}$ & $\%$ of total $N$ & 97 & $40 \%$ & 0.493 \\
\hline $\begin{array}{l}\text { The landowner intends to use the area of NF for } \\
\text { commercial harvesting purposes in the future }\end{array}$ & $\%$ of total $N$ & 97 & $26 \%$ & 0.440 \\
\hline There is a conservation reserve on the property & $\%$ of total $\mathrm{N}$ & 97 & $22 \%$ & 0.416 \\
\hline The survey respondent is male & $\%$ of total $\mathrm{N}$ & 132 & $76 \%$ & 0.430 \\
\hline $\begin{array}{l}\text { The landowner has achieved up to tertiary education } \\
\text { level }\end{array}$ & $\%$ of total $N$ & 132 & $34 \%$ & 0.476 \\
\hline $\begin{array}{l}\text { The landowner intends to pass the property on to a } \\
\text { family member }\end{array}$ & $\%$ of total $N$ & 130 & $58 \%$ & 0.496 \\
\hline $\begin{array}{l}\text { Off-farm income is earned by the landowner or a } \\
\text { family member who lives on the property }\end{array}$ & $\%$ of total $N$ & 130 & $66 \%$ & 0.475 \\
\hline $\begin{array}{l}\text { The majority of income is eamed from farming } \\
\text { activities }\end{array}$ & $\%$ of total $N$ & 130 & $77 \%$ & 0.423 \\
\hline $\begin{array}{l}\text { The landowner does not have a mortgage on the } \\
\text { property }\end{array}$ & $\%$ of total $N$ & 129 & $40 \%$ & 0.492 \\
\hline
\end{tabular}

Note: * Where the number of observations $(\mathrm{N})$ does not equal 132 this indicates missing data except for questions related to native forest where $\mathrm{N}=97$.

Overall, the mean values for characteristics for both the Choice survey sample and BW survey sample are similar. Some minor differences are that BW survey respondents were slightly younger, fewer earned the majority of their income from farming, and they had owned their properties for a shorter period of time.

\subsubsection{Landowner demographic data}

Respondents were asked to identify the gender of the person filling out the survey; 76 percent indicated they were male. The gender distribution of survey respondents is 
similar to that found in previous surveys of farmers in Tasmania where 83 percent of respondents were male (Jennings and van Putten 2003). Of the 5,654 persons who identified themselves as farmers or farm managers in the 2001 Census of Population and Housing, 72 percent were male.

The average age of survey respondents was 49 years. Forty-six percent of survey respondents were less than 50 years of age. The oldest respondent was 80 and the youngest was 23 (Table 9). Female respondents were on average somewhat younger than males.

Table 9: Survey respondent age statistics for males and females (Choice survey data).

\begin{tabular}{lccc}
\hline & Males & Females & All \\
\hline Number of observations & 99 & 29 & 128 \\
\hline Survey respondents less than 50 years old & $42 \%$ & $59 \%$ & $46 \%$ \\
\hline Average age & 52.1 & 45.7 & 49.1 \\
\hline Maximum age & 80 & 65 & 80 \\
\hline Minimum age & 29 & 23 & 23 \\
\hline
\end{tabular}

The average age of respondents and the percentage under 50 compare well to the 2001 Census of Population and Housing, where 53 percent of farmers or farm managers were less than 50 years old. ${ }^{59}$ While all respondents identified their gender, four respondents (three of whom were fernale) did not report their age.

Survey respondents were asked how many children were living on the property. Three survey respondents did not indicate whether they had any children living on the property while 40 percent of respondents indicated they had no children. This is roughly comparable to the 2001 Census of Population and Housing for farmers and farm managers ${ }^{60}$ where 48 percent of respondents did not have dependent children. Overall, respondents had an average 2.38 children living on the property. The highest number of children living on the property was five.

Respondents were asked to indicate the highest level of education they had achieved. Forty-three percent of respondents reached secondary level, 32 percent technical or TAFE level, and the remaining 34 percent had reached university level. The number

\footnotetext{
${ }^{59}$ Occupation (ASCO2) and SEXP Sex by AGEP Age.

${ }^{60}$ Oceupation (ASCO2) by FMTF Family Type.
} 
of farmers who had reached secondary level was higher than that found by the 2001 Census of Population and Housing where 23 percent of farmers and farm managers completed level $12 .^{61}$ The number of landowners who had achieved tertiary level education in this survey was also higher than that found in a previous Tasmanian survey by Jennings and van Putten (2003) were it was 24 percent.

There are some observable demographic differences in the current survey between male and female respondents (Table 10). Female respondents were somewhat younger and had achieved a higher level of education than male respondents. This result is consistent with Jennings and van Putten (2003).

Table 10: Demographic differences between male and female survey respondent (Choice survey data).

\begin{tabular}{|c|c|c|c|c|c|}
\hline Variable & $\begin{array}{l}\text { Number } \\
\text { of obs } \\
\text { Females }\end{array}$ & $\begin{array}{l}\text { Number } \\
\text { of obs } \\
\text { Males }\end{array}$ & $\begin{array}{l}\text { Mean } \\
\text { value } \\
\text { Females }\end{array}$ & $\begin{array}{c}\text { Mean value } \\
\text { Males } \\
\end{array}$ & $\begin{array}{l}\text { Sig }(2- \\
\text { tailed) }\end{array}$ \\
\hline Age & 29 & 99 & 45.690 & 52.091 & 0.005 \\
\hline Tertiary education & 32 & 100 & 0.500 & 0.290 & 0.042 \\
\hline No mortgage & 30 & 99 & 0.600 & 0.343 & 0.016 \\
\hline Reside & 32 & 100 & 1.000 & 0.900 & 0.001 \\
\hline NW region & 32 & 100 & 0.250 & 0.470 & 0.021 \\
\hline
\end{tabular}

There were significantly fewer female respondents in the Northwest of the State. Females also more frequently had no mortgage and were resident on the property.

\subsubsection{Information level}

To ascertain how well-informed landowners were in relation to conservation issues, survey respondents were asked if they regularly received information from any of a list of organisations. Around 40 percent of respondents indicated that they regularly received information from either Greening Australia or Landcare/Coastcare. A further 35 percent indicated they received information from PFT. More than 45 percent of respondents received information from two or more sources.

These results are similar to those found in a previous survey of Tasmanian landowners by Jennings and van Putten (2003) who found that 57 percent of respondents were members of, or received information from, Landcare and/or Greening Australia, and 40 percent of landowners were members of, or received information from, PFT.

${ }^{61}$ Occupation (ASCO2) by SEXP Sex and HSCP Highest Level of Schooling Completed for Persons. 


\subsubsection{Business and property demographics}

With the aim of gathering information about the business and property characteristics, survey respondents were asked if they earned any off-farm income. Sixty-six percent of landowners indicated that they earned off-farm income. Seventy-seven percent of respondents indicated the majority of their income was derived from farming activities. Of those whose primary income source was farming, 60 percent also earned off-farm income. In a previous landowner survey by Jennings and van Putten (2003) the percentage of respondents earning off-farm income was 64 percent.

The same survey by Jennings and van Putten (2003) found that slightly over 60 percent of landowners owed no debt on their farm. This was higher than found in this research, where 40 percent of respondents did not owe any debt on their property. Thirty-three percent of respondents had a mortgage of up to 25 percent of the value of the property and 22 percent had a mortgage between 25 and 50 percent of the value the property. ${ }^{62}$

A total of 82 percent of landowners reported their average Gross Farm Tumover (GFT). The highest reported GFT was $\$ 3$ million per annum. The average annual GFT was $\$ 599,000$, or around $\$ 1,700$ per hectare. Thirty percent of respondents reported an annual GFT greater than $\$ 500,000$. Only 8 percent of respondents reported a GFT of less than $\$ 50,000$ per annum. These figures vary somewhat from the national estimates of the Agricultural Finance Survey last carried out in 19992000 (Australian Bureau of Statistics 2000). In this survey 12 percent of farm businesses reported a turnover of $\$ 500,000$ and more than 18 percent of farm businesses reported a tumover of less than $\$ 50,000$.

Forty-two percent of respondents were from the Central region of Tasmania, whilst 23 percent were from the South and 36 percent from the North. Reported annual GFT was highest for the Central region at $\$ 714,115$, followed by the Northern region at $\$ 569,634$ and lowest in the Southern region at $\$ 441,045$. The average property size for all respondents was around 3,000 hectares. The smallest reported size was 12 hectares and the largest was 111,000 hectares. The average farm size was largest for

\footnotetext{
62 A total of three respondents did not indicate their mortgage debt level. Over 85 percent of landowners who indicated their primary source of income was farming also indicated they owed a debt on the property.
} 
the Central region at a reported 5,340 hectares, followed by 2,397 in the South and 456 in the North.

Property sizes are consistent with the pattern of economic activity in the three regions in Tasmania. In the Northern region of Tasmania the main agricultural activities are cropping and dairy. These are more intensive agricultural activities that are generally carried out on the fertile soils of the north-west region. The large extensive grazing properties are mainly located in the Central region. More recently, grazing activities are combined with cropping, with the introduction of pivot irrigation systems. This is evident in the survey data, as over 50 percent of landowners in the Central region reported undertaking three agricultural activities, growing wool, producing meat, and cropping. This is higher than the central region where 33 percent reported undertaking three activities.

Landowners were asked if they owned, managed, or owned and managed their property. Ninety-two percent of respondents owned and managed the property. Landowners indicated they had owned their property for an average of 32 years (the minimum was one year and the maximum was 181 years). The long period of ownership indicates that some landowners interpreted the question: "How long have you owned the property?" as "How long has your family owned the property?". Seven respondents did not indicate how long they had owned the property.

Ninety-two percent of respondents resided on the property. Thirty-eight percent of properties were privately owned, 33 percent were owned as a partnership, 18 percent as a family trust, and 16 percent as a private or public company. This pattern is consistent with the results of the previous landowner survey by Jennings and van Putten (2003).

There are some observable regional demographic differences particularly between the South and the two other regions (Table 11 ). 
Table 11: Regional demographic differences (Choice survey data).

\begin{tabular}{|c|c|c|c|c|c|}
\hline Variable & $\begin{array}{l}\text { Number } \\
\text { of obs } \\
\text { South }\end{array}$ & $\begin{array}{l}\text { Number of } \\
\text { obs Central } \& \\
\text { North West }\end{array}$ & $\begin{array}{l}\text { Mean } \\
\text { value } \\
\text { South }\end{array}$ & $\begin{array}{l}\text { Mean value } \\
\text { Central \& } \\
\text { North West }\end{array}$ & $\begin{array}{l}\text { Sig. }(2 \\
\text { tailed })^{*}\end{array}$ \\
\hline $\begin{array}{l}\text { Number of years the property } \\
\text { has been owned** }\end{array}$ & 30 & 95 & 22.242 & 35.258 & 0.034 \\
\hline $\begin{array}{l}\text { Number of years involve in } \\
\text { conservation }\end{array}$ & 31 & 101 & 8.9352 & 15.525 & 0.020 \\
\hline $\begin{array}{l}\text { The landowner does not have } \\
\text { a mortgage on the property }\end{array}$ & 31 & 98 & 0.677 & 0.316 & 0.001 \\
\hline $\begin{array}{l}\text { The landowner owns and } \\
\text { manages the property }\end{array}$ & 31 & 101 & 0.7742 & 0.960 & 0.024 \\
\hline $\begin{array}{l}\text { There is a conservation } \\
\text { reserve on the property }\end{array}$ & 25 & 72 & 0.56 & 0.208 & 0.003 \\
\hline
\end{tabular}

* Only variables significant at $5 \%$ are shown.

** The average was not corrected for the landowners who interpreted the question as:

"How long has your family owned the property?"

Table 11 shows that landowners in the southern region had owned their property for a shorter length of time and had also been involved in conservation for a shorter period of time than the two other regions. However, a higher number of landowners in the South had conservation reserves on their property.

\subsubsection{Native forest and conservation management}

Seventy-three percent of respondents indicated they had an area of native forest on their property. The average size of the native forest area was 1,200 hectares. The largest reported area was 50,000 hectares and the smallest was 12 hectares.

Fifty-nine percent of respondents who owned native forest used it for grazing, while 40 percent indicated they did not use it for anything. Twenty-one percent of respondents indicated using their native forest for commercial timber harvesting and 20 percent for hunting. Twenty-six percent of respondents indicated they had commercial native forest harvesting intentions for the future. Of those respondents who had future harvesting intentions, 85 percent had also harvested in the past. Eleven percent of respondents were unsure whether they were going to undertake any commercial harvesting in the future. These findings are consistent with those of Jennings and van Putten (2006).

Table 12 shows that 73 percent of respondents indicated they had been involved in conservation management. Almost half of respondents indicated that they managed a part of their property for specific conservation purposes. Although 27 percent of respondents indicated they had not been involved in conservation management, 69 
percent of these respondents indicated they had established shelter belts or protected native vegetation. This inconsistency might indicate that the definition of what constitutes conservation management was interpreted differently by survey respondents.

Table 12: Environmental and conservation management by survey respondents (Choice survey data).

\begin{tabular}{lc}
\hline Environmental and conservation mangement & Number of proportion \\
& respondents of all
\end{tabular}

\begin{tabular}{lll}
\hline Respondents involved in environmental management & 97 & 0.73 \\
\hline Respondents who managed part of their property for conservation & 64 & 0.48 \\
\hline Respondents who received funding for fencing native vegetation & 70 & 0.53 \\
\hline Respondents with formal conservation reserves on their property & 29 & 0.22 \\
\hline $\begin{array}{l}\text { Respondents who received funding to establish formal conservation } \\
\text { reserves on their property }\end{array}$ & 24 & 0.18 \\
\hline
\end{tabular}

Respondents were asked whether they had established a formal conservation reserve on their property. As shown in Table 12, 22 percent of respondents had established such a reserve on their property, and 18 percent of all respondents had received funding to do this. Two percent of respondents were unsure about whether they had a formal conservation reserve on their property or not.

A high proportion of respondents had undertaken some form of environmental management on their property (Table 13). Two-thirds of respondents had established shelter belts on their property and almost 60 percent had protected vegetation.

Table 13: Environmental management by survey respondents (Choice survey data).

\begin{tabular}{lccc}
\hline & Number of & Proportion of all \\
\hline Environmental management action & respondents & respondents \\
\hline Erosion control / salinity prevention & 79 & 0.60 \\
\hline Protection of vegetation & 77 & 0.58 \\
\hline Shelter & 99 & 0.75 \\
\hline
\end{tabular}

The proportion of landowners who had undertaken at least one of the listed activities was higher than in a previous study by Jennings and van Putten (unpublished). In the latter study, only 40 percent of respondents had undertaken at least one management activity from a list of activities (most frequently 'planting trees for shelter'). Only 20 percent of respondents indicated they undertook recreational activities on their property.

Table 14 shows that 53 percent of respondents had received funding to fence native vegetation. Almost one third of respondents had rcceived trees for revegetation. 
Overall, more than two-thirds of landowners had received at least one form of assistance listed in Table 14 to achieve environmental outcomes on their properties.

Table 14: Proportion of landowners who received some form of assistance to achieve environmental outcomes on their property (Choice survey data).

\begin{tabular}{lcc}
\hline Assistance & $\begin{array}{c}\text { Number of } \\
\text { respondents }\end{array}$ & $\begin{array}{c}\text { Proportion of all } \\
\text { respondents }\end{array}$ \\
\hline Money for fencing & 70 & 0.53 \\
\hline Money for revegetation & 30 & 0.23 \\
\hline Trees for revegetation & 40 & 0.30 \\
\hline Labour assistance for revegetation & 25 & 0.19 \\
\hline Money for improving soil management & 4 & 0.03 \\
\hline Scientific advice (e.g. identification of animals) & 16 & 0.12 \\
\hline Technical advice (e.g. management of animals) & 17 & 0.13 \\
\hline Administrative assistance (e.g. filling out form) & 15 & 0.11 \\
\hline Legal advice (e.g. implication of covenants) & 11 & 0.08 \\
\hline
\end{tabular}

Survey respondents indicated they had undertaken environmental and conservation management activities for an average of 19 years. Many respondents reported the time period to be the same as the number of years the property had been owned by them or their family. The longest time was reported as .120 years. It seems that this question was interpreted in a similar vein to the question asking the respondent how long they had owned the property. ${ }^{63}$

There are some demographic differences between survey respondents who owned native forest and those who did not (Table 15).

Table 15: Demographic differences between forest owning respondents and non-forest owning respondents (Choice survey data).

\begin{tabular}{|c|c|c|c|c|c|}
\hline $\begin{array}{l}\text { Variable } \\
\text { D }\end{array}$ & $\begin{array}{l}\text { Number of } \\
\text { respondents } \\
\text { Forest } \\
\text { owners }\end{array}$ & $\begin{array}{l}\text { Number of } \\
\text { respondents } \\
\text { Non-Forest } \\
\text { owners }\end{array}$ & $\begin{array}{l}\text { Mean } \\
\text { value } \\
\text { Forest } \\
\text { owners }\end{array}$ & $\begin{array}{l}\text { Mean yalue } \\
\text { Non-Forest } \\
\text { owners }\end{array}$ & $\begin{array}{c}\text { Sig } \\
(2 \text {-tailed })^{*}\end{array}$ \\
\hline $\begin{array}{l}\text { The landowner resides } \\
\text { on the property }\end{array}$ & 97 & 35 & 0.897 & 1.000 & 0.001 \\
\hline The size of the property & 97 & 35 & 3864.158 & 389.423 & 0.009 \\
\hline $\begin{array}{l}\text { The property is situated } \\
\text { in the North West region } \\
\text { of Tasmania }\end{array}$ & 97 & 35 & 0.289 & 0.543 & 0.011 \\
\hline
\end{tabular}

* Only variables significant at $5 \%$ are shown.

The average size of the farm was significantly smaller for respondents who did not own native forest. Significantly more survey respondents who did not own native forest resided in the North West region of Tasmania. This may be a reflection of the

${ }^{63}$ These outliers were retained in the dataset used for the analysis. 
economic activities carried out in this region. The North West farms are generally smaller and carry out intensive agricultural activities such as cropping and dairying. Due to the fertility of the soils in this region of Tasmania, much of the native forest has been cleared for agriculture and hence fewer and generally smaller remnants of native forest remain (Scanlan, Prinsley et al. 1992).

\subsubsection{Joining an incentive program}

In Section 2 of the survey, respondents were presented with incentive program choice questions. The orthogonal design of the survey (Section 6.2.2.4) resulted in four different versions of the survey. Of the 132 respondents, 63 answered surveys with design 1 or its complement. Sixty-nine respondents answered surveys with design 2 or its complement.

Eighty-four of the 132 survey respondents indicated at least once that they would choose to voluntarily join a program if offered the market value or more than the market value. The remaining respondents indicated they would not join an incentive program under any circumstance. The proportion of respondents who always chose the status quo of not joining under any circumstance is lower than that found in the Finnish study by Home (2004), ${ }^{64}$ where two-thirds of respondents expressed a preference for no additional conservation.

\subsubsection{Estimated market value}

Before respondents were asked to answer the choice question, they were asked to identify the size of the area of native forest to which the choice question applied. Obviously, this question only applied to the 97 respondents who owned an area of native forest. The average size of the native forest owned by these respondents was 421 hectares.

After identifying the size of the native forest area, respondents were asked to estimate a fair market value per hectare of their native forest. The average market value that was estimated by respondents was $\$ 6,175$ per hectare. The median market value was estimated at $\$ 4,000$ per hectare. The highest market value was estimated at $\$ 200,000$

\footnotetext{
64 Although this Finnish study method was different to the approach in this research, it could potentially indicate some difference between Australian and Finnish landowners in the willingness to participate in a program that adds conservation areas to the reserve system.
} 
per hectare, based on its coastal location. The lowest estimated market value was $\$ 250$ per hectare. Twelve respondents did not answer this question and an average value of $\$ 5,000$ was assumed for these respondents in the model presented in Section 8.4.1..$^{65}$

Respondents were asked to indicate the basis for their estimate of fair market value. The majority of respondents based their estimation on the value of similar land in the region (Table 16).

Table 16: Landowner approach to valuing the native forest on their property (Choice survey data).

\begin{tabular}{|c|c|c|}
\hline $\begin{array}{l}\text { Basis for estimating a foir market } \\
\text { value of the lend with rative } \\
\text { forest }\end{array}$ & $\begin{array}{l}\text { Number of } \\
\text { respondents } \\
\text { (number) }\end{array}$ & $\begin{array}{l}\text { Average value of the land } \\
\text { with native forest } \\
\text { (\$) }\end{array}$ \\
\hline What the LO paid for the land & 14 & 3,299 \\
\hline Value of similar land in the region & 49 & 10,697 \\
\hline Government valuation & 12 & 3,793 \\
\hline Value of the timber on the land & 18 & 4,264 \\
\hline Other: & 11 & \\
\hline Aesthefic/ brodiversity valte & 2 & $1,500,4,942$ \\
\hline Income foregone & 1 & 3.000 \\
\hline Personal valie & 1 & 5,000 \\
\hline Stbdivtston volue" & 2 & $16,000,30,000$ \\
\hline Posifion/location ${ }^{\text {th }}$ & 3 & $17.297,50.000,200.000$ \\
\hline
\end{tabular}

* The total number does not add up to 85 as some respondents chose more than one option.

** Landowners who said their land valuation was due to either subdivision or position/location generally also based this value on the value of similar land in the region, explaining the high average land value for that item.

Respondents who owned native forest were asked whether they believed the area of forest had any conservation value. A total of 69 respondents believed their native forest had conservation value. Sixteen respondents did not know whether the forest had conservation value or not and 12 respondents did not answer this question.

Respondents who did not own native forest were asked to imagine that 10 percent of their property was covered in native forest and that this forest could be protected for conservation by means of joining an incentive program. ${ }^{66}$ The average reported size of this imaginary forest was 36 hectares, which was smaller than the average area for forest owners.

\footnotetext{
${ }^{65}$ The 12 landowners who had not estimated a market value for their land were not significantly different to other survey respondents in terms of their socio-economic characteristics.

${ }^{66}$ The assumed average value of $\$ 5,000$ per hectare applied to these respondents.
} 


\subsection{Attitude data and analysis}

In section 3 of the survey respondents were asked to rate 24 statements about the role and impact of conservation reserves on private land. The purpose of this part of the survey was to identify any attitudes the respondents might hold in relation to the role and outcome of reserve establishment, in particular the effect on the productive capacity of the land and the environmental outcome. These attitudes were translated into landowner types using a Principal Component Analysis (PCA). The Likert-rating scores ${ }^{67}$ were used in the PCA to determine whether there were any significant relationships among the variables. The use of Likert-rating scores in a PCA is a commonly used approach (e.g. Boxall and Adamowicz 2002). Analysis of the attitude question data draws on the methodology previously described in Section 5.3 and previously applied to the BW survey data in Section 7.3. The PCA analysis presented below is carried out for the 97 respondents who owned an area of native forest. These 97 respondents form the basis for the 'forced choice' latent class model (Section 8.4.1).

The PCA is also carried out separately for all survey respondents $(n=132)$ which forms the basis for the "voluntary" model (Section 8.4.2). The PCA for this model is presented in Appendix 5 to avoid excessive duplication of presented results. A comparison of variables that make up the factors between the two PCAs was also included in Appendix 5.

The average rating and standard deviation of the 24 statements concerning the role and impact of conservation reserves on private land is shown in Table $17 .^{68}$ An explanation of the codes was previously given in Table 1 .

\footnotetext{
${ }^{67}$ A score of 1 is strongly agree, 2 is agree, 4 is dișagree, and 5 is strongly disagrce. A score of 3 indicates the respondent feels "neutral" about the statement.

${ }^{68}$ The attitude statements in Section 3 of the survey are the same as those presented to respondents of the BW survey (Section 7.3). The BW survey contained two more statements that were dropped in the Choice survey as feedback indicated they were considered confusing and not easily classified.
} 
Table 17: Respondent rating of the role and outcome of conservation reserves on private land (Choice survey data).

\begin{tabular}{|c|c|c|c|c|c|c|c|}
\hline Codes & Mean & $\begin{array}{l}\text { Stu. } \\
\text { Dev. }\end{array}$ & $\begin{array}{l}\text { Number of } \\
\text { Jeponxtents } \\
\text { strongly } \\
\text { agree }\end{array}$ & $\begin{array}{l}\text { Nuinber } \\
\text { of } \\
\text { respondents } \\
\text { agree }\end{array}$ & $\begin{array}{l}\text { Number } \\
\text { of } \\
\text { respondents } \\
\text { neutral }\end{array}$ & $\begin{array}{l}\text { Number } \\
\text { of } \\
\text { respondests } \\
\text { disagree }\end{array}$ & $\begin{array}{c}\text { Number } \\
\text { of } \\
\text { respondents } \\
\text { strongly } \\
\text { disagree }\end{array}$ \\
\hline BEAUTY & 1.896 & 0.810 & 33 & 44 & 15 & 4 & 0 \\
\hline BENOTH & 2.417 & 0.954 & 15 & 39 & 33 & 5 & 4 \\
\hline COMPLEX & 3.021 & 1.164 & 11 & 22 & 26 & 28 & 9 \\
\hline DIVERSE & 2.969 & 1.195 & 14 & 20 & 25 & 29 & 8 \\
\hline EROSION & 2.260 & 0.857 & 15 & 51 & 21 & 8 & 1 \\
\hline EXPMAN & 2.542 & 1.020 & 16 & 31 & 33 & 13 & 3 \\
\hline FIRE & 2.323 & 1.132 & 27 & 30 & 25 & 9 & 5 \\
\hline FULFIL & 2.375 & 0.881 & 14 & 43 & 29 & 9 & 1 \\
\hline FUTGEN & 2.740 & 1.130 & 9 & 40 & 24 & 13 & 10 \\
\hline IMAGE & 2.021 & 0.707 & 22 & 51 & 22 & 1 & 0 \\
\hline INCOP & 2.979 & 0.979 & 7 & 21 & 40 & 23 & 5 \\
\hline INCRED & 3.219 & 1.092 & 7 & 20 & 22 & 39 & 8 \\
\hline INCSEC & 3.042 & 1.172 & 13 & 16 & 30 & 28 & 9 \\
\hline LEARNING & 2.354 & 0.878 & 11 & 52 & 24 & 6 & 3 \\
\hline LIVELY & 3.281 & 1.161 & 10 & 13 & 25 & 36 & 12 \\
\hline OTHERUSE & 2,906 & 1.324 & 16 & 26 & 20 & 19 & 15 \\
\hline PESTS & 1.917 & 1.028 & 39 & 39 & 8 & 7 & 3 \\
\hline PROPVALUE & 2.833 & 1.106 & 13 & 22 & 36 & 18 & 7 \\
\hline PROTECT & 2.156 & 0.950 & 24 & 44 & 19 & 7 & 2 \\
\hline SHADE & 3.083 & 1.106 & 10 & 18 & 29 & 32 & 7 \\
\hline STOCK & 2.115 & 0.789 & 17 & 58 & 15 & 5 & 1 \\
\hline TIME & 2.927 & 0.992 & 10 & 18 & 40 & 25 & 3 \\
\hline WEEDS & 2.281 & 1.028 & 22 & 42 & 17 & 13 & 2 \\
\hline WILDL & 2.156 & 1.034 & 26 & 43 & 18 & 4 & 5 \\
\hline
\end{tabular}

Table 17 shows that none of the respondents strongly disagreed with the statement that establishing reserves creates a good image for landowners (IMAGE). Reserves were also perceived to be a good way to add to the beauty of the landscape (BEAUTY) as 80 percent of landowners agreed with this statement. Even though more than three quarters of respondents believed that reserve establishment created a haven for animals that are a pest to farming (PESTS), more than three quarters also believed that reserves were of value to stock for grazing purposes (STOCK).

As part of the PCA, the communalities for all attitude variables were examined (Appendix 6). Communalities are estimates of the variance of each variable accounted for by the factor solution. All variables with communality scores greater than 0.2 were assumed to fit well with the factor solution. The next step in the PCA was determination of the number of factors. There are several methods by which this is usually done, including Cattell's scree test, eigenvalues greater than 1, and interpretability of the resultant factors. Using a combination of these methods, two 
factors were extracted. The total variance explained by the attitude variables is shown in Table 18.

Table 18: Total variance explained in PCA for forest owners (Choice survey data).

\begin{tabular}{|c|c|c|c|c|c|c|c|c|c|}
\hline \multirow[t]{2}{*}{$\begin{array}{l}\text { Compo } \\
\text { nent }\end{array}$} & \multicolumn{3}{|c|}{ Initial Eigenyalues } & \multicolumn{3}{|c|}{$\begin{array}{l}\text { Extraction Sums of Squared } \\
\text { Loadings }\end{array}$} & \multicolumn{3}{|c|}{$\begin{array}{l}\text { Rotation Suns of Squared } \\
\text { Loadings }\end{array}$} \\
\hline & Total & $\begin{array}{l}\text { \% of } \\
\text { Var. }\end{array}$ & Cum. \% & TotaI & $\begin{array}{l}\% \text { of } \\
\text { Var. }\end{array}$ & Cum. \% & Total & $\begin{array}{l}\text { \% of } \\
\text { Var. }\end{array}$ & Cum. \% \\
\hline 1 & 8.775 & 41.783 & 1.783 & 8.775 & 41.783 & 41.783 & 5.715 & 27.214 & 27.214 \\
\hline 2 & 2.481 & 11.814 & 53.598 & 2.481 & 11.814 & 53.598 & 5.541 & 26.384 & 53.598 \\
\hline
\end{tabular}

* Components with eigenvalues smaller than 1 and/or that contribute less than $5 \%$ of the variance are not shown.

Table 18 shows that the first two components explain around 54 percent of the total variation of the original variables. Standard tests of the adequacy of the PCA indicate that a factor analysis is useful for this reduced variable set. A 0.866 Kaiser-MeyerOlkin Measure of Sampling Adequacy indicates that a high proportion of variance in the data is explained by the underlying factors. Further, the significance level of $<0.0001$ for Bartlett's test of sphericity, with approximate Chi-square of 22073.885 and 210 degrees of freedom, indicates relationships among the variables are significant.

The figures in Table 19 represent the partial correlation between the item and the Varimax rotated factor. The variables that have loadings greater than 0.400 (+ or -) for a particular component, called production focus $(\mathrm{PC1})$ and environmental focus (PC2), are shown. 
Table 19: Rotated component matrix (Choice survey data).

\begin{tabular}{|c|c|c|}
\hline & $\begin{array}{c}\text { Environntent } \\
\text { focts } \\
\text { PCl }\end{array}$ & $\begin{array}{l}\text { Production } \\
\text { focus } \\
\text { PC2 }\end{array}$ \\
\hline BEAUTY & 0.720 & \\
\hline BENOTH & 0.625 & \\
\hline COMPLEX & & 0.718 \\
\hline DIVERSE & -0.455 & 0.650 \\
\hline EXPMAN & & 0.693 \\
\hline FIRE & & 0.654 \\
\hline FULFIL & 0.779 & \\
\hline IMAGE & 0.668 & \\
\hline 1NCOP & 0.517 & \\
\hline INCRED & & 0.598 \\
\hline INCSEC & -0.442 & 0.700 \\
\hline LEARNING & 0.772 & \\
\hline LIVELY & -0.509 & 0.612 \\
\hline OTHERUSE & -0.628 & \\
\hline PESTS & & 0.608 \\
\hline PROPVALU & -0.579 & 0.451 \\
\hline PROTECT & 0.781 & \\
\hline SHADE & & 0.677 \\
\hline TIME & & 0.679 \\
\hline WEEDS & & 0.748 \\
\hline WILDL & 0.747 & \\
\hline
\end{tabular}

The environment focus, component $\mathrm{PCl}$, has high loadings for variables related to the positive impact of reserve establishment on the environmental values of the property, such as increased beauty, wildlife protection, as well as personal fulfilment. The factor loadings are negative for the impact of reserves on property values, the effect on livelihood and on income security, suggesting that reserve establishment does not have a negative impact on these factors.

The production focus, component $\mathrm{PC} 2$, has high positive loadings for all variables related to the negative impact of reserve establishment on the production capacity of an agricultural enterprise. These attitudes reflect the effect of reserve establishment on both current income and property values, and future asset values.

These factors are similar to those developed for the attitude data ${ }^{69}$ collected as part of the BW survey, although fewer variables are included in both the production focus

\footnotetext{
${ }^{69}$ Even though there were 24 questions in the BW survey and 26 in the Choice survey, overall the attitude questions were very similar. This allowed a degree of cross checking of the results. A twotailed test of the independence of the samples (BW and Choice) showed there was no significance difference between the Iwo groups in the rating of the attitude statements.
} 
and environmental focus components in the BW survey. ${ }^{70}$ Scores for the two factors were calculated for each survey respondent in the sample and these were included as variables (attitude_prod and attitude_env) in the latent class analysis (Section 8.4.1).

\subsection{Latent class results}

In the next sections the results of the choice model of Tasmanian landowner preferences for incentive program attributes are presented. Two latent class models are estimated. The first model simulates a situation where landowner enrolment in the program is compulsory (Section 8.4.1). The second model simulates a situation where entry into a program is on a voluntary basis (Section 8.4.2).

The models incorporate incentive program variables, socio-economic variables, and proxies for attitude. LatentGOLD choice (4.0) was used for the latent class analyses. Some basic statistics and the definitions for the variables used in the models are discussed in Section 8.3.1.

\subsubsection{Definition of latent class variables}

The continuous socio-economic variables included in the model are shown in Table 20.

\footnotetext{
${ }^{70}$ Both the production focus and environmental focts in the BW analysis contained seven variables that were the same as those in the choice analysis. The choice analysis contained an additional five variables for the production foctus and three variables for the environmental focus.
} 
Table 20: Statistics for the continuous socio-economic variables (Choice survey data).

\begin{tabular}{|c|c|c|c|c|c|c|c|c|}
\hline Variable & $\begin{array}{l}\text { Description of } \\
\text { variable }\end{array}$ & Mean & $\begin{array}{l}\text { Std. } \\
\text { Dev. }\end{array}$ & Min & $\mathrm{Max}$ & $\begin{array}{l}\text { Skewness } \\
95 \%\end{array}$ & $\begin{array}{l}\text { Kurtosis } \\
99 \%\end{array}$ & $\begin{array}{l}\text { \# or } \\
\text { obsing }\end{array}$ \\
\hline $\begin{array}{l}\text { number_- } \\
\text { child }\end{array}$ & $\begin{array}{l}\text { Number of children } \\
\text { living on the property } \\
\text { (years) }\end{array}$ & 1.44 & 1.39 & 0 & 5 & .3825 & 1.860 & 129 \\
\hline years_own* & $\begin{array}{l}\text { Number of years the } \\
\text { property has been } \\
\text { owned by the LO } \\
\text { (years) }\end{array}$ & 32.13 & 34.37 & 1 & $181^{*}$ & 2.332 & 8.828 & 125 \\
\hline farmsize & $\begin{array}{l}\text { The size of the } \\
\text { property (ha) }\end{array}$ & 2,943 & 11,017 & 12 & 111,195 & 7.891 & 73.301 & 132 \\
\hline $\begin{array}{l}\text { years_inv_ } \\
\text { cons }\end{array}$ & $\begin{array}{l}\text { Number of years } \\
\text { involved in cons. } \\
\text { Activities (years) }\end{array}$ & 13.977 & 17.062 & 0 & $120 *$ & 2.636 & 14.123 & 97 \\
\hline gft & $\begin{array}{l}\text { Gross farm turnover } \\
\text { (\$/annum) }\end{array}$ & 599,011 & 681,259 & 1000 & $\$ 3 \mathrm{M}$ & 1.860 & 5.923 & 107 \\
\hline res_size & $\begin{array}{l}\text { The size of any area } \\
\text { of NF (ha) }\end{array}$ & 885 & 4,545 & 1 & 49,420 & 9.443 & 99.032 & 97 \\
\hline age & $\begin{array}{l}\text { The age of the LO } \\
\text { (years) }\end{array}$ & 50.64 & 10.73 & 23 & 80 & .312 & 2.914 & 128 \\
\hline
\end{tabular}

Note: * As discussed in Section 8.1.3, 31 percent of landowners indicated they had owned the property for more than 30 years. Some landowners may have interpreted this question in relation to the length of family ownership or involvement rather than personal ownership.

Logarithmic transformations of variables are appropriate to achieve symmetry in the central distribution (Cohen 1969). Where either the skewness and kurtosis values were outside the -3 and 3 range, the $\log$ of the variable was taken. This transformation applied to years_inv_cons, years_onn,farmsize, gft, and res_size. The basic statistics for the discrete socio-economic variables are shown in Table 21. Much of this information was previously discussed in Section 8.1. 
Table 21: Discrete socio-economic and attitude variable names and statistics (Choice survey data).

\begin{tabular}{|c|c|c|c|c|}
\hline Variahle name & Description of variable & $\begin{array}{l}\text { \# of } \\
\text { Obs: }\end{array}$ & Mean & St Der. \\
\hline own_and_manage & LO owns and manages the property & 132 & 0.92 & 0.277 \\
\hline partn_fam_own & Propeny is owned as a partnership or by the family & 132 & 0.49 & 0.502 \\
\hline reside & The LO resides on the property & 132 & 0.92 & 0.266 \\
\hline wool_meat_crop & $\begin{array}{l}\text { The LO uses the properly to grow wool, meal, and } \\
\text { crops }\end{array}$ & 132 & 0.33 & 0.473 \\
\hline region62 & $\begin{array}{l}\text { The property is st tuated in the southern region of } \\
\text { Tasmania }\end{array}$ & 132 & 0.23 & 0.426 \\
\hline off_farm_inc & $\begin{array}{l}\text { OfT-farm income is eamed by the LO or a family } \\
\text { member who lives on the property }\end{array}$ & 130 & 0.66 & 0.475 \\
\hline maj_inc_farm & $\begin{array}{l}\text { The majonty of income is esmed from farming } \\
\text { actuvities }\end{array}$ & 130 & 0.77 & 0.423 \\
\hline no_mortgage & The LO does not have a morigage on the property & 129 & 0.40 & 0.492 \\
\hline veg_protect & LO has protected vegetation for conservation & 132 & 0.58 & 0.495 \\
\hline trees_or_labour & $\begin{array}{l}\text { Lo has received trees or labour/assistance to plant } \\
\text { trees for conservation on the propenty }\end{array}$ & 132 & 0.39 & 0.489 \\
\hline own_NF & The LO owns an area of NF & 132 & 0.73 & 0.443 \\
\hline no_use_NF & The LO does not use the area of NF for anything & 97 & 0.40 & 0.493 \\
\hline fut_harv_NF & $\begin{array}{l}\text { The LO intends to use the ares of NF for commerctal } \\
\text { harveslung purposes in the furure }\end{array}$ & 97 & 0.26 & 0.440 \\
\hline reserve_or_prop & There is a conservation reserve on the properiy & 97 & 0.22 & 0.416 \\
\hline fund_4_reserve & $\begin{array}{l}\text { The Lo has recelved funding to establish this reserve } \\
\text { in the past }\end{array}$ & 97 & 0.18 & 0.387 \\
\hline manage_4_cons & $\begin{array}{l}\text { The } L O \text { manages an area of the property for } \\
\text { conservation purposes }\end{array}$ & 97 & 0.66 & 0.502 \\
\hline gender & The survey respondent is male & 132 & 0.76 & 0.430 \\
\hline tert_edu & The $L O$ has achieved up to tertiary education level & 132 & 0.34 & 0.476 \\
\hline GA_member & $\begin{array}{l}\text { The LO recelves information from, or is a member of } \\
\text { Greening Australia }\end{array}$ & 132 & 0.38 & 0.487 \\
\hline caregr_member & $\begin{array}{l}\text { The LO receives infornation from, or is a member of } \\
\text { a land or coust care group }\end{array}$ & 132 & 0.39 & 0.490 \\
\hline pass_farm_on & $\begin{array}{l}\text { The LO intends to pass the property on to a family } \\
\text { member }\end{array}$ & 130 & 0.58 & 0.496 \\
\hline
\end{tabular}

The conservation incentive program attributes that have two levels entered the utility function as binary variables (Table 22). The two levels indicate the relative "restrictiveness" of the attribute. ${ }^{7 t}$ For example in the context of the legal attribute, a covenant is more restrictive than a management agreement.

\footnotetext{
7 'Restrictiveness' in this context also relates to the apparent 'flexibility' of the program, i.e. upfront payments are perceived as more flexible than tax relief. Not having to pay for technical assistance is perceived as a more flexible arrangement than offering assistance on a fee for service basis.
} 
Table 22: Binary program characteristics, variable names and codes (Choice survey).

\begin{tabular}{lll}
\hline $\begin{array}{l}\text { Variable } \\
\text { name }\end{array}$ & $\begin{array}{l}\text { Description of yariable } \\
\text { More restrictive }\end{array}$ & $\begin{array}{l}\text { Description of variable } \\
\text { Less restrictive }\end{array}$ \\
\hline legal & $\begin{array}{l}\text { The legal implication is that a permanent } \\
\text { covenant is placed on the title of the land } \\
\text { (covenant) }\end{array}$ & $\begin{array}{l}\text { The legal implication is a temporary } \\
\text { management agreement for the land } \\
\text { (managreement) }\end{array}$ \\
\hline landuse & $\begin{array}{l}\text { No use of the land is permitted after } \\
\text { reserve establishment } \\
\text { (nousepermit) }\end{array}$ & $\begin{array}{l}\text { Limited use of the land is permitted } \\
\text { after reserve establishment } \\
\text { (limiteduse) }\end{array}$ \\
\hline paymethod & $\begin{array}{l}\text { The compensation is paid via tax relief } \\
\text { (taxrelief) }\end{array}$ & $\begin{array}{l}\text { The compensation is paid via an } \\
\text { upfront payment } \\
\text { (upfrontpay) }\end{array}$ \\
\hline & $\begin{array}{l}\text { The technical assistance available after } \\
\text { reserve establishment is on a fee-for- } \\
\text { service basis } \\
\text { (fee4service) }\end{array}$ & $\begin{array}{l}\text { The technical assistance available after } \\
\text { reserve establishment is free of charge }\end{array}$ \\
\hline
\end{tabular}

The variable compfund is the amount of compensation funding the landowner is offered for setting aside land for conservation. This variable used in the latent class analysis has two forms: the first is based on average land values in the 'voluntary' model (e.g. $\$ 5,000 / \mathrm{ha}, \$ 6,250 / \mathrm{ha}, \$ 2,500 / \mathrm{ha}$, and $\$ 3,500 / \mathrm{ha}$ ); the second is based on the estimated land value as reported by survey respondents in the 'forced choice' model (e.g. $\$ 6,175 / \mathrm{ha}, \$ 7,719 / \mathrm{ha}, \$ 3,088 / \mathrm{ha}$, and $\$ 4,632 / \mathrm{ha}$ ). These latter values are relative to the self-reported market value (e.g. market value, one-quarter more than the market value, half the market value, three-quarters of the market value).

As multi-collinearity is commonly found in non-experimental data, the correlation coefficients between all program attributes, socio-economic and attitude variables were determined (Appendix 7). Highly collinear variables cause regression parameters to be inefficient and can cause the signs of the regression coefficient to be counter-intuitive (Gujarati 1988). In this analysis a value of 0.5 or higher was used as the cut-off value for inclusion in the analysis.

The variable size_ $n f$ was excluded from the analysis as the correlation coefficient with farmsize was greater than 0.7 and with years_inv_cons was greater than 0.5 . Further farmsize was also excluded from the analysis as the correlation coefficient with years_inv_cons was greater than 0.5. Res-size was retained as a farmsize related variable. 


\subsection{Steps followed in estimation of latent class models}

Landowners are heterogeneous in terms of observable characteristics such as gender and age, and unobservable characteristics such as attitude. Landowner heterogeneity is reflected in their preferences for the attributes of conservation programs. In order to better understand landowner behaviour, landowner choice of conservation incentive program is combined with landowner attitude data, individual property and business characteristics, as well as landowner characteristics, using a latent class approach (McFadden 1986).

Two econometric models are developed. The first model, referred to as the "forced choice' model, applies the latent class regression approach to a choice model in which survey respondents choose between two conservation incentive programs. The survey respondent is forced to choose between two conservation incentive programs as the option of not joining either is not included. ${ }^{72}$ This model is estimated using choice data only for those survey respondents who currently own native forest (97 of the 132 survey respondents). ${ }^{73}$

In the second model, referred to as the 'voluntary' choice model, survey respondents choose between one of three options: two conservation incentive programs and a third option of not joining any program. Overall, a relatively high number of observed choices (67 percent of observations) were for the option of not joining (or status quo). Status quo observations are sometimes removed from the analysis of choice data (e.g. Horne 2004). However, when status quo observations are removed, some bias may be introduced, as only respondents who choose an alternative other than the status quo are retained. The 'voluntary' model is estimated using choice data for all survey respondents, including the 27 percent of survey respondents who did not own any native forest.

For both models different combinations of attributes were used to describe the two programs presented to the respondent in the choice question. The five incentive

\footnotetext{
${ }^{72}$ Although a very different experiment, Crouch, Devinney et al. (2006) also applied a choice scenario where choice was restricted and no "no choice option" was provided.

${ }^{73}$ There were no significant demographic or socio-economic differences between non-forest owners and forest owners.
} 
program attributes, and the levels used in the choice question were reported in Table 22.

Estimation of both the 'forced choice' and 'voluntary' models involves the following steps (based on Magidson and Vermunt (n.d.)):

1 Estimate a series of latent class models using only incentive program attributes for different numbers of classes and examine the statistical information criteria for the models;

2 Re-estimate the latent class models incorporating socio-economic and attitudinal covariates and compare the statistical information criteria for these models to those in step 1 above;

3 Select the optimal number of latent classes on the basis of the fit statistics;

4 Estimate a final latent class regression model imposing parameter restrictions across latent classes for program attributes that are not significantly different between classes;

5 Present and interpret the coefficients for the prograin attributes and covariates for the final model.

Sections 8.4.1 and 8.4.2 present and interpret the results of the estimated 'forced choice' and 'voluntary' models respectively.

\subsection{1 'Forced choice' model}

Following the procedure described in Section 8.4 , the first step in developing the 'forced choice' model was to estimate latent class models using the five program attributes for different numbers of classes. ${ }^{74}$ Table 23 shows the fit statistics for 1 to 4 latent class regression models. ${ }^{75}$

\footnotetext{
${ }^{74}$ The way in which the classes are selected is explained on the pages that follow.

${ }^{75}$ LatentGOLD choice (4.0) was used to estimate al] latent class models.
} 
Table 23: Fit statistics of 1, 2, 3 and 4 latent class 'forced choice' regression model (Choice survey data).

\begin{tabular}{|c|c|c|c|c|c|c|c|c|c|c|}
\hline Model & LL & $\begin{array}{l}\text { BIC } \\
\text { (LL) }\end{array}$ & $\begin{array}{l}\text { AlC } \\
\text { (LL) }\end{array}$ & 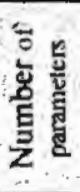 & $\mathrm{L}^{2}$ & 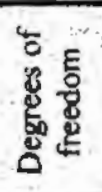 & $\begin{array}{c}\text { p-value } \\
\quad\end{array}$ & 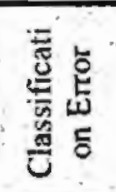 & $R^{2}(0)$ & $R^{2}$ \\
\hline 1-Class & -479.10 & 981.07 & 968.20 & 5 & 818.51 & 92 & $<0.001$ & 0.000 & 0.146 & 0.145 \\
\hline 2-Class & -423.42 & 897.17 & 868.85 & 11 & 707.16 & 86 & $<0.001$ & 0.009 & 0.355 & 0.354 \\
\hline 3-Class & -368.25 & 814.27 & 770.50 & 17 & 596.81 & 80 & $<0.001$ & 0.031 & 0.533 & 0.528 \\
\hline 4-Class & -339.63 & 784.47 & 725.25 & 23 & 539.57 & 74 & $<0.001$ & 0.050 & 0.699 & 0.696 \\
\hline
\end{tabular}

The statistical indicators show that all models are significant at the 5 percent level and that the 4-class model fits best, as the BIC and AIC are lowest for the 4-class 'forced choice' model. The log likelihood values (LL) show improvement of the model fit with increasing number of classes. Almost 70 percent of the variance is explained by the 4-class model. ${ }^{76}$

Latent class 'forced choice' models 1 to 4 were then re-estimated, including two attitude variables ${ }^{77}$ (attitude_env and attitude _prod). Individual factor scores were included for these attitude variables in the latent class regression. The model also included dummies for a socio-economic variable (gender) and an 'experience' variable (trees_fund). A continuous property characteristic variable (res_size) was also included. All covariates are significant at the 5 percent level. The model was initially run with all variables listed in Tables 20 and 21 and subsequently reduced to include only those variables significant at the 5 percent level. The results for the fit statistics are shown in Table 24.

\footnotetext{
${ }^{76}$ The last two columns of Tables 23 and 24 show 2 different $R^{2}$ measures. The baseline for the $R^{2}(0)$ is the null model containing no predictors at all, where each alternative is equally likely to be selected. For the $\mathrm{R}^{2}$ null model each alternative is predicted to be selected with a probability equal to the overall observed marginal distribution.

77 The attitude variables were developed in Section 8.2 where a PCA of 24 attitudinal statements was undertaken. This exercise identified two factors which were lahelled prod_attitude and env_attitude. Individual factor scores were included as variables in the latent class regression model.
} 
Table 24: Fit statistics for 1,2,3 and 4 latent class 'forced choice' model including significant covariates (Choice survey data).

\begin{tabular}{|c|c|c|c|c|c|c|c|c|c|c|}
\hline Model & $\mathrm{LL}$ & $\begin{array}{c}\mathrm{BlC} \\
\text { (ILL) }\end{array}$ & $\begin{array}{l}\text { AlC } \\
\text { (LL) }\end{array}$ & $\frac{5}{\mathrm{E}}$ & $4=$ & 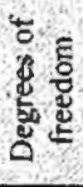 & p-value & 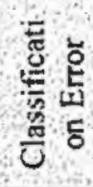 & $R^{2}=(0)$ & $\mathrm{R}^{2}$ \\
\hline 1-Class & -474.01 & 970.85 & 958.03 & 5 & 948.03 & 91 & $<0.001$ & 0.000 & 0.146 & 0.145 \\
\hline 2-Class & -411.09 & 895.22 & 854.19 & 16 & 822.19 & 80 & $<0.001$ & 0.016 & 0.343 & 0.342 \\
\hline 3-Class & -345.59 & 814.43 & 745.19 & 27 & 691.19 & 69 & $<0.001$ & 0.049 & 0.518 & 0.513 \\
\hline 4-Class & -310.26 & 793.97 & 696.53 & 38 & 620.53 & 58 & $<0.001$ & 0.037 & 0.677 & 0.675 \\
\hline
\end{tabular}

All 'forced choice' models that include covariates in Table 24 are significant at the 5 percent level. The lower BIC indicates that the 4-class model is a better fit than the 1 class model. The BIC falls from 970.85 for the 1-class model which does not recognise landowner heterogeneity, to 793.97 for the 4-class model. ${ }^{78}$ The AIC for the 4-class model is also lower than for the 3-class model. However, as discussed in Section 4.5.1.2, the AIC can become less reliable with increased numbers of classes. The $\mathrm{R}^{2}$ statistic, assessing the percentage variance explained by the dependent variables, increases from 14.5 percent for the 1-class model to 51.3 percent for the 3 class model with covariates and 67.5 percent for the 4-class model.

The BIC and the $\mathrm{R}^{2}$ statistics indicate that the 4-class model performs best. To assess if the $\mathrm{R}^{2}$ statistic obtained for the 4-class model represents a significant improvement over the 3-class model, a p-value was estimated using the conditional bootstrap method. The bootstrap p-value can be used to confirm whether the power of the design is sufficient and the number of segments in the final model is adequate (Magidson, Eagle et al. n.d.). Results conclude that the gain from moving from a 3 to a 4-class model was not statistically significant for the 'forced choice' model. ${ }^{79}$

The third step was to select the optimal number of latent classes on the basis of the fit statistics. Comparing the fit statistics reported in Table 23 to those in Table 24, it is evident that, on the basis of the BIC and the $\mathrm{R}^{2}$ statistic alone, the 4-class model without covariates performed best. However, the decrease in the value of the BIC

\footnotetext{
${ }^{78}$ A 5-class model was also estimated with no reduction in the BIC compared to the 4-class model.

${ }^{79}$ If the difference in model fit between the two models is not significant, the more restricted model may also be accepted as true and therefore preferred on grounds of being more parsimonious. On the other hand, if the difference is significant, the more restricted model can be rejected in favour of the less restricted model (LatentGOLD version 4 help menu).
} 
between the low of 784.47 for the 4-class model without covariates and the 3-class model with covariates was only 39.28. Since there are no clear nules in relation to selecting the number of classes on the basis of the statistical criteria alone (Morey, Thatcher et al. 2006), interpretation of the coefficient estimates suggested that inclusion of the covariates added significantly to describing and understanding class membership. Therefore, step 4 was undertaken using the 3-class model with covariates.

The five covariate model was re-estimated allowing for independence for program attributes across classes that were not significantly different between groups. The formal test of equality of parameters across classes for paymethod, given by the pvalue and the Wald $\Leftrightarrow$ statistic, was greater than 0.05 . As there was no significant difference between the 3 classes for this attribute, the parameter restriction was applied.

The final 3-class 'forced choice' model is significant at the 5 percent level and contains three latent classcs. The final model includes six covariates and parameter restrictions for one program attribute. There is little difference in the $\mathrm{R}^{2}$ statistic for the 3-class model shown in Table 24 and the final 3-class 'forced choice' model with both explaining around 51 percent of the variance. ${ }^{80}$ The reported $R^{2}$ value for the final 3-class model is high in comparison to other studies where an adjusted $R^{2}$ value between 22.4 and 13.7 percent was reported by Scarpa and Thiene (2004) and between 39 and 41 percent by Popper, Kroll et al. (2004). The LL for the final 3-class model is 619.25 .

On the basis of the BIC alone the final 3-class'forced choice' model is superior to the model without the equality of parameters for paymethod (Table 24). The BIC is 805.64 for the final model as opposed to 814.43 for the 3-class model without independence for program attributes.

Overall, the final 3-class 'forced choice' model does well at separating individuals into groups having a dissimilarity index of 0.91 . By comparison, Morey, Thatcher et al. (2006) reported an entropy measure (similar to the dissimilarity index) of 84 percent. The predictive power of the final 3-class 'forced choice' model is also

\footnotetext{
${ }^{80}$ The model is significant at the 5 percent level; there are 25 parameters and 71 degrees of freedor.
} 
illustrated by the high number of observations ( 82 percent) that are correctly classified (Table 25).

Table 25: Classification of 'forced choice' model observations (percentage of observed program choice) (Choice survey data).

\begin{tabular}{l|ccc}
\hline & Program 1 & Program 2 & Total \\
\hline OBSERVED & \multicolumn{3}{|c|}{ PREDICTED } \\
\hline Program 1 & $277(81 \%)$ & $67(19 \%)$ & 344 \\
\hline Program 2 & $68(16 \%)$ & $356(84 \%)$ & 424 \\
\hline Total & 345 & 423 & 768 \\
\hline
\end{tabular}

Table 25 above shows similar patterns of classification for program 1 and 2, with 81 percent of observed choices for program 1 and 84 percent of observed choices for program 2 correctly classified.

Covariate classification statistics indicate how well class membership can be predicted on the basis of an individual's covariate values. The final 'forced choice' model has a covariate classification error of 27 percent. The $\mathrm{R}^{2}$ statistic for the covariates indicates that 37 percent of the variance in the dependent variable can be explained by covariates.

On the basis of the above statistical indicators, in particular the low BIC for the final 3-class 'forced choice' model and the low model prediction enror, the presence of heterogeneous preferences and the need for separate utility function estimates is suggested. The utility functions for each landowner class are developed in the next section.

\subsubsection{Utility parameters for forced choice' model}

Each of the three latent choice classes is characterised on the basis of the covariates included in the final 3-class 'forced choice' model. These coefficients are referred to as segment membership parameters in Boxall and Adamowicz (2002). The estimated segment membership parameters $\left(\hat{\lambda}_{s}\right)$ and the estimated utility function parameters $\left(\hat{\beta}_{s}\right)$ for the 3-class 'forced choice' model are jointly estimated and shown in Tables 26 and 27. 
Table 26: Parameters, standard error, $z$ statistics, Wald and p-value for attitude and socio-economic variables for the 3 class 'forced choice' model (Choice survey data).

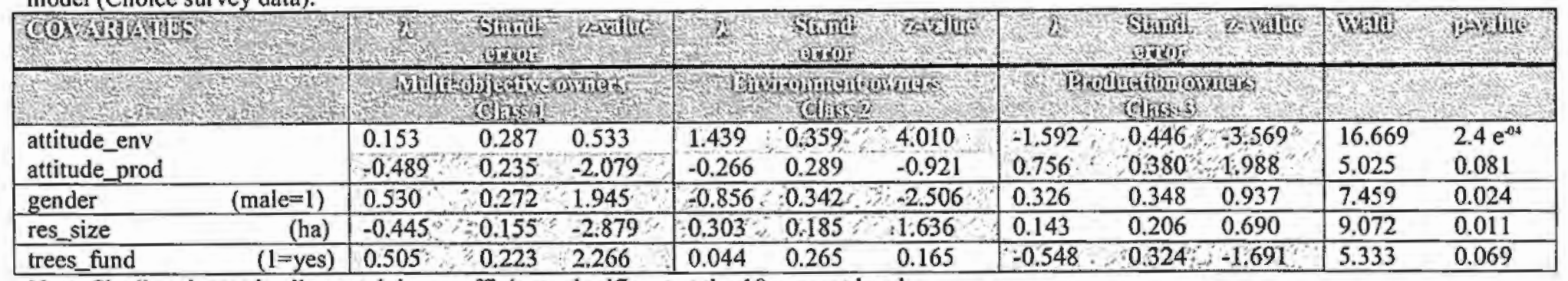

Note: Shading denoted cells containing coefficients significant at the 10 percent level.

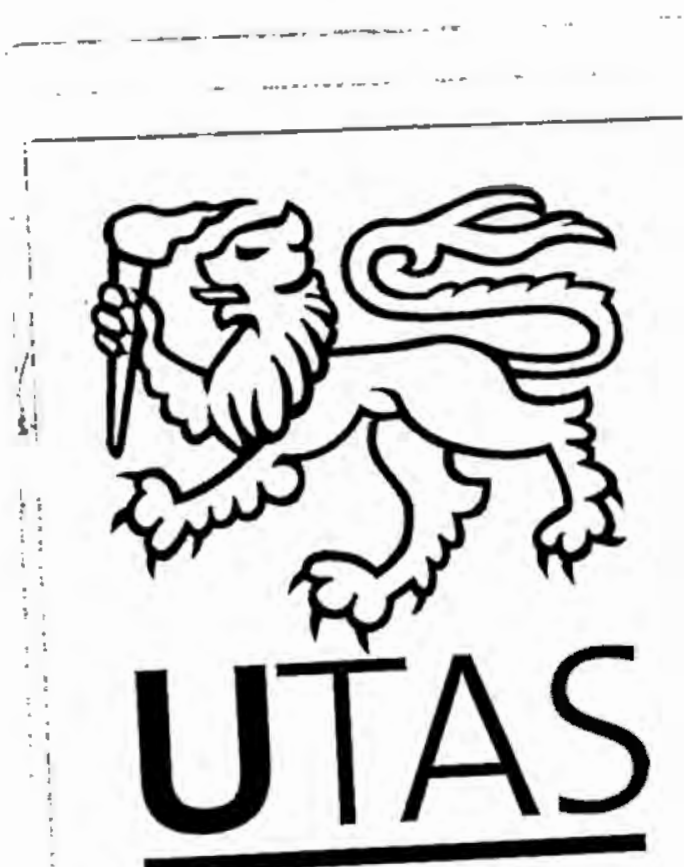


The first two rows of Table 26 show that each of the three classes in the final 'forced choice' model can be described in terms of the member's attitude to the role and outcome of establishing reserves on private land. ${ }^{81}$

Estimated coefficients for both attitudinal variables are significantly different to zero at the 5 percent level for landowners in class 3. The reported signs on the attitude variables indicate that members of this class believe that establishing conservation reserves negatively affects production. Members of this class also believe that reserve establishment does not have a positive environmental outcome. Members of this class have been labelled production owners. This is the smallest of three classes and respondents had a 16 percent chance of being in this class. The relative size of the groups closely resembles that of Karppinen (1998) who also found that investors, who are similar to production owners in this study, were the smallest class. Respondents had a 13 percent chance of being in this class.

Results suggest that in contrast to production owners, members of class 1 , labelled multi-objective owners, do not believe that establishing conservation reserves negatively affects production. Respondents had a 55 percent chance of being in this class. The coefficient on attitude_env is not significant for this class. Kline, Alig et al. (2000) also found that multi-objective owners accounted for the largest group in their sample.

The attitude_env variable is significant at the 5 percent level for members of class 2 . Landowners in this class have been labelled environment owners, as they believe that a positive environmental outcome is achieved by establishing conservation reserves. Respondents had a 29 percent chance of being in the environment owner class. The coefficient on attitude_prod is not significant for this class.

The three landowner classes closely resemble those found in previous research in Tasmania. Jennings and van Putten (2006) determined that Tasmanian landowners could be separated into four groups on the basis of their stated objectives of forest ownership: the groups were labelled income and investment owners, non-timber

\footnotetext{
${ }^{81}$ The assignment of individuals to the three landowner classes " ... is probabilistic and every respondent has a positive probability of being a member of each of the [ ] groups" (Boxall and Adamowicz 2002, p.437).
} 
output owners, and multi-objective owners ${ }^{82}$ essentially being the same groups as in the current study.

Table 26 shows that forest owners can also be described in terms of several socioeconomic and property characteristics. Multi-objective owners have a higher probability of being male (0.530) while environment owners are more likely to be female $(-0.856) .{ }^{83}$ Gender was also found to influence decision patterns in joining conservation programs in other studies (e.g. Stern and Dietz 1994). Females had more strongly held views towards environmental protection than males, and females also had more positive environmental attitudes (e.g. Jennings and van Putten 2003). Owens and Cooney (1998) explain this more positive environmental attitude by asserting that perhaps women make decisions based on 'feelings' which would increase environmental concem. Other authors found that gender does not affect attitudinal outcomes (e.g. Henderson 1998).

Multi-objective owners own smaller reserves $(-0.445)$, and environment owners own larger reserves (0.303). Studies undertaken in Europe and elsewhere have found that larger farms increased the likelihood of participating in incentive schemes (e.g. Skeratt 1994; Drake, Bergström et al. 1999; Dupraz, Vanslembrouck et al. 2003). None of these studies has related the size of the parcel of land to specific landowner classes.

Multi-objective owners are more likely to have received funding to plant trees in the past (0.505). Production owners are less likely to have received funding to plant trees in the past $(-0.548)$. Previous experience may mean that the landowner is more aware of the potential benefits of conservation which may affect the choice decision. The effect of past participation in incentive schemes on the increased likelihood of entry into another scheme has been well researched (e.g. Drake, Bergström et al. 1999; Wynn, Crabtree et al. 2001; and Dupraz, Vanslembrouck et al. 2003). However, one study by Lynch, Hardie et al. (2002) found no differences in the likelihood of joining an incentive program between landowners who had pre-existing experience with a particular conservation management activity and those who did not.

\footnotetext{
82 The fourth group were agricultural owners who were not identified in this current research.

${ }^{83}$ Clearly reference can only be made here to the stated sex of the survey respondent which may not be consistent with a high level of decision-making power or influence within the household.
} 
No relationship was found in this current research between age and the likelihood of joining an incentive program, as also found by Wilson (1997). Age has been found to be significant in other studies. For instance, increasing age had a negative effect on joining agri-environmental programs in a European study (Dupraz, Vanslembrouck et al. 2002). Similarly, in the United States increasing age negatively affected a landowner's willingness to join a program to protect riparian zones (Lynch, Hardie et al. 2002).

The utility function parameters for the program attributes for the 3-class 'forced choice' model are shown in Table $27 .^{84}$ As discussed earlier in this section, the effect of one attribute (paymethod) was restricted to be the same between classes.

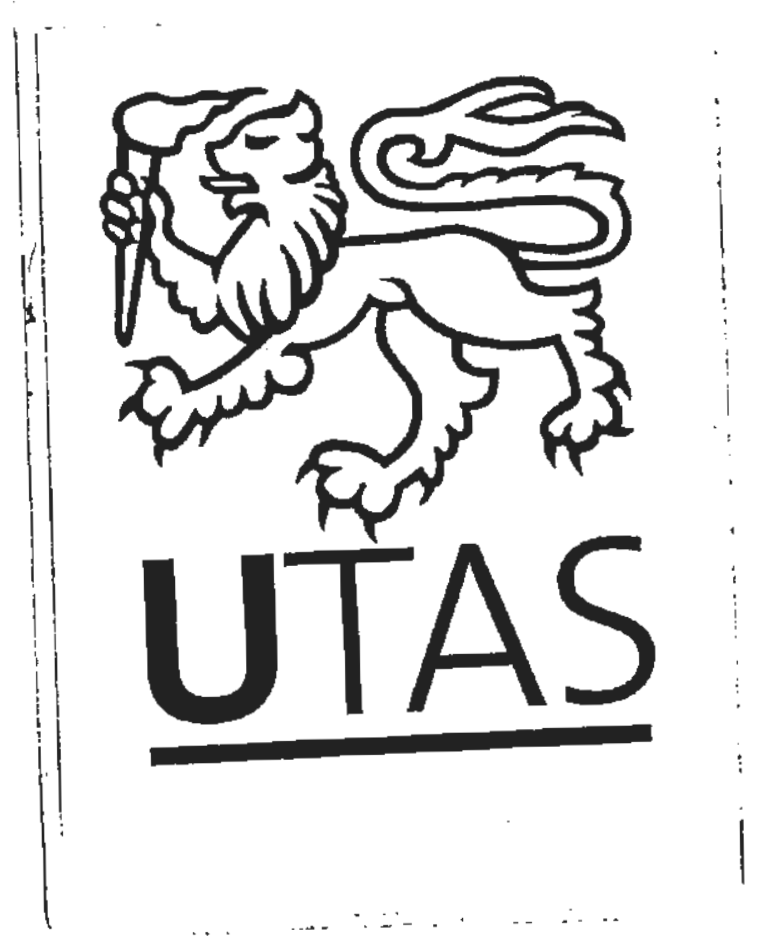

${ }^{84}$ The coefficients are symmetrical as the respondent was forced to choose between two options only. The coefficients for the levels of each attribute add up to zero. 
Table 27: Parameters, standard error, $\mathrm{z}$ statistics, Wald and p-value for program attributes for a 3 class 'forced choice' model (Choice survey data).

\begin{tabular}{|c|c|c|c|c|c|c|c|c|c|c|c|c|c|c|c|}
\hline 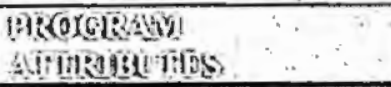 & if? & 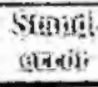 & arilue & (i) & $\begin{array}{l}\text { Suliti } \\
\text { (4) }\end{array}$ & wables: & $6 \%$ & $\begin{array}{l}\text { Shario } \\
\text { derint }\end{array}$ & Es influe & Wम10! & it & 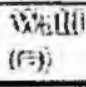 & pianda & Netal & $\begin{array}{l}\text { Siil } \\
\text { ivere }\end{array}$ \\
\hline$\because \because$ & \multicolumn{3}{|c|}{ 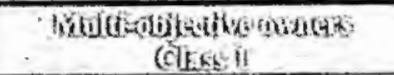 } & \multicolumn{3}{|c|}{ 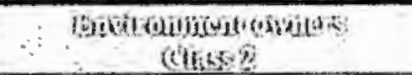 } & \multicolumn{3}{|c|}{ 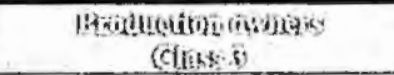 } & & & & & & \\
\hline ASC & 2.665 & 0.659 & 4.046 & -0.553 & 0.826 & -0.670 & -2.112 & 1.034 & -2.043 & 16.608 & $2.5 \mathrm{e}^{-4}$ & & & & \\
\hline Compfund & 0.016 & 0.018 & 0.889 & 1.423 & 0.338 & 4.211 & -0.0002 & 0.045 & 0.004 & 18.06 & $4.3 \mathrm{e}^{-4}$ & 17.59 & $1.5 \mathrm{e}^{-4}$ & 0.437 & 0.647 \\
\hline $\begin{array}{r}\text { covenant } \\
\text { managreement }\end{array}$ & $\begin{array}{l}-0.767 \\
0.767\end{array}$ & $\begin{array}{l}0.096 \\
0.096\end{array}$ & $\begin{array}{l}-8.023 \\
8.023\end{array}$ & $\begin{array}{l}0.207 \\
0.207\end{array}$ & $\begin{array}{l}0.141 \\
0.141\end{array}$ & $\begin{array}{l}-1.463 \\
1.463\end{array}$ & $\begin{array}{l}0.813 \\
-0.813\end{array}$ & $\begin{array}{l}0.150 \\
0.150\end{array}$ & $\begin{array}{l}5.425 \\
-5.425\end{array}$ & 114.84 & $1.0 \mathrm{e}^{-24}$ & 94.96 & $2.4 \mathrm{e}^{21}$ & $\begin{array}{l}-0.356 \\
0.356\end{array}$ & $\begin{array}{l}0.555 \\
0.555\end{array}$ \\
\hline $\begin{array}{r}\text { limiteduse } \\
\text { nousepermit }\end{array}$ & $\begin{array}{l}0.629 \\
-0.629\end{array}$ & $\begin{array}{l}0.093 \\
0.093\end{array}$ & $\begin{array}{l}6.787 \\
-6.787\end{array}$ & $\begin{array}{l}0.905 \\
-0.905\end{array}$ & $\begin{array}{l}0.220 \\
0.220\end{array}$ & $\begin{array}{l}4.115 \\
-4.115\end{array}$ & $\begin{array}{l}-0.220 \\
0.220\end{array}$ & $\begin{array}{l}0.139 \\
0.139\end{array}$ & $\begin{array}{l}-1.586 \\
1.586\end{array}$ & $72 . \overline{26}$ & $1.4 \mathrm{e}^{-15}$ & 32.66 & $8.1 \mathrm{e}^{-8}$ & $\begin{array}{l}0.581 \\
-0.581\end{array}$ & $\begin{array}{l}0.362 \\
0.362\end{array}$ \\
\hline $\begin{array}{r}\text { taxrelief } \\
\text { upfrontpay }\end{array}$ & $\begin{array}{l}-0.092 \\
0.092\end{array}$ & $\begin{array}{l}0.052 \\
0.052\end{array}$ & $\begin{array}{l}-1.765 \\
1.765\end{array}$ & $\begin{array}{l}-0.092 \\
0.092\end{array}$ & $\begin{array}{l}0.052 \\
0.052\end{array}$ & $\begin{array}{l}-1.765 \\
1.765\end{array}$ & $\begin{array}{l}-0.092 \\
0.092\end{array}$ & $\begin{array}{l}0.052 \\
0.052\end{array}$ & $\begin{array}{l}-1.765 \\
1.765 \\
\end{array}$ & 3.11 & 0.078 & 0.00 & . & $\begin{array}{l}-0.092 \\
0.092\end{array}$ & $\begin{array}{l}0.000 \\
0.000\end{array}$ \\
\hline $\begin{array}{l}\text { fee4service } \\
\text { freetechadv }\end{array}$ & $\begin{array}{l}0.023 \\
-0.023\end{array}$ & $\begin{array}{l}0.068 \\
0.068\end{array}$ & $\begin{array}{l}0.347 \\
-0.347\end{array}$ & $\begin{array}{l}-0.572 \\
0.572\end{array}$ & $\begin{array}{l}0.185 \\
0.185\end{array}$ & $\begin{array}{l}-3.095 \\
3.095\end{array}$ & $\begin{array}{l}0.048 \\
-0.048\end{array}$ & $\begin{array}{l}0.135 \\
0.135\end{array}$ & $\begin{array}{l}0.358 \\
-0.358\end{array}$ & 9.65 & 0.022 & 9.21 & 0.010 & $\begin{array}{l}-0.152 \\
0.152\end{array}$ & $\begin{array}{l}0.276 \\
0.276\end{array}$ \\
\hline
\end{tabular}

Note: Cells containing coefficients significant at the 10 percent level have been shaded

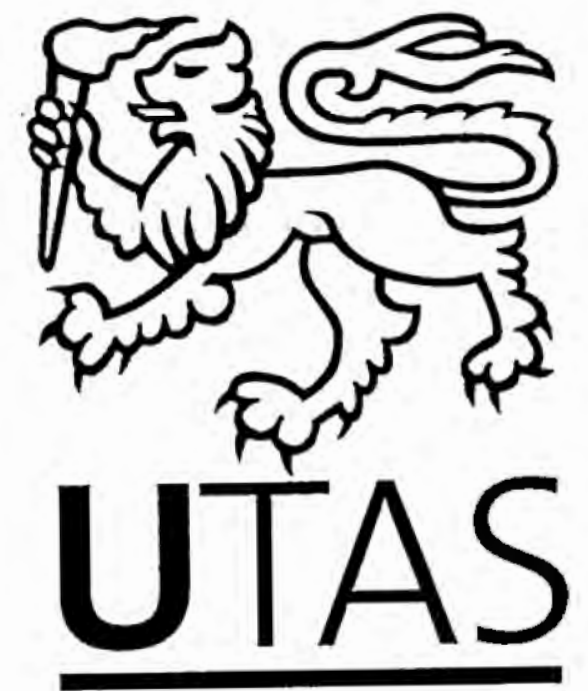


Table 27 shows that a higher level of compensation funding has a positive impact on utility for environment owners and is not significant for the other two landowner classes. $^{85}$ The effect of maintaining limited land use after reserve establishment on utility was broadly similar for environment owners and mtlli-objective owners. Restricting all land use options for reserved areas decreases the probability of choosing a program with this characteristic for these two landowner classes. The size of the coefficient suggests that the effect was slightly greater for environment owners. For production owners the sign of the coefficient for land use is significant and the opposite to the other two landowner classes.

The pattern for environment owners and multi-objective owners is also similar for entering into a temporary management agreement. These two landowner classes receive positive utility from entering into a management agreement, while production owners receive positive utility from placing a permanent covenant on title. ${ }^{86}$

There is no difference between the landowner classes in their preference for upfront payments of compensation funding as opposed to tax relief. Access to free technical advice after reserve establishment has a positive utility only for environment owners.

The ASC, the constant that captures the impact of unobserved factors not captured by the attributes (see Adamowizc et al. 1998), is significant and negative for production owners and positive and significant for multi-objective owners.

\subsection{2 'Voluntary' choice model}

In this section the results of estimating the 'voluntary' choice model are presented and interpreted. This model is based on the choice question where respondents were presented with three choice options: two conservation incentive programs; and a third option of not joining any program. A latent class regression is applied to choice data for all 132 survey respondents, including those who did not own any native forest. ${ }^{87}$

\footnotetext{
${ }^{85}$ A small nutnber of landowners did not provide an estimate of the average market value for their land (Section 8.1.6). For those landowners a market value for their land of $\$ 5,000$ per hectare was assumed. The model results do not change significantly if the average value of $\$ 6,175$ per hectare had been assumed (based on the average land value reported by other landowners).

${ }^{86}$ A discussion of the results is presented in Chapter 9.

87 The 'voluntary' model was also carried out for forest owners only (respondents comprising the sample for the 'forced choice' model). Even though the covariates for the socio-economic variables
} 
The steps presented in Section 8.4 are again used to estimate the final model. In the first step the latent class regression models for 1 to 4 classes were estimated using all five program attributes. The various fit statistics for each of the four models are reported in Table 28.

Table 28: Fit statistics for 1,2,3 and 4 latent class 'voluntary' regression models (Choice survey data).

\begin{tabular}{|c|c|c|c|c|c|c|c|c|c|c|}
\hline & LL & $\begin{array}{l}\text { BIC } \\
\text { (LL) }\end{array}$ & $\begin{array}{l}\text { AIC } \\
\text { (LL) }\end{array}$ & 妾 & $L^{2}$ & 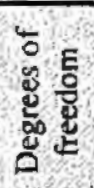 & p-value & $\sum_{\frac{3}{3}}^{=}$ & $\mathbf{R}^{2}(0)$ & $\mathbf{R}^{2}$ \\
\hline 1-Class & -842.73 & 1729,41 & 1703.46 & 9 & 957.33 & 123 & $<0.001$ & 0.000 & 0.311 & 0.074 \\
\hline 2-Class & -704.76 & 1502.29 & 1447.52 & 19 & 681.38 & 113 & $<0.001$ & 0.032 & 0.508 & 0.339 \\
\hline 3-Class & -638.60 & 1418.81 & 1335.21 & 29 & 549.08 & 103 & $<0.001$ & 0.029 & 0.590 & $\overline{0.449}$ \\
\hline 4-Class & -603.12 & 1396.67 & 1284.24 & 39 & 478.11 & 93 & $<0.001$ & 0.037 & 0.656 & 0.538 \\
\hline
\end{tabular}

All four 'voluntary' models are significant at the 5 percent level. As expected, the log likelihood values (LL) show improvement of the model fit with increasing number of classes. The 4-class model explains 54 percent of the variance and the BIC for the 4class choice model is lowest.

As outlined in step two (Section 8.4) the 1 to 4-class 'voluntary' models were reestimated including three attitude variables. The model also included dummies for three socio-economic variables: tertiary education (tert_edu), gender (gender), and region (region62). All covariates are significant at the 5 percent level. ${ }^{88}$ Fit statistics for the re-estimated models are reported in Table 29.

Table 29: Fit statistics for 1, 2, 3 and 4 latent class 'voluntary' model including significant covariates (Choice survey data).

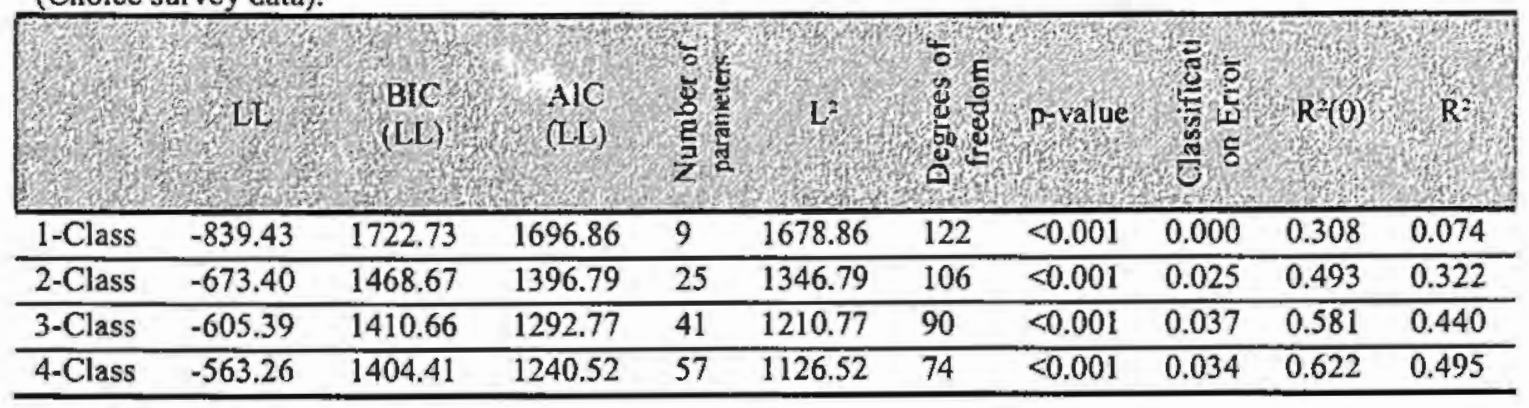

differed between the models, the sign of the covariates for the attitude variables and the program attributes were the same for both models.

${ }^{88}$ The model was initially run with all variables listed in Tables 20 and 21 and subsequently reduced to include only those variables significant at the 5 percent level. 
All four 'voluntary' models shown in Table 29 are significant at the 5 percent level. The BIC is lowest for the 4-class 'voluntary' model which includes all six covariates. The BIC falls from 1722.73 for the 1-class model that does not account for heterogeneity to 1404.41 for the 4-class 'voluntary' model. The lower BIC indicates that 4-class model has a better fit than the 1-class model. ${ }^{89}$ As in the 'forced choice' model, the AIC for the 4-class 'voluntary' model is lower than for the 3-class model. However, as previously discussed, the AIC can become less reliable with increased numbers of classes.

The $\mathrm{R}^{2}$ increases from 7.4 percent for the 1 -class model, which does not allow for preference heterogeneity, to 44 percent for the 3-class model with covariates, and 50 percent for the 4-class model. To assess whether the $\mathrm{R}^{2}$ statistic obtained for the 4class model would be a significant improvement over the 3-elass model, the p-value can be estimated using the conditional bootstrap method. The conditional bootstrap analysis indicated that the improvement of moving to a 4-class model was not statistically significant.

Step 3 described in Section 8.4 was to select the optimal number of latent classes on the basis of the fit statistics. Comparing the fit statistics reported in Table 28 to those in Table 29 it is evident that, on the basis of the BIC and the $\mathrm{R}^{2}$ statistic alone, the 4class model without covariates performs best. This result was also found for the 'forced choice' model. Again, the decrease in the value of the BIC between the 4class model without covariates and the 3 -class model with covariates is small.

Interpretation of the coefficient estimates suggests that inclusion of the covariates adds significantly to describing and understanding class membership. For these reasons, the next step, where the effect of three program attributes across latent classes (step 4 in Section 8.4) are constramed, uses the 3-class model with covariates.

The final 3-class, six covariate 'voluntary' model was re-estimated while inposing parameter restrictions across latent classes for program attributes for which no significant difference was identified (the Wald $(=)$ statistic was greater than 0.05 ). As there was no significant difference between the 3 classes for landuse, paymethod, and techassist, the parameter restriction was applied.

\footnotetext{
89. Again, as applied in the 'forced choice' model, no further decrease in the BIC is observed going from a 4-class to a 5-class model.
} 
The final 3-class 'voluntary' model contains three latent classes, includes six covariates and parameter restriction for three of the program attributes was applied. The final 3-class model is significant at the 5 percent level..$^{90}$ A BIC value of 1379.88 is determined for the final 3-class model. This value is lower than any of the BIC values reported in Tables 28 and 29 above.

Overall, the $\mathrm{R}^{2}$ statistic is 43 percent for the final 3-class model. The final model performs well at separating individuals into classes with a dissimilarity index of 82 percent. The predictive power of the final model can also be assessed using the number of correctly classified respondent choices (Table 30). Overall, the final 3class 'voluntary' model correctly predicts 79 percent of the 1048 observed choices.

Table 30: Classification of the final 3-class 'voluntary' model observations (percentage of observed program choice) (Choice survey data).

\begin{tabular}{l|cccc}
\hline & Program 1 & \multicolumn{4}{c}{ Program 2 } & Not join & Total \\
\hline OBSERVED & \multicolumn{4}{|c}{ PREDICTED } \\
\hline Program 1 & $91(54 \%)$ & $23(14 \%)$ & $55(33 \%)$ & 169 \\
\hline Program 2 & $19(11 \%)$ & $103(58 \%)$ & $57(32 \%)$ & 179 \\
\hline Not join & $41(6 \%)$ & $26(4 \%)$ & $633(90 \%)$ & 700 \\
\hline Total & 151 & 152 & 745 & 1048 \\
\hline
\end{tabular}

As Table 30 shows, the model correctly predicts 54 percent of observed choices for program 1. Of the 169 observed program 1 choices, 14 percent were misclassified into program 2 choice and 33 percent were misclassified into 'not joining'. A similar pattern of misclassification can be observed for observed program 2 choices. For program 2, a total of 58 percent of observed choices was correctly classified and 32 percent were misclassified into 'not joining'. A significantly higher percentage of observed choices were correctly classified for the option of not joining, which is 90 percent. The final 3-class model therefore has a high level of accuracy in predicting instances where the respondent chooses not to join (comprising 67 percent of the total number of observed choice options), as only 6 percent of observed choices of not joining were misclassified into choosing program 1 , and 4 percent into choosing program 2.

Covariate classification statistics indicate how well class membership can be predicted on the basis of an individual's covariate values. The 'voluntary' model has

\footnotetext{
${ }^{90}$ The final 3-class model includes 29 parameters and 102 degrees of freedom.
} 
a classification error based on covariates of 31 percent. The $\mathrm{R}^{2}$ statistic for the covariates indicates that 29 percent of the variance of the program choice can be explained by covariates.

On the basis of the above statistical indicators, in particular the low BIC for the final 3-class 'voluntary' model and the low model prediction enror, the presence of heterogeneous preferences and the need for separate utility function estimates is suggested. The utility functions for the three landowner classes are reported in the section below.

\subsubsection{Utility parameters for 'voluntary' model}

Each of the three latent choice classes is characterised on the basis of the covariates included in the final 3-class 'voluntary' model. Estimated segment membership $\left(\hat{\lambda}_{s}\right)$

parameters are shown in Table 31 . The estimated utility function parameters $\left(\hat{\beta}_{s}\right)$ for the program attributes for the final 3-class 'voluntary' model are subsequently shown in Table 32. 
Table 31: Parameters, standard error, z statistics, Wald and p-value for attitude and socio-economic variables for the 3 class 'voluntary' model (Choice survey data).

\begin{tabular}{|c|c|c|c|c|c|c|c|c|c|c|c|}
\hline coriglum & $\begin{array}{r}23 \\
\end{array}$ & $\begin{array}{l}\text { Sontil } \\
\text { Moth }\end{array}$ & 4rolis & $\begin{array}{r}25 \\
-25 \\
\end{array}$ & $\begin{array}{l}\text { Sinio } \\
\text { Saredi }\end{array}$ & Fariturs & 4 & $\begin{array}{l}\text { Sirudid } \\
\text { (arror: }\end{array}$ & (25 thlige & (18016: & Hevalie \\
\hline & \multicolumn{3}{|c|}{ 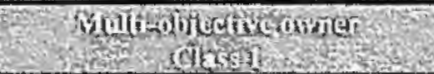 } & कु & 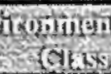 & 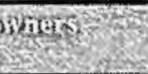 & & 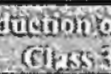 & गुसक 35 & & \\
\hline Prod_attitude & -0.137 & 0.182 & -0.754 & -0.875 & 0.222 . & -3.947 & 1.012 & 0.281 & 3.601 & 16.418 & $2.7 \mathrm{e}^{-1}$ \\
\hline Env_attitude & -0.075 & 0.192 & -0.389 & 0.806 & 0.245 & 3.289 & 0.731 & 0.278 & -2.632 & 10.916 & 0.004 \\
\hline Oppor_attitude & 0.375 & 0.180 & 2.089 & -0.502 & 0.221 & -2.277 & 0.127 & 0.217 & 0.584 & 6.713 & 0.035 \\
\hline Gender & 0.408 & 0.223 & 1.831 & -0.792 & $0.273^{\prime}$ & -2.903 & 0.383 & 0.290 & $1.323^{\prime a}$ & 9.288 & 0.010 \\
\hline (tertiary edu $=1$ ) & $0 . \overline{194}$ & 0.173 & 1.123 & 0.553 & 0.217 & -2.548 & -0.358 & 0.243 & 1.476 & 6.773 & 0.034 \\
\hline (south=1) & 0.432 & 0.225 & 1918 & -0.820 & 0.314 & -2.612 & 0.388 & 0.306 & 1.270 & 7.748 & 0.021 \\
\hline
\end{tabular}

Note: Cells containing coefficients significant at the 10 percent level have been shaded.

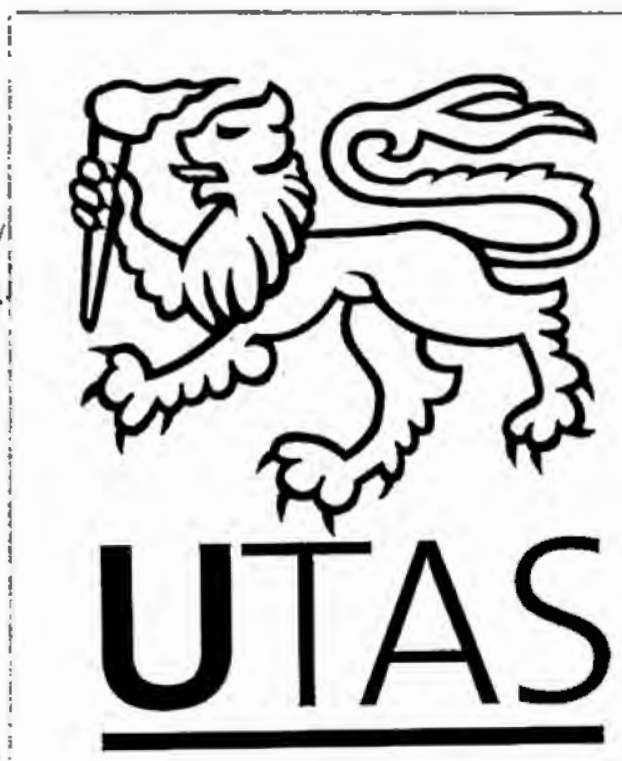


The first three rows of Table 31 show that each of the three classes in the final 'voluntary' model can be described in terms of member's attitude to the role and outcome of establishing conservation reserves on private land ${ }^{9 t}$. The coefficients on all three attitude variables ${ }^{92}$ for members of class 2 (labelled environment owners) are significant at the 5 percent level. The reported signs on the three attitude variables suggest that members of this class agreed strongly that environmental advantages are associated with establishing conservation reserves. Members of this class strongly disagreed that reserves negatively impact on production or on future opportunities.

The estimated coefficients for two of the attitude variables for members of class 3 (labelled production owners) are the opposite to those of environment owners. The members of this class did not identify positive environmental outcomes of establishing reserves but strongly agreed that establishing reserves has a negative production impact. The coefficient on oppor_attitude is insignificant for this class.

Members of class 1 did not believe that establishing conservation reserves negatively affects production. This was also found in the 'forced choice' model. Even though members also indicated a concern that reserve establishment would reduce future opportunities (which they did not in the 'forced choice' model), this class has been labelled multi-objective owners. ${ }^{93}$ Overall landowners had a 45 percent chance of being in the class labelled multi-objective owners, a 43 percent chance of being in the class labelled environment landowners, and a 12 percent chance of being in the class labelled production owners.

Table 31 also shows that multi-objective landowners can be described in terms of gender (they are more likely to be male) and region (they are more likely to own property in the south of the State). Environment landowners are more likely to be female, live in areas other than the south of the State, and to have achieved tertiary education. Production landowners are more likely to be male and to have lower education levels.

\footnotetext{
91 The construction of the attitudinal variables for inclusion in the voluntary model based on PCA was shown in Appendix 5. The three variables reflect environment focus, production focus, and focus on long term opportunity.

${ }^{92}$ As outlined in Section 8.2, the 'voluntary' model has three variables that resulted from the PCA, where as the 'forced choice' model had two variables (Appendix 5).

${ }^{93}$ Although it may be argued that this class of landowner is a "weak" multi-objective owner.
} 
The estimated utility function parameters for the program attributes for the final 3class 'voluntary' model are shown in Table 32. As discussed previously, all three attributes (landise, paymethod, and techassist) were restricted to be the same between classes. 
Table 32: Parameters, standard error, $\mathrm{z}$ statistics, Wald and p-value for program attributes for a 3 class 'voluntary' model (Choice survey data).

\begin{tabular}{|c|c|c|c|c|c|c|c|c|c|c|c|c|c|c|c|}
\hline 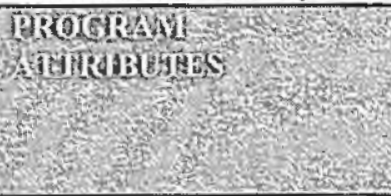 & 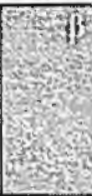 & 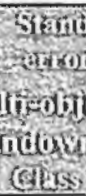 & $\begin{array}{l}\text { garilis } \\
\text { got }\end{array}$ & $\frac{19}{139}$ & Stain & feril & atit & 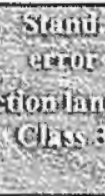 & 20 vallos & 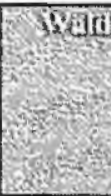 & ib & (घ) & wilic & 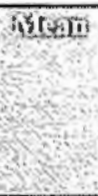 & $\frac{\text { Sidi }}{\text { Tiat }}$ \\
\hline ASC & 0.893 & 0.248 & 3.597 & 0.182 & 0.314 & 0.579 & $-1: 075$ & 0.359 & -2.994 & 14.709 & $6.4 \mathrm{e}^{4}$ & & & & \\
\hline Compfund & 0,801 & 0.078 & 10.330 & 0.727 & 0.314 & 2.315 & -0.136 & 0.110 & -1.230 & 117.25 & $3.0 \mathrm{e}^{.25}$ & 47.52 & $4.8 \mathrm{e}^{-11}$ & 0.654 & 0.298 \\
\hline $\begin{array}{rr}\text { Legal covenant } \\
\text { managreement } \\
\text { NOlegalagreem }\end{array}$ & $\begin{array}{l}-2.064 \\
-0.88 \\
2.948 \\
\end{array}$ & $\begin{array}{l}0.234 \\
0.203 \\
0.391\end{array}$ & $\begin{array}{l}-8.817 \\
4.356 \\
7.532\end{array}$ & $\begin{array}{l}-2.989 \\
-2.058 \\
5.047\end{array}$ & $\begin{array}{l}0.680 \\
0.761^{1} \\
1.185\end{array}$ & $\begin{array}{l}-4.399 \\
-2.705 \\
4.258\end{array}$ & $\begin{array}{l}1.181 \\
0.080 \\
-1.260 \\
\end{array}$ & $\begin{array}{l}0.254 \\
0.266 \\
0.451\end{array}$ & $\begin{array}{l}4.655 \\
0.300 \\
-2.797\end{array}$ & 159.84 & $6.4 \mathrm{e}^{-12}$ & 143.88 & $4.2 \mathrm{e}^{.30}$ & $\begin{array}{l}-2.061 \\
-1.268 \\
3.329\end{array}$ & $\begin{array}{l}1.289 \\
0.746 \\
1.980\end{array}$ \\
\hline $\begin{array}{r}\text { limiteduse } \\
\text { nousepermit } \\
\text { UNlimiteduse }\end{array}$ & $\begin{array}{l}0.218 \\
-0.566 \\
0.349 \\
\end{array}$ & $\begin{array}{l}0.137 \\
0.878 \\
0.367 \\
\end{array}$ & $\begin{array}{l}1.594 \\
-0.645 \\
0.951 \\
\end{array}$ & $\begin{array}{l}0.218 \\
-0.566 \\
0.349 \\
\end{array}$ & $\begin{array}{l}0.137 \\
0.878 \\
0.367 \\
\end{array}$ & $\begin{array}{l}1: 594 \\
-0.645 \\
0.951 \\
\end{array}$ & $\begin{array}{l}0.218 \\
-0.566 \\
0.349 \\
\end{array}$ & $\begin{array}{l}0.137 \\
0.878 \\
0.367 \\
\end{array}$ & $\begin{array}{l}1.594 \\
-0.645 \\
0.951 \\
\end{array}$ & 2.540 & 0.280 & 0.000 & . & $\begin{array}{l}0.218 \\
-0.566 \\
0.349 \\
\end{array}$ & $\begin{array}{l}0.000 \\
0.000 \\
0.000 \\
\end{array}$ \\
\hline $\begin{array}{r}\text { upfrontpay } \\
\text { taxrelief } \\
\text { NOpayment }\end{array}$ & $\begin{array}{r}0.032 \\
0.020 \\
-0.052 \\
\end{array}$ & $\begin{array}{l}0.045 \\
0.132 \\
0.101 \\
\end{array}$ & $\begin{array}{l}0.711 \\
0.152 \\
-0.515 \\
\end{array}$ & $\begin{array}{l}0.032 \\
0.020 \\
-0.052 \\
\end{array}$ & $\begin{array}{l}0.045 \\
0.132 \\
0.101 \\
\end{array}$ & $\begin{array}{l}0.711 \\
0.152 \\
-0.515 \\
\end{array}$ & $\begin{array}{l}0.032 \\
0.020 \\
-0.052 \\
\end{array}$ & $\begin{array}{l}0.045 \\
0.132 \\
0.101\end{array}$ & $\begin{array}{l}0.711 \\
0.152 \\
-0.515 \\
\end{array}$ & 0.023 & 0.990 & 0.000 & . & $\begin{array}{l}0.032 \\
0.020 \\
-0.052 \\
\end{array}$ & $\begin{array}{l}0.000 \\
0.000 \\
0.000 \\
\end{array}$ \\
\hline $\begin{array}{r}\text { fee } 4 \text { service } \\
\text { freetechadv } \\
\text { NOadvice }\end{array}$ & $\begin{array}{l}-0.12 \text { ? } \\
0.247 \\
-0.12 \text { ? }\end{array}$ & $\begin{array}{l}0.131 \\
0.534 \\
0.179\end{array}$ & $\begin{array}{l}-0.939 \\
0.463 \\
-0.687\end{array}$ & $\begin{array}{l}-0.123 \\
0.247 \\
-0.123\end{array}$ & $\begin{array}{l}0.131 \\
0.534 \\
0.179\end{array}$ & $\begin{array}{l}-0.939 \\
0.463 \\
-0.687\end{array}$ & $\begin{array}{l}-0.123 \\
0.247 \\
-0.123\end{array}$ & $\begin{array}{l}0.131 \\
0.534 \\
0.179\end{array}$ & $\begin{array}{l}-0.939 \\
0.463 \\
-0.687\end{array}$ & 0.882 & 0.640 & 0.000 & . & $\begin{array}{l}-0.123 \\
0.247 \\
-0.123\end{array}$ & $\begin{array}{l}0.000 \\
0.000 \\
0.000\end{array}$ \\
\hline
\end{tabular}

Note: Cells containing coefficients significant at 10 percent have been shaded. 
Table 32 shows that for all three landowner classes none of the payment methods or technical assistance was significant at the 5 percent level. The table also shows that maintaining limited land use after joining a program had a positive effect on utility for all three landowner classes, as the variable was restricted for all groups.

Compensation funding and the legal implications of programs were broadly similar for environment and multi-objective landowners. Compensation funding is significant and positive for both classes indicating that higher levels of compensation funding had a positive impact on utility. All three levels of the legal attribute are significant for both environment and multi-objective landowners at the 5 percent level. Both placing a permanent covenant on title and entering into a temporary management agreement had a negative impact on utility. A positive utility is associated with not having any legal implications.

Similar to the 'forced choice' model, the estimated coefficient for compensation funding is not significant at the 5 percent level for production landowners. A positive impact on utility is associated with entering into a covenant and a negative impact on utility with entering into a legal agreement for this class.

The ASC is significant and negative for production owners and significant and positive for multi-objective owners in the "voluntary choice" model. The negative ASC for production owners indicates that a status quo bias or so-called "endowment effect' may apply (Kahneman and Knetsch 1992 quoted in Adamowicz et al. 1998).

Program attribute coefficients presented in the preceding sections can be used to determine the welfare impact of joining incentive programs with different levels of restrictiveness. The next section focuses on deriving welfare impact estimates.

\subsubsection{Welfare impact of program restrictions}

Traditionally, choice models are used to estimate the welfare impact as a consequence of changing attribute levels. An estimate of an attributes' dollar value contribution to utility can be made by taking the ratio between the attribute coefficient and the coefficient for the attribute that is expressed in dollars (Adamowicz, Louviere et al. 1998). ${ }^{94}$ In this current study the attribute expressed in dollars is compensation

\footnotetext{
${ }^{94}$ The covariates are at their mean values.
} 
funding. It is possible to estimate the utility of a particular scenario based on different combinations of attributes and levels (e.g. Rolfe and Bennett 1996).

In this current study the welfare impact for both the 'forced choice' and the 'voluntary choice' models is estimated for incentive programs with different levels of 'restrictiveness'. The welfare impact for both models is estimated using methods as traditionally presented in other studies (Chapter 3).

Interpretation of welfare impacts in this current study is somewhat limited for both models because the estimated coefficient for compensation funding was not significantly different to zero for all landowner groups. For instance, for the 'forced choice' model (Section 8.4.1), the estimated coefficient for compensation funding $\beta_{\text {compund }}$ was not significantly different to zero for production owners or multiobjective owners. Consequently, Equivalent Variation (EV), calculated using equation 15 in Section 5.1.1, was not significantly different to zero for these owner groups. The above implies that the estimated utility of a particular scenario, based on different combinations of attributes and levels, can only be interpreted with any confidence for environment owners. Similarly, for the 'voluntary choice' model (Section 8.4.2), the results can be interpreted with confidence only for multi-objective owners and environment owners. The figures presented in Tables 33 and 34 that follow, have to be interpreted with care. ${ }^{95}$

The interpretation of the welfare impact for the 'voluntary choice' model follows that traditionally presented in choice studies (e.g. Rolfe and Bennett 1996; Home, Boxall et al. 2005). The estimated welfare impact for an attribute in the 'voluntary' model (Table 34 ) is relative to the status quo of not joining an incentive program.

For the 'forced choice' model the estimation of the welfare impact is more limited and not equally meaningful as that estimated for the 'voluntary choice' model. For the 'forced choice' model the choice was restricted to two programs and did not include the option of not joining any program. The estimated welfare impact for an attribute is therefore the difference between the restrictive level of the attribute and the less restrictive level. A comparison of the welfare impact between the two models

\footnotetext{
${ }^{95}$ The limited number of observations for both models is alsn potentially cause for concem in the interpretation of the welfare impact.
} 
(Chapter 9) is therefore limited due to the different interpretation of the welfare estimates.

The interpretation of the ASC for the 'forced choice' model also differs from the more traditional choice model, the "voluntary choice' model. In the 'voluntary choice' model the ASC is a dummy variable that equals one when the status quo option is chosen. If the ASC is negative it indicates that the utility associated with selecting either program, therefore moving away from the current situation, is negative. If the ASC is negative in the 'forced choice' model it indicates a negative utility associated with greater restrictiveness of the program. ${ }^{96}$

With the above in mind, in Table 33 below the welfare impact of two different incentive programs with different levels of 'restrictiveness' are estimated for the 'forced choice' model and compared to the most restrictive scenario. The description of the level of restrictiveness for each of the four binary program attributes was previously described in Table 22 . $^{97}$

\footnotetext{
${ }^{96}$ The less restrictive attributes are coded zero and the more restrictive attributes coded one in the datasheet that underlies the calculations for the 'forced choice' model.

${ }^{97}$ A covenant was more restrictive than a management agreement (legal), no use of the land was more restrictive than limited use (landise), tax relief was more restrictive/less flexible than upfront payment (paymethod), and fee for service was more restrictive than free of charge technical assistance (techassist).
} 
Table 33: Welfare impacts for changes in incentive program restrictiveness for the 'forced choice' model, and the lower and upper $95 \%$ confidence interval (Choice survey data).

\begin{tabular}{|c|c|c|c|}
\hline Restrictiveness scenario & $\begin{array}{l}\text { Multi-objective } \\
\text { owner }\end{array}$ & $\begin{array}{c}\text { Environment } \\
\text { owmer }\end{array}$ & $\begin{array}{c}\text { Production } \\
\text { owner }\end{array}$ \\
\hline Baseline-most restrictive program (\$/ha) & $-\$ 93,536$ & $-\$ 1,247$ & $.55 .00 \mathrm{~m}$ \\
\hline Lower $95 \%$ & $-5204,712$ & $-\$ 1,653$ & $\therefore 1,317 \mathrm{~m}$ \\
\hline Upper $95 \%$ & $517,0.011$ & $-\$ 840$ & $81,3160 \mathrm{~m}$ \\
\hline 1 Restrictive legal \& land use (\$/ha) & $.581,961$ & $-\$ 315$ & $-55.34 \mathrm{~m}$ \\
\hline Lower $95 \%$ & $-5147,135$ & $-\$ 721$ & $-91.37 \mathrm{~m}$ \\
\hline Upper $95 \%$ & 39,215 & $\$ 92$ & $81,3160.19$ \\
\hline WELFARE GAIN - scenario 1 & & $\$ 932$ & \\
\hline 2 Only restrictive legal (\$/ha) & -52.405 & $\$ 957$ & $-53.18 \mathrm{~m}$ \\
\hline Lower $95 \%$ & .5114 .941 & $\$ 550$ & $-\$ 1,315 m$ \\
\hline Upper $95 \%$ & 3.05 .272 & $\$ 1,363$ & $81.30 \% \mathrm{~min}$ \\
\hline WELFARE GAIN - scenario 2 & & $\mathbf{\$ 2 , 2 0 3}$ & 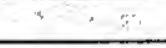 \\
\hline 3 Unrestrictive program (\$/ha) & 393.536 & $\mathbf{\$ 1 , 2 4 7}$ & $55.00 \mathrm{~m}$ \\
\hline Lower $95 \%$ & $-5 \mid 7,0,1 ;$ & 5840 & 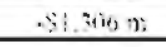 \\
\hline Upper $95 \%$ & $520,4,72$ & $\$ 1,653$ & 81.317 .31 \\
\hline WELFARE GAIN - scenario 3 & $\therefore \quad \therefore<$ & $\$ 2,494$ & $\pm \quad{ }^{\circ}$ \\
\hline
\end{tabular}

Baseline $=$ Covenant, no use permitted, tax relief, fee for service technical advice

Scenario $\mathrm{l}$ = Covenant, no use permitted, upfront funding, free technical advice

Scenario 2 = Covenant, limited use permitted, upfront funding, free technical advice

Scenario 3 = Management agreement, limited use permitted, upfront funding, free technical advice

* For the figures shown in grey the variable for funding amount (Table 27) was not significant at the 5 percent level.

Table 33 shows the welfare change (gain) in moving from the baseline, which is the most restrictive incentive program, to a less restrictive scenario. As expected, more restrictive incentive programs are less attractive to all forest owner groups. The welfare gain for environment owners from moving from the restrictive program to one where the funding method and technical advice availability attributes are less restrictive is $\$ 932$ per hectare. The gain in welfare would be $\$ 2,494$ for environment owners moving from the restrictive to the unrestrictive program.

The welfare impact of incentive programs with different levels of restrictiveness are also estimated for the 'voluntary choice' model in Table 34. 
Table 34: Welfare impacts for changes in incentive program restrictiveness for the 'voluntary choice' model, and the lower and upper $95 \%$ confidence interval (Choice survey data).

\begin{tabular}{|c|c|c|c|}
\hline Restrictiveness scenario & $\begin{array}{l}\text { Multi-objective } \\
\text { owner }\end{array}$ & $\begin{array}{c}\text { Environinent } \\
\text { owner }\end{array}$ & $\begin{array}{l}\text { Production } \\
\text { ownet }\end{array}$ \\
\hline 1 Most restrictive program (\$/ha) & $-\$ 3,399$ & $-\$ 5,020$ & $-\$ 3,850$ \\
\hline Lower $95 \%$ & $-\$ 4.941$ & $-\$ 6,595$ & -222.168 \\
\hline Upper $95 \%$ & $-\$ 1,856$ & $-\$ 3,445$ & $514,16,3$ \\
\hline 2 Restrictive legal \& land use (\$/ha) & $-\$ 2,951$ & $-\$ 4,527$ & -80.792 \\
\hline Lower $95 \%$ & $-\$ 5,105$ & $-\$ 6,186$ & $\$ 2,3,512$ \\
\hline Upper $95 \%$ & -5797 & $-\$ 2,868$ & 510.529 \\
\hline 3 Only restrictive legal ( $\$ / \mathrm{ha})$ & $-\$ 1,972$ & $-\$ 3,448$ & -512.268 \\
\hline Lower $95 \%$ & $-\$ 3,194$ & $-\$ 5,109$ & -528.907 \\
\hline Upper $95 \%$ & -5751 & $-\$ 1,787$ & 5.48011 \\
\hline 4 Unrestrictive program (\$/ha) & $-\$ 500$ & $-\$ 2,166$ & $-\$ 4,156$ \\
\hline Lower $95 \%$ & $\$ 1.702$ & $-\$ 2,680$ & 515,3174 \\
\hline Lower 95\% & $\$ 702$ & $-\$ 1,651$ & $57,618: 6$ \\
\hline
\end{tabular}

Scenario 1 = Covenant, no use permitted, tax relief, and fee for service technícal advice

Scenario 2 = Covenant, no use permitted, upfront funding, free technical advice

Scenario 3 = Covenant, limited use permitted, upfront funding, free technical advice

Scenario 4 = Management agreement, limited use permitted, upfront funding, free technical advice

* For the figures shown in grey the variable for funding amount (Table 32) was not significant at the 5 percent level.

Table 34 shows the WTA compensation estimates for joining a program with different levels of restrictiveness. Even though not joining an incentive program is the most attractive option to all landowner classes in the 'voluntary choice' model, the $E V$ for joining a restrictive program is less than the average agricultural land value in Tasmania (Section 8.1.6). As expected, welfare gains are smaller with more restrictive programs for multi-objective owners. The $E V$ for joining a restrictive program is greater for environment owners than for multi-objective owners.

Although the majority of landowners prefer not to join an incentive program the ASC was significant and positive for multi-objective owners (Table 32) indicating there was no status quo bias or so-called endowment effect (Kahneman and Knetsch 1992 quoted in Adamowicz et al. 1998).

The range for the $E V$ estimates as shown in Tables 33 and 34 were calculated with an approximation formula (equation 34) as " ... there are no simple exact formulas for the mean and variance of the quotient of two random variables in terms of moments of the two random variables" (Mood, Graybill et al. 1974, p.180):

$$
\operatorname{var}\left[\frac{X}{Y}\right] \approx\left(\frac{\mu_{X}}{\mu_{Y}}\right)^{2}\left(\frac{\operatorname{var}[X]}{\mu_{X}^{2}}+\frac{\operatorname{var}[Y]}{\mu_{Y}^{2}}-\frac{2 \operatorname{cov}[X, Y]}{\mu_{X} \mu_{Y}}\right)
$$


The standard errors for each of the ratios between an attribute coefficient and the coefficient for the compensation funding attribute (expressed in dollars) are shown in Appendix 9.

\subsubsection{A two-step estimation procedure of landowner preferences}

In this research a PCA was used to describe forest owner groups on the basis of their attitude toward the role and outcome of establishing reserves on private land. As outlined in Section 8.2 the measurement of attitude was undertaken using Likert scale rating scores. Two factors were estimated for the 'forced choice' model. In Sections 8.4.1 and 8.4.2 preferences for program attributes were estimated for respondents, characterised by their attitude using a latent class analysis.

In this section the latent class approach is compared to a two-step estimation process, consisting of cluster analysis and logit regression. ${ }^{98}$ Both the latent class and the twostep approaches group together similar cases and explain the association among a set of observed variables. Individuals in the same class cannot be distinguished from each other on the basis of their observed responses.

In the two-step approach, firstly the factor scores obtained in the PCA (Section 8.2) were used as the grouping variables in a $\mathrm{K}$-means cluster analysis. Cluster analysis is commonly used to classify individuals into groups on the basis of their attitude (e.g. Kuuluvainen, Karppinen et al. 1996; Kline, Alig et al. 2000; Jennings and van Putten 2006). A brief outline of cluster analysis is presented in Appendix 10.

For each cluster of landowners (as opposed to class of landowner) the preferences for incentive program attributes are subsequently estimated using a straightforward logit approach. An outline of binary choice models is presented in Appendix 11. A logit or multinomial logit approach has previously been used in other studies for this type of analysis by for instance Stevens, White et al. (2002), Söderqvist (2003), and Horne (2004). The results of latent class analysis have been contrasted to mixed logit by Hensher and Greene (2003b) for the choice of road types in New Zealand, and to conditional logit by Scarpa, Drucker et al. (2003) for the choice of piglet breeds. The study by Hensher and Greene (2003b) found that no “... unambiguous

\footnotetext{
98 The 'voluntary' model will not be compared to the two-step estimation method, but results of the cluster analysis for all 132 respondents indicated similar results to those for the 97 forest owners.
} 
recommendations could be made as to the superiority of any of the two approaches" (Scarpa and Thiene 2004, p.3).

The results presented in Section 8.4.5 after a discussion of some difference between latent classes and clusters.

\subsubsection{Some differences between clusters and latent classes}

As mentioned above, in cluster analysis (specifically $\mathrm{k}$-means cluster analysis) an adhoc distance measure is used for classification. The probabilities in latent class analysis are used to define "closeness" to each "class" or "cluster" centre and thus formalise the $\mathrm{K}$-means clustering approach in terms of a statistical model. In the latent class analysis individuals in the same class share a common probability distribution among the observed variables, estimated by maximum likelihood methods.

An important difference between latent class and $\mathrm{K}$-means clustering is that latent class provides various diagnostic tools to determine the optimal number of classes (e.g. BIC as shown in Section 5.1.2). In $\mathrm{K}$-means cluster analysis the number of clusters into which the data are to be grouped is determined prior to the analysis.

Another difference between the methods is that the latent class model can include exogenous variables referred to as covariates (see, for instance, Section 8.4.1) thus allowing classification and description to be carried out simultaneously using a single uniform maximum likelihood estimation algorithm. For K-means cluster analysis, discriminant analysis has to be used to determine differences between clusters.

\subsubsection{Two step estimation results}

As discussed in Section 5.3 a unique factor score was computed for each survey respondent for two principal components. These scores are now used as the grouping variables in a $\mathrm{K}$-means cluster analysis. The aim of this is to identify groups of landowners on the basis of their systematic attitude to the role and outcome of establishing reserves on private land. The results suggest that landowners in Tasmania can be classified into three clusters, as shown in Table 35. Cluster labels generally reflect the attitude associated with the principal components with the highest positive score. The cluster results are significant at the 5 percent level. 
Table 35: Final cluster centres and number of cases in cluster (Choice survey data).

\begin{tabular}{|cccc|}
\hline PCA factor & $\begin{array}{c}\text { Cluster } 1 \\
\text { Clinulti-objective } \\
\text { owners }\end{array}$ & $\begin{array}{c}\text { Cluster 2 } \\
\text { Cenvironinent } \\
\text { owners }\end{array}$ & $\begin{array}{c}\text { Cluster 3 } \\
\text { CLroduction } \\
\text { owners }\end{array}$ \\
\hline attitude_env & 0 & 1 & -1 \\
\hline attitude_prod & -1 & 0 & 1 \\
\hline Total respondents in cluster & $39(41 \%)$ & $34(35 \%)$ & $23(24 \%)$ \\
\hline
\end{tabular}

Table 35 shows that the largest cluster (Cl) represents 41 percent of the sample. Members of this cluster have a negative score on the production factor. This suggests that members of this group do not believe that the establishment of reserves on private land has a negative impact on production. Members of this cluster are labelled CLmulti-objective owners.

The second largest cluster ( $\mathrm{C} 2)$ represents 35 percent of the sample. It appears that members of this cluster viewed conservation on private land exclusively as having a positive environmental effect. Members of this cluster are referred to as CLenvironment owners.

The members of the smallest cluster (C3), making up 24 percent of the forest owners, viewed conservation on private land as having a regative effect on income and future wealth and security. Negative mean scores on all other factors suggest that these individuals may not have viewed financial outcome as being complementary to the restrictions put on the land. As in the latent class approach the members of $\mathrm{C} 3$ are referred to as CLproduction owners.

The scores show the same attitude pattern as the groups that were formed on the basis of the latent class analysis (Table 26). However, some differences in class sizes can be observed between the two approaches. For instance, production owners make up only 15 percent of respondents in the latent class analysis as opposed to CLproduction owners who make up 24 percent in the cluster approach. The largest groups in the analyses are the multi-objective owners and CLmulti-objective owners, but in the latent class approach they make up 55 percent of the total whereas in the cluster analysis they make up $4 \mathrm{l}$ percent. Overall, the size of the classes is more evenly distributed in the cluster analysis compared to the latent class. 
Even though the same attitude groups were developed using the cluster and the latent class analysis, only 37 percent of observations were classified into the same group using both methods ${ }^{99}$ (Table 36).

Table 36: Cross classification of respondents into landowner classes and clusters by the latent class and cluster methods (Choice survey data).

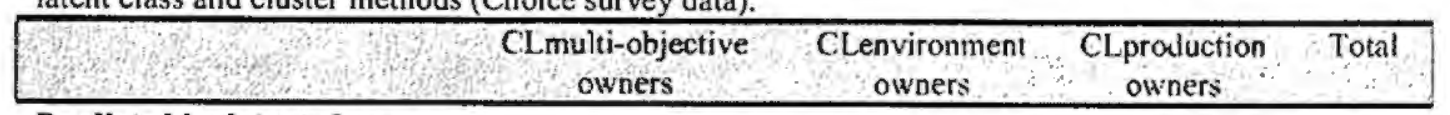

Predicted by latent class method Predicted by cluster method

\begin{tabular}{lcccc}
\hline Multi-objective owners & $26(49 \%)$ & $17(32 \%)$ & $10(19 \%)$ & 53 \\
\hline Environment owners & $4(14 \%)$ & $11(39 \%)$ & $13(46 \%)$ & 28 \\
\hline Production owners & $9(60 \%)$ & $6(40 \%)$ & $0(0 \%)$ & 15 \\
\hline Total & 39 & 34 & 23 & 96 \\
\hline
\end{tabular}

Table 36 shows that none of the respondents who were classified as production owners in the latent class approach were similarly classified in the cluster method. In contrast, almost half of the multi-objective owners were classified into the same group in both methods.

For each of the forest owner clusters a logit model was estimated. The number of correctly classified observations and the statistical indicators of the logit model fit for each of the forest owner clusters are shown in Table 37.

Table 37: Program choice classification and model statistics for forest owner clusters (Choice survey data).

\begin{tabular}{lccc|}
\hline Classification & $\begin{array}{c}\text { Cluster } \\
\text { CLmulti-objective }\end{array}$ & $\begin{array}{c}\text { Clenvironment } \\
\end{array}$ & Clproduction \\
\hline Correct classification of program 1 & $181(65 \%)$ & $168(64 \%)$ & $133(69 \%)$ \\
\hline Correct classification of program 2 & $213(62 \%)$ & $179(63 \%)$ & $125(71 \%)$ \\
\hline Total correct classification & $394(63 \%)$ & $347(64 \%)$ & $258(70 \%)$ \\
\hline LR chi2(5) & 56.67 & 68.45 & 96.62 \\
\hline Prob > chi2 & 0.000 & 0.000 & 0.000 \\
\hline Log likelihood & 404.188 & -342.844 & -206.770 \\
\hline Pseudo R2 & 0.066 & 0.091 & 0.189 \\
\hline
\end{tabular}

\footnotetext{
${ }^{99}$ Note that the respondents were classifred on the basis of probabilities using the latent class method. The following is an example of the probabilities for four landowners into the classes and the subsequent modal classification.
}

\begin{tabular}{|c|c|c|c|}
\hline \multicolumn{4}{|c|}{ 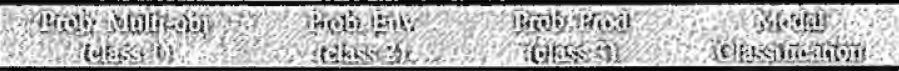 } \\
\hline 0.5751 & 0.4248 & 0.0001 & 1 \\
\hline 0.431 & 0.5689 & 0,0001 & 2 \\
\hline 0.9089 & 0.0888 & 0.0023 & 1 \\
\hline 0.1591 & 0 & 0.8409 & 3 \\
\hline
\end{tabular}


As shown in Table 37, the logit regression models for the three forest owner clusters are significant at the 5 percent level. Around 65 percent of observations are correctly classified for the three forest owner clusters. This is lower than the number of correctly predicted observation in the latent class model, which was 81 percent for program 1 and 84 percent for program 2 with overall 82 percent correctly predicted observations. The $\mathrm{R}^{2}$ statistic for each of the forest owner clusters is low at 7 percent, 9 percent, and 19 percent, for clusters 1,2 , and 3 respectively. ${ }^{100}$

The logit regression coefficient estimates for each of the three forest owner clusters are shown in Table 38. None of the socio-economic and property characteristics was significant in the logit models.

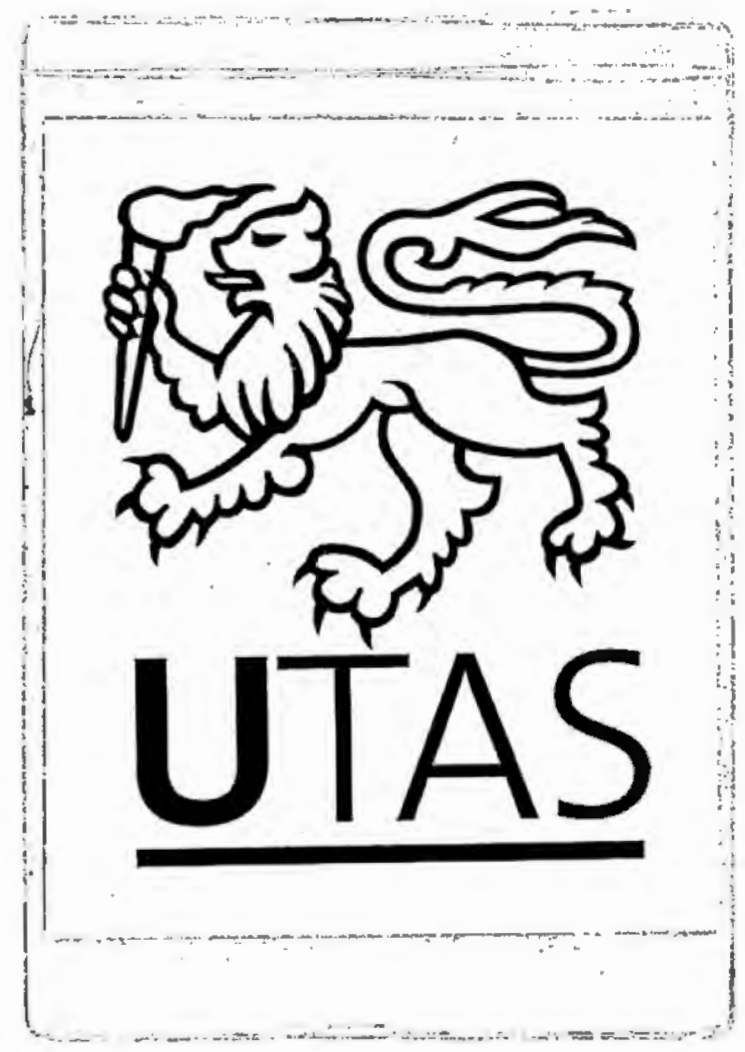

${ }^{100}$ The R statistic of the latent class model cannot be compared to this statistic as it is not 0-1- bounded. 
Table 38: Parameters, standard error, $z$ statistics, and p-values for logit models program attributes for three clusters of forest owner groups (Choice survey data).

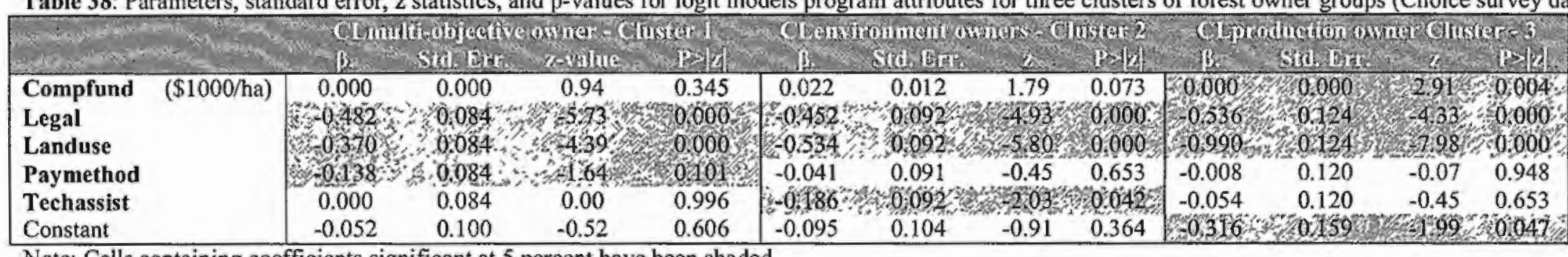

Note: Cells containing coefficients significant at 5 percent have been shaded.

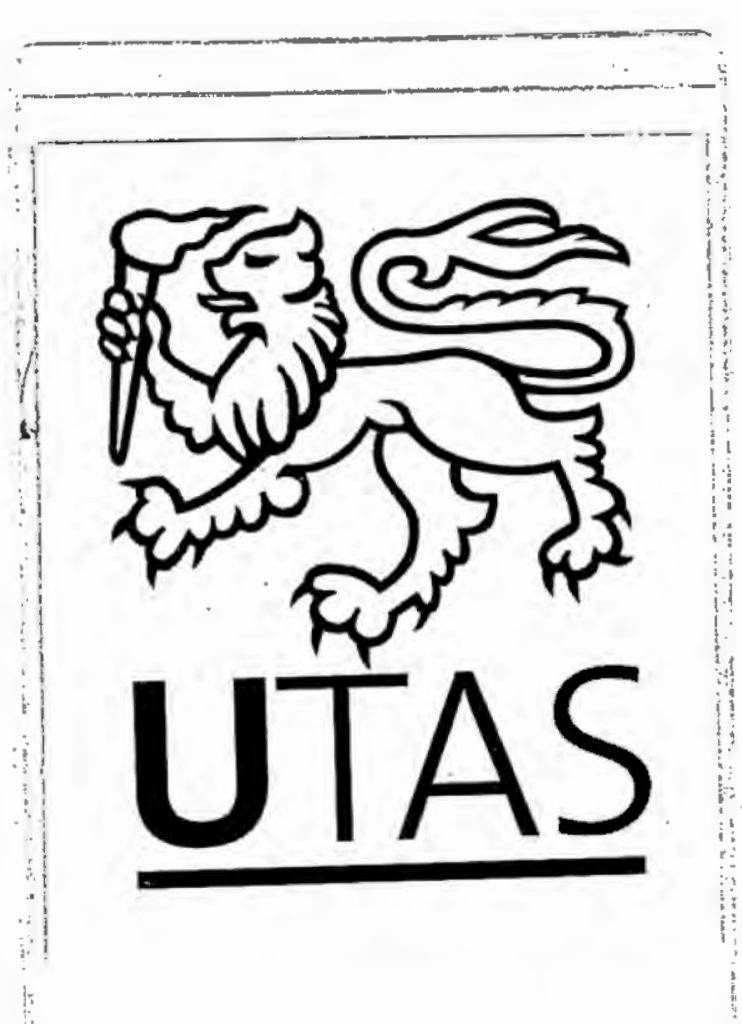


The results of Table 38 show that there is little difference between the three landowner clusters in the coefficients and the signs of the coefficients. Overall, the coefficients indicate that all landowner clusters prefer less restrictive programs. Cluster differences lie mainly in the size of the coefficients.

There are a number of similarities between Table 38 and Table 27 for the latent class results. For instance, in the modelling approaches the coefficient for the legal arrangement has the greatest effect for multi-objective owners and CLmulti-objective owners and the land use restrictions has the greatest effect for environment owners and CLenvironment owners. Getting free technical advice has a positive utility for only one forest owner group in the models namely environment owners and CLenvironment owners. Compensation funding does not significantly contribute to multi-objective owner or CLmulti-objective owner preferences for program attributes in the two modelling approaches.

Nevertheless, there are some important differences in the results produced using the two approaches. The most important is CLproduction owners are more similar in terms of their preferences for program attributes to the other two groups in the twostage logit regression. In the two-stage approach this landowner group received positive utility from being forced to enter less restrictive incentive programs (the same as the other two groups). In the latent class analysis, however, unlike other landowners, production owners had higher utility associated with increasing levels of program 'restrictiveness' (i.e. the land use and legal implications). The coefficient for compensation funding is not significant in the latent class model for production owners, but, although only small, the coefficient is positive and significant in the logit model.

Several socio-economic landowner characteristics, such as gender, were significant in the latent class approach. Latent class can include these exogenous variables as it allows classification and description of the landowners to be carried out simultaneously using a maximum likelihood estimation algorithm. Even though the logit approach allows the inclusion of socio-economic variables as independent variables in model estimation, none were significant. 
The utility coefficients for the program attributes presented in analysis above can be used to determine the welfare impact of joining more restrictive incentive programs, as in Section 8.4.3 for the latent class model.

\subsubsection{Welfare impact for logit model}

The welfare impact for the cluster analysis in combination with a logistic regression was calculated using the coefficients shown in Table 38. Table 39 below shows the welfare impact for the same restrictiveness scenarios that were previously presented for the 'forced choice' latent class model in Table 33.

Table 39: The welfare impact of program attributes for changes in the restrictiveness of the incentive program attribute for the logit regression model (Choice survey data).

\begin{tabular}{|c|c|c|c|}
\hline Restrictiveness scenario & $\begin{array}{l}\text { C.Lmulti-objective } \\
\text { owners }\end{array}$ & $\begin{array}{l}\text { CLenyironment } \\
\text { owners }\end{array}$ & $\begin{array}{l}\text { CLproduction } \\
\text { owners }\end{array}$ \\
\hline 1 Most restrictive program (\$/ha) & $\begin{array}{c}\$ 1: 0.2 \delta^{2} \\
15 ! .22151 .45:)^{*}=\end{array}$ & $\frac{556(0) 2}{(524(1)(352)}$ & $\begin{array}{c}\$ 21.57 \\
(-\$ 34 / \$ 77)\end{array}$ \\
\hline $\begin{array}{l}2 \text { Restrictive in terms of legal aspect and } \\
\text { land use permitted (\$/ha) }\end{array}$ & 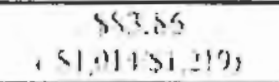 & $\begin{array}{l}435,02 \\
1,67.789\end{array}$ & $\begin{array}{c}\$ 19.89 \\
(-\$ 25 / \$ 67)\end{array}$ \\
\hline 3 Only restrictive on legal aspect ( $\$ / h a)$ & $\begin{array}{c}53019 \\
1552,4: 4,1\end{array}$ & $\begin{array}{l}-+1+26 \\
\text { 1.52, } 51230\end{array}$ & $\begin{array}{c}-\$ 7.02 \\
(-\$ 9 / \$ 24)\end{array}$ \\
\hline
\end{tabular}

scenario 1 = Covenant, no use permitted, tax relief, and fee for service technical advice

scenario 2 = Covenant, no use permitted, upfront funding, free technical advice

scenario 3 = Covenant, limited use permitted, upfront funding, free technical advice

* For the figures shown in grey the variable for funding amount (Table 37) was not significant at the 5 percent level.

** The figure shown in brackets is the confidence interval

Table 39 shows that the most restrictive incentive programs are least attractive to all forest owner groups. The coefficient for compensation funding is only significant at the five percent level for CLproduction owners only.

The greatest difference between the two estimation methods can be observed for production owners and CLproduction owners, ${ }^{101}$ although the coefficient for compensation funding is only significant in the logit method. The welfare change estimated using the logit regression method is only around $\$ 29(21.57+7.02)$. Overall, the logit regression results for production owners would seem counter intuitive for a group of landowners who feel that establishing reserves will have a negative impact on production and believe that it has no beneficial environmental outcome.

\footnotetext{
${ }^{101}$ Although this is not surprising as the production owners in the latent class model were not the same production owners as in the logit model.
} 
The premise in this dissertation was that landowners have well defined preferences for incentive program attributes. These preferences are latent and the answers to both the choice and attitude questions are manifestations of those preferences. If this is true, it makes sense to use both the choice and attitude data to estimate the preferences.

The similarity in preferences for program attributes between the groups in the logit approach and the counter intuitive relative welfare implications for CLproduction owners also suggests that the latent class approach is more powerful in differentiating between the groups. After all, latent class analysis can simultaneously estimate the utility function using exogenous variables (attitudes and socio-economic characteristics) as well as choice data.

Although both approaches are straiglitforward computationaliy, the information that is inherent in the choice data and contributes to the difference between production owners and the other two groups cannot be incorporated in the logit regression method. The logit estimation may, therefore, be less informative and lack richness and thus may potentially be a less accurate model of landowner preferences for incentive program attributes. 


\section{Discussion and conclusions}

Conservation incentive programs that encourage landowners to set aside areas of privately owned forest have existed in Australia for more than two decades (Figgis 2004). Nevertheless, a comprehensive analysis of landowners' decision framework has not previously been undertaken. This dissertation provides such an analysis by combining information on the socio-economic characteristics of landowners, their attitudes and property characteristics, with incentive program choice data, within an econometric model of landowner behaviour.

Chaptcr 8 reported the results of estimating two models describing landowners' decision framework for the enrolment of forested land in conservation incentive programs using the latent class econometric technique. Chapter 9 further discusses these results with respect to the research objectives set out in Section 1.2. Specifically, it focuses on landowner preferences for incentive program attributes and the welfare implications of program design; it compares landowner preferences where entry is voluntary and forced; and it compares landowners' and program designers' perceptions of attribute importance. This chapter also focuses on a number of methodological issues and suggests direction for future research. The discussion begins with a brief summary of the latent class results for the 'forced choice' model.

\subsection{Landowner preferences for program attributes: the forced choice case}

The 'forced choice' model had high explanatory power and correctly classificd more than 80 percent of observations which is bigh when compared to other studies (e.g. Scarpa and Thiene 2004; Popper, Kroll et al. 2004; Morey, Thatcher et al. 2006). An optimal number of three latent classes, multi-objective owners, environment owners, and production owners, was determined, and separate utility functions were estimated for three landowner classes.

Landowner classes could be characterised by their attitudes to the role and outcome of establishing conservation reserves on private land as described by two principal component attitude factors (Section 8.2). The largest landowner class, multi-objective owners, believed that establishing reserves did not negatively affect farm productivity. 
In contrast, the smallest class, production owners, believed that reserve establishment negatively affected productivity. They also believed there were no positive environmental outcomes associated with establishing reserves. A third class, environment owners, believed there was a positive environmental outcome from establishing reserves (the results were reported in Table 26 ).

Landowner classes were also described by their socio-economic characteristics. Environment owners were more likely to be female; multi-objective owners were more likely to be male. A relationship was found between the size of the native forest area and participation in incentive programs. Environment owners were shown to be more likely to own larger tracts of forest than other types of landowners. The largest forest owner class, multi-objective owners, was most likely to own smaller native forest areas. Production owners were least likely and multi-objective owners were most likely to have been involved in any conservation initiatives in the past.

Separate utility functions were estimated for the three landowner classes, and results indicated that the characteristics of landowner choice differed between classes. The overall utility function was significant at the 5 percent level for all landowner classes (Table 24). The following discussion focuses on three facets of landowner choice: utility function coefficients; the relative importance of incentive program attributes; and estimated welfare measures.

Economic theory suggests that incentive programs that offer higher levels of funding will be more attractive (Section 3.2.1). Higher participation rates in programs that offer greater monetary rewards were found empirically by, for instance, Osmond and Gale (1995), Lynch, Hardie et al. (2002) and Stevens, White et al. (2002). Surprisingly, in this research, where entry was forced, compensation funding had a significant impact on program choice for environment owners only (Table 27). Compensation funding was not a driver of program choice for the other two landowner classes.

However, payment method did have a significant impact on program choice for all landowner classes. Moreover, this effect did not vary between landowner classes. All landowners preferred programs that make compensation payments available upfront rather than via tax relief. This is consistent both with the notion that landowners have a positive rate of time preference (e.g. Gallagher and Andrew 1997) and with the 
possibility that landowners place value on the "transaction" (Tversky and Kahneman 1984; Thaler 1985). That is, the transaction connects the action of setting aside an area of land and the payment for that action. Another possible explanation is that landholders did not pay enough tax to be able to take advantage of tax relief provisions.

It was expected that less restrictive programs would be more appealing to landowners. Empirical evidence reviewed in Chapter 3 confirmed that shorter commitment periods were more attractive (e.g. Esseks and Kraft 1986; Gasson and Hill 1990; Stevens, White et al. 2002; Home 2004) as they allowed landowners to retain greater flexibility in terms of succession (Eggertsson 1990). Also, more land use options were retained with less restrictive programs, reducing the opportunity cost of reservation (e.g. Wilson 1997).

Results confirm that program attributes that describe "restrictiveness" (legal arrangement and land use options) were significant determinants of choice for all three landowner classes. Both multi-objective owners and environment owners preferred programs that allowed them to keep land use options open for the future. However, production owners preferred incentive programs involving more stringent legal arrangements and allowing no alternative land use after reserve establishment. ${ }^{102}$ The results of the attitudinal survey indicated that production owners believed that reserve establishment negatively impacted productivity. Further, 80 percent of production owners believed establishing reserves would make management of their property more complex. Possibly, if forced to join a program, production owners preferred certainty of land use and permanency of legal arrangement as this allowed them to more easily incorporate the production consequences of reservation in farm plans. Production owners also favoured minimal ongoing third party involvement in management decisions regarding their property, and thus favoured programs that provide less flexibility. Even though more restrictive programs allow only "conservation uses" of the land, the outcomes are certain and require no further negotiation with incentive program staff or government officials. Another possible

\footnotetext{
102 There is a probability of 59 percent that a forest owner who chooses to implement a legally-binding covenant on their forest is a production owner. Stmilarly, there is a 63 percent chance that if full restrictions on the use of the land are accepted, this is by production owners. These probabilities are calculated on the basis of the probability means shown in Appendix 8.
} 
explanation may be that production owners preferred to "fence and forget" while other groups understood that active management was required.

Although not significant for production owners or multi-objective owners, environment owners preferred incentive programs that offer access to free technical advice. The technical knowledge necessary to manage a conservation area can be specialised and extensive. Accordingly, landowners may not have the ability to manage reserves for environmental outcomes and, once committed to a scheme, may find their current knowledge inadequate. This is supported by anecdotal evidence from existing programs where landowners are given legal and administrative assistance to establish conservation covenants. Program managers often describe landowners as being concemed about the complexities of protecting land (e.g. changing the details on the title of the land or determining the optimal management options). These factors may therefore constitute real barriers to participation in programs (Jim Mulcahy, 2006, pers. comm.). Additionally, over 70 percent of environment owners surveyed believed that establishing a reserve increases landowner understanding of the environment, hence may simply want to learn more about environmental management. Environment owners did not appear concerned about ongoing third party involvement in farm management.

Overall, there is clear evidence that program attributes do influence landowner choice behaviour in the context of forced entry. While choice behaviour was generally as expected, compensation funding seems to play a smaller role in program choice than anticipated. There is also clear evidence of significant differences in the choice behaviour of different landowner classes. In particular, only environment owners were driven in their program choice by compensation funding and free technical advice, suggesting a focus on the financial implications of incentive programs. While compensation funding was not a significant driver for production owners, they were the only class who preferred more restrictive land use and legal arrangements.

The differences between landowner classes in their preferences for program attributes can be further explored by examining the relative importance of program attributes on program choice (Figure 5). The amount of compensation funding was most important 
for environment owners, ${ }^{103}$ contributing over 95 percent to program choice. Program attributes that reflect the relative "restrictiveness" of the program together contributed less than 5 percent to their choice of program. ${ }^{104}$

Figure 5: Relative importance of program attributes by landowner class for the 3-class 'forced choice' model.

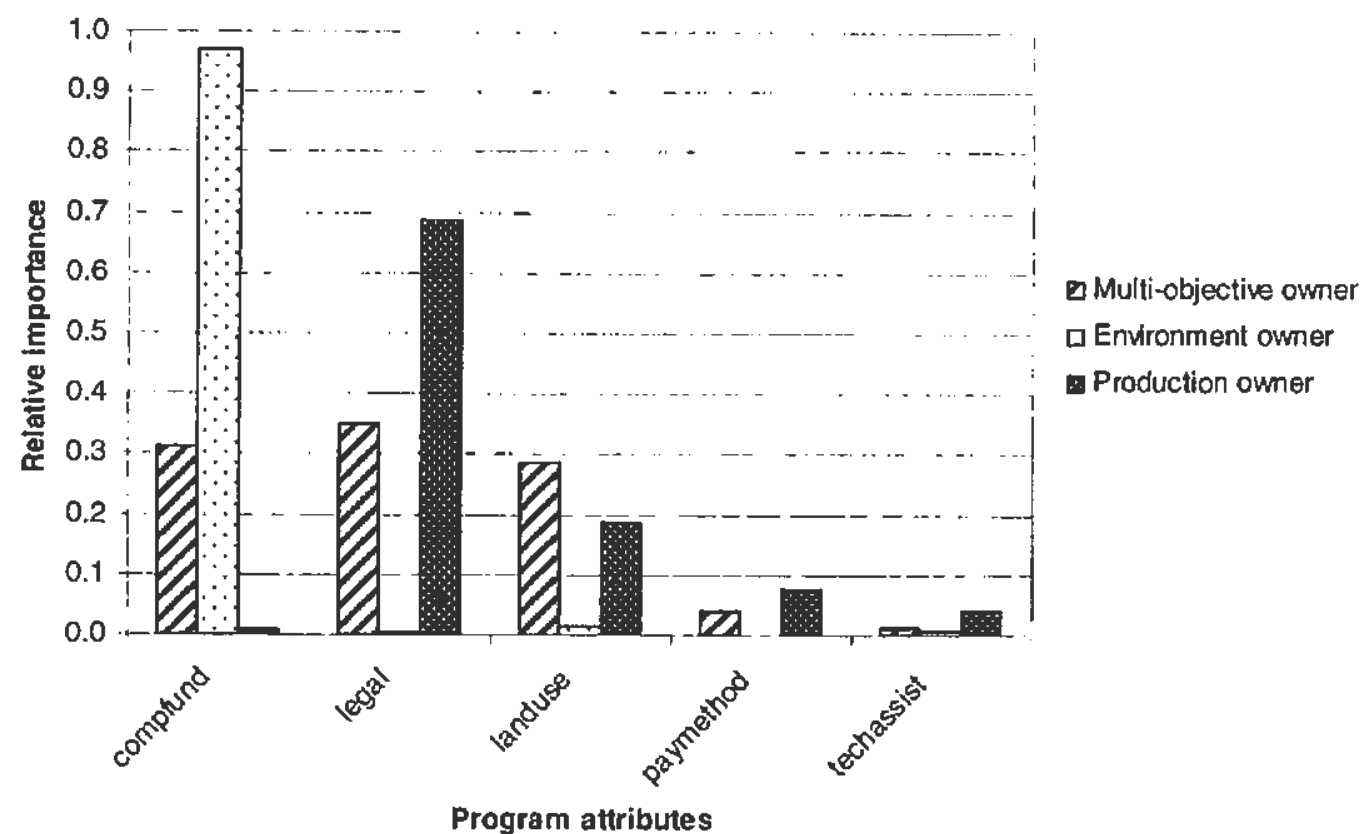

Figure 5 shows that the "restrictiveness" of the program, in particular the legal aspect, contributed almost 70 percent to production owner choice. Compensation funding contributed less than 1 percent to the choice. The legal mechanism, land use implications, and compensation funding each contributed approximately 30 percent to multi-objective owners' choice. Combined, payment method and technical advice contributed less than 10 percent to program choice for all landowner classes.

Estimated utility function coefficients (Table 27) were used to derive the welfare change in moving from a restrictive incentive program to a less restrictive incentive program (Table 33). The estimated welfare change was only significantly different to zero for environment owners. Although environment owners were driven in their

${ }^{103}$ Relative importance values are calculated on the basis of the probability means shown in Appendix 8. The relative importance is independent of the level of the attribute.

${ }^{104}$ This importance measure is similar to that measured by the BW survey, in which the attributes were ranked according to their importance. In the BW results landowners ranked the land use implications as the most important, followed by compensation funding. The legal arrangements were ranked below technical advice which was ranked third most important. These results were for all respondents and were not estimated separately for landowner attitude groups due to the small sample size. 
program choice by compensation funding, the welfare gain from moving from a restrictive program to an unrestrictive program was only $\$ 2,494$, less than half of the estimated average agricultural land value in Tasmania. This suggests that, if entry in incentive programs is forced, with relatively low amounts of compensation, environment owners are still likely to join 'restrictive' conservation programs. Although compensation funding for the other two landowner groups was not significant in their choice, the welfare gain in moving to less restrictive programs is real.

\subsection{Landowner preferences for program attributes: the voluntary case}

One of the aims of this research was to compare landowner choice behaviour in 'voluntary' and 'forced choice' scenarios (Section 1.2). This involved presenting landowners with a second choice experiment in which it was possible to elect not to join either of the programs. As with the 'forced choice' model, the three landowner classes were characterised by their attitude to the role and outcome of establishing conservation reserves. ${ }^{105}$ The estimated utility function coefficients for the 'voluntary' model were reported in Table 32 (Section 8.4.2). The utility function was significant at the 5 percent level for all landowner classes (Table 29).

When presented with the option of not joining either program, 67 percent of landowners chose not to join (Table 30). ${ }^{106}$ This may be because landowners, for a variety of reasons, are reluctant to change the basis of their land management (e.g. Morris and Potter 1995; Wynn, Crabtree et al. 2001; Hazell and Williams 2003). Of all landowner classes, environment owners were most likely to join a program. Production owners were least likely to join any program. Other studies have also found that individuals who had a strong conservation or environmental ethic are more likely to join a conservation program (e.g. Home 2004).

Table 40 shows the signs of the estimated utility function coefficients for the 'voluntary' and 'forced choice.' models.

\footnotetext{
${ }^{105}$ Atound 50 percent of respondents were classified into the same landowner group for both models. The size and attitude of the three landowner classes was similar in the two models.

${ }^{106}$ In the context of this research it represents the status quo.
} 
Table 40: The signs of the estimated utility coefficients for the 'forced choice' and 'voluntary' model (Choice survey data).

\begin{tabular}{|c|c|c|c|c|c|c|}
\hline & Multi-c & ve owners & En & $\begin{array}{l}\text { onment } \\
\text { ners }\end{array}$ & Pr & $\begin{array}{l}\text { uction } \\
\text { nets }\end{array}$ \\
\hline & Forced & Voluntary & Forced & Voluntary & Forced & Voluntary \\
\hline Compensation funding & ns & + & + & + & ns & $\mathrm{ns}$ \\
\hline Legal arrangements & - & - & - & - & + & + \\
\hline Land use options & - & - & - & - & + & - \\
\hline Payment method & - & ns & - & ns & - & ns \\
\hline Technical advice & ns & - & - & - & ns & - \\
\hline
\end{tabular}

ns $=$ not significant at the 5 or 10 percent level.

Landowner preferences for program attributes were broadly similar in the 'voluntary' and 'forced choice' models. For instance, compensation funding and legal arrangements remained significant drivers of program choice for environment owners when choice was voluntary. Production owners' preference for more restrictive legal arrangements was also consistent across models. Overall, environment owner and multi-objective owner preferences showed strong similarities in both models, and production owners remained markedly different.

However, there were a number of notable differences in the results. While compensation funding was not a significant driver of choice behaviour in the 'forced choice' scenario for multi-objective owners, results suggest that this class of landowner preferred higher levels of compensation funding when entry to programs was voluntary.

In the 'voluntary' model both the direction and magnitude of landowner preferences for land use restrictions, payment method, and technical advice did not vary between landowner classes (Table 32). All landowner classes preferred to join programs where technical assistance was provided free of charge, whereas, when enrolment was forced, technical advice was not a significant driver of choice for environment owners and production owners. In addition, although payment method did not significantly influence choice in the 'voluntary' scenario for any of the landowner classes, more flexible payment arrangements were preferred in the 'forced choice' scenario.

Environment owner and multi-objective owner preferences for less restrictive land use options did not vary between the models, however, production owner preferences differed. In the 'voluntary' scenario production owners preferred programs that retained limited use of the land; in the 'forced choice' scenario they preferred to use the reserved land exclusively for conservation purposes. 
Differences between the two models can also be observed in the relative importance of the attributes (Figure 6).

Figure 6: Relative importance of program attributes by landowner class for the 3-class 'voluntary" model.

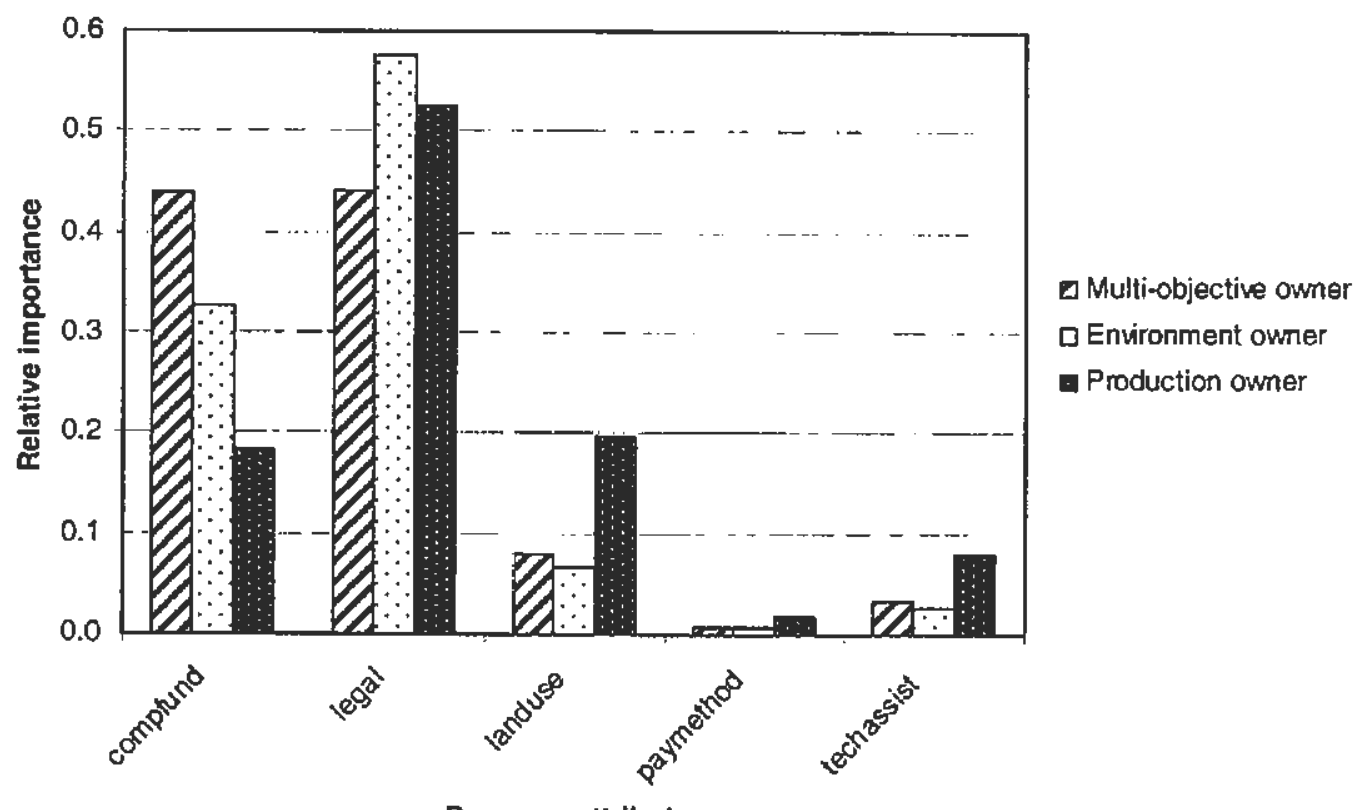

Program attributes

Overall, there was greater homogeneity between landowner classes in the relative importance of program attributes in the 'voluntary' scenario than in the 'forced choice' scenario (Figure 5). For instance, in the 'voluntary' scenario the legal implications contributed around 50 percent to the choice for all landowner classes. In the 'forced choice' scenario, the legal attribute made only a negligible contribution to the choice for environment owners. A possible explanation may be that this group assumed that being forced to join was synonymous with having legally binding restrictions, and therefore ascribed less importance to this attribute. ${ }^{107}$

A major change in the relative importance of compensation funding was observed for environment owners. When environment owners were forced to join a program, compensation funding contributed over 90 percent; in the 'voluntary' scenario this percentage fell to around 30 . In contrast, compensation funding became more important to production owners in the 'voluntary' situation.

\footnotetext{
${ }^{107}$ It may also be that the differences between the model coefficients and the importance may be due to some "psychological reaction" when placed in a situation of being forced to choose versus one where the choice is voluntary. It is beyond the scope of this current research to further speculate on this issue.
} 
In both choice scenarios, and for all landowner classes, the legal arrangements and compensation funding amount were more important to the choice than land use restrictions. Payment method and technical assistance contributed less than 10 percent to the choice in both scenarios.

Overall, the relative importance of program attributes remained largely the same for multi-objective owners. In the 'voluntary' scenario both compensation funding and the legal arrangements were equally important to environment owners. The relative importance of compensation funding and legal arrangements increased for production owners in the 'voluntary' scenario.

The estimated utility coefficients were used in Section 8.4 .3 to derive the welfare impact of different incentive program scenarios for both models (Tables 33 and 34). There is limited opportunity to compare the welfare changes between the two models for the different restrictiveness levels due to the different interpretation of the welfare change (Section 8.4.3). In the 'forced choice' model, the welfare gain from moving from a restrictive program to an unrestrictive one, for environment owners, was lower than the average agricultural land values.

In the 'voluntary choice' scenario, the $E V$ for joining a restrictive program for environment owners was also lower than the average agricultural land values in Tasmania perhaps indicating some non-monetary utility from joining. The $E V$ of joining a less restrictive program for multi-objective owners was smaller in the 'voluntary' scenario than the EV for environment owners. This inay be due to the lack of productive intentions that environment owners may have had for the land, hence experiencing relatively greater gains from more restrictive programs. Overall, for the small proportion of landowners who voluntarily joined a program the welfare losses were lower than the average agricultural land values, even though their preferences for program attributes differed.

As shown above, landowner preferences for program attributes differed when they were forced to join a program compared to a situation where choice was voluntary. The difference in landowner preferences between choice scenarios and between landowner classes will be of interest in the design of incentive programs. The implication of the results of this research for program design is the subject of the next section. 


\subsection{Concluding remarks}

One of the contributions of this dissertation was the way in which the Best-Worst (BW) survey added to the analysis. Firstly, the BW survey assisted in reducing the number of program attributes to a 'manageable' number for the subsequent Choice experiment. The ten program attributes determined by the focus group were ranked in order of importance using the $\mathrm{BW}$ approach. ${ }^{108}$ The five most important were used in the Choice survey.

Secondly, the BW survey formed the basis for testing policy makers' understanding of landowner preferences for program attributes. After all, if policy makers do not understand which program attributes are important in a landowner's decision process, poorly designed and implemented programs and promotion efforts may result. For this purpose, the BW survey was administered to both policy makers and landowners. Policy makers were asked to rate the most and least important attributes from a landowner's point of view. This allowed testing of policy makers' ability to reproduce landowner ranking of attributes.

Results indicated no statistical difference in the ranking of attributes between groups. Both landowners and policy makers ranked land use implications as most important and compensation funding amount as second most important. The only difference in ranking suggests that policy makers believed landowners gave more weight to the legal implications of joining a program than landowners revealed they did (Table 3). At least in a BW experiment, based on this it may be concluded that policy makers had a good understanding of how landowners rank program attributes.

As noted previously, most conservation incentive programs in Australia and Tasmania are based on voluntary participation (Section 2.4). However, in this research only 33 percent of landowners were willing to take up these incentives and the obligations that went with them. Low participation in voluntary programs is one reason why Tasmanian reservation targets have not been met (Resource Planning and Development Commission 2003). The results of the current research confirm that

\footnotetext{
${ }^{108}$ In this current research the design of the Choice survey, using the BW ranking approach, was not compared to what the design may have been had the traditional focus group been used. Moreover, it is not known if members of the focus group and their respective 'class membership' may have biased the relative ranking of attribute importance.
} 
relying on voluntary conservation programs may not attract sufficient participation to meet protection targets. ${ }^{109}$

Increasing the amount of compensation funding offered by incentive programs has been perceived as the main, and most direct, avenue of addressing low program uptake by landowners. This research showed that when choice is voluntary, increasing participation was best achieved by offering programs that allowed flexibility in terms of the legal arrangements and other program attributes. The WTA compensation for joining programs with this level of restrictiveness was lower than the average Tasmania land values for two of three landowner groups (around $\$ 4,500$ per hectare for environment owners and $\$ 3,000$ per hectare for multi-objective owners). This research also suggests that, when forced to enter, environment owners were the only class for whom compensation was important, and the welfare gain from having less restrictive program attributes was only small.

The results of this research also have implications for the design of conservation programs when entry is compulsory. In particular, the results suggest that welfare losses to landowners can be minimised by offering flexible schemes. Although compensation funding contributed to program choice only for environment owners, welfare gains from offering less restrictive programs were small. This landowner class appeared to be engaged in issues concerning conservation and seemed to need limited financial support, gaining more from legal and administrative assistance. Compensation was not a main driver of program choice for production owners but they differed in their preferences for the restrictiveness of the other program attributes. Production owners preferred programs that did not require them to combine conservation with productive land use and found more restrictive programs attractive.

\subsection{Recommendations for future research}

The research presented in this dissertation suggested a number of important directions for further enquiry, related to both policy and methodological objectives.

\footnotetext{
${ }^{109}$ In this it is assumed that low participation means low acreage protected. Obviously in some cases, where a small area is required for protection to meet conservation targets, 30 percent participation may be sufficient.
} 
Firstly, the focus of this research was on investigating the way in which landowners traded off incentive program attributes in the conservation incentive program choice environment. While this improved understanding of landowner choice behaviour can inform the process of program design, there is clearly a need for comprehensive benefit cost analyses of both conservation targets and specific conservation policies and programs. The research presented here has shown that conservation targets may not be achieved by relying on the voluntary uptake of conservation programs alone, and that forcing entry, perhaps through the compulsory acquisition of land of high biodiversity value, might be required. In either case, landowners may be subject to high welfare costs and the question of appropriate compensation would require further investigation. In other words, is there a net gain to society from protection?

Secondly, landowner beliefs about the role and impact of establishing conservation reserves on private land were shown to be important in determining participation and in explaining preferences for program attributes. Further research is needed to establish the way in which underlying values and general environmental attitudes help to shape these beliefs and to explore ways in which landowner beliefs can be modified, perhaps through better education and information provision about the links between reserve establishment and private and social outcomes.

The use of choice modelling to explore responses to changes in the policy environment is still quite novel. This dissertation has shown how choice modelling can be usefully applied to exploring landowners' behavioural responses to changes in the design of conservation programs. Extending the application of choice modelling for this purpose, in resource and environmental policy and in other areas, represents a third area of future research. This method may also aid in program attribute development in other disciplines, such as the health sciences. Moreover, investigation into the effect of the 'psychological reaction' to placing survey respondents in a situation of 'forced' versus 'voluntary' choice on attribute preference may provide further insights that may be relevant to many disciplines.

Fourthly, the use of a Best-Worst survey to complement the choice experiment in this research has highlighted the need for further work in understanding the evaluative processes involved in alternative stated-preference decision environments. While the attribute rankings of landowner and program designers as revealed by the $\mathrm{BW}$ 
experiment were not significantly different, landowner's ranking of attributes in the choice experiment did not mirror that of the BW.

Finally, this research has demonstrated the potential of latent class regression analysis in the context of choice of environmental programs. The results suggest that it can provide a richer interpretation of choice behaviour than more traditional estimation methods ${ }^{110}$, as was also found by Boxall and Adamowicz (2002) with respect to wilderness recreation behaviour. Future research may further establish the gains of using latent class over traditional methods.

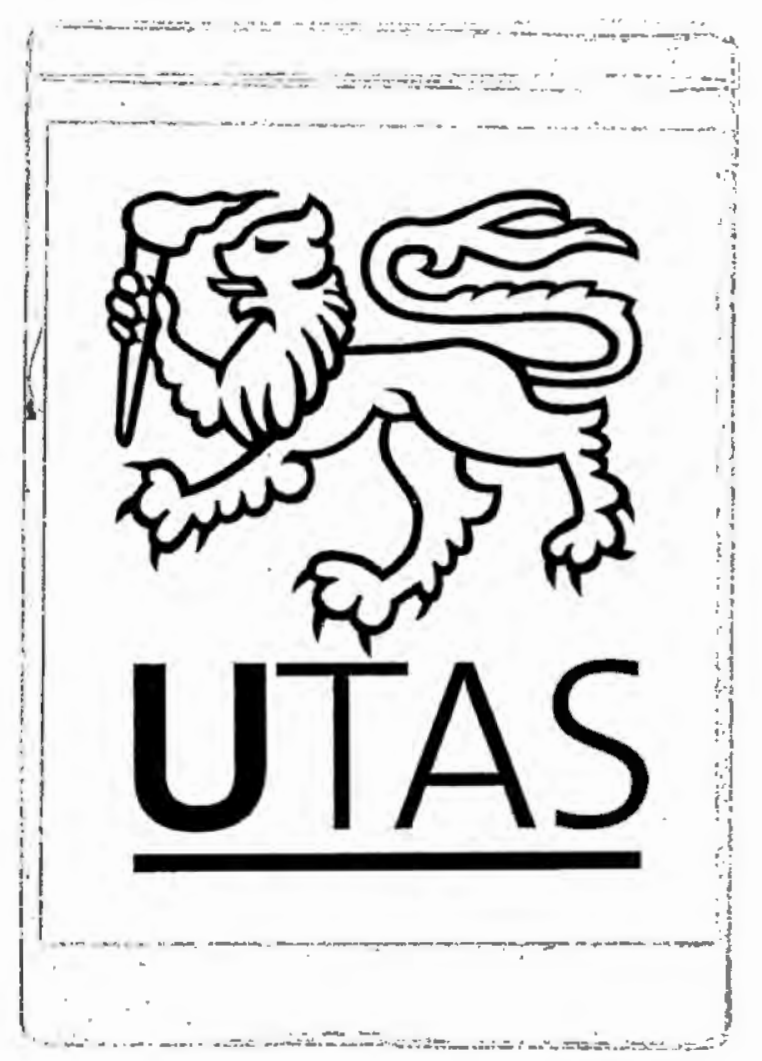

${ }^{110}$ The curiosity that the scores from the cluster analysis showed the same attitude pattern as latent class analysis, but that only about one third of the sample were classified in the landowner groups, is also worthy of further research. 


\section{References}

Action Salinity and Water Australia 2002, Investigating new approaches: A review of natural resource management pilots and programs in Australia that use market based instruments, Canberra. available on www.napswq.gov.au/publications/books/ mbi/pilot-program-review.html, viewed on 25 May 2007.

Adamowicz W., Boxall, P., Williams, M. \& Louviere J. 1998, Stated preference approaches for measuring passive use values: Choice experiments and contingent valuation, American Joumal of Agricultural Economics, vol 80, pp. 64-75.

Adamowicz W., Louviere J. \& Swait J. 1998, Introduction to attribute-based stated choice methods, final report, pp. 1-44.

Ajzen I. 2001, Nature and operation of attitudes, Annual Review of Psychology, vol. 52 , pp. 27-58.

Ajzen I., Brown T. C. \& Rosenthal L. H. 1996, Information bias in contingent valuation: effects of personal relevance, quality of information, and motivational orientation, Journal of Environmental Economics and Management, vol. 30, pp. 4357.

Anderson T. L. \& Hill P. J. 2004, The not so wild wild west: Property rights on the frontier, Stanford University Press, California.

Andreoni J. 1988, Privately provided public goods in a large economy: the limits of altruism, Journal of Public Economics, vol. 34, pp. 57-73.

Andreoni J. 1990, Impure altruism and donations to public goods: A theory of warmglow giving, Economic Joumal, vol. 100, pp. 464-477.

Aretino B., Holland P., Matysek A. \& Peterson D. 2001, Cost sharing for biodiversity conservation: A conceptual framework. Productivity Commission, Canberra.

Auger P., Devinney T. \& Louviere J. J. 2004, Consumer social beliefs: An international investigation using Best-Worst scaling methodology, Working paper. available on www.mbs.edu/index.cfm?objectid=951E3AF8-123F-A0D8425AFE7786090B56, viewed on 1 November 2007.

Australian Bureau of Statistics 1997, Environment protection expenditure, Catalogue number 4611.0, Canberra.

Australian Bureau of Statistics 2000, Agricultural Finance Survey 1999-2000, Catalogue number 7506.0, Canberra.

Australian Government 2007, What is natural resource management? Available on www.nrm.gov.au/nrm/manage.html viewed on 1 November 2007 . . 
Bates G. 2001, A duty of care for the protection of biodiversity on land. Canberra, Consultancy Report. available on www.pc.gov.au/research/consultancy/docpobol/, viewed on 1 November 2007.

Bateson P. 2001, Incentives for sustainable land management: Community cost sharing to conserve biodiversity on private lands, $A$ guide for local government, Melbourne, Australia. available on www.environment.gov.au/land/publications/ incent/index.html, viewed on 1 November 2007.

Becker G. S. 1992, The economic way of looking at life, Nobel Lecture 9 December 1992, Chicago. available on http://nobelprize.org/nobel_prizes/economics/ laureates/1992/becker-lecture.html, viewed on 1 November 2007.

Beedell J. \& Rehman T. 1999, Explaining farmers' conservation behaviour: Why do farmers behave the way they do? Journal of Environmental Management, vol. 57, pp. 165-176.

Beedell J. \& Rehman T. 2000, Using social-psychology models to understand farmers' conservation behaviour, Journal of Rural Studies, vol. 16, pp. 117-127.

Ben-Akiva M., McFadden D., Gärling T., Gopinath D., Walker J., Bolduc D., BörschSupan A., Delquié P., Larichev O., Morikawa T., Polydoropoulou A. \& Rao V. 1999, Extended framework for modelling choice behaviour, Marketing Letters, vol. 10, no. 3, pp. 187-203.

Bennett J. W. 1995, Private sector initiatives in nature conservation, Review of Marketing and Agricultural Economics, vol. 63, no. 3, pp. 426-434.

Bennett J. W. 1999, Some fundamentals of environmental choice modelling. Canberra, School of Economics and Management, University College, The University of New South Wales, Canberra, pp. 1-23.

Bijmolt T. H. A., Paas L. J. \& Vermunt J. K. 2003, Country and consumer segmentation: multi-level latent class analysis of financial product ownership, CentER Discussion Paper 2003-75, Tilburg University, The Netherlands.

Binning C. E. \& Young M. D. 1997, Motivating people: Using management agreements to conserve remnant vegetation, National R\&D Program on Rehabilitation, Management and Conservation of Remnant Vegetation, Environment Australia, Canberra, Environment Australia. available on www.lwa.gov.au/downloads/publications_pdf/PR970330.pdf, viewed on 10 May 2007.

Binning, C. E. \& Young M. D. 1999, Conservation hindered: The impact of local government rates and State land taxes on the conservation of native vegetation, Environment Australia, Canberra, National R\&D Program on Rehabilitation, Management and Conservation of Remnant Vegetation. available on www.environment.gov.au/land/publications/conserve/index.html, viewed on $10 \mathrm{May}$ 2007. 
Blamey R. K., Bennett J. W., Louviere J. J., Morrison M. D. \& Rolfe J. C. 2000, A test of policy labels in environmental choice modelling studies, Ecological Economics, vol. 32, pp. 269-286.

Blumenschein K., Blomquist G. C., Johannesson M., Horn N. \& Freeman P. 2007, Eliciting willingness to pay without bias: Evidence from a field experiment, The Economic Journal, vol. 118, no. 525, pp. 114-137.

Boxall P. C., Adamowicz W. and Tomasi T. 1996, A Nonparametric Test of the Traditional Travel Cost Model, Canadian Journal of Agricultural Economics, vol. 44, no. 2, pp. 183-193.

Boxall P. C. \& Adamowicz W. 2002, Understanding heterogeneous preferences in random utility models: A latent class approach, Environmental and Resource Economics, vol. 23, pp. 421-446.

Brotherton I. 1989, Farmer participation in voluntary land diversion schemes: Some observations from theory, Journal of Rural Studies, vol. 5, no. 3, pp. 299-304.

Bucholz K. K., Heath A. C., Reich T., Hesselbrock V. M., Krarner J. R., Nurnberger Jr. J. I. \& Schuckit M. A. 1996, Can we subtype alcoholism? A latent class analysis of data from relatives of alcoholics in a multicenter family study of alcoholism, Alcoholism: Clinical and Experimental Research, vol. 20, no. 8, pp. 1462.

Buckley P., Devinney T. \& Louviere J. J. 2004, A choice theoretic examination of foreign direct investment, Working paper. available on www2.agsm.edu.au/agsm/web.nsf/AttachmentsByTitle/FDI+4+July/\$FILE/FDI+4+Ju ly+2005.pdf, viewed on 1 November 2007 .

Burgess L. \& Street D. J. 1999, An interchange algorithm for four factor orthogonal main effect plans, Statistics and Computing, vol. 9, pp. 171-177.

Burgess L. \& Street D. J. 2005, Optimal designs for choice experiments with asymmetric attributes, Journal of Statistical Planning and Inference, vol. 134, pp. 288-301.

Burgess L. \& Street D. J. forthcoming, Optimal designs for choice experiments with asymmetric attributes, Journal of Statistical Planning and Inference.

Callan J. S. \& Thomas J. M. 2000, Environmental economics and management: theory, policy and applications, The Dryden Press, Fort Worth, USA.

Camerer C. 1999, Behavioural economics: Reunifying psychology and economics, Proceedings of the National Academy of Science, USA, Vol. 96, pp. 10575-10577.

Chan C., Laplagne P. \& Appels D. 2003, The role of auctions in allocating public resources, Productivity Commission, Melbourne.

Chisholm A. \& Dumsday R. 1988, Land degradation: Problems and policies, Cambridge University Press. 
Coase R. H. 1960, The Problem of Social Cost, Journal of Law and Economics, vol. 3, pp. 1-44.

Cochran W. G. \& Cox G. M. 1957, Experimental designs, John Wiley \& Sons Inc, New York.

Cohen J. 1969, Statistical power analysis for the behavioural sciences, Academic Press, New York.

Cohen S. H. \& Neira L. 2003, Measuring preference for product benefits across countries: Overcoming scale usage bias with Maximum Difference Scaling. ESOMAR, Latin America Conference Proceedings.

Cohen S. H. \& SHC \& Associates 2003, Maximum difference scaling: Improved measures to importance and preference of segmentation, Sawtooth Software, vol. 17.

Comerford E. \& Binney J. 2004, Choosing between incentive mechanisms for natural resource management: a practical guide for regional NRM bodies, Queensland Department of Natural Resources and Mines, Brisbane.

Commonwealth of Australia 2001, Interim report of the inquiry into the effects upon landholders and farmers of public good conservation measures imposed by Australian Governments, House of Representatives Standing Committee on Environment and Heritage.

Connor J., Ward J. \& Bryan B. 2007, Exploring the Cost Effectiveness of Land Conservation Auctions and Payment Policies, American Agricultural Economics Association (AAEA), Annual Meeting in Portland, Oregon, July 29 - August 1.

Connor J., Ward J. \& Tisdell J. n.d., Using experimental economics to design a diffuse source salinity credit trade poltcy, available on een.anu.edu.au/e05prpap/connor.pdf (viewed on 21 October 2007).

Cooper J. C. \& Keim R. W. 1996, Incentive payments to encourage farmer adoption of water quality protection practices, American Journal of Agriculiural Economics, vol. 78, pp. 54-64.

Corbett J. B. 2002, Motivations to participate in riparian improvement programs: Applying the theory of planned behaviour, Science Communication, vol. 23, no. 3, pp. 243-263.

Crase L. \& Maybery D. 2004, Personality and landholders' management of remnant bush and revegetation in the Murray Catchment, Australasian Journal of Environmental Management, vol. 11, no. 1, pp. 21-33.

Crouch G. I., Devinney T., Dolnicar S., Huybers T., Louviere J. \& Oppenwal H. 2006, Tourism and the competition for discretionary expenditure, Technical Report, CRC for Sustainable Tourism. 
CSIRO Wildlife and Ecology 2001, Motivating people: Using management agreements to conserve remnant vegetation, Consultancy Report Series CR97/0I, Canberra.

Dedrick J. P., Hall T. E., Hull I. V. \& Johnson J. E. 2000, The Forest BankTM: an experiment in managing fragmented forests, Journal of Forestry, vol. 98, no. 3, pp. 22-25.

Denys-Slee \& Associates 1998, Remnant native vegetation - perceptions and policies: A review of legislation and incentive programs, National Research and Development Program on Rehabilitation, Management and Conservation of Remnant Vegetation. available on www.environment.gov.au/land/publications/remveg/ pubs/remvegpc.pdf, viewed on 10 May 2007

Department of the Environment and Water Resources 2004, press release 2 August 2004, available on www.environment.gov.au/minister/ps/2004/psmr0laug204.html viewed on 18 May 2007.

Department of Environment and Water Resources 1992, National Strategy for Ecologically Sustainable Development, available on www.deh.gov.au/esd/national/nsesd/strategy viewed on 25 July 2006.

Department of Environment and Water Resources 2006 Biodiversity incentives, available on www.environment.gov.au/biodiversity/incentives viewed on 18 May 2007.

Department of Environment and Water Resources 2007, National reserve system program, available on www.environment.gov.au/parks/nrs/program/apply.html viewed on 18 May 2007.

Department of the Environment, Sport and Territories - Biodiversity Unit n.d., Australia's Biodiversity: an overview of selected significant components, Biodiversity Series, no. 2, Canberra.

Department of the Environment and Heritage n.d., Work in progress: Australia's commitment to the environment, available on www.environment.gov.aw/ about/publications/commitment/pubs/commitment.pdf viewed on 18 May 2007

Department of Primary Industries and Water - Threatened Species Section 2007, available on www.dpiw.tas.gov.au/inter.nsf/ ebPages/SJON-58E2VD?open viewed on 18 May 2007.

Department of Primary Industries and Water 2007, Managing Natural Resources, available on www.dpiw.tas.gov.au/inter.nsf/ WebPages/SSKA-6B56K5?open viewed on 18 May 2007.

Department of Primary Industries and Water n.d., available on www.dpiw.tas.gov.au/inter.nsf/Attachments/LJEM73246E/\$FILE/Review\%20and\%2 0Evaluation\%200f\%20PFRP.pdf viewed on 18 May 2007. 
Department of Sustainability and Environment 2005, Land for wildlife, available on www.dpi.vic.gov.au/DSE/nrenpa.nsf/LinkView/34933B99F789EF0E4A25677800115 944BA15AEEDADB3CA6C4A2567D600824A6C viewed on 18 May 2007.

Department of Sustainability and Environment 2007, Bush tender, available on www.dpi.vic.gov.au/DSE/nrence.nsf/LinkView/15F9D8C40FE51BE64A256A72007 E12DC8062D358172E420C4A256DEA0012F71C, viewed on 25 October 2007.

DeShazo J. R. \& Fermo G. 2002, Designing choice sets for stated preference methods: the effects of complexity on choice consistency, Journal of Environmental Economics and Management, vol. 44, pp. 123-143.

Dillman D. A. 1978, Mail and telephone surveys: the total design method, John Wiley and Sons, New York.

Doremus H. 2003, A policy portfolio approach to biodiversity protection on private lands, Environmental Science and Policy, vol. 6, pp. 217-232.

Drake L., Bergström P. \& Svedsäter H. 1999, Farmers' attitudes and uptake. countryside stewardship: Farmers, policies, and markets, in G. V. Huylenbroeck and M. Whitby (eds). Oxford, UK, Pergamon: 89-111.

Drost D., Long G., Wilson D., Miller B. \& Campbell W. 1996, Barriers to adopting sustainable agricultural practices, Journal of Extension, vol. 34, no. 6.

Dunlap R. E. \& van Liere K. D. 1978, The "New Environmental Paradigm": a proposed measuring instrument and preliminary results, The Journal of Environmental Education, vol. 9, pp. 10-19.

Dupraz P., Vanslembrouck I., Bonnieux F. \& van Huylenbroeck G. 2003, Farmers' participation in European agri-environmental policies, $10^{\text {th }}$ Congress of the European Association of Agricultural Economists, Zaragoza, Spain.

Earnhart D. 2002, Combining revealed and stated data to examine housing decisions using discrete choice analysis, Journal of Urban Economics, vol. 51, pp. 143-169.

Economic Focus 1998, The benevolence of self-interest, The Economist.

Eggertsson T. 1990, Economic Behaviour and Institutions, Cambridge University Press, Cambridge.

Environment Protection Authority 2002, Green offsets for sustainable development, Sydney, New South Wales, Environment Protection Agency, available on www.environment.nsw.gov.au/greenoffsets/index.htm viewed on 16 May 2007.

Erickson D. L., Ryan R. L. \& De Young R. 2002, Woodlots in the rural landscape: landowner motivations and management attitudes in a Michigan (USA) case study, Landscape and urban Planning, vol. 58, pp. 101-112. 
Ervin C. A. \& Ervin D. E. 1982, Factors affecting the use of soil conservation practices: Hypotheses, evidence, and policy implications, Land Economics, vol. 58, no. 3 , pp. 276-292.

Esseks J. D. \& Kraft S. E. 1986, Landowner views of obstacles to wider participation in the conservation reserve program, Journal of Soil and Water Conservation, November-December, pp. 410-414.

Farber S. \& Griner B. 2000, Valuing watershed quality improvements using conjoint analysis, Ecological Economics, vol. 34, pp. 63-76.

Farrara S., Ryana M., Donald R. \& Ludbrooka A. 2000, Using discrete choice modelling in priority setting: an application to clinical service developments, Social Science and Medicine, vol. 50, pp. 63-75.

Figgis P. 2004, Conservation on private lands: The Australian experience, IUCN, Gland Switzerland, available on www.ies.unsw.edu.au/current/Research\%20Papers/ PhillipsFINAL.doc, viewed on 5 November 2007.

Finn A. \& Louviere J. J. 1992, Determining the appropriate response to evidence of public concern: the case of food safety, Journal of Public Policy and Marketing, vol. 11 , no. 1, pp. 12-25.

Flynn T. N., Louviere J. J., Peters T. J. \& Coast J. unpublished, Best-worst scaling: What it can do for health care and how to do it, Submitted to the Journal of Health Economics, vol. 18 .

Force D. \& Bills N. 1989, Participation in the CRP: Implications of the New York experience, Journal of Soil and Water Conservation, September-October, pp. 512516.

Fransson N. \& Gärling T. 1999, Environmental concern: conceptual definitions, measurement methods, and research findings, Journal of Environmental Psychology, vol. 19, pp. 369-382.

Frykblom P. \& Shogren J. F. 2000, An experimental testing of anchoring effects in discrete choice questions, Environmental and Resource Economics, vol 16, pp. 329341.

Fujii S. \& Gärling T. 2003, Application of attitude theory for improved predictive accuracy of stated preference methods in travel demand analysis, Transportation Research Part A, vol. 37, pp. 389-402.

Gallagher T. J. \& Andrew J. D. 1997, Financial Management: Principles and Practice, Prentice-Hall, Inc.

Gärling T., Gillholm R. \& Gärling A. 1998, Reintroducing attitude theory in travel behaviour research, Transportation, vol. 25, pp. 129-146. 
Gasson R. \& Hill P. 1990, An economic evaluation of the farm woodland scheme, Farm Business Unit Occasional Paper, no 17, Department of Agricultural Economics, Wye College,

Gasson R. \& Potter C. 1988, Conservation through land diversion: a survey of farmers' attitudes, Journal of Agricultural Economics, vol. 39, no. 3, pp. 340-351.

Gilfedder L. \& Kirkpatrick J. 1995, A survey of landholder attitudes and intentions towards the long term conservation of native lowland grasslands, Canberra, Australian Nature Conservation Agency.

Gilfedder L. \& Kirkpatrick J. 1997, The influence of owners intentions on remnant bush conservation in Tasmania, Conservation Outside Nature Reserves, Centre for Conservation Biology, The University of Queensland.

Green W. H. 2003, Econometric analysis, Prentice Hall, New Jersey.

Greer T. V., Chuchinprakam N. \& Seshadri S. 2000, Likelihood of participating in mail survey research, Industrial Marketing Management, vol. 29, pp. 97-109.

Greiner R., Herr A. \& Stoeck1 N. 2003, Policies aimed at overcoming impediments to the implementation of on-farm conservation activities, $4^{\text {dh }}$ BioEcon Workshop on the Economics of Biodiversity Conservation, Venice.

Gujarati D. N. 1988, Basic Econometrics, McGraw-Hill Book Company.

Gunningham N. \& Young M. D. 2001, Redesigning environmental regulation: the case of biodiversity conservation, Environmental Law Alliance Worldwide, available at www.elaw.org/resources/text.asp?id=705 viewed on 18 May 2007.

Hanemann W. M. 1982, Applied welfare analysis with qualitative response models, Working Paper No 241, University of Califomia, Berkeley.

Harman H. H. 1967, Modern factor analysis, University of Chicago Press, Chicago.

Hartigan J. A. 1975, Clustering algorithms. John Wiley \& Sons, New York.

Hazell D. \& Williams M. 2003, Development of guidelines for the delivery of conservation incentives by regional organisations, Workshop Summary 21-22 July 2003, Adelaide, South Australia available on www.environment.gov.au/land/publications/incentives-qld/index.html viewed on 18 May 2007.

Hearne R. R. \& Salinas Z. M. 2002, The use of choice experiments in the analysis of tourist preferences for ecotourism development in Costa Rica, Journal of Environmental Management, vol. 65, pp. 153-163.

Hensher D. \& Greene W. H. 2003a, The mixed logit model: The state of practice, Transportation, vol. 30, pp. 133-176. 
Hensher D. \& Greene W. H. 2003b, A latent class model for discrete choice analysis: contrasts with mixed logit, Transportation Research Part B, no. 37, pp. 681-698.

Hensher D., Stopher P. R. \& Louviere J. J. 2001, An exploratory analysis of the effect of numbers of choice sets in designed choice experiments: an airline choice application, Journal of Air Transport Management, vol. 7, pp. 373-379.

Hensher D. A. \& Sullivan C. 2003, Willingness to pay for road curviness and road type., Transportation Research Part D, vol. 8, no. 2. Sydney, Transport and Environment, pp. 139-155.

Hillyer A. \& Atkins J. 2000, Greening your Title: A guide to best practice for conservation covenants, Information Sheet, available on www.wcel.org/wcelpub/2000/13247.pdf viewed on 18 May 2007.

Horne P. 2004, Forest owners' acceptance of incentive based policy instruments in forest biodiversity conservation - A choice experiment approach, AARES Conference, Melbourne, 11 - 13 February 2004.

Horne, P., Boxall, P. C. \& Adamowicz, W. 2005, Multiple use management of forest recreation sites: Spatially explicit choice experiment, Forest Ecology and Management, vol 207, pp. 198-199.

IUCN World Conservation Union, 1999, Species: Unprecedented extinction rate and it's increasing, available on www.iucn.org/en/news/archive/2001_2005/press/ species2000.html, viewed on 21 October 2007.

James D. 1997, Environmental incentives: Australian experience with economic instruments for environmental management, Ecoservices Pty Ltd for Environment Australia, Canberra.

Jenkins C. R. \& Dillman D. A. 1995, Towards a theory of self-administered questionnaire design: Survey measurement and process quality, in L. Lyberg, P. Biemer, M. Collins et al. (eds), Wiley-interscience, New York.

Jennings S. \& van Putten E. I. 2001, Modelling forest owner behaviour in north west Tasmania using a binary logit analysis, CRC for Sustainable Production Forestry, Hobart.

Jennings S. \& van Putten E. I. 2003, Objectives of non-industrial private forest owners in Tasmania, CRC for Sustainable Production Forestry, Hobart.

Jennings S. \& van Putten E. I. 2006, Typology of non-industrial private forest owners in Tasmania, Small-scale Forest Economics, Management and Policy, vol. 5, no. 1, pp. 37-56.

Jennings S. \& van Putten E. I. unpublished, Modelling forest owner behaviour in Tasmania, CRC for Sustainable Production Forestry, Hobart. 
Jobber D., Birro K. \& Sanderson S. M. 1988, A factorial investigation of methods of stimulating response to a mail survey, European Journal of Operational Research, vol. 37 , pp. 158-164.

Johnston R. J., Swallow S. K. \& Weaver T. F. 1999, Estimating willingness to pay and resource tradeoffs with different payment mechanisms: An evaluation of a funding guarantee for watershed management, Journal of Environmental Economics and Management, vol. 38, pp. 97-120.

Kabii T. 2004, Influences on the uptake of covenant mechanisms for nature conservation on private lands in Australia, Faculty of Communications, Health and Science. Perth, $\mathrm{PhD}$ thesis, Edith Cowan University.

Kahn J. R. 1995, The economic approach to environmental and natural resources, The Dryden Press, Fort Worth, USA.

Kahneman D. \& Tversky A. 1979, Prospect theory: An analysis of decision under risk, Econometrica, vol. 47, pp. 263-292.

Kahneman D. \& Tversky A. 1984, Choices, values, and frames, The American Psychologist, vol. 39, pp. 341-350.

Kahneman D \& Knetsch J. L. 1992, Valuing public goods: The purchase of moral satisfaction, Journal of Environmental Economics and Management, vol 22, pp. 5770 .

Kaiser F. G., Wölfing S. \& Fuhrer U. 1999, Environmental attitude and ecological behaviour, Journal of Environmental Psychology, vol. 19, pp. 1-19.

Kaiser H. 1958, The varimax criterion for varimax rotation in factor analysis, Psychometrica, vol. 23, pp. 187-200.

Kalifatix S. P. \& Tsogas M. H. 1994, Impact of the inclusion of an article as an incentive in industrial mail surveys, Industrial Marketing Management, vol. 23. pp. 137-143.

Kamppinen M. 1997, Cultural models of risk, Turku, Finland, Finland Futures Research Centre, Turku School of Economics and Business Administration.

Kamppinen M. \& Walls M. 1999, Integrating biodiversity into decision making, Biodiversity and Conservation, vol. 8, pp. 7-16.

Kaplan R. 1984, Human needs for renewable resources and supportive environments. land use and forest resources in a changing environment: the urban-Forest Interface, in G. A. Bradley. University of Washington Press, Seattle.

Keane M. P. 2004, Modelling health insurance choice using the heterogeneous logit model, Lecture presented at the Centre for Health Economics Research and Evaluation (CHERE), 24 June 2004, the University of Technology, Sydney. 
Kerr G. N. \& Sharp B. M. H. 2004, Lost streams: Offsite mitigation evaluation using choice modelling, Australian Agricultural and Resource Economics Society, Melbourne.

Kline J. D., Alig, R. J. \& Johnson, R. L. 2000, Forest owner incentives to protect riparian habitat, Ecological Economics, vol. 22, pp. 29-43.

Klosowski R., Stevens T., Kittredge D. \& Dennis D. 2001, Economic incentives for coordinated management of forest land: a case study of southern New England, Forest Policy and Economics, vol. 2, pp. 29-38.

Kraft S. E., Lant C. \& Gillman K. 1996, WQIP: An assessment of its chances for acceptance, Journal of Soil and Water Conservation, vol. 51, no. 6, pp. 494-450.

Krosnick J. A. 1999, Survey research, Annual Review of Psychology, vol. 50, pp. 537567.

Kruskal J. B. \& Wish M. 1978, Multidimensional Scaling, Sage Publications, Beverly Hills, California.

Kuuluvainen J., Karppinen H. \& Ovaskainen V. 1996, Landowner objectives and nonindustrial private timber supply, Forest Science, vol. 42, no. 3, pp. 300-309.

Lancaster K. 1971, Consumer demand: a new approach, Columbia University Press, New York.

Lancaster K. 1991, Modern consumer theory, Edward Elgar Publishing Limited, Aldershot, England.

Lee B. J, Fujiwara A., Zhang J. \& Sugie Y. 2003, Analysis of mode choice behaviours based on latent class models, $10^{\text {th }}$ International Conference on Travel Behaviour Research, 10-15 August 2003, Lucerne.

Lerch A. 1998, Property rights and biodiversity, European Journal of Law and Economics, vol. 6, pp. 285-304.

Likert R. 1932, A Technique for the Measurement of Attitudes, McGraw-Hill, New York.

Lilien G. L. \& Kotler P. 1983, Marketing decision making: A model building approach, Harper \& Row, New York.

Loftus T. T. \& Kraft S. E. 2003, Enrolling conservation buffers in the CRP, Land Use Policy, vol. 20, pp. 73-84.

Louviere J. J. 1991, Best-worst scaling: A model for the largest difference judgements, Working paper, University of Alberta, Alberta, Canada. 
Louviere J. J. 1994, Conjoint analysis, Advanced methods of marketing research, in R. P. Bagozzi, Blackwell Publishers, Cambridge, USA.

Louviere J. J., Burgess L., Street D. \& Marley A. A. J. 2004, Modelling the choices of single individuals by combining efficient choice experiment designs with extra preference information. Centre for the Study of Choice (CenSoC), University of Technology, Sydney.

Louviere J. J., Hensher D. A. \& Swait J. D. 2000, Stated choice methods: Analysis and application, Cambridge University Press, Cambridge.

Louviere J. J. \& Towhidul I. 2004, A comparison of importance weights/measures derived from choice-based conjoint, constant sum scales and best-worst scaling, The Centre for the Study of Choice, pp. 1-19.

Luzar E. J. \& Diagne A. 1999, Participation in the next generation of agriculture conservation programs: the role of environmental attitudes, Journal of SocioEconomics, vol. 28, pp. 335-349.

Lynch L., Hardie, I. \& Parker D. 2002, Analyzing agricultural landowners' willingness to install streamside buffers, Working Paper 02-01, Department of Agricultural and Resource Economics, The University of Maryland, College Park.

Lynne G. D., Shonkwiler J. S. \& Rola L. R. 1988, Attitudes and farmer conservation behaviour, American Journal of Agricultural Economics, vol. 70, no. 1-2, pp. 12-19.

Lynne G. D., Shonkwiler J. S. \& Wilson M. E. 1991, Water permitting behaviour under the 1972 Florida Water Resources Act, Land Economics, vol. 67, no. 3, pp. 340-351.

Magidson J., Eagle, T., \& Vermunt J. K. n.d., New developments in latent class choice models, available on www.statisticalinnovations.com/articles/choice_developments.pdf viewed on 16 May 2007.

Magidson J. \& Vermunt J. K. n.d., A nontechnical introduction to latent class models, available on www.statisticalinnovations.com/articles/ lcmodels2.pdf viewed on 8 October 2006.

Mallawaarachchi T., Blamey R. K., Morrison M. D., Johnson A. K. L. \& Bennett J. W. 2001, Community values for environmental protection in a cane farming catchment in Northern Australia: A choice modelling study, Journal of Environmental Management, vol. 62, pp. 301-316.

Marley A. A. J. \& Louviere J. J. 2005, Some probabilistic models of Best, Worst, and Best-Worst choices, Journal of Mathematical Psychology, vol. 49, pp. 464-480.

Mazzotta M. J. \& Opaluch J. J. 1995, Decision making when choices are complex: a test of Heiner's hypothesis, Land Economics, vol. 71, no. 4, pp. 500-515. 
McCutcheon A. 1987, Sexual morality, pro-life values, and attitudes toward abortion - a simultaneous latent structure analysis for 1978-1983, Sociological Methods and Research, vol. 16, no. 2, pp. 256-275.

McFadden D. 1974, Conditional logit analysis of qualitative choice behaviour, in Zarembka, P. Frontiers in econometrics, Academic Press, New York, pp. 105-142.

McFadden D. 1981, Econometric models of probabilistic choice. Structural analysis of discrete data with econometric applications, in C. Manski \& McFadden D., MIT press, Cambridge, Mass, pp. 198-272.

McFadden D. 1986, The choice theory approach to market research, Marketing Science, vol. 5, pp. 275-297.

McFarlane B. L. \& Boxall P. C. 2003, The role of social psychological and social structural variables in environmental activism: an example of the forest sector, Journal of Environmental Psychology, vol. 23, pp. 79-87.

Merchant C. 1992, Radical ecology: The search for a liveable World, Routledge, New York.

Mood A. M., Graybill F. A. \& Boes P. C. 1974, Introduction to the theory of statistics, McGraw-Hill.

Morey E., Thatcher J. \& Breffle W. 2006, Using angler characteristics and attitudinal data to identify environmental preference classes: A latent-class model, Environmental and Resource Economics, vol. 34, no. 1, pp. 91-115.

Morrison M. D., Blamey R. K., Bennett J. W. \& Louviere J. J. 1996, A comparison of stated preference techniques for estimating environmental values, The University of New South Wales, Canberra.

Mortimer D. 2003, The Landcare revolving loan fund: A development report, Rural Industries Research and Development Corporation Publication, no. 03/035, Canberra.

Mountford H. \& Keppler J. H. 1999, Financing incentives for the protection of biodiversity, The Science of the Total Environment, vol. 240, pp. 133-144.

Mulaik S. A. 1972, The foundations of factor analysis, McGraw-Hill Inc.

Murphy J. J., Allen P. G., Stevens T. H. \& Weatherhead D. 2005, A meta-analysis of hypothetical bias in stated preference valuation, Environmental and Resource Economics, vol. 30, pp. 313-325.

Murphy J. J., Stevens T. H. \& Weatherhead D. 2005, Is cheap talk effective at eliminating hypothetical bias in a provision point mechanism? Environmental and Resource Economics, vol 30, pp. 327-343. 
Murray-Prior R. 1998, Modelling farmer behaviour: a personal construct theory interpretation of hierarchical decision models, Agricultural Systems, vol. 57, no. 4, pp. 541-556.

Nahan M. 1999, Property Rights and Regulatory Takings, keynote address, WA PGA's Property Rights Conference, 25 June 1999, Mandurah.

Nancarrow C. \& Brace I. 2000, Saying the "right thing": Coping with social desirability bias in marketing research, Bristol Summer School Teaching and Review. Bristol, University of Western England available on www.uwe.ac.uk/bbs/trr/Issue3/Is3-2_2.htm viewed on 16 May 2007.

Nature Conservation Branch 2000, Threatened Species Strategy, Department of Primary Industries, Water and Environment, Hobart, Tasmania.

Osmond D. L. \& Gale J. A. 1995, Farmer participation in solving the nonpoint source pollution problem: The rural clean water program experience, North Carolina State University College of Agricultural \& Life Sciences, North Carolina State University, Raleigh.

Parks, P. J. \& Schorr J. P. 1997, Sustaining open space benefits in the Northeast: An evaluation of the Conservation Reserve Program, Journal of Environmental Economics and Management, vol. 32, pp. 85-94.

Pindyck R. S. \& Rubinfeld D. L. 1998, Econometric models and economic forecasts. Ed. 2, McGraw-Hill, New York.

Plantinga A. J., Alig R. \& Cheng H. 2001, The supply of land for conservation uses: evidence from the conservation reserve program, Resources, Conservation and Recycling, vol. 31, pp. 199-215.

Popper R., Kroll J. \& Magidson J. 2004, Application of latent class models to food product development: a case study, Sawtooth Software Conference Proceedings, available on www.statisticalinnovations.com/products/popper.pdf, viewed on 5 November 2007.

Praag, van B. M. S. 1968, Individual welfare functions and consumer behaviour: A theory of rational irrationality, Amsterdam, North-Holland Publishing Company.

Private Forests Tasmania 2006, available on http://www.privateforests.tas.gov.au viewed on 18 May 2007.

Productivity Commission 2001, Constraints on private conservation of biodiversity: Some challenges in managing Australia's tropical rainforests, Annual Conference of the Rainforest Cooperative Research Centre, 14- 15 November 2001, Cairns.

Protected Areas on Private Land Program 2003, Nature conservation on private land in Tasmania: A guide to programs and incentives, Lepartment of Primary Industries, Water and Environment, Hobart. 
Provencher B., Baerenklau K. A. \& Bishop R. C. 2002, A finite mixture logit model of recreational angling with serially correlated random utility, American Journal of Agricultural Economics, vol. 84, no. 4, pp. 1066-1075.

Provencher B. \& Moore R., 2006, A discussion of "Using Angler characteristics and attitudinal data to identify environmental preference classes: A Latent-Class Model" Environmental and Resource Economics, vol. 34, pp. 117-124.

Public Land Use Commission 1996, Inquiry into areas to be reserved under the Tasmanian-Commonwealth Regional Forest Agreement, Tasmanian Public Land Use Commission, Hobart.

Purvis A., Hoehn J. P., Sorenson V. L. \& Pierce F. J. 1989, Farmers' response to a filter strip program: Results from a contingent valuation survey, Journal of Soil and Water Conservation, vol. 44, no. 5, pp. 501-504.

Rolfe J. C. \& Bennett, J. W. 1996, Valuing International Rainforests: A Choice Modelling Approach, Vanuatu Forest Conservation Research Report No. 12, School of Economics and Management, The University of New South Wales, Canberra.

Rolfe J. C., Bernett J. W. \& Blamey R. K. 2000, An economic evaluation of broadscale tree clearing in the desert uplands region of Queensland, School of Economics and Management, University College, The University of New South Wales, Canberra, pp.1-22.

Rolfe J. C. \& Windle J. 2003, Valuing the protection of Aboriginal cultural heritage sites, Economic Record, vol. 79, pp. 585-595.

Ruijgrok E., Vellinga P. \& Goosen H. 1999, Dealing with nature, Ecological Economics, vol. 28, pp. 347-362.

http://en.wikipedia.org/wiki/Public good - ref-1Samuelson P. A. 1954, The Pure Theory of Public Expenditure, Review of Economics and Statistics, vol. 36, no. 4, pp. 387-389.

Sawtooth-Software 2002, Adaptive Conjoint Analysis, Sawtooth software viewed on 16 May $2007 \mathrm{http}: /$ www.sawtoothsoftware.com/techpap.shtml.

Scanlan J. C., Prinsley R., Pigott J. P., Wakefield S., van der Sommen F., Duncan F., Stadler T., McLellan R., \& Farago A. 1992, Retention of native woody vegetation on farms in Australia: Management considerations, planning guidelines and information gaps, Agroforestry Systems, vol. 20, pp. 141-166.

Scarborough H., Bennett J. W. \& Carr R. 2004, Using choice modelling to investigate equity preferences, AARES Conference, Melbourne, 11 - 13 February 2004.

Scarpa R., Drucker S., Anderson N., Ferraes-Ehuan V., Gomez C. R., Risopatrol R. \& Rubio-Leonel O. 2003, Valuing animal genetic resources in peasant economies: the case of the Box Keken creole pig in Yucatan, Ecological Economics, vol. 45, no. 3, pp. 427-443. 
Scarpa R. \& Thiene M. 2004, Destination Choice Models for rock climbing in the Northeast Alps: A latent class approach based on intensity of preferences, Land Economics, vol. 81, no. 3, pp. 426-444.

Schaberg R. H., Holmes T. P., Lee K. J. \& Abt R. C. 1999, Ascribing value to ecological processes: an economic view of environmental change, Forest Ecology and Management, vol. 114, pp. 329-338.

Scherer C. W. 1990, Communicating water quality risk, Journal of Soil and Water Conservation, March-April, pp. 198-200.

Schrader C. C. 1995, Rural greenway planning: the role of streamland perception in landowner acceptance of land management strategies, Landscape and urban Planning, vol. 33, pp. 375-390.

Schroeder H. W. \& Louviere J. J. 1999, Stated choice models for predicting the impact of user fees at public recreation sites, Journal of Leisure Research, vol. 31, no. 3 , pp. 300 .

Schultz W. P. \& Zelezny L. 1999, Values as predictors of environmental attitudes: evidence for consistency across 14 countries, Journal of Environmental Psychology vol. 19 , pp. 255-265.

Scott A., Watson S. M. \& Ross S. 2003, Eliciting preferences of the community for out of hours care provided by general practitioners: A stated preference discrete choice experiment, Social Science and Medicine, vol. 56, no. 4, pp. 803.

Sinden J. A. \& King D. A. 1990, Adoption of soil conservation measures in Manilla Shire, New South Wales, Review of Marketing and Agricultural Economics, vol. 58, no. 2, 3, pp. 179-192.

Skerratt S. J. 1994, Itemized payment systems within a scheme: the case of Breadalbane, in M. and M. Whitby, Incentives for Countryside Management: The Case of Environmentally Sensitive Areas, Wallingford, CABI.

Slovic P. 1987, Perception of risk, Science, vol. 236, pp. 280-285.

Smith S. 2001, Get paid to keep your native forests! - a unique program provides financial incentives to landowners for conservation covenants to protect the most important forests on private land, National Forum - Taking Care of the Bush: Nature Conservation on Private Land, Western Australia, National Trust of Australia Western Australia.

Söderqvist T. 2003, Are farmers prosocial? Determinants of the willingness to participate in a Swedish catchment-based wetland creation program, Ecological Economics, vol. 47, pp. 105-120.

Soule M. E. 1991, Conservation: Tactics for a Constant Crisis, Science vol. 253, pp. 744-750. 
Soule M. J., Tegene A. \& Wiebe K. D. 2000, Land Tenure and the Adoption of Conservation Practices, American Journal of Agricultural Economics, vol. 82, no. 4, pp. 993.

Steel B. S. 1996, Thinking globally and acting locally?: Environmental attitudes, behaviour and activism, Journal of Environmental Management, vol, 47, pp. 27-36.

Stephens S. 2001, Update of Voluntary Conservation Schemes for Nature Conservation on Private Land in Australia, Bush for Wildlife Information Sheet.

Stern P. C. \& Dietz T. 1994, The value basis of environmental concern, Journal of Social Issues, vol. 50, no. 3, pp. 65-84.

Stevens T. H., Belkner R., Dennis D., Kittredge D. \& Willis C. 2000, Comparison of contingent valuation and conjoint analysis in ecosystem management, Ecological Economics, vol. 32, pp. 63-74.

Stevens T. H., White S, Kittredge D. B. \& Dennis D. 2002, Factors affecting NIPF landowner participation in management programs: a Massachusetts case study, Journal of Forest Economics, vol. 8, pp. 169-184.

Stewart W. P., Anderson B. S., Fesenmaier D. R. \& Lue C. 1993, Highway Welcome Center surveys: Problems with nonresponse bias, Journal of Travel Research, vol. 31, no. 3 , pp. 53-57.

Stoneham G., Crowe M., Platt S, Chaudri V., Soligo J. \& Strappazzon L. 2000, Mechanisms for biodiversity conservation on private land, Natural Resources and Environment, Victoria.

Stoneham G., Chaudhri V., Strappazzon L. \& Ha A. 2002, Auctions for conservation contracts: an empirical examination of Victoria's BushTender Trial. Paper presented to the Australian Agricultural and Resource Economics Society Conference, Canberra.

Strauss A. 1945, The Concept of Attitude in Social Psychology, Journal of Psychology, vol. 19. pp. 329-339.

Sullivan P. F., Kessler R. C. \& Kendler K. S. 1998, Latent class analysis of lifetime depressive symptoms in the National comorbidity survey, American Journal of Psychiatry, vol. 155, pp. 1398-1406.

Swait J. 1994, A structural equation model of latent segmentation and product choice for cross-sectional revealed preference choice data, Journal of Retailing and Consumer Services, vol, 1, pp. 77-89.

Thaler R. H. 1985, Mental accounting and consumer choice, Marketing Science, vol. 4, pp. 199-214. 
Thackway R. \& Cresswell I. D. 1995, An interim biogeographic regionalisation for Australia: A framework for establishing the national system of reserves, Australian Nature Conservation Agency, Canberra.

Thackway R. \& Olsson K. 1999, Public/private partnerships and protected areas: selected Australian case studies, Landscape and Urban Plaming, vol. 44, pp. 87-97.

Thatcher J., Morey E. \& Craighead E. 2003, Using patient characteristics and attitudinal data to identify treatment preference groups: a latent-class model, Department of Economics, Working Paper, University of New Mexico.

Thurstone L. L. 1927, A law of comparative judgment, Psychological Review, vol. 34, pp. 273-286.

Thurstone L. L. 1959, The measurement of valtues, The University of Chicago Press, Chicago.

Tisdell C. \& Harrison S. R. 1999, Compensation for the taking of natural resource interests: Principles and practices in recent Queensland cases, Australian Joumal of Environmental Management, vol. 6, no. 2, pp. 99-108.

Tversky A. \& Kahneman D. 1974, Judgement under uncertainty: Heurristics and biases, Science, vol. 185, pp. 1124-1131.

Tversky A., Slovic P. \& Kahneman D. 1990, The causes of preference reversal, The American Economic Review, vol. 80, no. 1, pp. 204-217.

Tyagi P. K. 1989, The effects of appeals, anonymity and feedback on mail survey response patterns from salespeople, Journal of the Academy of Marketing Science, vol. 17, pp. 234-241.

United Nations Environment Program n.d., Economics, trade and incentive measures, available on www.biodiv.org/programmes/socio-eco/incentives viewed on $17 \mathrm{July}$ 2004.

Upper South East 2003, Dryland salinity and flood management, Project update, available on http://www.dwlbc.sa.gov.au/land/programs/use/index.html viewed on 16 May 2007.

van Bueren M. 2001, Emerging markets for environmental services: implications and opportunities for resource management in Australia, Canberra, Rural Industries Research and Development Corporation.

Vanclay F. M. 2004, Social principles for agricultural extension to assist in the promotion of natural resource management, Australian Journal of Experimental Agricultute, vol. 44, no. 3, pp. 213-222.

Vanclay F. M. \& Lawrence G. 1995, The environmental imperative: eco-social concerns for Australian agriculture, Central Queensland University Press, Rockhampton, Queensland. 
Veiga J. F. 1984, Getting the mail questionnaire returned: Some practical research design, Journal of Applied Psychology, vol. 59, pp. 217-218.

Vercoe J. 2003, Voluntary conservation on private land: Tasmania's private forest reserve program lessons and opportunities, Honours thesis, Department of Geography and Environmental studies, University of Tasmania, Hobart.

Vermunt J. K. \& Magidson J. 2005, Latent GOLD Choice 4.0 user's manual, Statistical Innovations Inc. Belmont, Maine.

Walker J. \& Ben-Akiva M. 2002, Generalized random utility model, Mathematical Social Sciences, vol. 43, pp. 303-343.

Whitten S. M. \& Bennett J. W. 2001, Non-market values of wetlands: A choice modelling study of wetlands in the Upper South East of South Australia and the Murrumbidgee River Floodplain in New South Wales, Canberra, School of Economics and Management, University College, The University of New South Wales.

Whitten S., van Bueren M. \& Collins D. n.d., An Overview of Market-Based Instruments and Environmental Policy in Australia, Proceedings of the 6th Annual AARES National Symposium, RIRDC, available on www.ecosystemservicesproject.org/html/publications/docs/MBIs_overview.pdf viewed on 21 October 2007.

Wiebe K. D., Tegene A. \& Kuhn B. 1997, Finding common ground on public and private land, Journal of Soil and Water Conservation, May-June, pp. 162-165.

Wilson G. A. 1996, Farmer environmental attitudes and ESA participation, Goeforum, vol. 27, no. 2, pp. 115-131.

Wilson G. A. 1997, Factors influencing farmer participation in the environmentally sensitive areas scheme, Journal of Environmental Management, vol. 50, pp. 67-93.

Windle J. \& Rolfe J. C. 2002, Whose values count? Using choice modelling to assess values held by indigenous people for floodplain development, Australian Agricultural and Resource Economics Society, Canberra.

Wittink D. R. \& Cattin P. 1989, Commercial use of conjoint analysis: An update, Journal of Marketing, vol. 53, no. 3, pp. 91-96.

Wynn G., Crabtree B. \& Potts J. 2001, Modelling farmer entry into the environmentally sensitive area schemes in Scotland, Journal of Agricultural Economics, vol. 52, no. 1, pp. 65-82.

Yamaguchi K. 2000, Multinomial logit latent-class regression models: an analysis of the predictors of gender-role attitudes among Japanese women, American Journal of Sociology, vol. 105, no. 6, pp. 1702-1740. 
Young M. D. \& Gunningham N. 1997, Mixing instruments and institutional arrangements for optimal biodiversity conservation, Conservation Outside Nature Reserves, Centre for Conservation Biology, The University of Queensland.

Young M. D., Gunningham N., Elix J., Lambert J., Howard B., Grabosky P. \& McCronc E. 1996, Reimbursing the future: An evaluation of motivational, voluntary, price-based, property-right, and regulatory incentives for the conservation of biodiversity, Biodiversity Series, Paper No. 9 , available on www.environment.gov.au/biodiversity/publications/series/paper9/chapter7 viewed on 1 November 2007.

\section{Pers Comm}

Mr. Jim Mulcahy, Conservation Agreements Officer, Protected Areas on Private Land program, Tasmanian Land Conservancy, Hobart.

Dr. David Rankin, Research Officer, Environment and Energy, Australian Bureau of Statistics, Hobart, 


\section{Appendix 1 - Best-Worst experimental design}

The experimental design contains a total of 18 sets, 10 attributes, and 5 attributes per set. The design is shown below.

$\mathrm{t}=10, \mathrm{k}=5, \mathrm{~b}=18, \mathrm{r}=9, \lambda=4, \mathrm{E}=0.8889$

\begin{tabular}{|c|c|c|c|c|c|}
\hline & \multicolumn{5}{|c|}{ BIBD } \\
\hline 1 & 1 & 3 & 4 & 9 & 5 \\
\hline 2 & 2 & 9 & 10 & & \\
\hline 3 & 10 & 4 & & & 3 \\
\hline 4 & 3 & 6 & & & 4 \\
\hline 5 & 1 & 5 & & & 4 \\
\hline 6 & 4 & 2 & & & 5 \\
\hline 7 & 3 & 7 & 9 & & 5 \\
\hline 8 & 5 & 8 & 10 & & 6 \\
\hline 9 & 4 & 6 & 9 & 8 & 7 \\
\hline 10 & 7 & 10 & 3 & & 8 \\
\hline 11 & 5 & 8 & & 9 & 2 \\
\hline 12 & 6 & 10 & 1 & 4 & 9 \\
\hline 13 & 7 & 4 & 2 & 10 & 9 \\
\hline 14 & 8 & 9 & 1 & 5 & 10 \\
\hline 15 & 10 & 5 & 2 & 6 & 1 \\
\hline 16 & 6 & 7 & 3 & 2 & 1 \\
\hline 17 & 9 & 1 & 7 & 8 & 2 \\
\hline 18 & 10 & 2 & 8 & 3 & 4 \\
\hline
\end{tabular}

\begin{tabular}{|c|c|c|c|c|c|}
\hline & \multicolumn{5}{|c|}{ COMPLEMENT } \\
\hline 1 & 2 & 6 & 7 & 8 & 10 \\
\hline 2 & 1 & 4 & 5 & 7 & 8 \\
\hline 3 & 1 & 2 & 6 & 8 & 9 \\
\hline 4 & 2 & 5 & 7 & 9 & 10 \\
\hline 5 & 3 & $\overline{6}$ & 8 & 9 & 10 \\
\hline 6 & 1 & 3 & 7 & 9 & 10 \\
\hline 7 & 1 & 2 & 4 & 8 & 10 \\
\hline 8 & 1 & 2 & 3 & 4 & 9 \\
\hline 9 & 1 & 2 & 3 & 5 & 10 \\
\hline 10 & 2 & 4 & 5 & 6 & 9 \\
\hline 11 & 1 & 4 & 6 & 7 & 10 \\
\hline 12 & 2 & 3 & 5 & 7 & 8 \\
\hline 13 & 1 & 3 & 5 & 6 & 8 \\
\hline 14 & 2 & 3 & 4 & 6 & 7 \\
\hline 15 & 3 & 4 & 7 & 8 & 9 \\
\hline 16 & 4 & 5 & 8 & 9 & 10 \\
\hline 17 & 3 & 4 & 5 & 6 & 10 \\
\hline 18 & 1 & 5 & 6 & 7 & 9 \\
\hline
\end{tabular}

Where:

$(t)=$ program attributes

$(k)=$ number of attributes presented in a block

(b) = total number of blocks

$(r)=$ Number of times the attribute appears in the experiment

$(\lambda)=$ Number of times an attribute appears in combination with each other attribute $\mathrm{E}=$ design efficiency factor 


\section{Appendix 2-Best-Worst survey}

\section{Question 1}

Which organisation do you work for?

\section{Question 2}

Approximately how many years have you worked in

jobs related to resource conservation? Years

\section{Question 3}

How would you best describe you position? (tick only one)
Scientific officer
$\square$ Extension officer
$\square$ Policy officer
$\square$ Administration
$\square$ Management
$\square$ Other

\section{Question 4}

How often do you spend time out in the field, working on properties of conservation significance? (tick only one)
Frequently ( 3 times or more per week) $\square$ Regularly (once or twice per week) $\square$ Not very often (on average less than once per month)

$\square$ Never

\section{Question 5}

How often do you have face-to-face interactions with landowners who own land of conservation

Frequently ( 3 times or more per week)

$\square$ Regularly (once or twice per week) significance? (tick only one) $\square$ Not very often (on average less than once per month)

$\square$ Never 


\section{SECTION 3 - OUTCOMES OF INCENTIVE PROGRAM}

In this section we would like you to indicate what you think landowners believe the least important and the most important attributes of a conservation incentive program are. You are asked to do this 18 times, each time you are presented with a different set of 5 program attributes. Asking you to repeat this process 18 times will allow us to find out how you value each attribute in comparison to every one of the others.

\section{For example}

Tick only one

\begin{tabular}{|l|lll|}
\hline Part $x \times$ & Most important & Tick only one Program attribute & Least infportant \\
\hline$\square$ & Application procedure & $\square$ \\
$\square$ & Technical support availability & $\square$ \\
$\square$ & Land use restriction & $\square$ \\
\hline$\square$ & Legal mechanism & $\square$ \\
\hline
\end{tabular}

\section{Tick only one}

Which program attribute do you think is most important and which do you think is least important to a landowner who is thinking about joining an incentive program to protect native vegetation?

Part 1

\begin{tabular}{|lll|}
\hline Most important & Tick only one Program attribute & Least important \\
\hline$\square$ & Funding amount & $\square$ \\
$\square$ & Funding agency & $\square$ \\
$\square$ & Program duration & $\square$ \\
$\square$ & Application procedure & $\square$ \\
$\square$ & Technical support availability & $\square$ \\
\hline
\end{tabular}

Part 2

\begin{tabular}{|lll|}
\hline Most important & Tick only one Program attribute & Least important \\
\hline$\square$ & Payment method & $\square$ \\
$\square$ & -Application procedure & $\square$ \\
$\square$ & Monitoring \& survey requirements & $\square$ \\
$\square$ & Funding allocation process & $\square$ \\
$\square$ & Funding agency & $\square$ \\
\hline
\end{tabular}

Part 3

\begin{tabular}{|lll|}
\hline Most important & Tick only one Program attribute & Least important \\
\hline$\square$ & Monitoring \& survey requirements & $\square$ \\
$\square$ & Program duration & $\square$ \\
$\square$ & Technical support availability & $\square$ \\
$\square$ & Land use restriction & $\square$ \\
$\square$ & Funding agency & $\square$ \\
\hline
\end{tabular}

Part 4

\begin{tabular}{|llc|}
\hline Most important & Tick only one Program attribute & Least important \\
\hline$\square$ & Funding agency & $\square$ \\
$\square$ & Funding allocation process & $\square$ \\
$\square$ & Funding amount & $\square$ \\
$\square$ & Legal mechanism & $\square$ \\
$\square$ & Program duration & $\square$ \\
\hline
\end{tabular}

Part 5

\begin{tabular}{|lll|}
\hline Most important & Tick only one Program attribute & Least important \\
\hline$\square$ & Funding amount & $\square$ \\
$\square$ & Technical support availability & $\square$ \\
$\square$ & Land use restriction & $\square$ \\
$\square$ & Payment method & $\square$ \\
$\square$ & Program duration & $\square$ \\
\hline
\end{tabular}


Which program attribute do you think is most important and which do you think is least important to a landowner who is thinking about joining an incentive program to protect native vegetation?

Part 6

\begin{tabular}{|lll|}
\hline Most important & Tick only one Program attribute & Least important \\
\hline$\square$ & Program duration & $\square$ \\
$\square$ & Payment method & $\square$ \\
$\square$ & Funding allocation process & $\square$ \\
$\square$ & Legal mechanism & $\square$ \\
$\square$ & Technical support availability & $\square$ \\
\hline
\end{tabular}

Part 7

\begin{tabular}{|c|c|c|}
\hline Most important & Tick only one Program attribute & Least important \\
\hline$\square$ & Funding agency & $\square$ \\
\hline$\square$ & Land use restriction. & $\square$ \\
\hline$\square$ & Application procedure & $\square$ \\
\hline$\square$ & Funding allocation process & $\square$ \\
\hline$\square$ & Technical support availability & $\square$ \\
\hline
\end{tabular}

Part 8

\begin{tabular}{|lll|}
\hline Most important & Tick only one Program attribute & Least important \\
\hline$\square$ & Technical support availability & $\square$ \\
$\square$ & Legal mechanism & $\square$ \\
$\square$ & Monitoring \& survey requirements & $\square$ \\
$\square$ & Land use restriction & $\square$ \\
$\square$ & Funding allocation process & $\square$ \\
\hline
\end{tabular}

Part 9

\begin{tabular}{|c|c|c|}
\hline Most important & Tick only one Program attribute & Least important \\
\hline 口 & Program duration & $\square$ \\
\hline$\square$ & Funding allocation process & $\square$ \\
\hline$\square$ & Application procedure & $\square$ \\
\hline$\square$ & Legal mechanism & $\square$ \\
\hline$\square$ & Land use restriction & $\square$ \\
\hline
\end{tabular}

Part 10

\begin{tabular}{|lll|}
\hline Most important & Tick only one Program attribute & Least important \\
\hline$\square$ & Land use restriction & $\square$ \\
$\square$ & Monitoring \& survey requirements & $\square$ \\
$\square$ & Funding agency & $\square$ \\
$\square$ & Funding amount & $\square$ \\
$\square$ & Legal mechanism & $\square$ \\
\hline
\end{tabular}

Part 11

\begin{tabular}{|c|c|c|}
\hline Most important & Tick only one Program attribute & Least important \\
\hline$\square$ & Technical support availability & $\square$ \\
\hline$\square$ & Legal mechanism & $\square$ \\
\hline$\square$ & Funding agency & $\square$ \\
\hline$\square$ & Application procedure & $\square$ \\
\hline & Payment method & \\
\hline
\end{tabular}

Part 12

\begin{tabular}{|lll|}
\hline Most important & Tick only one Program attribute & Least important \\
\hline$\square$ & Funding allocation process & $\square$ \\
$\square$ & Monitoring \& survey requirements & $\square$ \\
$\square$ & Funding amount & $\square$ \\
$\square$ & Program duration & $\square$ \\
$\square$ & Application procedure & $\square$ \\
\hline
\end{tabular}


Which program attribute do you think is most important and which do you think is least important to a landowner who is thinking about joining an incentive program to protect native vegetation?

Part 13

\begin{tabular}{|lll|}
\hline Most important & Tick only one Program attribute & Least important \\
\hline$\square$ & Land use restriction & $\square$ \\
$\square$ & Program duration & $\square$ \\
$\square$ & Payment method & $\square$ \\
$\square$ & Monitoring \& survey requirements & $\square$ \\
$\square$ & Application procedure & $\square$ \\
\hline
\end{tabular}

Part 14

\begin{tabular}{|lll|}
\hline Most important & Tick only one Program attribute & Least important \\
\hline$\square$ & Legal mechanism & $\square$ \\
$\square$ & Application procedure & $\square$ \\
$\square$ & Funding amount & $\square$ \\
$\square$ & Technical support availability & $\square$ \\
$\square$ & Monitoring \& survey requirements & $\square$ \\
\hline
\end{tabular}

Part 15

\begin{tabular}{|lll|}
\hline Most important & Tick only one Program attribute & Least important \\
\hline$\square$ & Monitoring \& survey requirements & $\square$ \\
$\square$ & Technical support availability & $\square$ \\
$\square$ & Payment method & $\square$ \\
$\square$ & Funding allocation process & $\square$ \\
$\square$ & Funding amount & $\square$ \\
\hline
\end{tabular}

Part 16

\begin{tabular}{|lll|}
\hline Most important & Tick only one Program attribute & Least important \\
\hline$\square$ & Funding allocation process & $\square$ \\
$\square$ & Land use restriction & $\square$ \\
$\square$ & Funding agency & $\square$ \\
$\square$ & Payment method & $\square$ \\
$\square$ & Funding amount & $\square$ \\
\hline
\end{tabular}

Part 17

\begin{tabular}{|lll|}
\hline Most important & Tick only one Program attribute & Least important \\
\hline$\square$ & Application procedure & $\square$ \\
$\square$ & Funding amount & $\square$ \\
$\square$ & Land use restriction & $\square$ \\
$\square$ & Legal mechanism & $\square$ \\
$\square$ & Payment method & $\square$ \\
\hline
\end{tabular}

Part 18

\begin{tabular}{|lll|}
\hline Most important & Tick only one Program attribute & Least important \\
\hline$\square$ & Monitoring \& survey requirements & $\square$ \\
$\square$ & Payment method & $\square$ \\
$\square$ & Legal mechanism & $\square$ \\
$\square$ & Funding agency & $\square$ \\
$\square$ & Program duration & $\square$ \\
\hline
\end{tabular}


In this section we ask you to indicate how strongly you agree or disagree with 26 statements about the role and impacts of establishing reserves on private land.

Conservation reserves on private land are:

\begin{tabular}{|c|c|c|c|c|c|c|}
\hline & & \multicolumn{5}{|c|}{ Please tick $\square$ only 1 of the 5 options } \\
\hline & & $\begin{array}{c}++ \\
\text { Strongly } \\
\text { Agree }\end{array}$ & $\begin{array}{c}+ \\
\text { Agree } \\
\end{array}$ & $\begin{array}{c}+1- \\
\text { Neutral } \\
\end{array}$ & $\begin{array}{c}- \\
\text { Disagree } \\
\end{array}$ & $\begin{array}{c}* \\
\text { Strongly } \\
\text { Disagree }\end{array}$ \\
\hline A & An effective way to ensure wildife survival & $\square$ & $\square$ & $\square$ & $\square$ & $\square$ \\
\hline B & $\begin{array}{l}\text { Can be expensive as they lead to reduced } \\
\text { productivity due to shading }\end{array}$ & $\square$ & $\square$ & $\square$ & $\square$ & $\square$ \\
\hline $\mathrm{C}$ & $\begin{array}{l}\text { Reduce the potential to earn income from } \\
\text { the rest of the property }\end{array}$ & $\square$ & $\square$ & $\square$ & $\square$ & $\square$ \\
\hline D & Create a good image for landowners & $\square$ & $\square$ & $\square$ & $\square$ & $\square$ \\
\hline E & Expensive to manage & $\square$ & $\square$ & $\square$ & $\square$ & $\square$ \\
\hline$F$ & Will benefit others as much as the landowner & $\square$ & $\square$ & $\square$ & $\square$ & $\square$ \\
\hline G & Threaten the landowners' livelihood & $\square$ & $\square$ & $\square$ & $\square$ & $\square$ \\
\hline $\mathrm{H}$ & Give the landowner a sense of fulfilment & $\square$ & $\square$ & $\square$ & $\square$ & $\square$ \\
\hline I & Add to the beauty of the landscape & $\square$ & $\square$ & $\square$ & $\square$ & $\square$ \\
\hline J & Will mainly benefit the future generation & $\square$ & $\square$ & $\square$ & $\square$ & $\square$ \\
\hline K & $\begin{array}{l}\text { Will increase the landowner's understanding } \\
\text { of the environment }\end{array}$ & $\square$ & $\square$ & $\square$ & $\square$ & $\square$ \\
\hline $\mathrm{L}$ & $\begin{array}{l}\text { Provide a good way to protect species from } \\
\text { extinction }\end{array}$ & $\square$ & $\square$ & $\square$ & $\square$ & $\square$ \\
\hline M & Create a harbour for weeds & $\square$ & $\square$ & $\square$ & $\square$ & $\square$ \\
\hline N & $\begin{array}{l}\text { Increase the fire threat to the landowners' } \\
\text { property }\end{array}$ & $\square$ & $\square$ & $\square$ & $\square$ & $\square$ \\
\hline 0 & Of value for stock shelter and control & $\square$ & $\square$ & $\square$ & $\square$ & $\square$ \\
\hline$P$ & $\begin{array}{l}\text { Increase the opportunities to earn income } \\
\text { from recreation/tourism }\end{array}$ & $\square$ & $\square$ & $\square$ & $\square$ & $\square$ \\
\hline Q & Take up a lot of time to manage & $\square$ & $\square$ & $\square$ & $\square$ & $\square$ \\
\hline $\mathbf{R}$ & $\begin{array}{l}\text { Should be left alone with minimal } \\
\text { management }\end{array}$ & $\square$ & $\square$ & $\square$ & $\square$ & $\square$ \\
\hline S & $\begin{array}{l}\text { Reduce the landowners' opportunity to } \\
\text { diversify }\end{array}$ & $\square$ & $\square$ & $\square$ & $\square$ & $\square$ \\
\hline$T$ & $\begin{array}{l}\text { Best established where neighbours work } \\
\text { together to protect areas }\end{array}$ & $\square$ & $\square$ & $\square$ & $\square$ & $\square$ \\
\hline U & $\begin{array}{l}\text { Will reduce the potential for soil erosion and } \\
\text { salinity }\end{array}$ & $\square$ & $\square$ & $\square$ & $\square$ & $\square$ \\
\hline V & Reduce the property value & $\square$ & $\square$ & $\square$ & $\square$ & $\square$ \\
\hline W & $\begin{array}{l}\text { Will make the management of the remainder } \\
\text { of the property more complicated }\end{array}$ & $\square$ & $\square$ & $\square$ & $\square$ & $\square$ \\
\hline$x$ & Reduce the security of future income & $\square$ & $\square$ & $\square$ & $\square$ & $\square$ \\
\hline Y & $\begin{array}{l}\text { Only desirable if there is no other valuable } \\
\text { use for the land }\end{array}$ & $\square$ & $\square$ & $\square$ & $\square$ & $\square$ \\
\hline $\mathbf{Z}$ & $\begin{array}{l}\text { Create a harbour for animals that are a pest } \\
\text { to farming }\end{array}$ & $\square$ & $\square$ & $\square$ & $\square$ & $\square$ \\
\hline
\end{tabular}


If you think that the "Funding amount" is most important and "Monitoring \& survey requirements" are least important to you, your answer would look like the following:

Tick only one

\begin{tabular}{|ccc|}
\hline $\begin{array}{c}\text { Most } \\
\text { important }\end{array}$ & Tick only one Program attribute & $\begin{array}{c}\text { Least } \\
\text { important }\end{array}$ \\
\hline$\square$ & Land use restriction & $\square$ \\
$\square$ & Monitoring \& survey requirements & $\square$ \\
$\square$ & Funding agency & $\square$ \\
$\square$ & Funding amount & $\square$ \\
$\square$ & Legal mechanism & $\square$ \\
\hline
\end{tabular}

Tick only one

\section{Application procedure}

The administrative procedure involved in applying for incentive program funding. For example the landowner may need to discuss reservation options with a negotiator employed by an incentive program or may simply need to fill out an application.

\section{Funding allocation process}

The way in which the program determines eligibility for the funding. For example the agency may choose the best application or the best and cheapest application.

\section{Funding agency}

Whether the agency that delivers the incentive program is public or private sector.

\section{Funding amount}

The amount of money paid to the landowner for participation in an incentive program as a proportion of a "fair market value"

\section{Land use restriction}

The restrictions defining what the landowner is and isn't allowed to do with the land after reserve establishment. For example the landowner may be allowed to graze the reserve area occasionally or no productive use at all may be permitted.

\section{Legal mechanism}

The nature of the legal restrictions that are placed on the land after reserve establishment. For example the conservation values of the land may be protected by a permanent covenant or a temporary management agreement.

\section{Monitoring \& survey requirements}

The flora and fauna monitoring and survey requirements for a landowner after reserve establishment

\section{Payment method}

The method by which the money (funding amount) is paid to the landowner. For example the money may be paid in a lump-sum or in instalments.

\section{Program duration}

How long the landowner is expected to participate in the program (i.e. representing the timeframe over which funding payments are made and over which monitoring is required)

\section{Technical support availability}

The availability and cost of technical support after reserve establishment. 


\section{Appendix 3 - Choice survey}

\section{What is the survey about?}

In Tasmania, government and non-government organisations have been running different incentive programs for landowners for many years. For example there exist a number of environmental programs that provide incentives to landowners to fence native vegetation, to plant trees to prevent erosion, and protect riverbanks. There are also conservation programs that offer money incentives to landowners to set aside areas of native vegetation as "formal reserves".

Landowners across Tasmania are likely to respond differently to the different details (also called attributes) of the conservation incentive programs. Some landowners will base their decision of whether to join a program or not only on the amount of money they receive for the land they are setting aside as reserve. Other landowners may be guided more by the land use restrictions that would apply to the land if they were to join a program (they may not be able to graze the area any longer). Some landowners will want more money the more severe they believe the restrictions are. Other program attributes that are likely to have an impact on the decision to join a program or not, may be the way the incentive money is paid (in a lump sum or installments), or the technical support that's available after the reserve is established.

We believe it is important to understand the landowners' views on these issues. In this survey we are interested in the opinion of both landowners who have native forest and those who don't and this includes your opinion. We want to know how a program would look that you would join, and what your overall requirements and standards are. You may feel that there is no program that you would join regardless of what's on offer. If so, we need to know.

We hope you will take the time to participate in this survey so that incentive programs available in the future can take your views and opinions on board.

\section{How long it will take you}

We estimate that it will take you $\mathbf{1 0}$ to $\mathbf{1 5}$ minutes to complete the survey. Participation in this survey is entirely voluntary. The survey is anonymous, the researchers will be unable to identify participants and no participant will be identifiable in any of the research output.

Returning the survey

After you have filled out the survey please place it in the stamped envelope that is provided and mail it back to us by the $19^{\text {th }}$ of August 2005 .

Thank you for helping make incentive programs more responsive to your needs. 


\section{Researcher contact details}

Dr. Sarah Jennings (sarah.jennings@utas.edu.au or (03) 6226 2828) and Ingrid van Putten (i.vanputten@utas.edu.au or (03) 62262820 ) can be contacted for questions and comments on the survey. Results from the study will be posted on the publicly accessible School of Economics website after completion of the study (see fcms.its.utas.edu.au/commerce/econ).

\section{Type of survey questions}

To make it easier for us to understand your views, and to limit our demands on your time, this survey contains mostly multiple-choice questions. We use a repeated choice technique in section 2 which asks you to answer the same multiple choice question a number of times but each time with slightly different details. This approach is used because it makes your choice easier to understand. It is not used to test you or to test the consistency of your answers.

We have included a separate sheet that explains some of the terms used in this survey.

\section{how the survey is laid out}

The survey consists of 4 sections. The questions in the $1^{\text {st }}$ section are about your property and the management of your property. In the $2^{\text {nd }}$ section we want to hear your opinion on the details that make up an incentive program that would appeal to you. In the $3^{\text {rd }}$ section you are asked to rate a number of statements about private nature reserves. The last section contains a few questions about you.

\section{Ethics approval}

The study has been approved by the Human Research Ethics Committee (Tasmania) Network. If you have any concerns of an ethical nature about the study, please contact the Executive Officer of the Human Research Ethics Committee (Tasmania) Network, Amanda McAully (Ph (03) 6226 2763). 


\section{Question 1}

Are you? (tick only one)

$\square$ The owner and manager of the property

The owner (but not the manager) of the property

Other

\section{Question 2}

How long have you owned this property?

Years

\section{Question 3}

What are the ownership details of the property?

\section{(tick only one)}

$\square$ Private ownership

$\square$ Partnership

$\square$ Family trust

$\square$ Private or public company

$\square$ Other

\section{Question 4}

Do you reside on the property?
(tick only one)
$\square$ Yes
$\square$ No

\section{Question 5}

Approximately how large is your property?

(delete one)

\section{Question 6}

What agricultural activities do you undertake on your property?

(tick any that apply)

$\square$ Don't use it for any agricultural activity

$\square$ Wool

$\square$ Meat

$\square$ Dairy

$\square$ Cropping

$\square$ Horticulture

$\square$ Other

\section{Question 7}

Which two numbers does your $\square 62$ telephone number start with? $\quad \square 63$

\section{Question 8}

How many years have you been involved in resource conservation and management?

\section{Question 9}

Do you manage areas on your property for the following noncommercial purposes?

(tick any that apply) Hectares/Acres 


\section{Question 10}

Have you received any of the following forms of support for managing areas on your property in the past 5 years?
(tick any that apply)
$\square$ Money for fencing
Money for revegetation
$\square$ Trees for revegetation
$\square$ Labour assistance for revegetation
$\square$ Money for improving soil management
$\square$ Scientific advice (eg. identification of animals)
Technical advice (eg. management of animals)
Administrative assistance (eg. filling out form)
$\square$ Legal advice (eg. implication of covenants)
$\square$ Other

\section{Question 11}

Is there any native forest on your property?
Yes $\square$ No
(Please go to the next question - 12) (Please go to question 19 on page 4)

(delete one)

\section{Question 12}

Approximately how large is the area of native forest on your property?

\section{Question 13}

Do you manage areas of native forest on your property for the following commercial uses?

\section{(tick any that apply)}

Don't use it for anything

$\square$ Grazing

Commercial timber harvesting

$\square$ Hunting

$\square$ Commercial seed collection

Other

\section{Question 14}

(tick only one)

Do you have any plans to harvest any $\square$ Yes of your native forest for commercial $\square$ No purposes in the future?

$\square$ Don't know

(tick only one)

\section{Question 15}

Is there a formal conservation reserve anywhere on your property?

\section{Question 16}

Have you received funding to establish a conservation reserve on your property?

\section{Question 17}

Do you manage any part of your property specifically for conservation without it being formally protected?

\section{$\square$ Yes}

$\square$ No

$\square$ Don't know

(tick only one)

$\square$ Yes

$\square$ No

$\square$ Don't know

(tick only one)

$\square$ Yes

$\square$ No

$\square$ Don't know 


\section{Question 18}

\section{For landowners WHO OWN an area of native forest}

To set the scene for the next section of the survey we ask you to think about a particular area of native forest on your property that has some conservation value (it doesn't matter what the type of forest is or where it is on your property). If you don't own an area of forest with conservation values please think of any other tract of native forest on your land. Please answer these brief questions about that area of native forest.

Approximately how large is the area of native forest you are thinking of?

In your opinion, what would be a fair market value for this area of native forest?

The estimate of the fair market value of this area of native forest was made on the basis of

In your opinion, does this area have conservation value? (delete one) Hectares/Acres

(de/ete one)

$\$$. per Hectare/Acre

\section{(tick any that apply)}

$\square$ What I paid for the land

$\square$ Value of similar land in the district

$\square$ Government valuation

$\square$ What I could get if I sold the timber

$\square$ Other

$\square$ Yes
$\square$ No
$\square$ Don't know

For the next section please assume you could enrol the area of native forest you described above in a conservation incentive program. Enrolling the land may mean you will have to change the use of that land but you would retain ownership of the land.

\section{Please now proceed to page 5 and answer all 8 parts of question 20}




\section{Question 19}

\section{For landowners who DON'T OWN an area of native forest}

Even though you currently don't own any land with native forest, we are interested in your opinion about the sort of incentive program that would appeal to you if you did own forested land.

To set the scene for the next two sections please place yourself in the position of someone who owns an area of native forest. Please imagine that $10 \%$ of your property is covered with one single contiguous block of native forest.

Approximately how large would the area of native forest be?

(delete one) Hectares/Acres

Say that similar forested land in your region has sold for around $\$ 5,000$ per hectare in the past year. On this basis a fair market value for the area of native forest would be $\$ 5,000$ per hectare times the size of the area you indicated above.

Imagine that this forest has conservation value and is eligible to be enrolled in a conservation incentive scheme. Enrolling the land may mean you will have to change the use of that land but you would retain ownership of the land. Please keep this area of native forest in mind.

Please now proceed to page $\mathbf{5}$ and answer all $\mathbf{8}$ parts of question $\mathbf{2 0}$ 


\section{Question 20}

We would like you to tell us which of two incentive programs you would prefer if you could enrol the forested land described previously in a conservation incentive program. You are given the option of choosing between two programs that are different in a maximum of 5 possible ways. You are asked to repeat this exercise 8 times. The repetition will help you to think about the difficult tradeoffs between the various aspects of programs and help us to design programs that make better use of taxpayer's money.

Please refer to the back of the glossary insert for an example of this question.

There are two incentive programs you can enrol your land in (program 1 and 2 below). Which one would you choose?

\begin{tabular}{|l|c|c|}
\cline { 2 - 3 } \multicolumn{1}{l|}{ Part 1 } & \multicolumn{1}{c|}{ Program 1 } & \multicolumn{1}{c|}{ Program 2 } \\
\hline Funding amount & $1 / 2$ the market value & $3 / 4$ of the market value \\
Legal mechanism & Temporary management agreement & Permanent covenant \\
Land use restriction & No use permitted & Limited use permitted \\
Payment method & Tax relief & Up-front lump sum payment \\
Technical support availability & Free of charge & Fee for service \\
\hline
\end{tabular}
Of these two programs
my preferred one is
ㅁ 1
$\square \quad 2$
I would voluntarily enrol
my land in program
$\square \quad 1$
$\square \quad 2$
Please check you have answered both $A$ and $B$ above

\begin{tabular}{|c|c|c|}
\hline Part 2 & Program 1 & Program 2 \\
\hline Funding amount & Exactly the market value & $11 / 4$ of the market value \\
\hline Legal mechanism & Temporary management agreement & Permanent covenant \\
\hline Land use restriction & No use permitted & Limited use permitted \\
\hline Payment method & Up-front lump sum payment & Tax relief \\
\hline Technical support availability & Free of charge & Fee for service \\
\hline
\end{tabular}
Of these two programs
my preferred one is
$\square \quad 1$
$\square \quad 2$
I would voluntarily enrol my land in program 


\begin{tabular}{|c|c|c|}
\hline Part 3 & Program 1 & Program 2 \\
\hline Funding amount & $11 / 4$ of the market value & $1 / 2$ the market value \\
\hline Legal mechanism & Permanent covenant & Temporary management agreement \\
\hline Land use restriction & No use permitted & Limited use permitted \\
\hline Payment method & Tax relief & Up-front lump sum payment \\
\hline Technical support availability & Fee for service & Free of charge \\
\hline
\end{tabular}

Of these two programs

my preferred one is

$\square \quad 1$

๑ 1 $\square \quad 2$

․ 2

I would voluntarily enrol my land in program

Please check you have answered both $\mathrm{A}$ and $\mathrm{B}$ above

Please check you have answered both A and B above

\section{Part 4}

Funding amount

Legal mechanism

Land use restriction

Payment method

Technical support availability

Of these two programs

my preferred one is

I would voluntarily enrol

my land in program
Program 1

$3 / 4$ of the market value

Temporary management agreement

Limited use permitted

Tax relief

Free of charge
Program 2

Exactly the market value

Permanent covenant

No use permitted

Up-front lump sum payment

Fee for service

\section{Part 5}

Funding amount

Legal mechanism

Land use restriction

Payment method

Technical support availability

\section{$\square \cdot 1$}

$\square: 1$

$\square \quad$ Neither 1 nor 2

Please check you have answered both $A$ and $B$ above
Of these two programs

my preferred one is

I would voluntarily enrol

my land in program
Program 1

Exactly the market value

Permanent covenant

No use permitted

Up-front lump sum payment

Free of charge
Program 2

$11 / 4$ of the market value

Temporary management agreement

Limited use permitted

Tax relief

Fee for service

Please check you have answered both $A$ and $B$ above 
Part 6

Funding amount

Legal mechanism Land use restriction Payment method Technical support availability

Temp

Program 1

$3 / 4$ of the market value

Temporary management agreement

No use permitted

Up-front lump sum payment

Fee for service
Program 2

Exactly the market value

Permanent covenant

Limited use permitted

Tax relief

Free of charge
Of these two programs
my preferred one is
$\square \quad 1$
$\square \quad 2$
2
I would voluntarily enrol
my land in program
Neither 1 nor $\square \quad 2$
Please check you have answered both $A$ and $B$ above

\begin{tabular}{|l|c|c|}
\cline { 2 - 3 } \multicolumn{1}{l|}{ Part 7} & \multicolumn{2}{c|}{ Program 1 } \\
\hline Funding amount & $11 / 4$ of the market value & $1 / 2$ the market value \\
Legal mechanism & Permanent covenant & Temporary management agreement \\
Land use restriction & Limited use permitted & No use permitted \\
Payment method & Up-front lump sum payment & Tax relief \\
Technical support availability & Free of charge & Fee for service \\
\hline
\end{tabular}
Of these two programs
my preferred one is
ㄴ 1
2
I would voluntarily enrol
my land in program
Please check you have answered both $A$ and $B$ above
2

\begin{tabular}{|l|c|c|}
\cline { 2 - 3 } \multicolumn{1}{l|}{ Part $\mathbf{8}$} & Program 1 & Program 2 \\
\hline Funding amount & $3 / 4$ of the market value & Exactly the market value \\
Legal mechanism & Permanent covenant & Temporary management agreement \\
Land use restriction & Limited use permitted & No use permitted \\
Payment method & Tax relief & Up-front lump sum payment \\
Technical support availability & Free of charge & Fee for service \\
\hline
\end{tabular}

A
Of these two programs
my preferred one is
$\square \quad 1$
$\square \quad 2$
I would voluntarily enrol
my land in program
Please check you have answered both $A$ and $B$ above

B 


\section{Question 21}

Ne ask you to indicate how strongly you agree with 24 statements about the role and mpacts of establishing conservation reserves on private land.

\section{Conservation reserves on private land:}

\begin{tabular}{|c|c|c|c|c|c|c|}
\hline & & $\begin{array}{c}++ \\
\text { Strongly } \\
\text { Agree }\end{array}$ & $\stackrel{+}{+}$ & Neutral & Disagree & $\begin{array}{l}\text { S-- } \\
\text { Strongly } \\
\text { Disagree }\end{array}$ \\
\hline A & Reduce the property value & $\square$ & $\square$ & $\square$ & $\square$ & $\square$ \\
\hline$B$ & Are of value for stock shelter and control & $\square$ & $\square$ & $\square$ & $\square$ & $\square$ \\
\hline$C$ & $\begin{array}{l}\text { Reduce the potential to earn income from } \\
\text { the rest of the property }\end{array}$ & $\square$ & $\square$ & $\square$ & $\square$ & $\square$ \\
\hline$D$ & Create a good image for landowners & $\square$ & $\square$ & $\square$ & $\square$ & $\square$ \\
\hline$E$ & Are expensive to manage & $\square$ & $\square$ & $\square$ & $\square$ & $\square$ \\
\hline$F$ & Will benefit others as much as the landowner & $\square$ & $\square$ & $\square$ & $\square$ & $\square$ \\
\hline G & Threaten the landowners' livelihood & $\square$ & $\square$ & $\square$ & $\square$ & $\square$ \\
\hline H & Give the landowner a sense of fulfilment & $\square$ & $\square$ & $\square$ & $\square$ & $\square$ \\
\hline I & Add to the beauty of the landscape & $\square$ & ㅁ & $\square$ & $\square$ & $\square$ \\
\hline ] & Will mainly benefit the future generation & $\square$ & $\square$ & ㅁ & $\square$ & $\square$ \\
\hline K & $\begin{array}{l}\text { Will increase the landowners' understanding } \\
\text { of the environment }\end{array}$ & 口 & $\square$ & 口 & $\square$ & $\square$ \\
\hline L & $\begin{array}{l}\text { Provide a good way to protect species from } \\
\text { extinction }\end{array}$ & $\square$ & $\square$ & $\square$ & $\square$ & $\square$ \\
\hline$M$ & Create a harbour for weeds & $\square$ & $\square$ & $\square$ & $\square$ & $\square$ \\
\hline N & Increase the fire threat to the property & $\square$ & $\square$ & $\square$ & $\square$ & $\square$ \\
\hline 0 & $\begin{array}{l}\text { Can be expensive as they lead to reduced } \\
\text { productivity due to shading }\end{array}$ & $\square$ & $\square$ & $\square$ & $\square$ & $\square$ \\
\hline$P$ & $\begin{array}{l}\text { Increase the opportunities to earn income } \\
\text { from recreation/tourism }\end{array}$ & $\square$ & $\square$ & $\square$ & $\square$ & $\square$ \\
\hline Q. & Take up a lot of time to manage & $\square$ & $\square$ & $\square$ & $\square$ & $\square$ \\
\hline $\mathrm{R}$ & $\begin{array}{l}\text { Reduce the landowners' opportunity to } \\
\text { diversify }\end{array}$ & 口 & $\square$ & $\square$ & $\square$ & $\square$ \\
\hline$S$ & $\begin{array}{l}\text { Will reduce the potential for soil erosion and } \\
\text { salinity }\end{array}$ & $\square$ & 口 & $\square$ & $\square$ & $\square$ \\
\hline$T$ & $\begin{array}{l}\text { Are an effective way to ensure wildlife } \\
\text { survival }\end{array}$ & $\square$ & $\square$ & $\square$ & 口 & $\square$ \\
\hline U & $\begin{array}{l}\text { Will make the management of the remainder } \\
\text { of the property more complicated }\end{array}$ & 口 & $\square$ & $\square$ & $\square$ & $\square$ \\
\hline$V$ & Reduce the security of future income & ㅁ & ㅁ & $\square$ & ㅁ & $\square$ \\
\hline W & $\begin{array}{l}\text { Are only desirable if there is no other } \\
\text { valuable use for the land }\end{array}$ & $\square$ & $\square$ & $\square$ & $\square$ & $\square$ \\
\hline$x$ & $\begin{array}{l}\text { Create a harbour for animals that are a pest } \\
\text { to farming }\end{array}$ & $\square$ & $\square$ & $\square$ & $\square$ & $\square$ \\
\hline
\end{tabular}


Some of the questions in this section are of a personal nature. This information adds to the completeness of our analysis. We assure the confidentiality of the information you provide. Even if you don't complete the whole section below, please mail us the rest of the survey as it will still provide valuable information.

Question 22

Gender of the person who filled out $\square$ Male this survey

\section{Question 23}

How would you best describe your main occupation?

\section{Question 24}

How old are you?

\section{Question 25}

What is the highest education level you achieved

\section{Question 26}

Please indicate if you regularly receive information from any of the following organisations?

\section{Question 27}

What do you intend to do with your property when you no longer want to manage it?

\section{Question 28}

Number of dependent children

\section{Question 29}

Do you or a family member living on the property earn off-farm income?

\section{Question 30}

Do you earn the majority of your income from farming?

\section{Question 31}

How big is the mortgage you have on the property?

\section{Question 32}

What is you average annual gross farm turnover?

\section{(tick only one)}

$\square$ Female

\section{(tick only one)}

Up to secondary

$\square$ TAFE or trade training

$\square$ University or postgraduate

\section{(tick any that apply)}

$\square$ Greening Australia

$\square$ Local Coastcare / Landcare group

$\square$ Private Forests Tasmania

$\square$ Other.

(tick only one)

$\square$ Pass it on to a family member

$\square$ Sell up

$\square$ Not sure

$\square$ Other (tick only one)

$\square$ Yes

$\square$ No

(tick only one)

$\square$ Yes

$\square$ No

(tick only one)

$\square$ I don't have a mortgage on the property

Less than $25 \%$ of the property value

Between $25 \%$ - $50 \%$ of the property value Between $50 \%-75 \%$ of the property value

More than $75 \%$ of the property value 
Thank you very much for participating in this survey! 


\section{Example}

This is what the two programs look like

\section{Part}

Funding amount Legal mechanism Land use restriction Payment method

Technical support availability

You are asked to answer two parts A and B. In part A you are asked to indicate if you prefer program 1 or 2 (even if in reality you would not consider enrolling your land in either of them).
You like program 1 best - tick this box
Of these two programs
my preferred one is

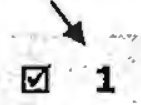
ㄴ 2

In part B you are then asked to indicate which program in reality you would enrol your land in. If you would choose not to enrol your land, you can choose "neither 1 nor $2^{\prime \prime}$.

\section{If you would enrol your land in program 1 - tick this box}

B I would voluntarily enrol my land in program

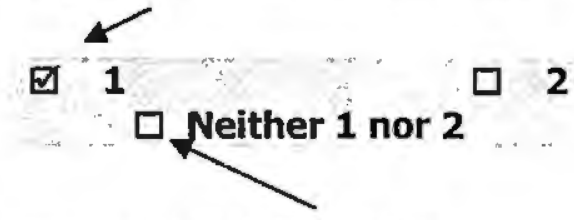

\section{Funding amount}

The amount of money paid to the landowner for participation in an incentive program expressed as a proportion of the estimated "fair market value".

\section{Land use restriction}

The restrictions defining what the landowner is and isn't allowed to do with the land after reserve establishment. For example the landowner may be allowed limited use such as occasional grazing of the reserve area. If no use is allowed, the landowner will have to manage the area for conservation only.

\section{Legal mechanism}

The nature of the legal restrictions that are placed on the land after reserve establishment. For example the conservation values of the land may be protected by a permanent covenant, which means that the title of the land is changed. The land will be identified on the title as conservation reserve for ever. This title change will be retained when the land is sold. A temporary management agreement is a contract between government and the landowner that changes the use and management of the land for a maximum of 20 years.

\section{Payment method}

The method by which the money (funding amount) is paid to the landowner. For example the money may be paid in a lump-sum or by means of tax relief.

\section{Technical support availability}

The availability and cost of technical support after reserve establishment. 


\section{Appendix 4-Choice survey experimental design}

This design has 5 attributes, the first 4 attributes have 2 levels and the last one has 4 levels. All main effects and the interaction between the first 2 level attribute and the 4 level attribute can be estimated independently of each other. There are 2 options (plus "do nothing") in each of the 16 choice sets and each row in the table below represents 1 choice set.

\begin{tabular}{|c|c|c|c|c|c|c|c|c|c|c|c|}
\hline & 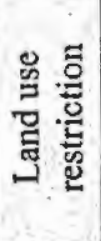 & 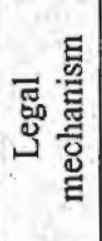 & 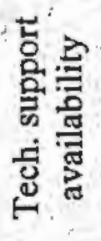 & 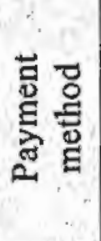 & 嘔 & & 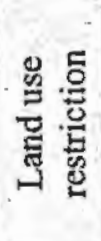 & 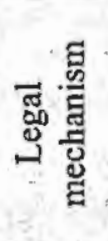 & 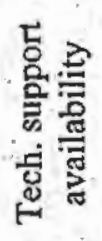 & 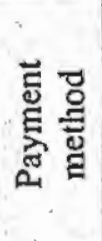 & 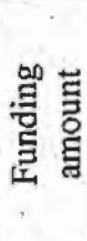 \\
\hline & \multicolumn{5}{|c|}{ Design I survey 1} & & \multicolumn{5}{|c|}{ Design 2 survey 3} \\
\hline 1 & 0 & 0 & 0 & 0 & 0 & la & 1 & 1 & 1 & 1 & 1 \\
\hline 2 & 0 & 1 & 1 & 1 & 0 & $2 a$ & 1 & 0 & 0 & 0 & 1 \\
\hline 3 & 0 & 0 & 1 & 1 & 1 & $3 a$ & 1 & 1 & 0 & 0 & 2 \\
\hline 4 & 0 & 1 & 0 & 0 & 1 & $4 a$ & 1 & 0 & 1 & 1 & 2 \\
\hline 5 & 0 & 1 & 0 & 1 & 2 & $5 a$ & 1 & 0 & 1 & 0 & 3 \\
\hline 6 & 0 & 0 & 1 & 0 & 2 & $6 a$ & 1 & 1 & 0 & 1 & 3 \\
\hline 7 & 0 & 1 & 1 & 0 & 3 & $7 a$ & 1 & 0 & 0 & 1 & 0 \\
\hline \multirow[t]{2}{*}{8.} & 0 & 0 & 0 & 1 & 3 & $8 \mathrm{a}$ & 1 & 1 & 1 & 0 & 0 \\
\hline & \multicolumn{5}{|c|}{ Design 1 survey 2} & & \multicolumn{5}{|c|}{ Design 2 survey 4} \\
\hline 9 & 1 & 0 & 0 & 0 & 0 & $9 a$ & 0 & 1 & 1 & 1 & 1 \\
\hline 10 & 1 & 1 & 1 & 1 & 0 & $10 \mathrm{a}$ & 0 & 0 & 0 & 0 & 1 \\
\hline 11 & 1 & 0 & 1 & 1 & 1 & $11 \mathrm{a}$ & 0 & 1 & 0 & 0 & 2 \\
\hline 12 & 1 & 1 & 0 & 0 & 1 & $12 \mathrm{a}$ & 0 & 0 & 1 & 1 & 2 \\
\hline 13 & 1 & 1 & 0 & 1 & 2 & $13 a$ & 0 & 0 & 1 & 0 & 3 \\
\hline 14 & 1 & 0 & 1 & 0 & 2 & $14 \mathrm{a}$ & 0 & 1 & 0 & 1 & 3 \\
\hline 15 & 1 & 1 & 1 & 0 & 3 & $15 \mathrm{a}$ & 0 & 0 & 0 & 1 & 0 \\
\hline 16 & 1 & 0 & 0 & 1 & 3 & $16 a$ & 0 & 1 & 1 & 0 & 0 \\
\hline
\end{tabular}

As 8 choice sets were included in each survey, and the design above shows 32 choice sets, this was divided into 4 different surveys that were mailed out. A random order in the 16 choice sets of both designs was generated. ${ }^{111}$ The first 8 of design 1 were then included in survey 1,9 through 16 of design 1 were included in survey number 2. 1a to 8 a choice sets of design 2 were included in survey number 3 , and $9 a$ through 16a of design 2 were included in survey number 4 .

${ }^{111}$ For design number one this was $2,1,4,5,12,9,11,10,15,6,13,14,16,8,7$, and 3 


\section{Appendix 5 - Principal component analysis}

A PCA and the VARIMAX rotation method (SPSS version 11.0.0) was used to condense the original 26 attitude variables to form a reduced number of interpretable variables (Mulaik 1972). Variables with extraction communality values smaller than 0.2 were dropped from the PCA (Table i). STOCK, FUTGEN, and EROSION did not fit well with the factor solution.

Table i: Communalities for all attitude variables (Choice survey data).

\begin{tabular}{lc}
\hline & \\
\hline BEAUTY & Extraction \\
\hline BENOTH & 0.531 \\
\hline COMPLEX & 0.426 \\
\hline DIVERSE & 0.645 \\
\hline EROSION & 0.630 \\
\hline EXPMAN & 0.167 \\
\hline FIRE & 0.482 \\
\hline FULFIL & 0.454 \\
\hline FUTGEN & 0.716 \\
\hline IMAGE & 0.114 \\
\hline INCOP & 0.446 \\
\hline INCRED & 0.268 \\
\hline INCSEC & 0.412 \\
\hline LEARNING & 0.686 \\
\hline LIVELY & 0.663 \\
\hline OTHERUSE & 0.634 \\
\hline PESTS & 0.516 \\
\hline PROPVALU & 0.375 \\
\hline PROTECT & 0.539 \\
\hline SHADE & 0.656 \\
\hline STOCK & 0.562 \\
\hline TIME & 0.066 \\
\hline WEEDS & 0.474 \\
\hline WILDL & 0.559 \\
\hline & 0.583 \\
\hline
\end{tabular}

With all communalities now greater than 0.2 the next step in the PCA is determination of the number of factors. There are several methods by which this is usually done, including Cattell's scree test, eigenvalues greater than 1 , and interpretability of the resultant factors. Using a combination of these methods it was decided to extract 2 factors. 
Table ii: Total variance explained in PCA for all respondents (Choice survey data).

\begin{tabular}{|c|c|c|c|c|c|c|c|c|c|}
\hline \multirow[t]{2}{*}{$\begin{array}{l}\text { Conip } \\
\text { onient }\end{array}$} & \multicolumn{6}{|c|}{ Initial Eigenvalues. } & \multicolumn{3}{|c|}{$\begin{array}{c}\text { Rotation Sums of Squared } \\
\text { Loadings }\end{array}$} \\
\hline & Total & $\begin{array}{l}\% \text { of } \\
\text { Var. }\end{array}$ & Cum \% & Total & $\begin{array}{l}\% \text { of } \\
\text { Var. }\end{array}$ & Cum \% & Total & $\begin{array}{l}\% \text { of } \\
\text { Var. }\end{array}$ & Cum \% \\
\hline 1 & 8.698 & 36.240 & 36.240 & 8.698 & 36.240 & 36.240 & 5.568 & 23.200 & 23.200 \\
\hline 2 & 2.519 & 10.497 & 46.737 & 2.519 & 10.497 & 46.737 & 5.139 & 21.414 & 44.613 \\
\hline 3 & 1.873 & 7.804 & 54.540 & 1.873 & 7.804 & 54.540 & 2.382 & 9.927 & 54.540 \\
\hline
\end{tabular}

* Components with eigenvalues smaller than 1 and/or that contribute less than $5 \%$ of the variance are not shown.

The first two components explain around 55 percent of the total variation of the original variables. Standard tests of the adequacy of the PCA indicate that a factor analysis is useful for this reduced variable set. A 0.878 Kaiser-Meyer-Olkin Measure of Sampling Adequacy indicates a high proportion of variance in the data explained by the underlying factors. Further the significance level of 0.000 for Bartlett's test of sphericity, with approximate Chi-square of 44371.977 and 276 degrees of freedom, indicates there are significant relationships among the variables.

The attributes with loadings greater than 0.400 ( + or - ) in the rotated component matrix for two principal components are shown in Table iii.

Table iii: Rotated component matrix (Choice survey data).

\begin{tabular}{|c|c|c|c|}
\hline$\therefore \quad \therefore \quad \therefore$ & $\begin{array}{l}\text { Procluction } \\
\text { iimpact . } \\
\text { PC1 }\end{array}$ & $\begin{array}{l}\text { vironmental } \\
\text { impact } \\
{ }_{\mathrm{PC} 2}\end{array}$ & $\begin{array}{l}\text { Long tern } \\
\text { opportunity inupact } \\
\text { PC3 }\end{array}$ \\
\hline PROPVALUE & 0.457 & -0.469 & \\
\hline INCRED & 0.643 & & \\
\hline EXPMAN & 0.686 & & \\
\hline LIVELY & 0.652 & & \\
\hline WEEDS & 0.747 & & \\
\hline FIRE & 0.597 & & 0.494 \\
\hline SHADE & 0.699 & & \\
\hline TIME & 0.725 & & \\
\hline DIVERSE & 0.671 & & \\
\hline COMPLEX & 0.713 & & \\
\hline INCSEC & 0.706 & & \\
\hline PESTS & 0.498 & & \\
\hline BENOTH & & 0.514 & \\
\hline IMAGE & & 0.647 & \\
\hline FULFIL & & 0.737 & \\
\hline BEAUTY & & 0.728 & \\
\hline LEARNING & & 0.750 & \\
\hline PROTECT & & 0.799 & \\
\hline WILDL & & 0.775 & \\
\hline OTHERUSE & & -0.494 & 0.562 \\
\hline INCOP & & & -0.486 \\
\hline STOCK & & & -0.633 \\
\hline FUTGEN & & & 0.649 \\
\hline
\end{tabular}

Extraction Method: Principal Component Analysis. Rotation Method: Varimax with Kaiser Normalization. Rotation converged in 3 iterations. 
The first component ( $\mathrm{PCl}$ ) has high positive loadings for all of the variables concerned with the perceived negative impact of reserve establishment on the production capacity of an agricultural enterprise. These attitudes reflect the effect of reserve establishment on both current income and property values, and future asset values.

The second component ( $\mathrm{PC} 2$ ) has high loadings for variables related to the positive impact of reserve establishment on the environmental values of the property such as increased beauty, wildlife protection, as well as personal fulfilment. The factor loading for the impact PROPVALUE in PC2 is in the opposite direction to PC1 suggesting a strong disagreement with the negative impact reserve establishment has on overall property values.

The third component (PC3) has high loadings for variables indicating that respondents in this group do not believe the establishment of reserves on their property will be of benefit to them directly either in terms of agricultural production or environmental outcomes. This group focuses mainly on the longer term outcomes of reserve establishment. Additionally, the factor loading for OTHERUSE is in the opposite direction to PC2 indicating that the PC3 group believe that reserves are only desirable if there is no other valuable use for the land.

The first two components are similar to those developed for the BW survey attitude data $^{\mathrm{I} I 2}$, although there are fewer variables included in both the production impact and environmental impact components in the BW survey. ${ }^{113}$

Scores for the three factors were calculated for each of the survey respondents in the sample and these were included as variables (prod_attitude, env_attitude, and oppor_att) in the latent class analysis (Section 8.4).

The envattitude and prod_attitude components are compared to the att_env and att_prod, and components from the PCA used in the 'voluntary' model in Table iv.

\footnotetext{
${ }^{112}$ As the attitude questions were included in both the BW and Choice survey this allowed a degree of cross checking of the results. A two tailed test of the independence of the samples (BW and choice) showed there was no significance difference between the two groups in the rating of the attitude statements.

${ }^{113}$ Both the production impact and environmental impact in the BW analysis contained seven variables that were the same as those in the choice analysis. The choice analysis contained an additional five variables for the production impact and three variables for the environnental impact.
} 
Table iv: Comparison of components used in the 'voluntary' and 'forced choice' models (Choice survey data).

\begin{tabular}{|c|c|c|c|c|}
\hline & \multicolumn{2}{|c|}{ ENVIRONMIENT } & \multicolumn{2}{|c|}{ PRODUCTION } \\
\hline & 'voluntary' & 'forced choice' & 'voluntary' & 'forced choice' \\
\hline beauty & 0.728 & 0.720 & & \\
\hline benoth & 0.514 & 0.625 & & \\
\hline complex & & & 0.713 & 0.718 \\
\hline diverse & & -0.455 & 0.671 & 0.650 \\
\hline expman & & & 0.686 & 0.693 \\
\hline fire & & & 0.597 & 0.654 \\
\hline fulfil & 0.737 & 0.779 & & \\
\hline image & 0.647 & 0.668 & & \\
\hline incop & *in oppor & 0.517 & & \\
\hline incred & & & 0.643 & 0.598 \\
\hline incsec & & -0.442 & 0.706 & 0.700 \\
\hline leaming & 0.750 & 0.772 & & \\
\hline lively & 0.652 & -0.509 & & 0.612 \\
\hline otheruse & -0.494 & -0.628 & & \\
\hline pests & & & 0.498 & 0.608 \\
\hline propvalu & -0.469 & -0.579 & 0.457 & 0.451 \\
\hline protect & 0.799 & 0.781 & & \\
\hline shade & & & 0.699 & 0.677 \\
\hline time & & & 0.725 & 0.679 \\
\hline weeds & & & 0.747 & 0.748 \\
\hline wildl & 0.775 & 0.747 & & \\
\hline
\end{tabular}

Note: incop, fire, otheruse, stock, and futuregen comprised the future opportunity used in the 'voluntary' model and do not appear in the table.

Table iv shows that the results for the two PCA are similar in terms of the variables that make up the environment and production groups. 


\section{Appendix 6-Communalities for principal component analysis}

Table v: Communalities for all attitude variables (Choice survey data).

\begin{tabular}{lc}
\hline & Extraction \\
\hline PROPVALUE & 0.474 \\
\hline INCRED & 0.461 \\
\hline IMAGE & 0.382 \\
\hline EXPMAN & 0.427 \\
\hline BENOTH & 0.358 \\
\hline LIVELY & 0.625 \\
\hline FULFIL & 0.606 \\
\hline BEAUTY & 0.590 \\
\hline LEARNING & 0.604 \\
\hline PROTECT & 0.627 \\
\hline WEEDS & 0.560 \\
\hline FIRE & 0.448 \\
\hline SHADE & 0.570 \\
\hline INCOP & 0.283 \\
\hline TIME & 0.482 \\
\hline DIVERSE & 0.630 \\
\hline WILDL & 0.609 \\
\hline COMPLEX & 0.674 \\
\hline INCSEC & 0.697 \\
\hline OTHERUSE & 0.506 \\
\hline PESTS & 0.290 \\
\hline EROSION & 0.209 \\
\hline STOCK & \\
\hline FUTGEN & \\
\hline
\end{tabular}

All communalities greater than 0.2 were retained. 


\section{Appendix 7 - Correlation coefficients}

Table vi: Correlation coefficients (Choice survey data).

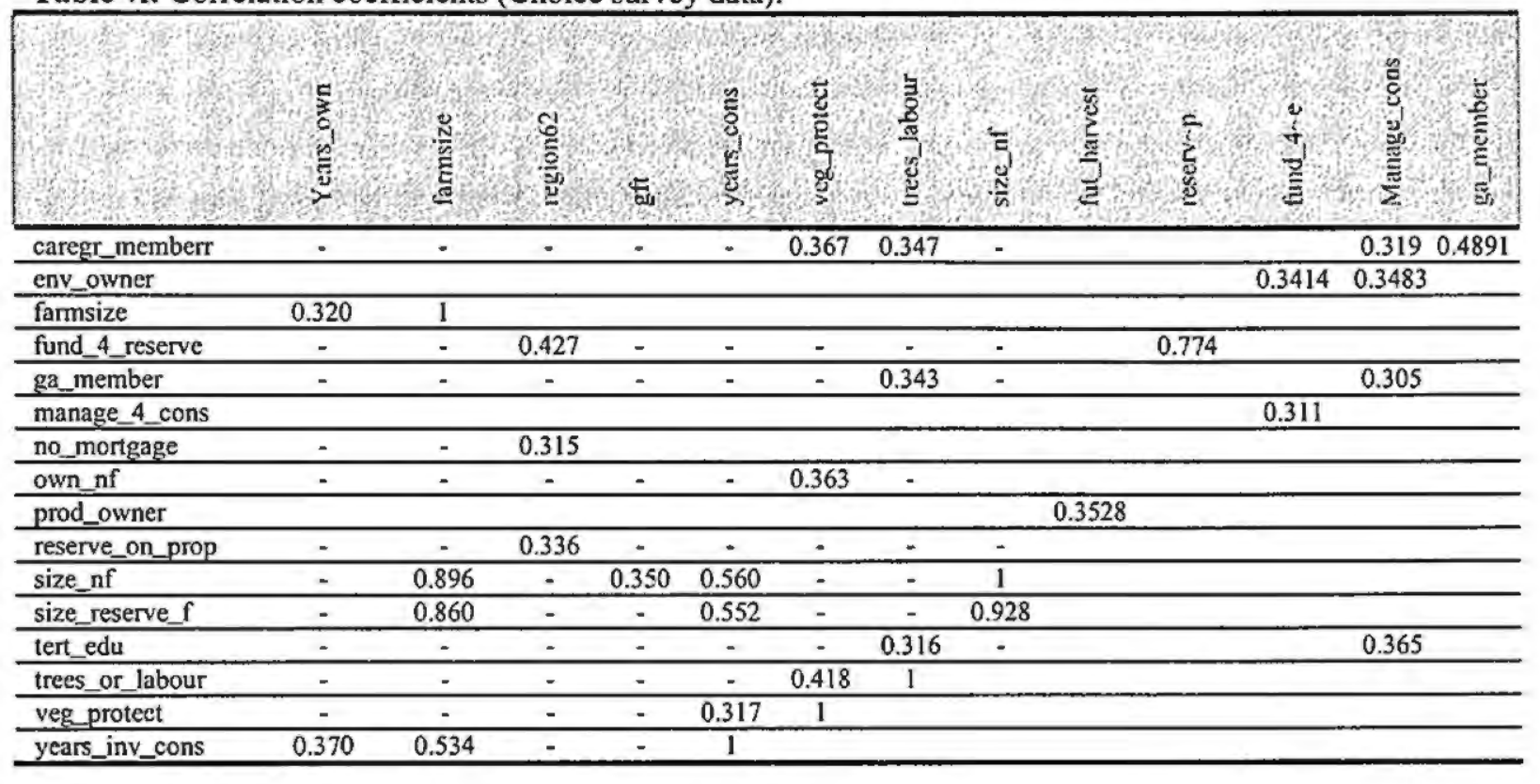




\section{Appendix 8 - Probability means}

The re-scaled parameters shown as column percentages in Table vii above can also be presented as row percentages. Row percentages provide information regarding the dimensions of the groups by showing class membership probabilities. The probabilities sum to one across landowner classes. Vermunt \& Magidson (2005) report the formulas to obtain the reported probability means in detail. In summary, the probability of being in latent class $x$ given choice $a$ on "set" $p$.

$\hat{P}_{p}(x \mid a)=\frac{\hat{P}(x) \hat{P}_{p}(a \mid x)}{\sum_{x^{\prime}=1}^{K} \hat{P}\left(x^{\prime}\right) \hat{P}_{p}\left(a \mid x^{\prime}\right)}$

Table vii: Probability means for the 3-class 'voluntary choice' model (Choice survey data).

\begin{tabular}{|c|c|c|c|c|}
\hline ans & 14 & 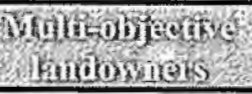 & 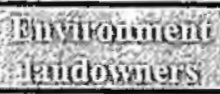 & 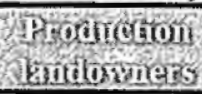 \\
\hline \multirow[t]{5}{*}{ Compfund* } & NOfund & 0.0454 & 0.0653 & 0.8893 \\
\hline & $\$ 2,500$ & 0.245 & 0.293 & 0.462 \\
\hline & $\$ 3,750$ & 0.3738 & 0.4075 & 0.2187 \\
\hline & $\$ 5,000$ & 0.4598 & 0.4568 & 0.0834 \\
\hline & $\$ 6,250$ & 0.5098 & 0.4615 & 0.0287 \\
\hline \multirow[t]{3}{*}{ Legal } & covenant & 0.0324 & 0.0015 & 0.966 \\
\hline & managreement & 0.2447 & 0.0091 & 0.7462 \\
\hline & NOlegalagreem & 0.5008 & 0.4906 & 0.0087 \\
\hline \multirow[t]{3}{*}{ Landuse } & limiteduse & 0.4489 & 0.4281 & 0.123 \\
\hline & nousepermit & 0.4489 & 0.4281 & 0.123 \\
\hline & UNlimiteduse & 0.4489 & 0.4281 & 0.123 \\
\hline \multirow[t]{3}{*}{ Paymethod } & upfrontpay & 0.4489 & 0.4281 & 0.123 \\
\hline & taxrelief & 0.4489 & 0.4281 & 0.123 \\
\hline & NOpayment & 0.4489 & 0.4281 & 0.123 \\
\hline \multirow[t]{3}{*}{ Techassist } & fee4service & 0.4489 & 0.4281 & 0.123 \\
\hline & freetechadv & 0.4489 & 0.4281 & 0.123 \\
\hline & NOadvice & 0.4489 & 0.4281 & 0.123 \\
\hline \multicolumn{3}{|c|}{ 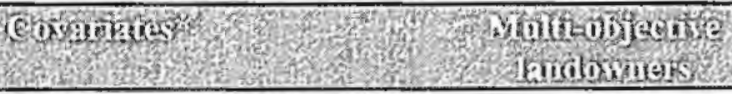 } & 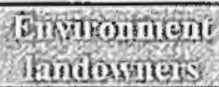 & 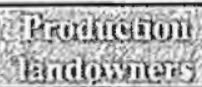 \\
\hline \multirow[t]{2}{*}{ Gender } & $($ female $=0)$ & 0.4185 & 0.4554 & 0.126 \\
\hline & $($ male $=1)$ & 0.4587 & 0.4193 & 0.122 \\
\hline \multirow[t]{2}{*}{ Tert_edu ( $\mathrm{r}$} & o tertiary edu $=0$ ) & 0.3616 & 0.5338 & 0.1046 \\
\hline & (tertiary edu=1) & 0.6157 & 0.2263 & 0.158 \\
\hline \multirow[t]{2}{*}{ Region62 } & (not in south $=0$ ) & 0.3852 & 0.5143 & 0.1005 \\
\hline & (south=1) & 0.6543 & 0.1505 & 0.1952 \\
\hline
\end{tabular}

Note: * Values for the attitude covariates are not shown as the probability means are given at the mean value and cannot be interpreted in a meaning fil way. 
Table viii: Probability means for the 3-class 'forced choice' model (Choice survey data).

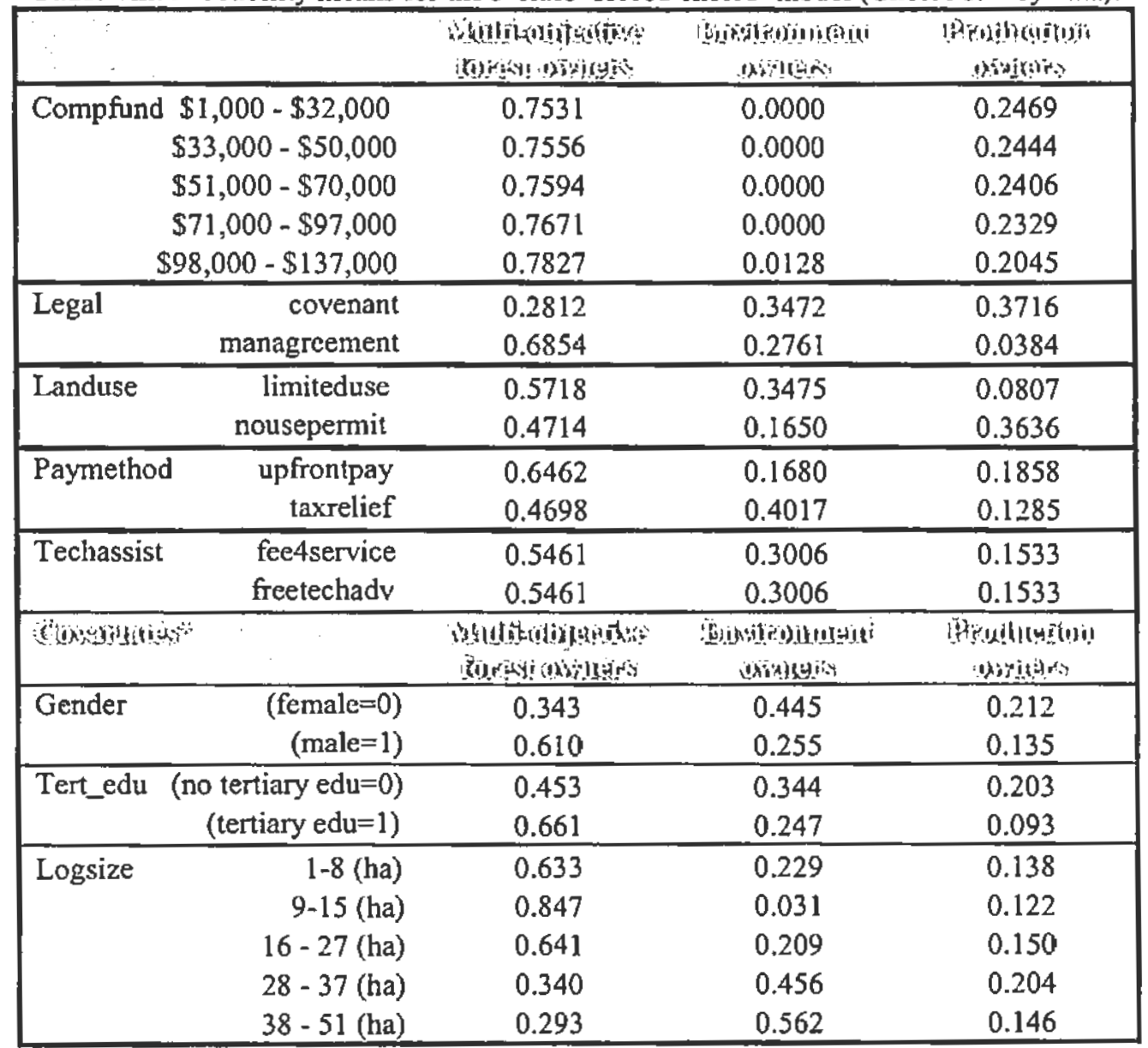

Note: * Values for the attitude covariates are not shown as the probability means are given at the mean value and cannot be interpreted in a meaningful way. 


\section{Appendix 9 - Standard errors}

Table iv: Standard errors for the quotient of wo variables for the linecel choice' model (Choice surney data).

\begin{tabular}{|c|c|c|c|c|c|}
\hline $1.111: 911198161$ & W1:3: & \multicolumn{2}{|c|}{$1,0,2: 3$} & \multicolumn{2}{|c|}{ up: } \\
\hline Cov/S (nulti) & 55.018 & 5 & $(1(1 ;, 24)$ & 5 & $1 . . \$(1)$ \\
\hline nouse's (nulii) & 44.605 & $\$$ & $(5.17)$ & 5 & $8+22$ \\
\hline tax/s (mulii) & 7.210 & 5 & (12.05) & $s$ & 1.416 \\
\hline fectser S (multi) & $+4.2+5$ & 5 & $(4.27)$ & 5 & 4.22 \\
\hline Cov/s (cm) & $0.10 \mathrm{~s}$ & $s$ & $(0.25)$ & 5 & (1).(1).4) \\
\hline noblses (cm) & 0.122 & 5 & 0.51 & $\$$ & 0.76 \\
\hline $\operatorname{tax} 5(\mathrm{ctin})$ & 0.0 .40 & 5 & $(0.10)$ & $S$ & $(0 .(12)$ \\
\hline fectsers (cmu) & $0 . \overline{136}$ & $\xi$ & $(0.5 .1)$ & $\$$ & $(0.27)$ \\
\hline Cor $\$$ (prod) & 008,001 & $\$$ & (615.3127) & $\xi$ & 00.4 .805 \\
\hline nouse's (prod) & 241.253 & $s$ & $(2+15.151)$ & $\$$ & 247.355 \\
\hline taxs (prod) & 102.367 & $s$ & $(101,000)$ & $\$$ & 102.825 \\
\hline lectuces (prod) & 53,973 & $\$$ & $(54.21 .1)$ & $\$$ & 53.732 \\
\hline
\end{tabular}

Table x: Standard crass for the quoticnt of two variables for the "voluming choice' masel (Chaice surey data).

\begin{tabular}{|c|c|c|c|c|c|}
\hline 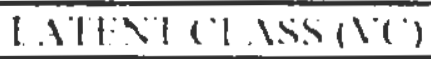 & $810 !$ & linerv" & & & $\Rightarrow 4510$ \\
\hline Cor:s (multi) & 0.221 & $s$ & $(2.80)$ & $s$ & $(2.36)$ \\
\hline $\operatorname{Man} \$$ (multi) & $0.20 !$ & s & $(1.31)$ & $\$$ & $(0.90)$ \\
\hline Limuse $S$ (multi) & 0.365 & $s$ & 0.10 & $\$$ & 0.44 \\
\hline Nousc's (multi) & 1.100 & $\$$ & (1.81) & $\$$ & 0.39 \\
\hline TaxS (multi) & 0.057 & $\$$ & $(0.02)$ & $\$$ & 0.10 \\
\hline Upfront s. (multi) & 0.165 & 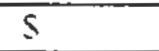 & $(0.14)$ & $\$$ & 0.10 \\
\hline Fectier S (multi) & 0.164 & 5 & $(0.32)$ & 5 & 0.01 \\
\hline fresendvices (multi) & $0.66 \mathrm{~S}$ & $\$$ & $(0.36)$ & $\$$ & 0.98 \\
\hline $\operatorname{Cov} 5$ (cnv) & 1.284 & $s$ & $(5.40)$ & $\$$ & $(2.53)$ \\
\hline $\operatorname{Man} \leqslant(\operatorname{sn} x)$ & 0.139 & $\$$ & $(2.97)$ & $s$ & $(2.69)$ \\
\hline Limusic S (cnv) & 0.112 & 5 & 0.19 & $s$ & 0.41 \\
\hline Nouse S (env) & 0.110 & $\$$ & $(0,89)$ & $S$ & $(0.67)$ \\
\hline Tลx: & 0.07 .4 & $\xi$ & $(0.03)$ & $\$$ & 0.12 \\
\hline Upfront S (cms) & 0.152 & $\$$ & $(0.12)$ & $\dot{s}$ & 0.18 \\
\hline fectsers (env) & 0.107 & 5 & $(0.28)$ & $\$$ & $(0.0(1)$ \\
\hline frecendrices (emv) & 0.113 & $s$ & 0.23 & $\$$ & 0.45 \\
\hline Covs (prod) & 5.963 & $s$ & $(1+1.60)$ & $\$$ & $(2.74)$ \\
\hline Mann S (prod) & 0.477 & $\$$ & $11.06)$ & $\$$ & $(0.11)$ \\
\hline Limuses (prod) & 3.745 & 5 & $(5.35)$ & $\$$ & 2.14 \\
\hline Nouse S (nod) & +.036 & $s$ & 0.14 & 5 & 8.21 \\
\hline Tax $\$$ (prod) & 4.453 & 5 & $14.60)$ & 5 & 4.22 \\
\hline Upfrone's (prod) & 3.019 & 5 & $(3.17)$ & $s$ & 2.87 \\
\hline fectisers (prod) & 3.566 & $s$ & 12.061 & $\$$ & 4.77 \\
\hline freendrices (prod) & 4.002 & 5 & $(5.82)$ & $\$$ & 2.18 \\
\hline
\end{tabular}




\section{Appendix 10 - Cluster analysis}

Cluster analysis is a multivariate analysis technique that seeks to organise information about variables into groups, or clusters, which are highly internally homogenous and highly externally heterogeneous. The cases are initially assigned randomly to $K$ clusters. Cases are then moved around between clusters iteratively in order to minimise some measure of cluster variability. Cluster variability is measured with respect to the mean value of the cluster for the classifying variables, hence the name $K$-means clustering. If more than one classifying variable is used to define the clusters, the distance (dissimilarities) between clusters is measured in multidimensional space (e.g. Euclidean distance).

More formally, the heterogeneity between the data for a given partition $P(M, K)$ of $M$ cases into $K$ clusters, where each of the $M$ cases lies in just one of the $K$ clusters, is measured by an error $e[P(M, K)]$. Suppose the $\mathrm{i}^{\mathrm{ith}}$ case of the $\mathrm{j}^{\text {th }}$ variable has value $A(\mathrm{i}, \mathrm{j})$ such that $\mathrm{i}=1, \ldots . M$ and $j=1, \ldots N$. The mean of the $\mathrm{j}^{\mathrm{jh}}$ variable over all the cases in the $1^{\text {th }}$ cluster, such that $\mathrm{I}=1, \ldots \mathrm{K}$, is denoted by $\mathrm{B}(\mathrm{l}, \mathrm{j})$. The number of cases in the lth cluster is $N(1)$. The distance between any two clusters $\mathrm{n}$ and $\mathrm{l}$ is:

$$
D(I, L)=\left(\sum_{J=1}^{N}[A(I, J)-B(L, J)]^{2}\right)^{1 / 2}
$$

and the error of the partition is:

$e[P(M, K)]=\sum_{i=1}^{M} D[I, L(I)]^{2}$

where $L(\mathrm{i})$ is the cluster containing the $\mathrm{i}^{\text {th }}$ case. The general procedure in $\mathrm{K}$-means clustering is to search for a partition with a small error by moving cases from one cluster to another. The search ends when no such movement reduces $e$ (Hartigan 1975). 


\section{Appendix 11 - Binary-choice models}

Binary-choice models assume that individuals are faced with a choice between two altematives and that the choice made depends on identifiable characteristics of the decision-maker and/or the choice. The objective in binary-choice modelling in this instance would be to predict the likelihood of an individual choosing to join an incentive program with given characteristics. More generally, the aim of binarychoice modelling is to find a relationship between a set of attributes describing a choice and the probability that the individual will make a given choice.

Following Gujarati (1988) and Pindyck and Rubinfeld (1998), the Linear Probability Model (LPM) of binary-choice expresses the dichotomous dependent variable $\left(Y_{i}\right)^{114}$ as a linear function of the explanatory variables $\left(\mathrm{X}_{\mathrm{i}}\right)$. The conditional expectation of $\mathrm{Y}_{\mathrm{i}}$, given $\mathrm{X}_{\mathrm{i}}$, can be interpreted as the conditional probability that the event will occur given $\mathrm{X}_{\mathrm{i}}$; in other words $\mathrm{P}_{\mathrm{i}}=\mathrm{E}\left(\mathrm{Y}=1 \mid \mathrm{X}_{\mathrm{i}}\right)$. However, although it is the case a priori that the conditional probability must lie between 0 and 1 , estimated probabilities in the LPM often lie outside the unit interval.

In addition, as the name suggests, the LPM assumes that the conditional probability of an event occurring increases linearly with $X$. In other words, the marginal or incremental effect of $\mathrm{X}$ is constant throughout the range of $\mathrm{X}$. In reality, one would expect that the conditional probability of a particular event occurring would be nonlinearly related to $X$, reflecting the fact that at both ends of the distribution of $X$ the probability of an event occurring will be virtually unaffected by small increases in $\mathrm{X}$.

This suggests the need for a binary-choice model where (i) the conditional probability of an action being taken increases as $\mathrm{X}$ increases but never steps outside the unit interval and (ii) the relationship between $P_{i}$ and $X$ is non-linear.

The binary logit and binary probit ${ }^{115}$ models achieve non-linearity and restrict predicted probabilities to the unit interval by using an S-shaped cumulative density

\footnotetext{
${ }^{114} Y_{1}$ is equal to 1 if a particular action is taken or choice is made; $Y_{1}$ is equal to 0 if the action is not taken or the choice is not made.

${ }^{115}$ The probit model (known also as the normit model) transforms the data using the cumulative normal probability function. The higher computational demands of this model and the generally weak theoretical justification for empioying a probit specification mean that the logit model is more widely
} 
function to transform the dichotomous $0-1$ dependent variable of the binary choice model. In the case of the logit model the transformation uses the cumulative logistic probability function and is specified as:

$P_{1}=\frac{1}{1+e^{-Z_{1}}}$

where $e$ is the base of natural logarithms and $\mathrm{Zi}=\mathrm{a}+\beta \mathrm{X} . \mathrm{A}$ and $\beta$ are the estimated parameters of the logit model.

The regression equation estimated in logit analysis is derived after simple manipulation of equation 33 giving

$$
L_{1}=\ln \left(\frac{P_{i}}{1-P_{1}}\right)=Z_{i}
$$

where the dependent variable in the regression equation is the natural logarithm of the odds that a particular choice will be made and the right hand side of the regression is linear in the parameters of the model. When only one or a few observations on each decision maker is available, estimation of the parameters of the logit model must be made using the maximum likelihood estimation procedure. The maximum likelihood procedure has a number of desirable properties. All parameter estimates will be consistent and efficient asymptotically. In addition, all parameter estimates are asymptotically normal, so that a $t$ test of parameter significance can be applied. Tests of the significance of all, or a subset, of the coefficients can be performed using the likelihood ratio (LR) test.

Estimated coefficients of equation 34 do not indicate the increase in the probability of the event occurring, given a one unit increase in the value of the independent variable. Rather, these coefficients reflect the effect of a change in an independent variable on $\ln \left[\mathrm{P}_{\mathrm{i}} /\left(1-\mathrm{P}_{\mathrm{i}}\right)\right]$ or the $\log$ of odds ratio. The marginal probability effects for the logit model are derived as follows:

$$
\frac{\partial P_{1}}{\partial X_{y}}=\frac{\beta_{\mathrm{j}} \cdot \mathrm{e}^{\mathrm{z}_{\mathrm{i}}}}{\left(1+\mathrm{e}^{\mathrm{z}_{\mathrm{t}}}\right)^{2}}
$$

used in empirical work. The predictive powers of the logit and probit specifications are generally comparable. 
where $\mathrm{j}$ denotes a particular independent variable. Given the non-linearity of the logit model specified in equation 39 , the marginal effects will depend on the original probability and the values of all other independent variables and their coefficients.

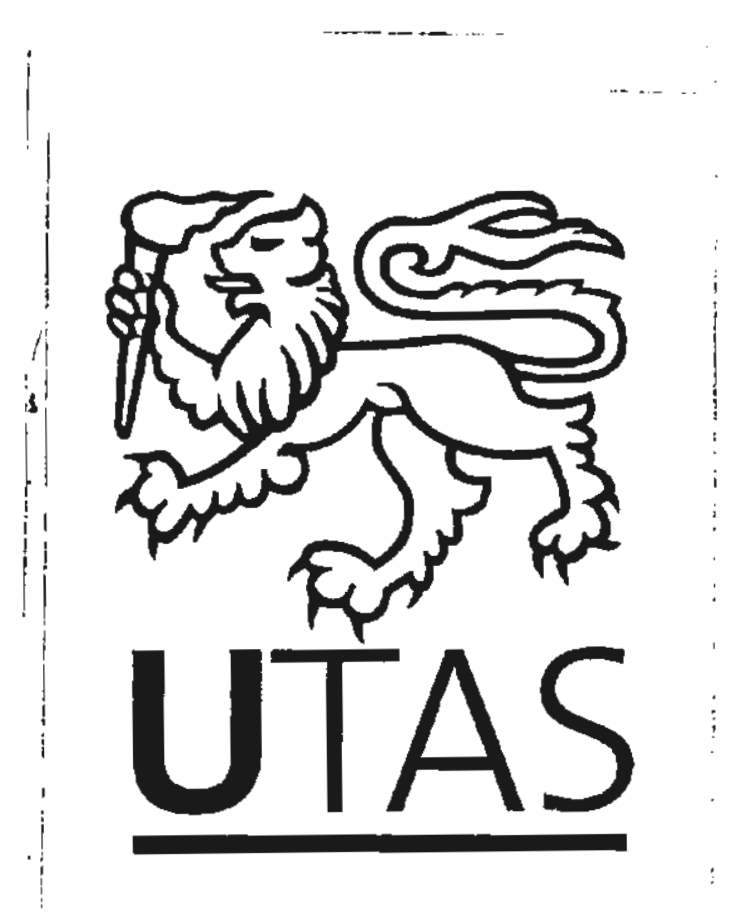

